\title{
Information as a workpiece
}

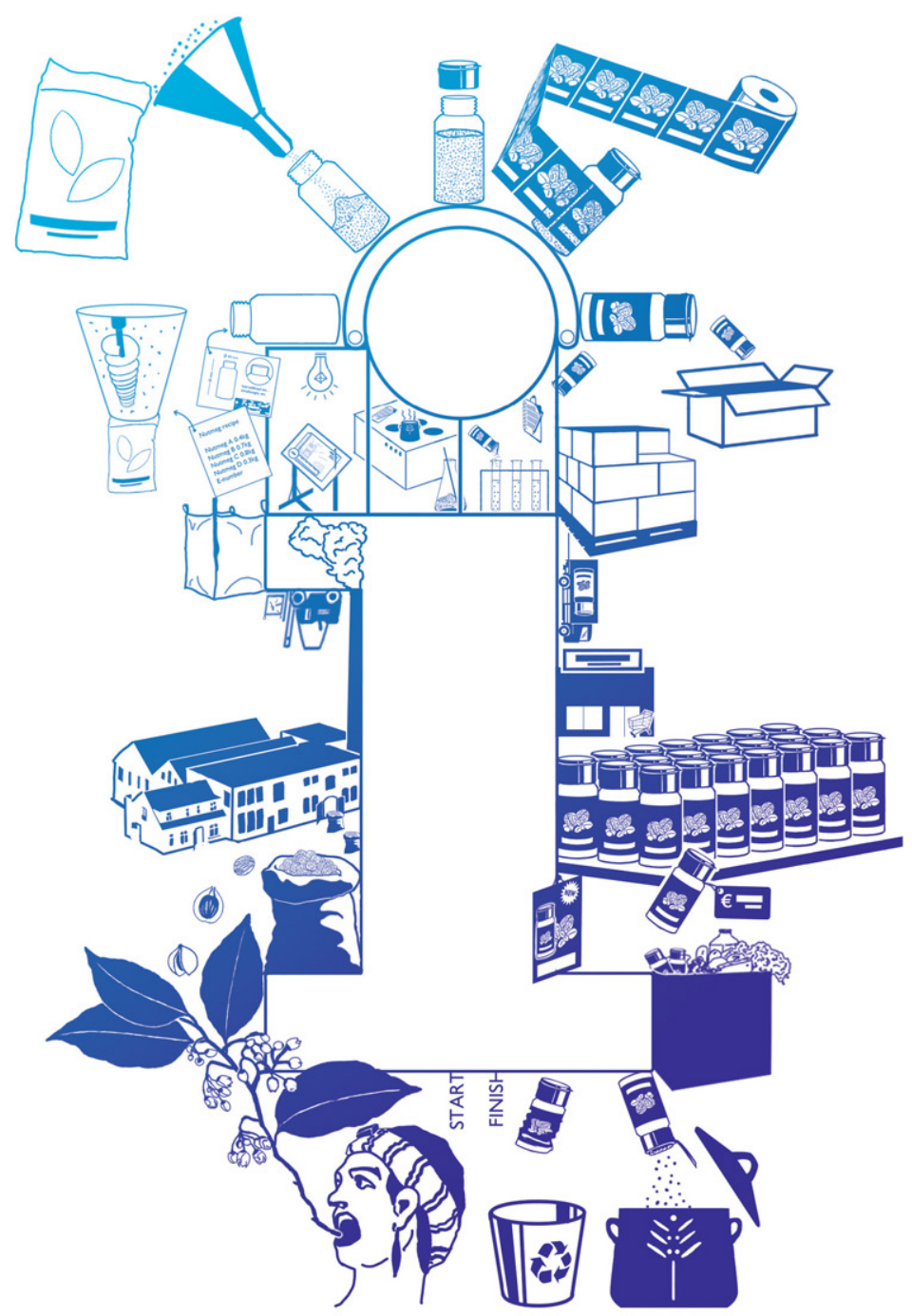

An architecture for content-driven design support 



\title{
INFORMATION AS A WORKPIECE: AN ARCHITECTURE FOR CONTENT-DRIVEN DESIGN SUPPORT
}

\author{
PROEFSCHRIFT \\ ter verkrijging van \\ de graad van doctor aan de Universiteit Twente, \\ op gezag van de rector magnificus, \\ prof. dr. T.T.M. Palstra, \\ volgens besluit van het College voor Promoties \\ in het openbaar te verdedigen \\ op donderdag 26 april 2018 om 16.45 uur \\ door \\ Jos de Lange \\ geboren op 5 november 1983 \\ te Almelo
}


Dit proefschrift is goedgekeurd door de promotoren:

Prof. dr. ir. F.J.A.M. van Houten

Prof. dr. ir. R. ten Klooster 
INFORMATION AS A WORKPIECE:

AN ARCHITECTURE FOR CONTENT-DRIVEN DESIGN SUPPORT 


\section{Graduation committee:}

Prof. dr. G.P.M.R. Dewulf

Prof. dr. ir. F.J.A.M. van Houten

Prof. dr. ir. R. ten Klooster

Prof. L. Roucoules

Prof. C.S.L. Schutte

Prof. dr. ir. A.C. Brombacher

Prof. dr. ir. B.R.H.M. Haverkort

Prof. dr. J. Henseler
University of Twente - Chairman/secretary

University of Twente - Promotor

University of Twente - Promotor

Arts et Métiers ParisTech, France

Stellenbosch University, South Africa

Eindhoven University of Technology

University of Twente

University of Twente

(c) Jos de Lange, 2018

ISBN: $978-90-365-4539-6$

DOI: $\quad 10.3990 / 1.9789036545396$

Printed by Ipskamp Printing, Enschede, The Netherlands

All rights reserved. No part of this publication may be reproduced, stored in a retrieval system or transmitted, in any form or by any means, electronic mechanical, photocopying recording or otherwise, without the prior written permission of the author. 



\section{VOORWOORD}

Dit proefschrift gaat over ontwerpondersteuning waarbij informatie als werkstuk beschouwd wordt. Het resultaat is een ontwerpvoorstel voor systemen gebaseerd op inhoud-gestuurde ontwerpondersteuning. Bij de totstandkoming van dit ontwerp heb ik tevens veel ondersteuning mogen ontvangen. Onmisbare ondersteuning die in geen enkel systeem te vatten is. Dank aan iedereen die betrokken is geweest en aan een aantal mensen in het bijzonder.

Dank aan mijn promotoren, Fred en Roland. Fred voor de bijzondere gave om binnen no-time de vinger op de zere plek te leggen, het daaropvolgende rustige advies en de vakkundige regie. Roland voor de vrijheid en aanmoediging om mijn eigen pad te volgen, je trouwe hulp en feedback, de schier oneindige stroom aan praktijkkennis en je relativeringsvermogen.

Dank aan Eric, voor je snelle en scherpe denken, de altijd rake feedback, de talloze discussies en je nimmer aflatende steun. Zonder jou was dit proefschrift er nooit gekomen.

Dank aan Roy en Ellen voor het talent om schrijfdagen tot een plezier te maken. Dank voor het delen van het leed, de discussies, feedback, afleiding en humor.

Dank aan het secretariaat, het sociale hart van ons departement. Voor jullie luisterend oor, morele ondersteuning en geweldige hulp. Speciaal dank aan Inge Dos Santos, zonder wie alle procedures rondom mijn promoveren al lang in het honderd waren gelopen.

Dank aan alle bedrijven, voor de betrokkenheid in het onderzoeksproject 'verpakkingsketens in blijvende balans' en voor de openheid en gastvrijheid tijdens de interview sessies.

Dank aan alle studenten die op welke wijze dan ook betrokken waren. Jullie zijn de reden dat mijn werk zo leuk is om te doen.

Dank aan mijn ouders Henk en Eef. Jullie warme opvoeding, liefde, humor en steun hebben me gebracht waar ik nu ben.

Dat een proefschrift schrijven voor de auteur een beproeving is, staat van te voren vast. Dat het een beproeving is voor hen die het dichts om hem heen staan, is ronduit oneerlijk. Daarom als laatste, dank aan de belangrijkste persoon: Erica. Wat ben ik trots dat ik je man ben, blij dat jij mijn vrouw bent en zo mogelijk nog blijer dat we samen Guusje hebben gekregen. God weet hoe veel geduld, steun en liefde jij mij gegeven hebt. Dank daarvoor.

Jos de Lange

Zwolle, maart 2018 


\section{ABSTRACT}

This thesis contributes to the field of Design Theory and Methodology (DTM) with a design support paradigm that originates in the evolving product definition. In DTM, this product definition is widely accepted as being the common purpose of development cycles. Also, information management is recognized as an important aspect in documenting both the evolvement and definition of the product. These elements, however, have not yet found an application as the footing for offering design support.

The overall theme of the research as described in this thesis is depicted as 'design support based on information management for design theory and methodology'. This results in a proposal, in the form of an architecture, for so-called content-driven design support. This induces new (design support) functionalities and approaches for this evolving product definition, in which information is seen as the workpiece of the development cycle.

With this, the base for the content-driven design support becomes the explicitly available information that product developers use and engender during the development cycle (e.g. concepts, drawings, cad-models, simulations, minutes, reports). In other words, the design support closely aligns with the daily practise of product development and the prevalence of the many outcomes stemming from the myriad activities involved.

To edify the proposed architecture from the initial inspiration to focus on the evolving information content, the thesis distinguishes five main components: an analysis on design support for product development, an information perspective on product development; a requirement specification; the solution principles and the previously mentioned architecture.

The analysis on product development addresses its characteristics as well as examples of practise and a literature review on available design support. The main outcome of this analysis is that current design support approaches are pre-dominantly based on generalised and aggregated insights in product development cycles rather than on actual design practise. From this, the information-value axiom "Information is the carrier of all (added) value in and of a product development cycle" is devised as the alternative starting point for reasoning about design support.

Based on the axiom a type of design support is proposed that is induced by the information generated during the actual design practise. This requires a different, information-based perspective on product development. Consequently, focus is first put on deconstructing the notion product development into its core concepts and essential proceedings. The resulting building blocks, perspectives and aims initiate a different idea of how design support can be offered. Contextualising the information perspective on product development is done by means of a new reference model.

One of the main contributions of this reference model is that it allows to deal with decisions in a new manner. For this, the decision impact model is established. This model links any decision back to the information workpiece leading to the following stated purpose: employ the evolving information content to explore the uncertain solution space and explicate possible consequences of development decisions in order to 
initiate, direct and facilitate effective and efficient decision making. Improving decision making is only relevant if the right decisions are addressed. The content-driven design support approach highly values the expertise of product developers in reaching both deterministic and non-deterministic decision making. For this reason, two underlying principles are addressed. Firstly, the collection of information concerning the evolving product definition needs to be established and needs to be made explicitly accessible as a 'workpiece' for the product development team. Secondly, an interface between this information and the tools needed to realise the envisaged design support has to be available as a 'workbench' for the product developer - from his or her own perspective.

The architecture synthesises all previously mentioned aspects into a blueprint for developing content-driven design support. This architecture exhibits the required core functionalities of the content-driven design support as well as the required core control principles.

Before addressing any type of implementation, the main approach must be validated. After all, it should be worthwhile to justify the (potentially enormous) effort that can be involved in actually implementing the design support approach. Consequently, the solution direction aims to demonstrate and test the validity of the chosen information perspective on design support. The architecture summarizes all aspects and defines the design proposal for a system based on content-driven design support. This architecture should not be seen as the final word on the matter or as the decisive end-result ready for use in daily practise. Rather, it is intended as an intermediate result that offers a solid base on which information-induced design support applications can be further developed and explored.

For this thesis, such an implementation is out of scope as it encompasses an entire new development trajectory. Such an implementation would not do justice to the generic nature of the architecture and the effort required to develop such a singular instantiation would be disproportionate to its added value in validating the new approach. Instead of using implementation as validation, a number of scenarios is introduced that simultaneously serve as examples and tests of how the architecture can be employed. From these scenarios preliminary requirements for potential implementation trajectories are deduced. This gives insight in the potentialities of the architecture, but it foremost provides an information basis on which developers - the experts - can better reach the right decisions on the appropriate issues. It allows them to fully exploit their creativity and communication skills to - conjointly with experts from different domains - establish the best implementation (approach) for the situation at hand. As such, it is the intention to use the architecture as the workbench, on which the evolving information content can become the effective and efficient implementation. 


\section{SAMENVATTING}

De bijdrage van dit proefschrift aan het onderzoeksveld van ontwerptheorie en -methodologie (OTM) is een ontwerp-ondersteuningsparadigma dat zijn oorsprong vindt in de zicht steeds evoluerende definitie van een product. In OTM wordt deze productdefinitie algemeen gezien als het gemeenschappelijke doel van ontwerpcycli. Hierin, wordt tevens informatiemanagement erkend als een belangrijk aspect bij het documenteren van zowel de ontwikkeling als de definitie van het product. Deze twee elementen - de product definitie en het daarbij horende informatie management - zijn echter nog niet eerder gebruikt als basis voor het bieden van ontwerpondersteuning.

Het algemene thema van het onderzoek zoals beschreven in dit proefschrift is te definiëren als 'ontwerpondersteuning op basis van informatiebeheer voor ontwerptheorie en -methodologie'. Dit onderzoek resulteert in een ontwerpvoorstel in de vorm van een architectuur voor zogeheten inhoud-gestuurde ontwerpondersteuning. Dit noopt tot nieuwe (ontwerpondersteuning gerelateerde) functionaliteiten en methoden voor deze evoluerende productdefinitie, waarin informatie wordt gezien als het werkstuk van de ontwikkelingscyclus.

Hiermee wordt de expliciet beschikbare informatie die ontwerpers zelf gebruiken en genereren tijdens ontwerpcycli (bijvoorbeeld concepten, tekeningen, CAD-modellen, simulaties, minuten, rapporten) de basis voor de inhoud-gestuurde ontwerpondersteuning. Hierdoor sluit de ontwerpondersteuning nauw aan bij de dagelijkse praktijk van productontwerp en de invloed van de vele uitkomsten die voortvloeien uit de diverse ontwerpactiviteiten.

Voor de het ontwerpvoorstel voor ontwerpondersteuning wordt de focus dus gelegd op deze dynamische informatie-inhoud. Om de voorgestelde architectuur op te bouwen vanuit deze initiële inspiratie, onderscheidt het proefschrift vijf hoofdcomponenten: een analyse van ontwerpondersteuning voor productontwerp, een informatieperspectief op productontwerp; een specificatie van eisen; de oplossingsprincipes en de eerder genoemde architectuur.

De analyse van productontwerp richt zich op praktijkvoorbeelden en literatuur welke resulteert in een karakterisering van productontwerp. Tevens wordt literatuur van beschikbare ontwerpondersteuning besproken. Het belangrijkste resultaat van deze analyse is dat de huidige ontwerp-ondersteunende aanpakken voornamelijk gebaseerd zijn op algemene, geaggregeerde interpretaties van productontwerpcycli in plaats van op de daadwerkelijke praktijk van product ontwerp. Hieruit blijkt het informatiewaarde axioma "Informatie is de drager van alle (toegevoegde) waarde in en van een productontwerpcyclus", als alternatief uitgangspunt voor redeneren over ontwerpondersteuning.

Op basis van dit axioma wordt een type ontwerpondersteuning voorgesteld die wordt geïnitieerd vanuit de informatie die wordt gegenereerd tijdens de eigenlijke ontwerppraktijk. Dit vereist een ander, op informatie gebaseerd perspectief op productontwerp. Daarom wordt eerst de nadruk gelegd op het ontleden van de notie productontwerp in kernbegrippen en de bijbehorende essentiële handelswijze. De resulterende bouwstenen, perspectieven en doelen leiden tot een ander idee van hoe ontwerpondersteuning kan worden aangeboden. Het contextualiseren van het informatieperspectief op pro- 
ductontwerp wordt gerealiseerd door middel van een nieuw referentiemodel. Eén van de belangrijkste bijdragen van dit referentiemodel is dat het beslissingen en de omgang daarmee in een ander daglicht stelt. Daartoe is het beslissing-impact-model ontwikkeld. Dit model koppelt elke beslissing aan het informatiewerkstuk, dat voortvloeit in het volgende doel: gebruik de zich ontwikkelende informatie-inhoud om de onzekere oplossingsruimte te verkennen en de mogelijke consequenties van ontwerpbeslissingen expliciet te maken ten einde effectieve en efficiënte besluitvorming te initiëren, dirigeren en faciliteren.

Het verbeteren van de besluitvorming is alleen relevant als de juiste beslissingen worden genomen. De inhoud-gestuurde ontwerp-ondersteunende aanpak hecht grote waarde aan de expertise van productontwerpers om zowel deterministische als niet-deterministische beslissingen te nemen. Om deze reden worden twee onderliggende principes geadresseerd. Allereerst moet alle beschikbare informatie aangaande de evoluerende productdefinitie worden gekoppeld. Tevens moet deze verzameling expliciet toegankelijk worden gemaakt als zijnde één "werkstuk" voor het productontwerpteam. Ten tweede moet er een koppeling tussen dit informatie-werkstuk en de gereedschappen - die nodig zijn om de beoogde ontwerpondersteuning te realiseren - beschikbaar zijn als een 'werkbank' voor de productontwerper - vanuit zijn of haar eigen perspectief.

De architectuur synthetiseert alle eerder genoemde aspecten in een blauwdruk voor het ontwikkelen van inhoud-gestuurde ontwerpondersteuning. Deze architectuur toont de vereiste kernfunctionaliteiten van dit nieuwe type ondersteuning en de vereiste controle-principes.

Alvorens tot implementatie over te gaan, moet deze nieuwe wijze van ontwerpondersteuning gevalideerd zijn. Het zal tenslotte de moeite waard moeten zijn om de (mogelijk enorme) inspanning te rechtvaardigen die betrokken kan zijn bij een daadwerkelijke implementatie van deze ontwerpondersteuning. Daarom is de oplossingsrichting zoals beschreven in dit proefschrift met name bedoeld om de validiteit van het gekozen informatieperspectief op ontwerpondersteuning te demonstreren en te testen. De architectuur definieert het ontwerpvoorstel voor een systeem op basis van inhoud-gestuurde ontwerpondersteuning. Deze architectuur moet echter niet opgevat worden als heen definitief resultaat of volledig systeemontwerp dat klaar is voor gebruik in de dagelijkse praktijk. Het is juist bedoeld als een tussenresultaat dat een solide basis biedt waarop informatie-gestuurde ontwerp-ondersteunende toepassingen verder kunnen worden ontwikkeld en verkend.

Een dergelijke implementatie valt buiten het bestek van dit proefschrift omdat het een volledig nieuw ontwikkelingstraject omvat. Een dergelijke implementatie zou geen recht doen aan de generieke aard van de architectuur en de moeite die het kost om één voorbeeld op basis van de architectuur te ontwikkelen zou onevenredig zijn met de toegevoegde waarde ervan bij het valideren van de nieuwe aanpak. In plaats van implementatie als validatie te gebruiken, worden een aantal scenario's geïntroduceerd die tegelijkertijd dienen als voorbeelden en tests van hoe de architectuur kan worden gebruikt. Uit deze scenario's worden voorlopige eisen voor mogelijke implementatietrajecten afgeleid. Dit geeft inzicht in de mogelijkheden van de architectuur, maar het biedt vooral een informatiebasis waarop ontwerpers - de experts - beter de juiste beslissingen kunnen nemen over de juiste kwesties. Het stelt hun in staat om hun creativiteit en communicatievaardigheden ten volle te benutten en - gezamenlijk met experts uit verschillende domeinen - de beste implementatie (aanpak) voor de huidige situatie te definiëren. Als zodanig is het de intentie de architectuur als werkbank te gebruiken, waarop de evoluerende informatie-inhoud een effectieve en efficiënte implementatie kan worden. 


\section{CONTENTS}

Voorwoord

VII

Abstract

Samenvatting $\quad$ XI

1. Introduction 1

1.1 Research area: design support for product development 1

1.2 A focus on information in product development cycles 2

1.3 A product development inspired research approach 3

1.4 Structure of thesis 4

2. Characteristics of product development $\quad 7$

2.1 Characterisation based on design practice situations 9

2.2 Common elements $\quad 12$

2.3 Evolving requirement specification $\quad 21$

2.4 Conclusion 24

3. Methodologies for product development 27

3.1 Scope and terminology 29

3.2 Characterisation of methodologies 30

3.3 Activity-based models 34

3.4 Actor, artefact and assets based models 37

3.5 Trends and challenges $\quad 40$

3.6 Evaluation 40

3.7 Conclusion 43

4. Information-value axiom $\quad 45$

4.1 Information-value axiom 47

4.2 Defining the notion information. 48

4.3 Terminology explored in four scenarios 50

4.4 Reference models 55

4.5 Reference model for information-based product development 57

4.6 Consequences of adopting the reference model 61

4.7 Conclusion 64

5. Exploration of information usage 65

$\begin{array}{lll}5.1 & \text { Information models and structuring principles } & 67\end{array}$

5.2 Current information usage $\quad 71$

$\begin{array}{lll}5.3 & \text { Summary of issues } & 77\end{array}$

5.4 Workpiece analogy 81

5.5 Conclusion $\quad 87$ 
6. Product definition as a workpiece 89

6.1 Stated purpose 91

6.2 Decision impact model 95

6.3 Consequences of decision making 98

$\begin{array}{ll}6.4 \text { Scenarios } & 104\end{array}$

$\begin{array}{ll}6.5 \text { Conclusion } & 108\end{array}$

7. Actor network as workpiece engine 111

$\begin{array}{lll}\text { 7.1 Requirement specification information workpiece } & 113\end{array}$

7.2 Interconnected information as principle solution $\quad 117$

$\begin{array}{lll}7.3 & \text { Actor network } & 119\end{array}$

$\begin{array}{lll}7.4 & \text { Use case } & 127\end{array}$

$\begin{array}{ll}7.5 & \text { Evaluation and discussion } \\ 7.6 & \text { Conclusion }\end{array}$

$\begin{array}{ll}7.6 \text { Conclusion } & 130\end{array}$

8. Mechanisms as tooling engine 133

$\begin{array}{lll}8.1 & \text { Requirement specification } & 135\end{array}$

8.2 The definition of a mechanism 141

8.3 Uncertainty and mechanisms 144

8.4 Integration of mechanisms in the actor network prototype 147

$\begin{array}{lll}8.5 & \text { Evaluation and discussion } & 149\end{array}$

$\begin{array}{ll}8.6 \text { Conclusion } & 150\end{array}$

9. Architecture for content-driven design support 153

9.1 An architecture as blueprint for workbench development 155

$\begin{array}{lll}9.2 & \text { Architecture } & 157\end{array}$

9.3 System consistency 161

$\begin{array}{lll}9.4 & \text { Scenarios } & 163\end{array}$

$\begin{array}{ll}9.5 \text { Conclusion } & 172\end{array}$

10. Conclusions and recommendations $\quad 175$

$\begin{array}{ll}10.1 \text { Conclusions } & 175\end{array}$

$\begin{array}{lll}10.2 & \text { Recommendations } & 179\end{array}$

$\begin{array}{ll}\text { References } & 183\end{array}$

$\begin{array}{ll}\text { Appendices } & 195\end{array}$

A. List of publications 197

B. Additional information design practise situations 199

C. Overview design methodologies and corresponding references $\quad 213$

D. Excerpts use case sustainable packaging $\quad 225$

E. Reliability of mechanisms $\quad 239$ 


\section{CHAPTER 7 INTRODUCTION}

Imagine a team of design engineers halfway a product development project on the verge of taking an important decision. There is a lively discussion about which concept should be continued. At the table are laptops, papers and notes, the inevitable postits, and some mocks ups. Several participants virtually join the discussion using long distance collaboration tools and devices. A screen in the corner shows a presentation of technical concepts, while another highlights the report on preferences of the consumers. There seems to be no correct answer for the concept choice. To name but a few considerations: the technical feasible concept is supposedly not favoured by the prospected consumer, whereas the preferred marketing concept might involve significant investments in either new production equipment or costs for outsourcing the production.

It is important to note that at this stage, none of the elements of the product is completely finished or certain. As such, the discussion encompasses not only the concept decision but also the quality of the information, the assumptions, preferences and influence of stakeholders and the potential consequences of all options. There is no apparent 'right' or 'wrong', all options seem to resolve some uncertainties in the development cycle, while simultaneously introducing new (potential) areas of uncertainty. At first sight this might seem an irremediable situation in which reaching consensus appears to be impossible. Yet this situation is archetypical for design engineers, making decisions with significant amounts of uncertainty involved. Moreover, usually in this context product developers thrive in creating innovative solutions, for both the product that is defined and the route for developing this product.

\subsection{RESEARCH AREA: DESIGN SUPPORT FOR PRODUCT DEVELOPMENT}

This thesis focusses on how to support product development situations such as the one outlined above. More specifically, this thesis focussed on design support tailored towards the government of product development cycles. Product development in this research is defined as being a specific subset of the design engineering discipline. The following definition of product development is used:

(new) product development is the creation of products with new or different characteristics that offer new or additional benefits to the customer ("CIRP Encyclopedia of Production Engineering," 2014).

This research originated from both design engineering and the field of product/packaging development. Consequently, the majority of the empirical studies stems from fast moving consumer goods (FMCGS) organisations in food and packaging. However, the scope of this thesis is not limited to packaging alone but tries to encompass all cases in which a discrete, physical products are developed. The multi-disciplinary character of product/packaging development cycles and the comprehensive nature of the subject 
in combination with the necessity to incorporate several theoretical oriented elements, has led to a thesis that has a more generic character. While the majority of the empirical data stems from industries related to the product/packaging development, the intention is to have a broader applicability.

Although thesis draws upon many fields of expertise such as manufacturing control, software engineering and information management, the main research field is considered to be Design Theory and Methodology (DTM). This field of design engineering science focusses on how design engineers develop products and tries to understand what design actually is. The core aim of this field is supporting product developers in understanding, practising and evaluating development cycles in order to make the practise more effective of efficient (Birkhofer, 2011; Eric Lutters, 2014; Tomiyama et al., 2009). As such, the core subject of this thesis is how to offer design support to product developers.

\subsection{A FOCUS ON INFORMATION IN PRODUCT DEVELOPMENT CYCLES}

Product development is closely related with manufacturing. The discipline could be considered as an offspring of industrialisation, period(s) in which the society has slowly transformed from being dominantly agrarian towards being dominantly industrial (Drukker, 2003). Industrialisation also had major consequences for the way which products were developed. Especially in mass-production, a wedge was driven between defining and actually making products. Consequently, the common result of (industrial) product development cycles nowadays is not the product itself but a definition of that product. This definition is always expressed in (any form of) information. Consequently, information management inevitably has a significant influence on the product development cycle.

With recent developments such as smart products and smart production environments the relevance of information in product development only increases. With industry 4.0 and additive manufacturing, technologies are becoming more complex and simultaneously more rapidly available which puts high demands on product developers to keep up in order to align product designs. There is an increasing, well-nigh continuous source of data and information available that goes beyond the traditional boundaries of the design and manufacturing environment, heavily influenced by ICT (Haverkort \& Zimmermann, 2017). Fuelled by new technologies on the and a growing need to take stewardship in offering sustainable products, responsibilities of a product development team do not stop once the design is finished and the first products have been launched. New types of 'direct' information, primarily based on sensory data stemming from various life cycle stages of products, offer a range of new possibilities. For instance, it has been beneficially used to prevent or guide maintenance or to allow for graceful degradation. Furthermore, such data goes beyond the traditional user-client boundaries and can be put to use for other purposes. For instance, twitter activity on smart phones can indicate the location of (extreme) events. With the rapid introduction of VR and $A R$ technologies a whole new way of using, combining and representation information is being made available for a broad audience.

With all these developments, data and information play an increasingly important role in product development cycles. This importance of information in product de- 
velopment cycles is widely acknowledged, especially in relation to the more generic knowledge management approached. However, the role of information for design support can be considered a changeling in DTM. In general, design support has focussed on either (CAD/CAE) tools that could aid the product developer or process de- or prescriptions that is used to educate, manage, understand and improve the process of designing. Despite several attempts to centralize information in offering generic design support (e.g. (Shear, 1971a, 1971b) and (Yassine, Falkenburg, \& Chelst, 1999)), the majority of DTM put emphasise on the process of designing and not on the information that is generated during that process.

Information is the language in which the key element of a product development is expressed. In current design methodologies this importance of information management is recognised. However, there are little to none design support methodologies based on this artefact definition. This dilemma between the importance of information in product development practise - e.g. in containing and expressing the product definition - versus the apparent suppositious role information has to play in offering design support, has led to a focus for this thesis on how information can be utilised in offering design support. This thesis thus recognizing the relevance of information in product development, and specifically addresses the role of information management in offering design support. It researches the potential for offering an information-based alternative for the now dominant process-driven design support systems, refuelling this information dimension in the field of design theory and methodology. Whereas 'offering design support' is thus the subject, information is considered the direct object of the thesis. Consequently, the overall theme of this research is defined as 'developing design support via information management for design support in design theory and methodology'.

\subsection{A PRODUCT DEVELOPMENT INSPIRED RESEARCH APPROACH}

The approach for this research is neither quantitative nor qualitative, nor does it follow a specific, predefined process of research methodology. Rather, it is best characterised as a design engineering science approach, in which the added value of a design proposal is developed for a specific researched problem area.

Cross et al. characterise design engineering science and put it between the humanities and the natural sciences, stating that engineering should have a own pillar with own language (Cross, 2011; K. Dorst \& Cross, 2001). They describe the absence of a unified strong body of accepted working approaches. Due to its relative young and interdisciplinary nature there is not one distinct approach. This is characterised by fundamental discussions on the nature of design engineering and the indistinct relation with science (Farrell \& Hooker, 2015; P. Galle \& Kroes, 2015). Next to 'science' and 'humanities', design/engineering is an essential aspect of human cognition. Science relies on objective observation and is rationalistic and deterministic; humanities relates to subjective observation and is interpretative and statistical. As the third pillar, design/ engineering aims for instigated improvement, while being constructive and determinative (Cross, 2006).

The research approach used for this project can be best described as if it were a design cycle itself. Overall, it is best described as a pragmatic approach in which the 
method, technique or tool is chosen based on suitability for the research problem or sub-problems. In this, logic, triangulation and argumentation serve as overall guiding mechanisms, which fits the overarching aim of instigated improvement.

Focus is not put on understanding real world phenomena or describing human behaviour but on finding solutions for discerned and motivated problems in that real world and for those humans. Just as the fundamental intent of any designed artefact is to change the equilibrium, this research has the intention to, however slightly - change the equilibrium in how the design engineering community develops design support.

Consequently, a slightly different vocabulary is used for research themes and topics than might be expected. There is no overall hypothesis on what expected results of the research is for instance, as the intention is to not thoroughly understand a phenomenon but to offer a proposal that intentionally alters the situation in which well-defined phenome occur. Therefore, instead of hypotheses and research questions, purposes and carefully substantiated and constructed aims play first fiddle. The design iteration cycle of analysis, synthesis and evaluation determine the gist of this research. Well-established tools and techniques for design cycles such as a requirement specification and the definition of future use scenarios are employed as research tools.

\subsection{STRUCTURE OF THESIS}

The product development inspired research approach is reflected in the coherence between the chapters. While each chapter has a distinct subject, character and theme, the chapters have an iterative character much as the iterations in development cycles.

Figure 1-1 shows these fundamental aspects of a development cycle. The corresponding coloured bars collectively summarize the distribution of the three aspects in this thesis.

Figure 1-2 indicates the overall structure of this thesis highlighting the coherence between the chapters. Appendix A lists all (co-)authored papers and their relation to this work. The chosen design research approach is reflected in this overview. The purpose of each chapter is briefly stated. Based on the elementary aspects of a the development cycle a characterisation of each chapter is given: the colours used in figure 1.1 for analysis, synthesis and evaluation correspond with the colours used per chapter in figure 1-2. Figure 1-2 also illustrates the structure of this thesis.

Figure 1-1 Basic design cycle elements with an overall characterisation of this thesis per element

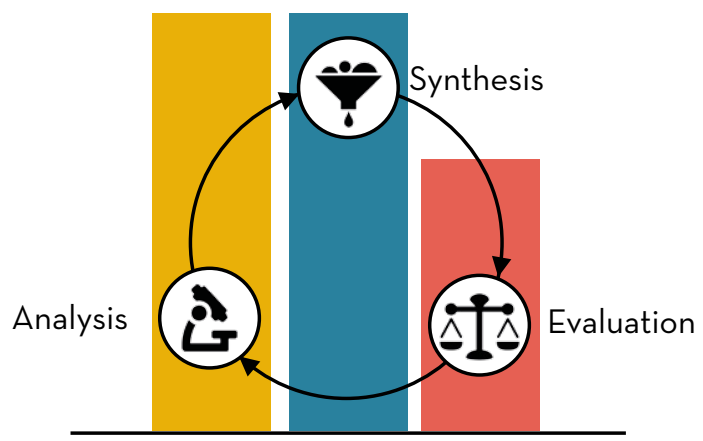




\section{$\S 1$ Introduction}

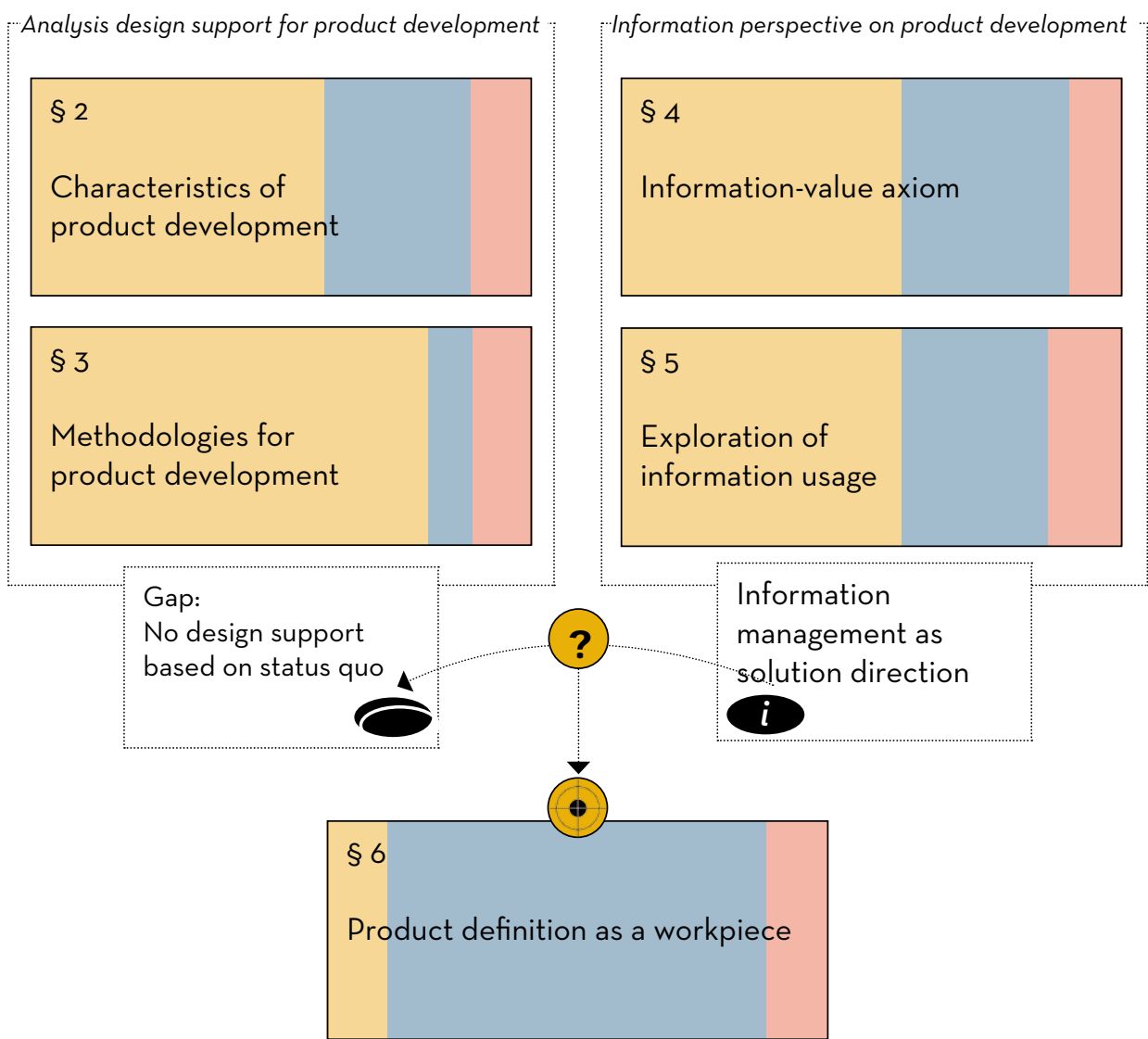

Solution principles

$\S 7$
Actor network as
workpiece engine

$$
\S 8
$$

Mechanisms as tooling engine

$$
\begin{aligned}
& \text { § } \\
& \text { Architecture for content-driven } \\
& \text { design support }
\end{aligned}
$$

\section{$\S 10$ Conclusions \& recommendations}

Figure 1-2 Subject and characterisation of chapters, coherence of thesis structure in five main components 
Chapter one introduces the theme: information management as design support facilitator for product development. Chapter ten concludes this thesis and discusses the result and recommendations for both future research as well as adjacent relevant research themes. In between there are five main components.

First an analysis of design support for product development (chapters two and three) that identifies a gap in this design support. Chapter two characterises product development. Chapter three reviews current design support methodologies for product development.

Second, an information perspective on product development (chapters four and five). From an information-value axiom a formal terminology and reference model is established in chapter four. Chapter five explores the information usage in product development, identifying issues and challenges of current information management and defining a different functionality for information in development cycles based on an analogy with (discrete) workpieces in a workshop.

Third, the product definition as a workpiece (chapter six) in which the requirement specification for the design proposal is defined. Out of the two previous building blocks and the corresponding chapters with different types of explorations and analyses, chapter six thus distils the requirement specification that delineates the desired solution. The foundation of this requirement specification is the so-called stated purpose in which the information perspective on product development as defined and explored in chapters four and five is utilized to fill the gap and challenges analysed and discussed in chapters two and three.

Fourth, the two solution principles (chapter seven and eight) that illustrate the ability to create the two main constituents as defined in the requirements specification: establishing a collection of information concerning the evolving product definition (chapter seven) and establish an interface between this information and the tools needed to realize the defined design support (chapter eight).

And fifth, the architecture (chapter nine) that synthesises all contributions up and from the information axiom: the reference model defined in chapter four, the vision on information usage as established in chapter five, the requirement specification as defined in chapter six and the two solution principles as developed in chapters seven and eight. Chapter nine results in the design proposal for content-driven design support. 


\section{CHAPTER 2}

\section{CHARACTERISTICS OF PRODUCT DEVELOPMENT}

There are many different perspectives on what design actually is. This chapter explores the characteristics that define the practice of design engineering. This is based on literature on design theories and methodologies and empirical research from the packaging industry. This empirical research covers development trajectories of packaging, brands, food, materials and manufacturing systems. The combination of this empirical research and literature results in a characterisation model revolving around the actors, their activities, assets and the artefact that is development. This model will serve as a base upon which current design models are reviewed in chapter three and as input for the development of the reference model defined in chapter four. 


\begin{tabular}{|c|c|c|c|c|c|}
\hline 1. Ideation & Gate & 1 2. Feasability & Gate 2 3. Development & Gate 34 . Testing & Gate \\
\hline \multicolumn{6}{|l|}{ Synopsis } \\
\hline $\begin{array}{l}\text { Offer supplier } \\
\text { Goal }\end{array}$ & & $\begin{array}{l}\text { Feasability study } \\
\text { Business case } \\
\text { B.O.Ms Involved } \\
\text { Costs, savings, ROI } \\
\text { Fillinglines } \\
\text { Filling weight } \\
\text { Footprint } \\
\text { Materials }\end{array}$ & $\begin{array}{l}\text { Site kick-off } \\
\text { Elaboration goal } \\
\text { Design artefact } \\
\text { Prel. tests } \\
\text { Audits } \\
\text { Parts for machinery } \\
\text { Plan \& order }\end{array}$ & $\begin{array}{l}\text { Test filling } \\
\text { Test transport } \\
\text { Enter final articles }\end{array}$ & \\
\hline
\end{tabular}

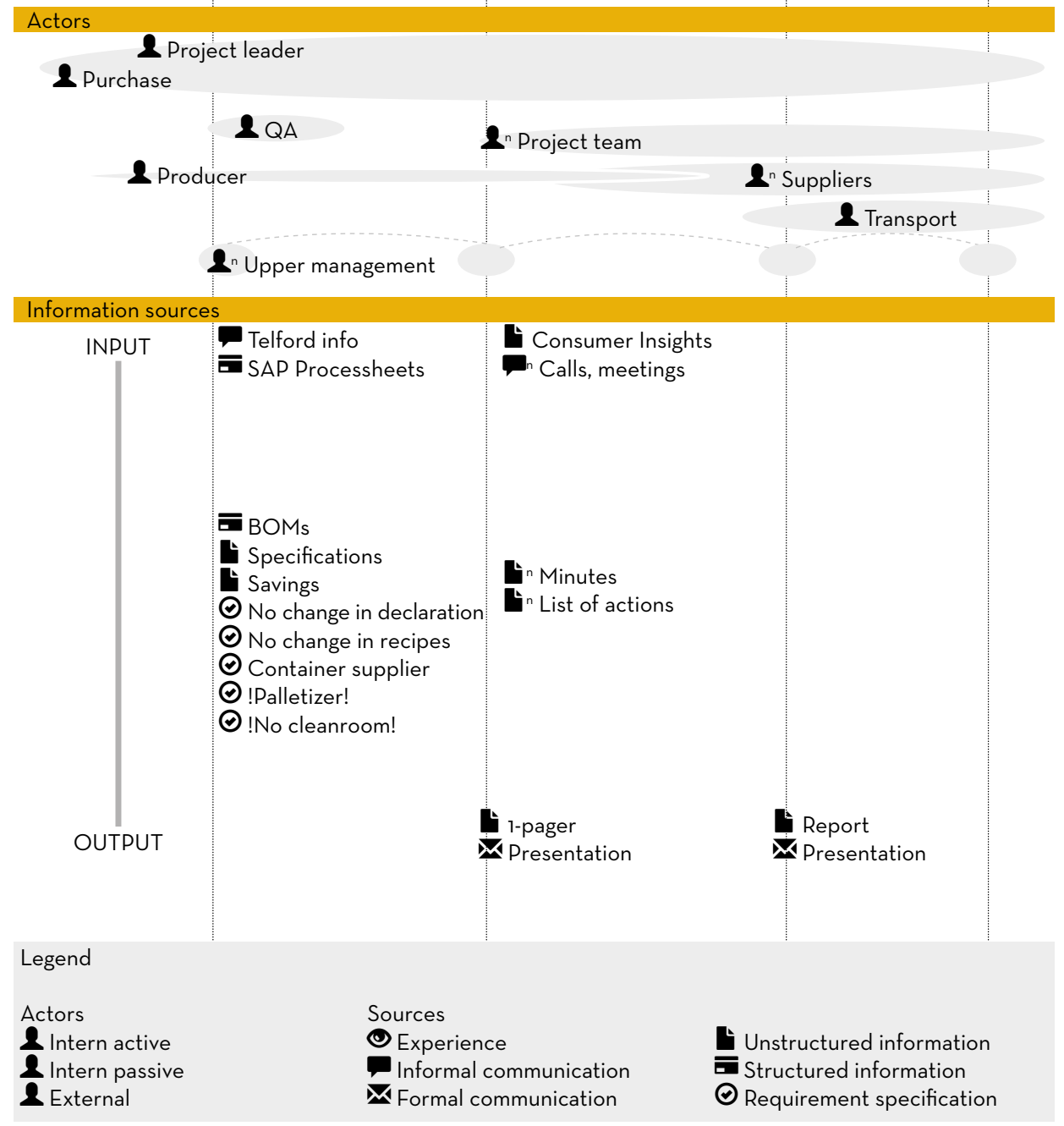

Figure 2-1 Overview development situation based on design engineering 


\section{1}

\section{CHARACTERISATION BASED ON DESIGN PRACTICE SITUATIONS}

Design practice - that is, the activities of men and women designing and developing products on a daily basis - is taken as a base for characterising product development. The aim is to capture the 'voice of everyday practise'.

The majority of the empirical data used in this section predominantly stems from fields related to packaging/ product development such as Fast Moving Consumer Goods and Material Science. A unique aspect of packaging development cycles is that it combines a broad range of disciples covering material and process engineering, manufacturing, design engineering, industrial engineering, marketing, graphical design and retail. While the overall subject in these empirical studies is the research and development of a product/packaging combination, for most involved industries their contribution to this overall concept is considered to be a product.

As it is impossible to fully explore and define each possible design practise, this research uses a set of five design practise situations. Each situation should be regarded as a representative of a certain type of product development. As such, each situation is based on similar organisations that are active in the same markets, have comparable organisational structures and have a comparable strategy for executing product development cycles. The set of development situations are chosen with the aim to illustrate the diversity of product development and design engineering practices. The situations are used as the practise reference throughout this thesis reflecting the 'voice of everyday practice'. The descriptions are based on a series of interviews and workshops aimed at capturing how product development and design engineering trajectories take place, what stakeholders are involved, how they cooperate and fulfil their responsibilities. These interview and gamification sessions were part of two larger research projects on packaging development in relation to sustainable development. One synopsis of such a session is illustrated in figure 2-1. More information about this context and the corresponding approaches can be found in appendix $B$. In clustering various similar cases per situation, a generic overview emerges that puts focus on the characteristics rather than the specific development trajectory per case. An overview of the design practise situations is given in table 2-1; thereafter a synopsis of each situation is given.

\subsubsection{Situation based on design engineering}

For large food processing companies and companies in the fast moving consumer goods, research \& development as well as the larger part of production is mostly done indoors. Focus is put on concurrent content-packaging development; projects have a relative short time-frame of around one year. In project team, generally different departments are involved in various stages of the development trajectory: marketing, packaging development, product development, purchase and production. The team has a commercial as well as a technical project leader. Government and activities are for the larger part prescribed by a company-specific stage-gate process, although experienced stage-gate users (implicitly) apply a less rigid, personalised version in everyday practice. Deliverables for gates are pre-determined and indisputable in order to ensure a contribution that meets expectations, while gradually building the packaging concept and the corresponding business case. 
Table 2-1 Overview design practice situations and the corresponding input

\begin{tabular}{|c|c|c|c|}
\hline Scenario & Keywords & Case & Goal \\
\hline \multirow[t]{3}{*}{$\begin{array}{l}\text { Development } \\
\text { based on design } \\
\text { engineering }\end{array}$} & \multirow[t]{3}{*}{$\begin{array}{l}\text { Packaging; } \\
\text { Engineering; } \\
\text { Management }\end{array}$} & Canister & $\begin{array}{l}\text { Merge two existing } \\
\text { canister designs } \\
\text { into one new } \\
\text { design }\end{array}$ \\
\hline & & Crate & $\begin{array}{l}\text { Design of crate } \\
\text { that fits standalone } \\
\text { bottles as well as } \\
\text { multi-packs }\end{array}$ \\
\hline & & Container & $\begin{array}{l}\text { Redesign of retail } \\
\text { packaging for baby } \\
\text { bottles and teats }\end{array}$ \\
\hline \multirow{3}{*}{$\begin{array}{l}\text { Development } \\
\text { based on market- } \\
\text { ing }\end{array}$} & \multirow{3}{*}{$\begin{array}{l}\text { Packaging; } \\
\text { Marketing; } \\
\text { Management }\end{array}$} & Cask & $\begin{array}{l}\text { Design cask for } \\
\text { home tap system }\end{array}$ \\
\hline & & Sachet & $\begin{array}{l}\text { Design packaging } \\
\text { for new product } \\
\text { category }\end{array}$ \\
\hline & & $\begin{array}{l}\text { Glass jars and met- } \\
\text { al containers }\end{array}$ & $\begin{array}{l}\text { Routine design } \\
\text { adaptions }\end{array}$ \\
\hline \multirow[t]{2}{*}{$\begin{array}{l}\text { Material develop- } \\
\text { ment and manufac- } \\
\text { turing }\end{array}$} & \multirow{2}{*}{$\begin{array}{l}\text { Packaging; } \\
\text { Manufacturing; } \\
\text { Technology; } \\
\text { Marketing }\end{array}$} & Can & $\begin{array}{l}\text { Design new closure } \\
\text { system for large } \\
\text { b2b cans }\end{array}$ \\
\hline & & Material & $\begin{array}{l}\text { Design of new } \\
\text { packaging material } \\
\text { and application } \\
\text { range }\end{array}$ \\
\hline \multirow[t]{3}{*}{ Retail } & \multirow[t]{3}{*}{$\begin{array}{l}\text { Food; Packaging; } \\
\text { Marketing }\end{array}$} & Drink carton & $\begin{array}{l}\text { New packaging } \\
\text { brand concept }\end{array}$ \\
\hline & & Flexible packaging & Improvement \\
\hline & & $\begin{array}{l}\text { Category packag- } \\
\text { ing herbs }\end{array}$ & $\begin{array}{l}\text { Sustainable pack } \\
\text { design for herbs }\end{array}$ \\
\hline $\begin{array}{l}\text { Development } \\
\text { based on prod- } \\
\text { uct-service }\end{array}$ & $\begin{array}{l}\text { Furniture; } \\
\text { Development; } \\
\text { Manufacturing }\end{array}$ & Furniture & $\begin{array}{l}\text { Product service } \\
\text { design }\end{array}$ \\
\hline
\end{tabular}


When expert knowledge is needed on for instance a new material, new machinery or life cycle analysis, external parties are involved. Sustainable development is included in the organisations strategy containing specific goals; important subjects in these goals are climate change, energy consumption, water footprint and waste prevention. Several of these key issues are measured and monitored throughout the organisation. Daily practice however learns that the goals do not resonate on the work floor. As aspects as costs and quality have a more direct impact on revenues, these are unwittingly prevailed at the decisive 'gate' of each stage. Simplified LCA-tools have been used, but are still bound to a few employees with a background in life cycle engineering.

\subsubsection{Situation based on marketing}

For beverage producers, portfolio adaptions coincide with creating several new use moments and corresponding different packaging concepts for the same product are needed. Packaging concepts are relatively new and are labelled innovative for the field of application.

A rather large team (+20 internal stakeholders as well as high involvement of several external parties) involves well-nigh every discipline within the R\&D department. Innovation managers, usually with a background in marketing, are in the lead. The team has several working groups for specific topics. As these topics sometimes address the same packaging components, this leads to overlapping responsibilities and unclear boundaries. The applied methodology is based upon the stage-gate procedure. Decision-making procedures are highly standardised, resulting in formal decision-making moments administered by a significant amount of documentation on progress in minutes and presentations. However, design rationale of decisions is not documented, and what seem to be highly influential decisions in retrospect have been made outside the frame of gated decision-making.

\subsubsection{Situation based on material development and manufacturing}

For material and semi-manufactured packaging suppliers, development trajectories have a relative long time span. The R\&D projects on packaging range from one year to eight years (increase benefit of material and include a multitude of internal stakeholders). Next to the focus on material and production, they give promotion and marketing some attention. As an example, the development of a new (packaging) material takes approximately 8 years and needs many specialised material and process engineers. The required investments in e.g. production lines are substantial, while the future use scenarios of the material and corresponding packaging concepts are only vaguely known at most. In deciding on the specifics of the new material, it is crucial to presage the requirements set by the (future) customers, current and upcoming legislation and production methods, as these decisions have major consequences on investments and therefore the future of the company.

On the contrary, for the development of e.g. a new closure system for B2B application, a small internal team of process engineers, quality experts, marketing, design engineers, process engineers and sales operate in an informal setting, members joining (or leaving) the project due to their personal competencies rather than formal job descriptions. While this contributes to an agile team that quickly responds to changing circumstances, there is little information on decisions, rationale; moreover, important progress is interwoven with communication. 


\subsubsection{Situation based on retail}

The market of fast moving consumer goods is flooded with small 'green' brands. The corresponding brand owners use a specific subset of what is considered sustainable - like fair trade, biological agriculture or corporate social responsibility - as the main proposition. Consequently, sustainability is of paramount importance for such relatively small brand owners. Their main business activity is focused on the brand and the corresponding product portfolio. Actual development, production and packing is done via partners or co-packers. The organisation thus has a guiding role rather than an executive role. The type of packaging is largely determined by these external stakeholders; as internal development is mainly focused on the graphical design. However, the brand owner still makes the final decision on a packaging concept. With this one decision, the larger part of the future environmental impact is set. In recognizing this influence, the organisation has established a set of guidelines that steers sustainable packaging development and provides the necessary counterbalance for the dominant factor of costs. The organisation is largely dependent on external parties for the necessary information.

\subsubsection{Situation based on product-service}

Currently, the office environment is changing more rapidly than ever, people are used to working with technology that makes their lives more convenient. Employees and facility managers expect good and flexible working environments and the best service. The organisation is responding to these market changes by expanding its role as a provider of product-service systems. Its furniture rental business is currently being extended and smart technological solutions are being developed that can gather information from products in use and feed it back to different stakeholders. There is a standardised process flow, however almost none of the development projects adhere to this process definition, resulting in a rather limited set of standard projects, and a large set of specialist projects. There is an effective but informal way of working in which various specialist departments all have their own flavour of approaches. Consequently, communication between departments is over-strained making the process less efficient. Significant factor is the data and information management and conversion, as the field of furniture is on the crossroads of architecture, product design and manufacturing (which is done in house) each with usage of specific software systems.

\subsection{COMMON ELEMENTS}

Although the development situations greatly vary in type of projects, industry and context, there are some obvious commonalities. It is important to note that the described situations are synoptic of character on purpose. Obviously actual development situations might include many more events and detail. While the synoptic descriptions are rather blunt and do cut some corners, the focus here is put on the underlying themes. Each project team involves various disciplines. These include the traditional fields of product design, marketing and manufacturing as described in literature (Andreasen, Hansen, \& Cash, 2015; Pahl, Beitz, Feldhusen, \& Grote, 2007; N. P. Suh, 1991). However, there is also a constant high involvement and decision power to other disciplines as quality assurance, purchasing and sales. As such, design engineering is considered to 
be trans-disciplinary, which is labelled both as an appealing side of the job (Ulrich \& Eppinger, 2015), as well as a potential hurdle in communication (Oude Luttikhuis, De Lange, Ten Klooster, \& Lutters, 2014). As backgrounds and responsibilities vary to a certain extent within the same project team, miscommunication is a common aspect and leads to challenges in alignment and understanding. Whereas the rationale of a design decision might be perfectly valid from one specific viewpoint, this might not be inherently true for all the other perspectives involved. A packaging concept might have the potential to fulfil a promising proposition value while its probable costs make it the least appealing option from a manufacturing point of view. This is influenced by contextual factors such as the culture of organisation, the backgrounds and prevalence of the involved actors, the complexity and novelty of the artefact (Reich, 2010). The overview of contextual factors of Nieberding (Nieberding, 2010) (figure 2-2) captures the many variables that influence the development cycle and suitable methodologies. This sheer amount of influences might explain the large diversity in design methodolo-

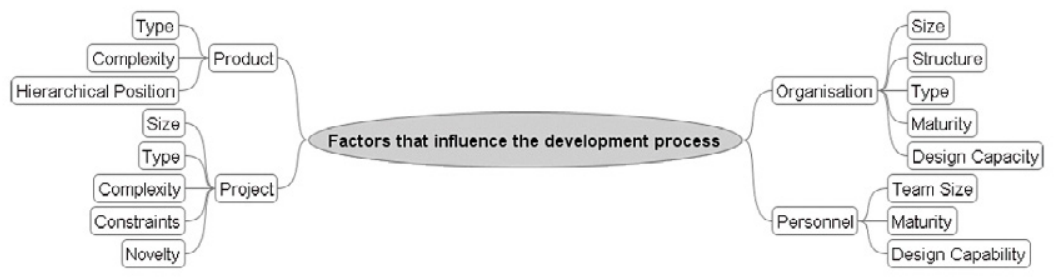

Figure 2-2 Factors influencing the development cycle (Nieberding, 2010)

gies available.

There is a common pattern of elements that collectively constitute a project. As such, product development can be described as a human activity that revolves around creating a (new) product definition using specialist tools and techniques in systematic, skilful but not necessarily deterministic manner. As such, the core elements of any design trajectory are designers/ designer engineers (actors), processes and tasks (activities), using tools \& techniques (assets) aimed at defining a product (artefact). For each element a description is given. Each element is used as a specific viewpoint on design engineering to describe characteristic aspects.

\subsubsection{Artefact}

Product development is a discipline that tries to solve problems and add value for the users through products. Consequently, the product or artefact is key element of any design project. By means of the artefact, the aspired value for a group of users can be fulfilled. Each design project has a fundamental common purpose to fulfil a set of values by means of a product. Even when a project is focused on a specific aspect that has little to do with the end-user, for example saving material weight of transport package, this aspired value fulfilment is still the cornerstone for all considerations. For that, all other elements and aspects of design engineering and product development, like tools, techniques and methods are the means. As such, product development might be best understood when looking at these artefacts, regardless of what type of product it is, a simple package or a full-fledged product service system such as an ATM. Whereas the 
Figure 2-3 Examples of (parts of) product definitions
${ }^{a}$ By Freeformer - Created and originally uploaded to the English Wikipedia by Freeformer, using the same filename., CC BY-SA 3.0, https://commons.wikimedia. org/w/index.php?curid=3733031

b. By Rick Dickinson [CC BY-SA 3.0 (https://creativecommons.org/licenses/ by-sa/3.0)], via Wikimedia Commons

By Thorsten Hartmann - Own work, CC BY-SA 3.0, https://commons.wikimedia. org/w/index.php?curid=735359

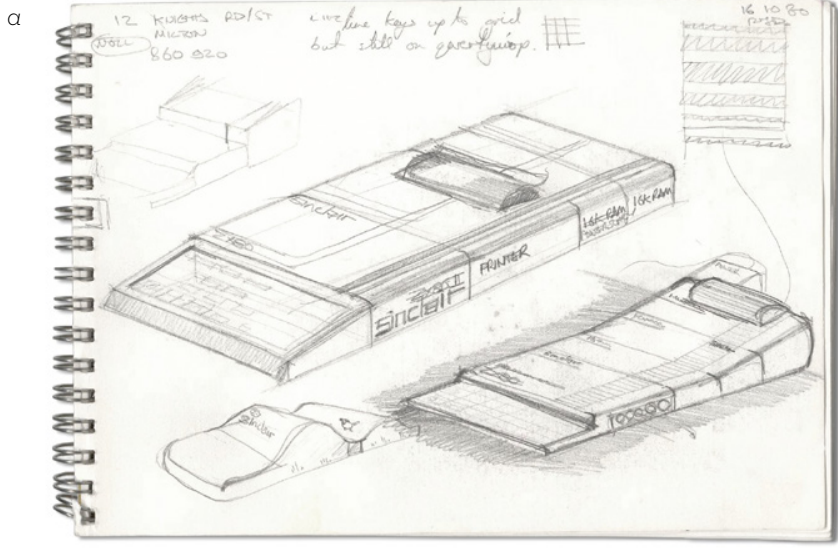

b
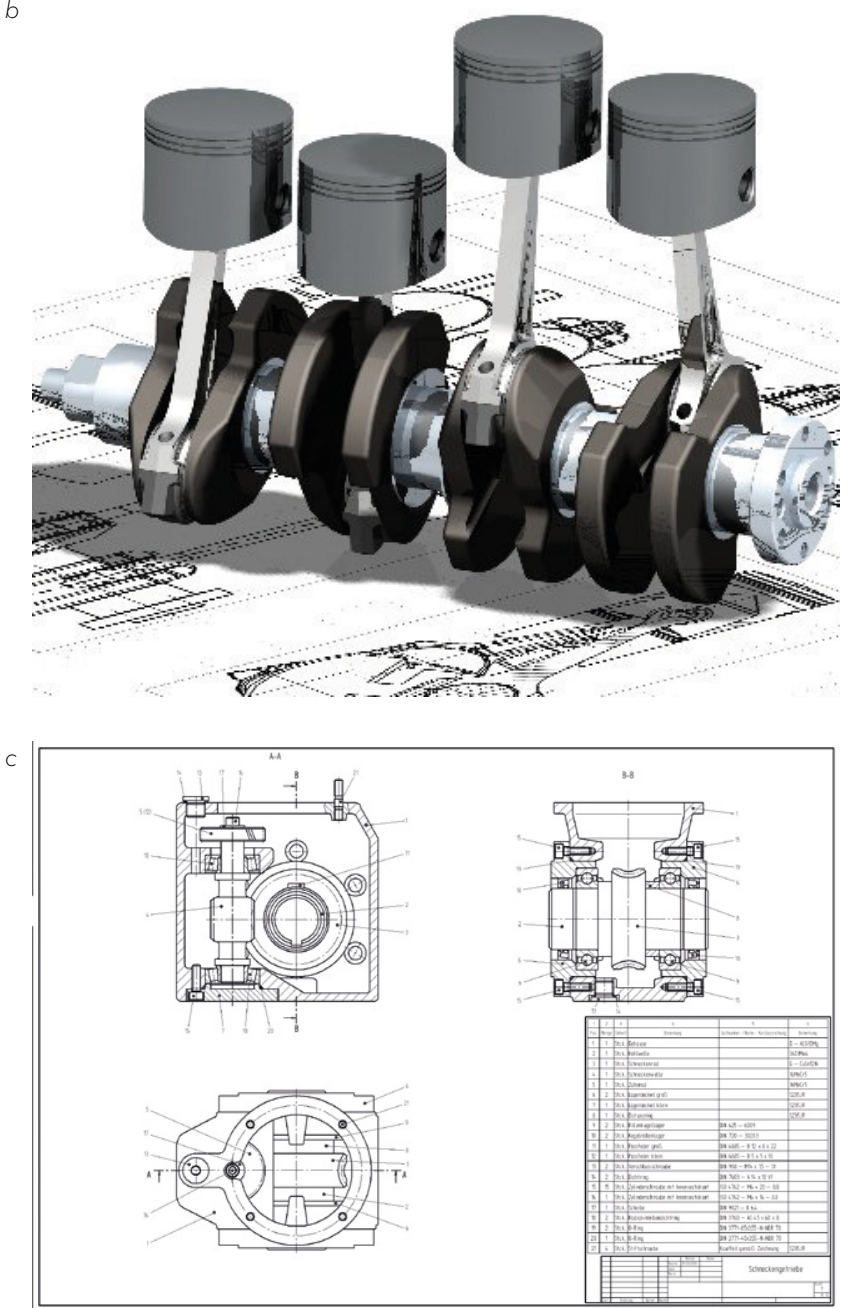
ultimate goal of designing is the produced artefact in use, that physical artefact itself is not the common result of a development cycle. Although physical models can play an important role in testing new s olutions and materializing abstract ideas, the result of a development cycle is not the product itself. Although some methodologies incorporate the actual production, it is the definition of that artefact that is commonly regarded as the result of a development cycle. Examples of such product definitions are given in figure 2-3.

The representations used to depict (aspects of) the artefact often serve multiple levels of aggregation simultaneously (D. Ullman, 2015). This ability of making representations of the future artefact is a key characteristic for a design engineer (Cross, 2006). However, in practice, the representations vary greatly among disciplines, from purely text-based briefings to CAD-models or even Virtual Reality models combining all types of languages (D. Ullman, 2015). The purpose of any representation is always to communicate. Whatever representation is dominant, the basic types are graphical, analytical, physical and/or semantic (Chandrasegaran et al., 2013). During a development cycle, (sub)definitions of artefacts are often incomplete representations that are nevertheless accepted on premise (Crilly, 2010). Not only the explicit information that constitutes the artefact is taken into account, but multiple assumptions on desired possible future states are taken into account as well. With every solution, the intent is to change a current situation into a desired or more preferred one. Rzevski stated this as "every design solution (produced artefact) will inevitably change equilibrium relationships within its environment and thus create unforeseen problems" (Rzevski, 1981).

With that, unforeseen consequences are inevitable and will create unforeseen problems in that new situation. Consequently, it is important to note that each representation might be incomplete and is likely to be view-dependent, as such while these sources of information aim to purposefully contribute to the product development cycle, simultaneously the same documents are potential sources of uncertainty. For instance, the development situation based on marketing (see section 2.1.2) entailed a visualisation of art directions of the packaging concept that were used as if it was the definitive concept and starting point for engineering the package. The interviews with the involved actors did not reveal a decision in which these concepts were deliberately chosen or were reviewed. It seemed that it simply entered the evolving product information as an artist impression supporting a value proposition and was then used as a reference point in realizing and defining the package. Consequently, drawings of a packaging concept that might have been intended as preliminary idea where conceived as being the definitive concept.

Out of the four common elements the artefact is considered the key defining element for product development. The produced artefact always has the intention to add value and therefore change the equilibrium. Characteristic of the artefact definition is that it commonly consists out of incomplete representations from various perspectives, especially during a development cycle. Nevertheless these incomplete representations are excepted on the premise they convey.

\subsubsection{Actor}

A design project typically involves contributions from a variety of stakeholders or actors within and across the borders of an organisation. This collection of individuals, 
departments and organisations that are involved in the design project are referred to as actors. Consequently, an actor is any (legal) entity that has an interest in and/or influence on a product development cycle.

All actors, often with different perspectives and interests, are involved in the decision-making processes during the development cycle, while continuously influencing and deciding on the future state and life cycle of the product under development. Consequently, actors encounter a large variety of interrelated variables and requirements, in different states of evolvement, belonging to many different life cycles. Moreover, all actors have their interests in different, possibly conflicting, aspects. Consequently, where the rationale of a design decision might be perfectly valid from one specific viewpoint, this might not be inherently true for all the other perspectives involved. For example, a packaging concept that is perfect from a marketing perspective, may be infeasible from a production point of view. Therefore, all actors need to negotiate and collaborate to eventually succeed in reaching consensus on the entire set of decisions to make, including the way in which requirements will be met.

Given the relevance and impact of the activities of all actors, identification of what grants any design engineer an authoritative impact can be decisive in the success and quality of development cycles. Therefore, many design methods and methodologies are accompanied by an overview of what abilities a good design engineer should master. Pahl, Beitz et al. characterise a design engineer to be a good problem solver that combines intelligence with creativity and a decisive attitude (Pahl et al., 2007). Ullman puts focus on the creative aspects of a design engineer and uses it as the common denominator that design engineers need to combine with risk taking, visualisation and intelligence (D. Ullman, 2015). In contrast, Nam Suh focusses on the analytical aspect in advocating a more rigorous, scientific base for design engineering (Nam P. Suh, 1998). In simultaneously defining the problem as well as the solution, actors need to combine a systematic perseverance with intuition and experience, purposefully using creativity and decision-making (Eric Lutters, van Houten, Bernard, Mermoz, \& Schutte, 2014).

The experience of actors is of great influence on any development trajectory. Here, experience is considered to be the personal set of expectations, based on the interpretation of prior encountered situations, that enables the analysis, understanding and evaluation of information. Experience enables the selection and use of the right set of knowledge (Ahmed, Blessing, \& Wallace, 1999) simultaneously it allows for learning in the current cycle and immediately distinguishes between process steps that can be executed almost implicitly and the ones that require specific attention.

Creativity is the ability that enables a design engineer to solve intricate and complicated problems or to alter the original situation in such a way that it prevents the problem to even happen. Creative thinking is highly unpredictable and has a subjective nature, whereas in retrospect its effect or rationale can often be logically explained (Kryssanov, Tamaki, \& Kitamura, 2001).

Complementary to the divergence of creativity, decision-making is the converging activity that determines the preferred course of action in a design trajectory. Simultaneously, there is an important aspect of consolidation in decision making: determining which available option is currently best and which alternatives are abandoned. Consequently, decision-making can be understood as the ability of an actor to foster and consolidate the product definition while amplifying the design rationale (Roucoules, Yahia, Es Soufi, \& Tichkiewitch, 2016). 
There are a multitude of approaches towards decision making, ranging from the linear more rational approach put forward by the work of Herbert Simon (Simon, 1996), to the more reflective practise as described by Schon (Schon, 2008). Both approaches recognise the fact that any decision made in a development cycle is made on incomplete information, incomparable or poorly detailed alternatives and potentially unjust information and therefore requires assumptions to be made on both the quality of the information and the potential consequences.

Influenced by his work for an administrative organisation, Herbert Simon advocates a rational approach towards decision making in which the aim should be to select the alternative that results in the preferred set of consequences.

The reflective approach is based on a descriptive model of how practitioners make decisions. Here, focus is put on the experience of the design practitioner in which intuition, creativity and improvisation lead to reflections that explains how design engineers meet the challenges of everyday decision making. It has formed on of the anchor points for a body of research - often referred to as design thinking (Kees Dorst, 2011). - that elaborates on the various models and modes of reasoning practised by design engineers.

When the mechanisms of decisions are thoroughly understood and precisely defined, some of these decisions might be accurately simulated or even completely replaced by algorithms. Mathematical approaches towards design engineering as formulated in the General Design Theory (Yoshikawa, 1987) and Axiomatic Design (Nam P. Suh, 1998) have initiated and influenced the field of design automation and decision support systems (Yin et al., 2015a).

Decision making in this research is understood as a principally human activity, in which automated, simulated decisions can play a supporting role, but can impossibly replace the actor due to the importance of creativity and intuition. It is recognised that decision processes may not always be rationally motivated as we are programmed based on habits and subconscious processes (Kahneman, 2003) and make extensive use of heuristics (Gigerenzer \& Gaissmaier, 2011). There are many reasons for this process of reasoning and aligning to stagnate. Well-known causes of inefficiency and ineffectiveness in the process are actors forced to await input or decisions of others, misapprehensions caused by divergent terminologies, myopic attempts for local optimisation and the infamous 'force of habits'. Such patterns in the design process, when adequately recognized can be used to offer support techniques for decision making and offer an design approach 'by least commitment' (Roucoules \& Tichkiewitch, 2015), Es-Soufi, Yahia, \& Roucoules, 2016). Important factors in decision making are the composition of the set of actors responsible for the decision, the manner in which the information is used and the perspective actors defined for decisions (van Riel, Semeijn, Hammedi, \& Henseler, 2011).Whichever approach is used, decisions need to be made based on a combination of incomplete information, intuition, goals and hard-to-make assumptions. To reach an adequate set of requirements and a correlating product definition, actors collectively need to understand each other's motives and consider (the rationale behind) contradicting proposals. Actors must establish, retrieve and reconsider decisions in relation to their rationale and the context that constitute a decision. Here, it is important to discern the consequences of individual decisions in a larger context, preventing from inadvertently imposing constraints on other decisions or actors. 
In literature, actors involved in product development are attributed high level skill sets. Actors involved in this discipline combine intelligence, intuition, creativity and decision making abilities.

\subsubsection{Activities}

The notion activity encompasses that what designers do to achieve a set goal, to initiate an alteration or to arrive at a satisfactory outcome. As such, activities constitute the actual performance of designing and engineering. When viewed from this angle, product development renders a character consisting of contrasting activities. It is characterised as being exploratory as well as investigative, rational as well as opportunistic, intuitive as well as systematic (Adams, 2015; Cross, 2006; Erbuomwan, Sivaloganathan, \& Jebb, 1996). Indeed, when generic sets of activities are viewed, all these types of activities have a place and intended purpose (Howard, Culley, \& Dekoninck, 2008; Kryssanov et al., 2001). However, the manner in which these activities are determined are diverse. The traditional approach, often labelled as systematic, is to determine activities on beforehand by careful planning and concise task descriptions (Howard et al., 2008; Pahl et al., 2007; Ulrich \& Eppinger, 2015). However, this is well-nigh impossible to achieve, as design is emergent, that is, the solution space and problem space co-develop (Cross, 2006). This is also the underlying gist of the trend of design thinking (Kees Dorst, 2011): the problem can be better understood by proposing and exploring (partial) solutions. Consequently, iterations are needed to revisit previous tasks (or stages) instigated by unexpected, unreliable, unexplainable or incorrect outcomes.

Given all the intangible interactions in design processes, approaches like the stage gate, aim to prescribe certain sets of activities and corresponding deliverables. However, explicitly stating such sets of activities does not unconditionally have as a consequence that these activities are then also strictly effectuated. Contrary to the prescriptive fashion in which these approaches express support, in practice, the approaches are rather used as semi-formal blueprints and accepted as control principles.

One of the reasons why it is well-nigh impossible to sustain explicit and administrative approaches in everyday practice, is that design processes inherently include and even rely on taking risks. While these characteristics have been widely recognised, it is also recognised that this has consequences in how we describe, prescribe and model design processes, and a balance between creativity and systematic approaches is needed in an artesian fashion (Eric Lutters et al., 2014). In an attempt to capture this dualistic character, combines two opposite perspectives: cumulative progression with disruptive reorientation (Crilly, 2010). With this combination, Crilly emphasizes that these two extremes do not exist in isolation but act as mutual boundary conditions.

Product development is a craft that requires a wide variety of skills which explains the variety and extremes in characteristics of the corresponding activities. A product development activity can be exploratory or investigative, rational or opportunistic and systematic or intuitive.

\subsubsection{Assets}

Assets are considered to be the toolbox and work shed of a design engineer. Assets are the tools and techniques applied by actors and the environment in which those tools and techniques are embedded (Eric Lutters et al., 2014). Additionally, the notion assets is used as a collective name for all ancillaries used in a design project and all auxiliaries 
that provide the necessary environment that enable useful and valuable operation. There are numerous tools and techniques available for design engineers, each with a specific scope, prerequisites and purposes that aid in how drafts, models or constructions are made, how a design team should reach a decision or in what fashion an activity should be performed. Some examples from the design practise situations are brainstorming techniques to come to a value proposition, decision support techniques to lay bare the advantages and disadvantages and (in every scenario) examples that enable actors to visualise ideas, drafts, concepts or full product definitions. The tools and techniques that enable visualisation, whether this is sketching with a pen or modelling with a cad-system, are characteristic for a design engineering environment and aid the designers in clear communication, critical thinking and channelling creativity (Cross, 2006).

In many ways, these tools and techniques are instruments for the design engineer, logical extensions that are fully ingrained in the daily practice. Consequently, the tools and techniques known and available by the design team affect the trajectory of the development cycle. For instance, in the development situation based on retailing, sustainable development is addressed using a specific set of written propositions in combination with an evaluation based on best practices and common sense, whereas in the development situations based on design engineering environmental assessment is done via a standardised protocol, using specialist software.

Auxiliaries also significantly affect development cycles. Systems in use, e.g. ERP, PLM and PDM, are often established entities of the design environment that a design team simply has to deal with. Being indispensable in governing the complete product development and life cycle, these systems can also negatively influence the development cycle. An example is the situation in which information is stored in a rigid and predetermined manner, as design practise situation based on design engineering illustrates: information about production lines and corresponding suitable packaging formats are not available on random search strings but only on specific article numbers of the ERP system.

The assets used in product development are first and foremost aids. However these auxiliaries and ancillaries do affect the way in which the artefact can be represented, the activity can be performed or the actor can influence the artefact.

\subsubsection{Key characteristics}

Obviously, the core elements as described and characterised above are connected. In a sense, these connections enable the product development cycle. Figure 2-4 combines the described aspects and characteristics with the actor-artefact-activity-assets model previously introduced. From it the before-mentioned dualistic character between systematic, analytical aspects and creative, intuitive aspects is obvious. Moreover, the figure states the input and impact that each of the aspects have at any given time in the process. This demonstrates that no development cycle has an unambiguous starting point, a predictable course nor a definitive end. Generally, design methods, or stage gate methods, mostly aim to compartmentalise the process (i.e. the activities) to such an extent that it can remain understood by the actors. With this, attention not only shifts away from the content of the development cycle to the more organisational and managerial perspectives on product development, but equally important, other 


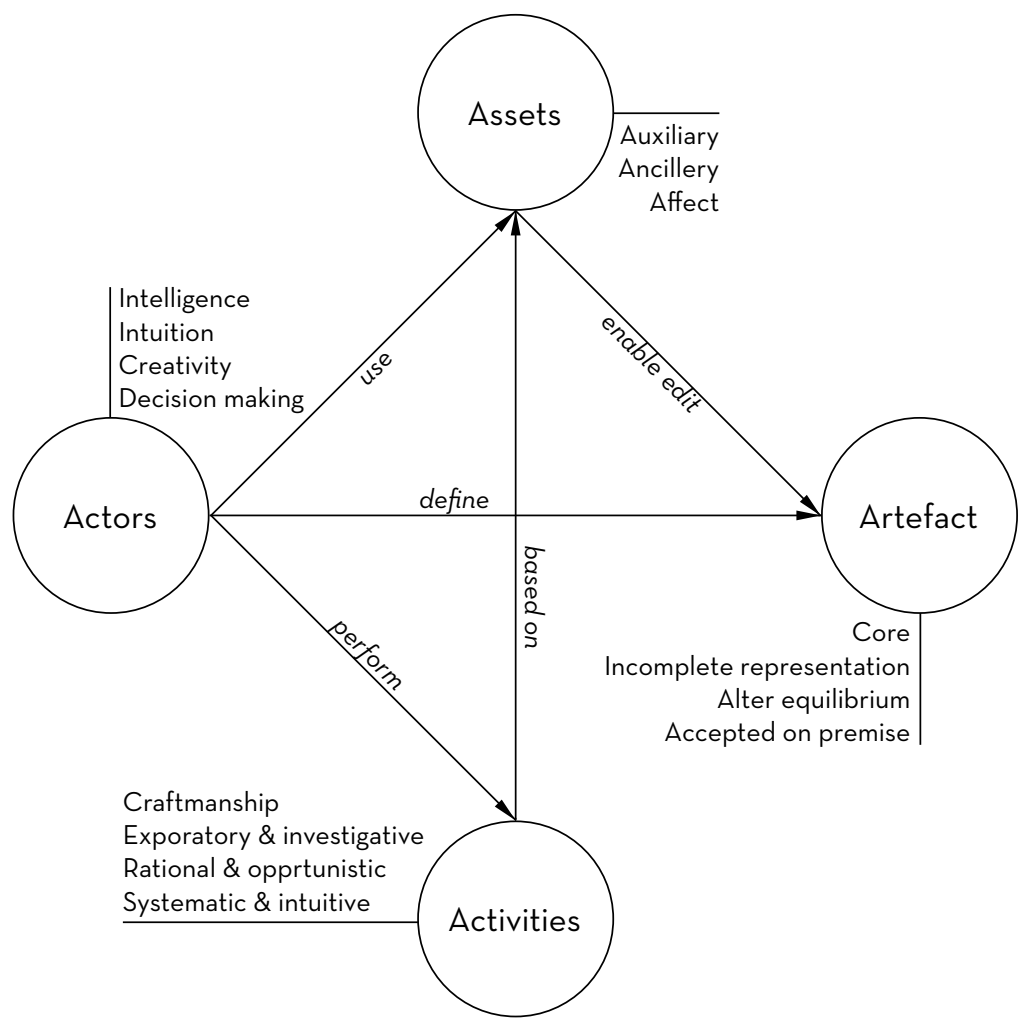

Figure 2-4 Model of actors, artefact, activities and assets and corresponding key characteristics

aspects (assets and artefact) have become undervalued. However, given the multi-variant and concurrent leverage of all four aspects over the entire development cycle, development processes are elusive in nature - with design methods rendering useful yet incomplete security. Design engineering is in essence a combination of both deterministic and non-deterministic processes that involves creating future solutions for future situations based on current information or an extrapolation thereof. After all, being a human activity, non-deterministic aspects are an inherent part of design engineering (Kryssanov et al., 2001). Consequently, for a design engineer neither the game of designing nor the rules of the game are self-evident or definite. This non-deterministic character has a strong relation with incompleteness and indefiniteness and unforeseen consequences and unpredictability. These resemble uncertain aspects that can have both a positive as well as a negative influence on the development cycle.

Labelling design engineering as a combination of deterministic and non-deterministic processes does not invalidate any systematic or analytical approach, it simply implies that the assumptions underlying such an approach might not hold true, nor be effective or efficient for all practical circumstances. For a product developer, this means that part of the job is to determine when pragmatism can or needs to prevail over theoretical soundness. Hence, there is need for constant consideration of which activities and assets are needed to fully develop, master and employ the craftsmanship 
(Eric Lutters et al., 2014). Consequently, actors need a high level of autonomy in practice design engineering.

Starting from an aleatory base, characterised by shortages of complete, decisive and reliable information, a development cycle (with all its explorations, iterations, endeavours and (re)considerations) constructs a definition of the artefact. This definition aims to be transparent, unambiguous and complete. In the evolvement of that definition, designers continuously aim to translate a set of abstract, concrete, vague and subjective requirements, perceptions and inspirations into well-defined solutions. Design engineers are particularly experienced in dealing with the uncertainty, ambiguousness and unpredictability that characterises the development cycle. It is the problem solving focus, creativity and the ability to make decisions under uncertainty that allows a designer to create new ideas and materialise the pursued added value (Kees Dorst, 2011). Design engineers excel in generating clear-cut product definitions from ideas, concepts, promises and gut feeling, rendering them visionary but inimitable at the same time. It is the creativity and artisan-ship of the designers that allow them to cope with the vagueness and indefiniteness that characterise the development cycles.

The non-deterministic aspects are not unique to the early stages of design, but have a more generic character. As a development trajectory progresses, the efforts needed to change the definition increase rapidly. Consequently, within the early stages of such trajectories, the potential to efficiently and effectively influence the future impact of the product(s) is the highest (Robert G. Cooper, 2008) while simultaneously these early stages are often characterised as fuzzy (Riel, Neumann, \& Tichkiewitch, 2013). Indeed, the start of a development cycle often seems more precarious than the later stages. However, this may be caused by the fact that many actors (implicitly) tend to assess the amount of uncertainty as a ratio against the amount of information already established. Obviously, if hardly any information is available, small indistinctnesses can drive this ratio to extremes. In the later stages of product development, when the product definition is much more elaborate, the relative impact of indistinctness on this ratio may appear much smaller. However, while building the product definition, every next step has a certain (absolute) amount of uncertainty involved. Interestingly enough, this amount is well-nigh independent on the magnitude of the set of all the future decisions looming. This is caused by the reflection that the vast majority of these decisions cannot yet carry meaning for or cannot yet influence the next design step. So, although the future impact of decisions in the earlier stages of product development may be more far-reaching, the actual amount of indistinctness that designers have to deal with does hardly change over the development cycle. In other words, for designers, every next step has fuzzy aspects of its own (De Lange, Oude Luttikhuis, \& Lutters, 2016).

With this, a development cycle is a venture that has a rolling horizon, in which every step attempts to produce an evolvement of the product definition, by assimilating the information, context and indistinctnesses that characterise the current state of affairs. Therefore, the fuzzy front end is not just the starting point of a development cycle. It rather is the ever-fuzzy next step that builds on the already consolidated product definition. 


\subsection{EVOLVING REQUIREMENT SPECIFICATION}

In product development the requirement specification is a key concept in which the aim is to relate each of the discussed elements (actor, artefact, activities and assets). As such, a requirement specification is an important integrating concept in product development. This section elaborates on the concept; the various types of requirements and their coherence; and the importance of iteration and evolvement.

Obviously, there is a clear relation between actors and requirements ( $E$ Lutters, Dankers, Oude Luttikhuis, \& De Lange, 2014). After all, requirements are formulated and met by actors in the design cycle, rendering all actors contributors to the evolving definition of the artefact. Traditionally, this artefact is often seen as a baton in a relay race: usually not all actors are simultaneously part of a development project. Howev$\mathrm{er}$, in practice, the product definition is more the consequence of a conjointly maintained responsibility. In consequence, an actor is focusses on specific requirements and specific parts of the product definition. Thus, to actualise an addition, change or evolvement of the artefact or requirement specification, an actor or set of actors is the moving force.

Many design methods assume that at the beginning of a design project, a univocal, structured and well-balanced requirement specification is available, or can be established (Tomiyama et al., 2009). Such requirement specifications address the quantifiable variables of the design process, leaving as little room for interpretation as possible. This aligns with the converging character of (especially) the embodiment and detail phases of design trajectories, whereas it is a contradiction with the uncertainties and equivocalities that are inherent to the earlier phases. In those earlier phases, requirements that are inordinate or over-specified may inadvertently bias decision-making or conceal auspicious solution directions for unclear reasons. This mainly happens if the requirement specification is 'written in stone' or is formulated in a way that is either too specific or too detailed. Such specifications may inadvertently fix constraints and possibilities too early in the process. This is even more true for specification types that inherently are not quantifiable as long as there is no embodiment of the solution that is available for evaluation or testing. For example, consumer or user behaviour is difficult to capture in terms of outlined requirements, although they are extremely relevant for, or even leading in, the design project.

Consequently, requirement specifications need flexibility and elaboration as concerns the level of aggregation. The required flexibility relates to the fact that requirement specifications need to evolve with the design project. The more information becomes available on the chosen solution (path), the more the requirement specification

Figure 2-5 Cohesion of requirement specification types (D. Lutters \& Van Houten, 2013)

stated purpose
\begin{tabular}{c|c|c|}
\hline $\begin{array}{c}\text { technical } \\
\text { specification }\end{array}$ & $\begin{array}{c}\text { functional } \\
\text { specification }\end{array}$ & $\begin{array}{c}\text { scenario based } \\
\text { specification }\end{array}$ \\
\cline { 1 - 2 } uncertainty & ambiguity \\
\hline
\end{tabular}


can be tailored to the actual artefact definition in the design project (Chandrasegaran et al., 2013). Thus, the requirement specification must evolve with the artefact and the project.

Next to this flexibility, it is important to have different ways of expressing requirements (Weissman, Petrov, \& Gupta, 2011). Dependent on the level of aggregation, requirements can refer to specific variables with specific values or to general depictions of what variables may be appropriate in the requirement specification of a product. For this reason, the requirement specification is subdivided in a number of levels (Miedema, van der Voort, Lutters, \& van Houten) (see figure 2-5). The first level comprises of the pre-imposed requirements of (external) stakeholders:

- The Stated Purpose is the predefined, formalised and static reference of a development process. It reflects the design brief, i.e. the original description of the design problem. With this, the stated purpose depicts keynotes (including e.g. laws, marketing and safety) that cannot be meddled with.

Based on this, the other types of specifications are established:

- Technical specifications are complete and unequivocal expressions of product requirements. In general, technical specifications express quantitative or easily quantifiable demands. (e.g. thickness of a suitcase shell)

- Functional specifications provide a description of desired future product behaviour. In general, they express concrete demands to abstract product models. (e.g. allowed consequences of a suitcase that falls from a staircase)

- Scenario-based specifications depict a 'possible future', thus placing emphasis on the product's environment and the interaction between product and that environment. Product behaviour is indicated in terms of what the environment, e.g. the user, can do with a product and how it will interact. (e.g. what might happen to the suitcase on a trip by airplane)

The rigour and expressiveness decrease from stated purpose to scenario based specification. Scenarios have a narrative character as compared to the structure and transparency of the stated purpose and technical specification. Consequently, scenarios give more room for interpretation and haggling. Translating scenarios via functional requirements into technical requirements is not straightforward: by definition, univocality and quantification entail subjectivity. The same stakeholders have to converge to the appropriate requirements, while executing the design cycle. Thus, product developers aim at problem solving, while requiring adequate ways of capturing, framing, converting and embedding the contingencies involved in selecting the individual (values of) requirement specifications to consider.

To be useful, the requirement specification must be reliable. However, it always contains uncertainty. Here, uncertainty means that consequences, extent or magnitude of circumstances, conditions or events are unpredictable - or credible probabilities to possible outcomes cannot be assigned. Although too much uncertainty is undesirable, manageable uncertainty gives the freedom to make creative decisions. This directly relates to the phasing in development cycles, ranging from the fuzzy-front-end to the nitty-gritties of near-production stages. Interestingly enough, this coincides with the observed need for quantification when evolving from scenarios via functional to tech- 
nical specifications, and the convergence while doing that (D. Lutters \& Van Houten, 2013). At the same time, requirement specifications also suffer from ambiguity; ambiguity is the situation in which it is not obvious or predictable which entities/uncertainties play a role. As such, it is a kind of second order uncertainty.

By neglecting or omitting uncertainties and ambiguities, designers may easier converge to adequate solutions, however, they cannot asses the risks involved (Schrödl \& Turowski, 2014). This leaves designers with the need to integrate uncertainties and ambiguities in requirement specifications that evolves with the project: the artefact definition always correlates with the requirement specification and vice versa, under influence of the decisions of all stakeholders.

In relating requirements to actors, the different types of requirement specifications (see figure 2-5) have different roles. The stated purpose is a kind of contextual set of depictions that determine the system boundaries of the artefact that can be achieved. In the resulting playing field, actors can work with technical specifications, which are individual elements in both the requirement specification and the artefact definition. Functional requirements are individual elements in the requirement specification, yet relate to at least one cluster of related elements in the artefact, thus influencing multiple actors. Scenarios affect multiple elements in both the artefact and the requirement specification; as scenarios address alternative solutions by definition, they also include different sets of actors.

\subsection{CONCLUSION}

Based on empirical data - product development situations capturing the 'voice of everyday practise' - common elements of design engineering were found in the set of actors, artefact, activities and assets. Each aspect is used to find key characteristics of design engineering based on examples from the scenarios as well as design engineering literature. The overall character of design engineering is defined as a combination of deterministic and non-deterministic aspects, which requires a high level of autonomy for design engineers to effectively and efficiently define the artefact under time pressure. Moreover, it illustrates the Janus-faced role of uncertainty, as it has not only a negative influence, but is also needed. In fact, without uncertainty the rationale behind the entire discipline would be lost.

To bring product development cycles to a conclusive and successful end result, the product development team needs to unequivocally convert the innumerous inputs, insights and influences into an objective and communicable product definition. For any practical application, this is unreachable, given the different (subjective) perspectives that play a role. Moreover, this is infeasible because of the inherent interwovenness and dependency of all information, activities and foremost decisions that conjointly determine the route to the end result. For product developers, the end result and the approach to reach that result cannot be separated. This is inherent to the non-deterministic character of product development cycles. The fact that many decisions, activities or evolvements in design are -in themselves- quite predictable or even straightforwardly deterministic does not detract from the overall multiformity of the development cycle. After all, if a certain step in the cycle is deterministic in nature, the perspective that instigates its use as well as the timeliness and the underlying information content 
that acts as an input may still render the -however predictable- outcome of the step as a non-deterministic contribution to the overall development cycle. Product developers continuously weigh the reliability of deliberate and reproducible considerations against the potential added value of daring ventures with many visible as well as implicit or hidden impacts. Striking a balance between reproducibility and potentiality is a non-deterministic act by definition. Consequently, this act is the core origin of indefiniteness in product development and with this the inducement of uncertainty in all its appearances.

In order to avoid adopting any implicit imposition of deterministic process dependencies, the different situations as depicted above are used to identify elements that constitute independent constituents of design cycles. In the next chapter, existing formal approaches for product development are discussed in order to be able to contextualise such elements. 



\section{METHODOLOGIES FOR PRODUCT DEVELOPMENT}

This chapter analyses the available design support for product development stemming from the field of Design Theory and Methodology (DTM). Considered as a specific sub branch of design engineering research, this field is concerned with offering support in understanding and executing design processes. Based on a selection of methodologies that is intended to be illustrative for the diversity of the field, an attempt is made to characterise how the previously described common elements, and both the deterministic and non-deterministic aspects are taken into account. The characterisation enables to analyse the current status in design support and define the challenges. As such, this analysis contextualizes the common elements described in the previous chapter. Together, the two chapters outline a relevant current gap in DTM. 
DTM covers a vast collection of subjects and research areas (Horváth, 2004). There is no strong consensus on terminology; one could address the research as a classification of specific types of design theories and models (e.g. Vermaas, 2014), or as a collection of principles, guidelines and heuristics (e.g. Fu, Yang, \& Wood, 2016). For this research, the following definitions are used ("CIRP Encyclopedia of Production Engineering," 2014):

- Design model: a simplified and abstract view of the development process

- Design methodology: the way in which design methods are used in the context of the organisation, the project, the product, all stakeholders, and all other aspects that influence the development cycle.

- Design method: a model that employs a series of steps to prescribe the development process

- Design tool: an instrument that enables performing a certain process within the overall development process.

The focus of this chapter is primarily on how designers can employ tools, techniques, models and methods to adequately approach design cycles. In this, the overarching notion design methodology offers a holistic view on the development cycle and covers all aspects thereof. Because of the complexity of such a holistic view, many depictions found in literature are at the interface of methodology and method. Prominent examples are Integrated Product Development of Andreasen REF, Systematic Approach for Engineering Design Approach of Pahl\& Beitz (Pahl et al., 2007), Axiomatic Design (N. P. Suh, 1991), Mechanical design process (D. Ullman, 2015). In this chapter, the indication 'methodology' is used, to avoid any unnecessary focus on definitions.

Design methodologies have a clear purpose in creating a framework in which design methods, tools and techniques are logically ordered and in which the basic principles are explained and applied (Birkhofer, 2011; Pahl et al., 2007). The success of this educational target is illustrated by the far-reaching influence design methodologies have had on design engineering curricula (Finger \& Dixon, 1989a; Tomiyama et al., 2009) .

The use of design methodologies in practise is less evident than in education. One explanation is that design methodologies put the primary focus on the overall process, whereas design practitioners are more focussed on the outcomes of that process (Gericke, Kramer, \& Roschuni, 2016). However, most methodologies serve design practitioners from industry as well, an overall aim that can be concluded as supporting design work (Birkhofer, 2011). For this thesis, focus is put on industry application and how the methodologies are or could be used as control principles for development cycles, addressing support in decision-making, communication, education and inspiration.

In supporting design practice, methodologies aim to provide for systematic, controlled procedures that enable design engineers to arrive at sound product definitions (Pahl et al., 2007). These procedures also aim to serve as a common ground that ensures a certain standardisation in processes and terminology. Consequently, it serves as a common language that aims for clear communication for everyone involved. Furthermore, methodologies aim to ease the workload and increase the overall effectiveness and efficiency of development cycles (Birkhofer, 2011). In all appearances, design methodologies therefore rely on an ability to capture the development cycle in reproducible and deterministic units. 
With regard to the non-deterministic aspects in design engineering, the overarching aim for design methodologies is to provide for a reliable process that increases the change of a sound and successful product definition. In other words, design methodologies aim to improve the predictability of both a good process and a good product definition. How this reliability is achieved reveals if and how the non-deterministic character of design engineering is taken into account. In this, uncertainty is the main criterion, being the defining aspect of non-determinism. The uncertainty paradox that results from this might be one of the explanations of why so many different design methodologies exist, without being extremely overlapping and without being fully contradictory.

\subsection{CHARACTERISATION OF METHODOLOGIES}

Based on the common elements as identified in the previous chapter, this section characterises design methodologies in order to contextualise design support and create a frame of reference. There is a large diversity in design methodologies. For instance, whereas VDI advocates a systematic approach that advocates a sequential progression from abstract to detailed descriptions of the product, Agile Product development (Thomke \& Reinertsen, 1998) promotes a cyclic highly iterative way of working that frequently shifts between abstract and detailed levels of aggregation. And where the double diamond model (Design council, 2006) highlights the distinct cognitive phases of convergence and divergence in the creative process (figure 3-1), axiomatic design ( $N$. P. Suh, 1991) focuses on the analytical aspects using a mathematical approach.

There are several reasons for this diversity. Obviously, the interdisciplinary character is causing design engineering to be the meeting point of various disciplines and accom-

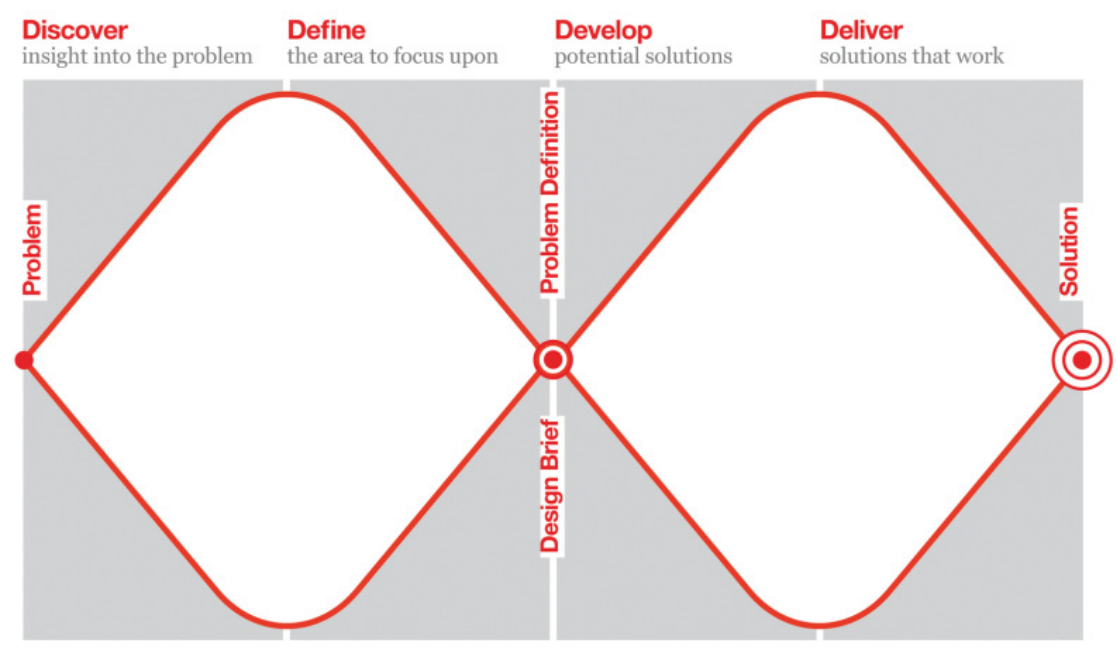

Figure 3-1 Double diamond model of design (Design council, 2006) 
panying views. Each discipline brings about a specific body of knowledge, fundamentals and principles that fosters and potentially add to the diversity.

Design Engineering has always been recognised as the merger of at least three disciplines: marketing, product development and manufacturing (N. P. Suh, 1991; D. G. Ullman). And with technologies rapidly evolving and products adapting to these technologies, there are calls to expand this set with e.g. electrical engineering and software engineering (Tomiyama et al., 2009).

As a design team commonly combines various disciplines, it is only logical that each industry, branch and even single companies have prevailing approaches. Consequently, approaches that are more formal are mixed with personal experience. Given the subjectivity in design methodologies, one has to look at existing overviews of design methods in a different way. (Eric Lutters et al., 2014).

The overview presented in figure 3-2 (next spread) shows the characterization of diverse design methodologies available for product development, this overview is based on the artefact-actor-activity-assets model presented in section 2.2.5. The selection of methodologies is derived from five review articles (Bayazit, 2004; Cross, 1993; Finger \& Dixon, 1989a, 1989b; Le Masson \& Weil, 2013; Tomiyama et al., 2009), supplemented with some additional methodologies that emerged from the empirical research. The selection of the reviews is chosen in such a manner that it covers the broad spectrum of design engineering approaches, ranging from the more art and architecture inspired approaches, to the mechanical and more scientific based approaches, and the axiomatic approaches.

From the design situations (section 2.1 and appendix B), the only methodology that was explicitly mentioned during the interviews and applied throughout an entire organisation was based on stage-gate principles as advocated by e.g. Cooper (R. G. Cooper, 1990) and Ulrich \& Eppinger (Ulrich \& Eppinger, 2015). Interests in agile product development (Thomke \& Reinertsen, 1998) and lean development (Ward \& Sobek II, 2014) were highlighted as potential future methodologies for governing product development, but where not implemented. Therefore, three methodologies originally stemming from adjacent disciplines have been added to the review: Stage Gate (Marketing) Cooper (R. G. Cooper, 1990), Agile Product Development (Software engineering) (Thomke \& Reinertsen, 1998), Lean Product Development (Ward \& Sobek II, 2014).

All methodologies that are discussed in the reviews have been characterised based upon the four elements introduced in the previous chapter: actor, activity, asset and artefact. Appendix $\mathrm{C}$ lists all found methodologies and the corresponding references. Obviously, most methodologies cover more, if not all elements. For instance, all methodologies consider design engineering to be a human activity, and could therefore be classified as actor. As such, the overview should not be understood as a rigid classification, rather it is an attempt to capture the gist of the available design methodologies. To determine with which element each methodology is best associated, the basis model and key distinctive elements of each methodology were consulted. 


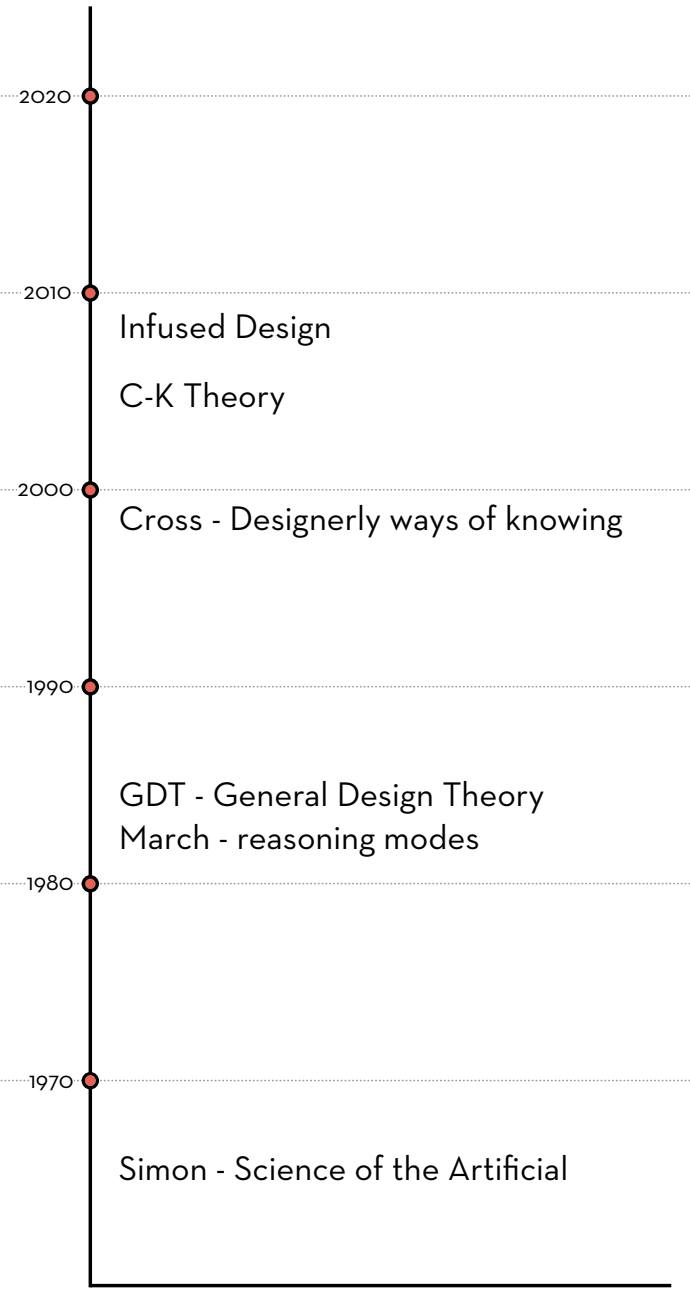

iii Ators

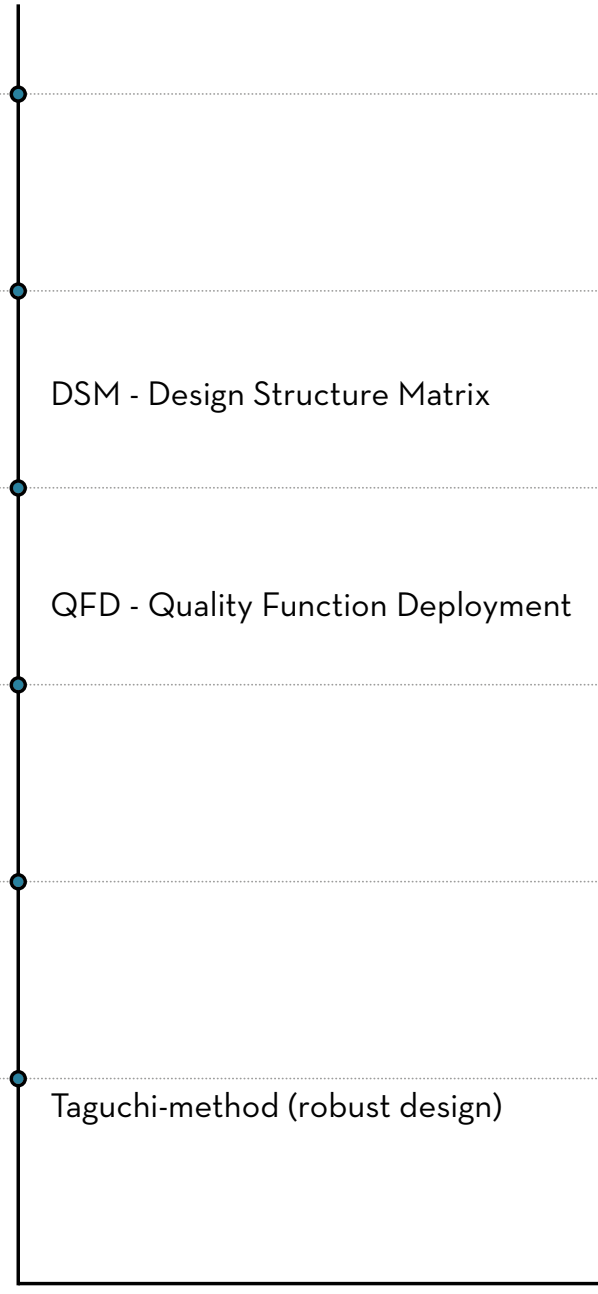

Assets

Figure 3-2 Overview of design methodologies characterised according the a4-model. Corresponding references are not taken up in the references section but are listed in Appendix C. 


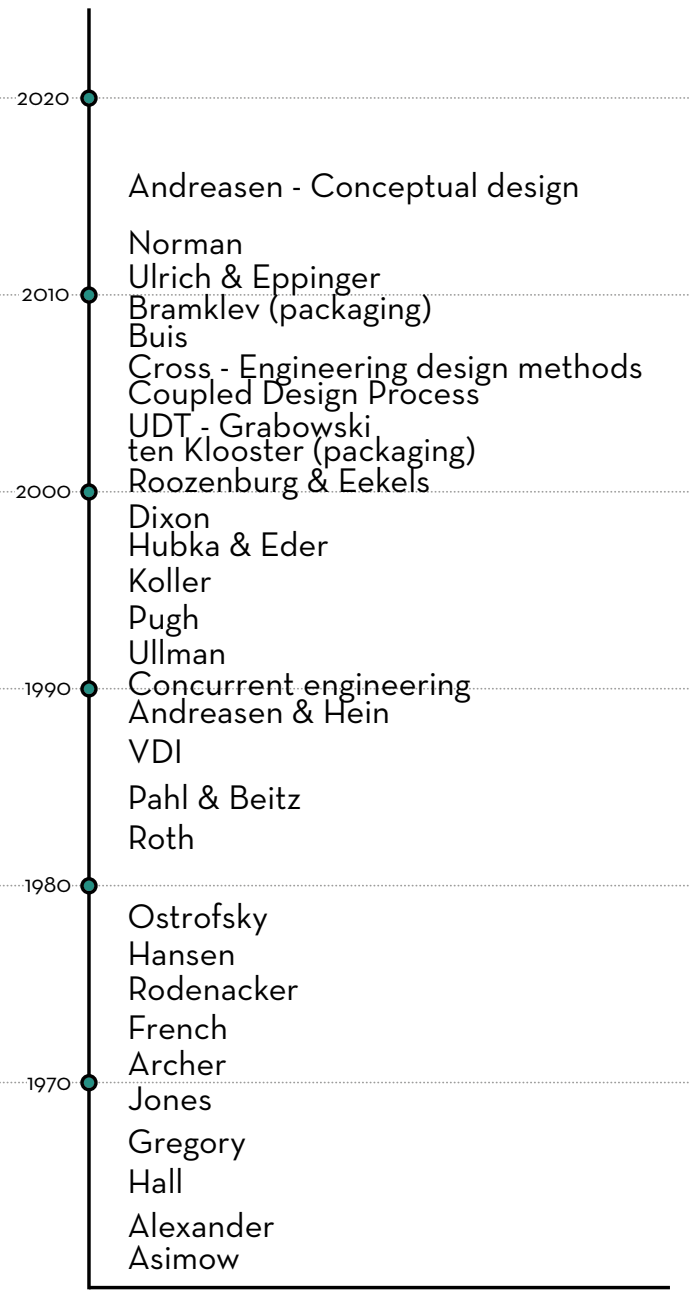

G

Activities

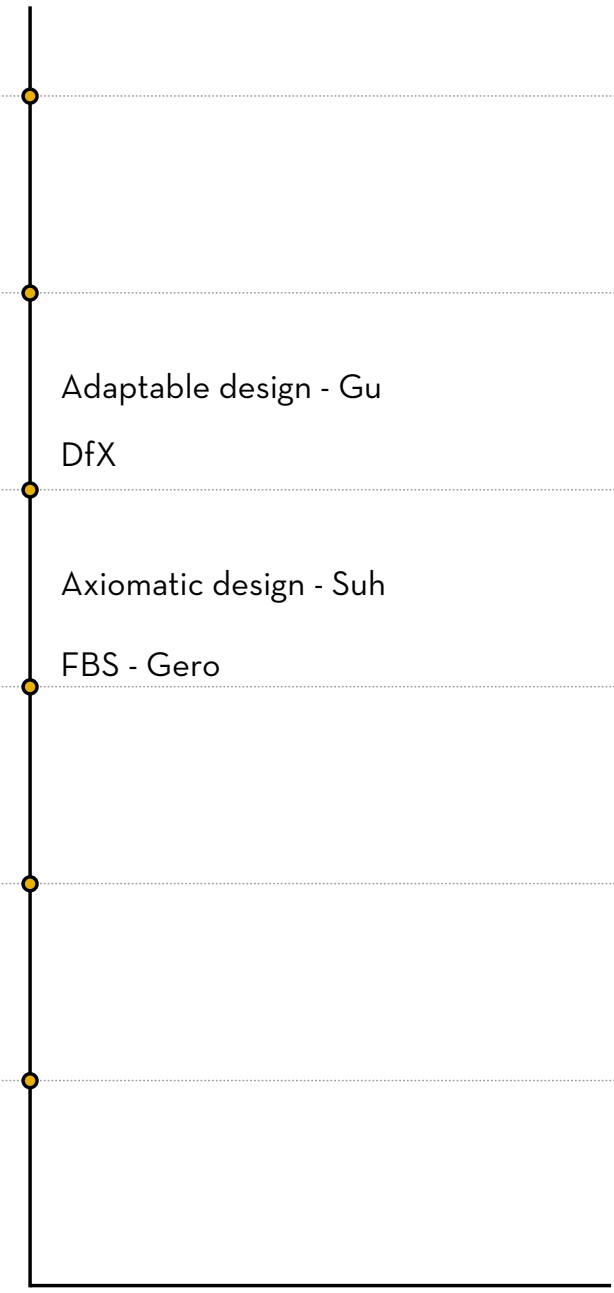

Artifact 


\subsection{ACTIVITY-BASED MODELS}

The vast majority of design methodologies base their approach on the activities that constitute the design process. Whereas in many of these methodologies the activities mentioned are roughly comparable, the way in which the activities are assumed to interrelate are characteristic for the different methodologies. In other words, the methodologies often focus on the procedure of designing. The overview is most certainly not an exhaustive list of all available methodologies and could therefore give a biased view. However, the list of activity-oriented approaches is only a small selection given the available elaborate overviews that only consider process-models of design engineering (e.g. (Howard et al., 2008; Pahl et al., 2007)). Furthermore, this seems to be in line with the general notion that design methodologies habitually start with a design process model representing the logical sequences (Tomiyama et al., 2009). These intentionally simplified depictions seem to provide ideal stepping stones for learning the design process, as is illustrated by the dominance of these prescriptive methodologies in education (Finger \& Dixon, 1989a; Tomiyama et al., 2009). The underlying process prescriptions provide clear pictures of what to do in which order, especially when users are unexperienced.

\subsubsection{Stage gate}

In managing product development trajectories, stage-gate oriented approaches are widespread means to control those trajectories. From research focusing on product/ packaging combinations, such approaches even seem to be a de facto industry standard. The methodology is often tailored to the specific organisation and context of use, leading to many company specific appearances and the obvious confusion that is the result of such a variety. However, the basic set of phases and gates (figure 3-3) are based on best practices of project teams known to be the top of the class (R. G. Cooper, 1990; Robert G. Cooper, 2008). In several comprehensive studies, their processes of new product development have been evaluated and mapped. The methods, techniques, and working approaches these project teams displayed are the key source for the stage-gate methodology. The approach divides the development cycle in phases in

Figure 3-3 Stage gate process (R. G. Cooper, 2001; Robert G. Cooper, 2008)

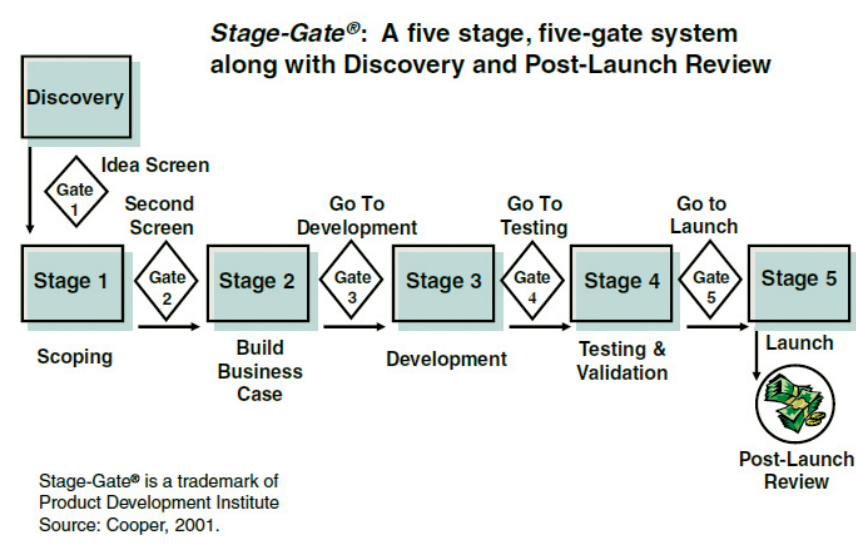


which various aspects of the design should be addressed. In recognizing that the quality of the result is the most critical success factor in successful new product development, great emphasis is put on a critical periodic assessment of projects, the so-called gates, in which the project is either killed or receives the necessary resources to proceed.

The gates are often established as official review meetings at which the project teams present the results of a certain stage and dedicated gate-keepers assess the progresses based on a set of criteria on financial, product and strategic aspects. As such, the gates are the primary means to separate the wheat from the chaff, ensuring efficient and effective use of R\&D budgets while minimizing the risk of project failure. The stagegate methodology provides powerful mechanisms to structure and execute projects, but more importantly, is aimed at learning from the best practices of the best design teams. These good intentions can lead to bad practical implication (Robert G. Cooper, 2008). For example, potential 'kill'-decisions are influenced by gate-keeper's irrational favourites. It seems that the importance of gate meetings can thus be severely impaired by either subjective personal preference or back channel diplomacy. Another often-heard critique is that gates lack impact: a 'go'-decision is not always accompanied by the allocation of required resources nor by a delineation of how to proceed. Consequently, such gate meetings are often diminished to mere formalities in which the essence - the product definition - gets lost.

In applying stage-gated approaches, the stages and corresponding gates tend to get promoted to an ideal image of development processes. Such idealisation renders the potential risk of misalignment between execution and control of a project, as the development process for most product/packaging combinations does not naturally and implicitly adhere to the underlying discrete, sequential model of the stage-gate approach. The resulting management perspective clouds the perception of the actual development trajectory and could lead to a process-oriented management approach in which the stage-gate approaches become metaphoric predictions. An interesting approach from the field of packaging uses the concept of stage gates but puts focus on the functional aspects and the corresponding decision making, not utilizing the stagegates as a formalised paths but as an reminder of important decisions and the logical hierarchy in functions (Klooster, 2002; D. Lutters \& Klooster, 2008).

In practise, creating a common understanding for everyone involved is one of the key benefits for applying process-oriented models as control procedures. Based upon this common - often simplified - understanding, hard deadlines and formal decision moments such as gates drive the process while adhering to strict budgets and resources. For this type of application stage gate procedures can be considered a de facto standard. These depictions are commonly accepted in industry as basic control principles in managing complex, multi-stakeholder, processes. It provides a rudimentary backbone for a project structure upon which activities, deadlines and documents can be established. Furthermore, such managerial uses of these models provide a check, a baseline, against which the actual activities can be compared, whether that is loosely in a stage or heavily prescribed in a review session at a gate. However, stage-gated process models do seem to have a predominantly managerial function that does not necessarily align with daily practise. Moreover, practical applications of the methodology seem to put focus on the (performance of) activities instead of the artefact itself. 


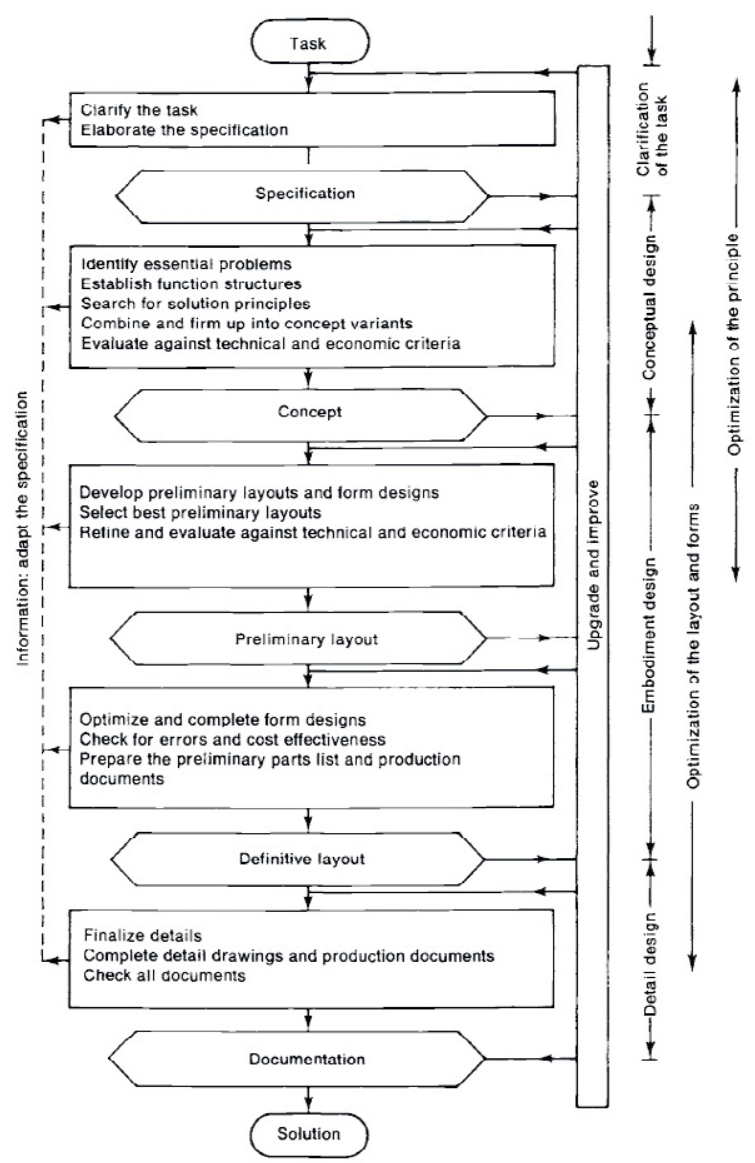

Figure 3-4 Process model by Pahl \& Beitz (Pahl et al., 2007)

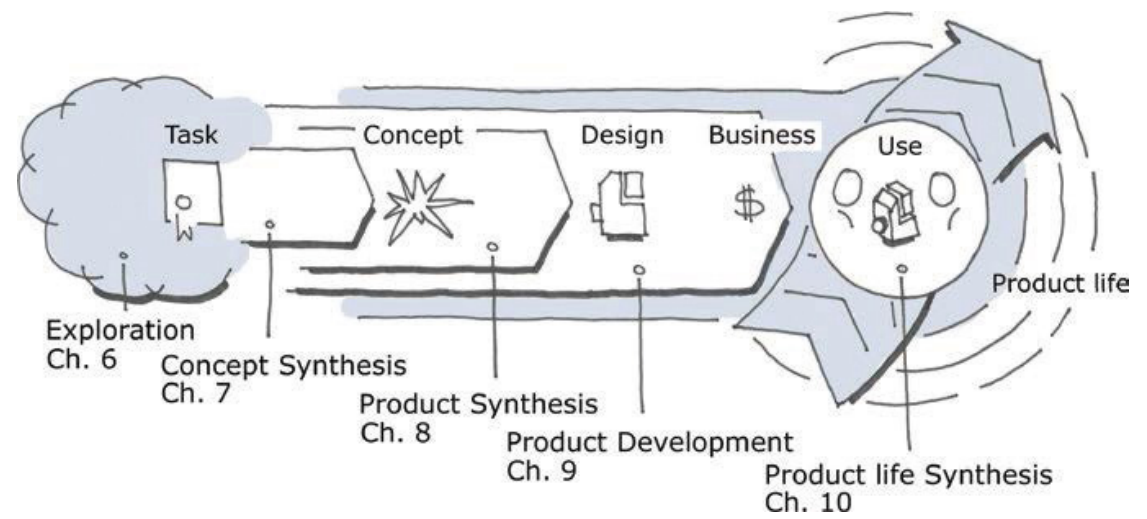

Figure 3-5 Encapsulated design model (Andreasen et al., 2015) 


\subsection{2 $\mathrm{P} \& \mathrm{~B} / \mathrm{VDI}$}

Comparable to the approach of stage-gated procedures, the systematic approach for Engineering Design is based on best practices (Pahl et al., 2007). An extensive group of experts from both academia and industry has formed the basics of the generic approach (figure 3-4). In recognizing that this abstract model never depicted reality, iterations between certain phases are considered to be a necessity. This generic approach serves as a framework for an extensive collection of design methods, tools and techniques (Pahl et al., 2007), which can be regarded as a standard work within the design engineering community. The methodology offers all steppingstones to be used for educational purposes as well as a toolbox to be used by design practitioners. However, as the core of the methodology is focused on the abstract model and the information is structured accordingly, one might have difficulty in using the methodology as most practitioners are not focused on the process but on the intended or expected outcomes (Gericke et al., 2016).

The methodology recognises non-deterministic aspects as being an intrinsic part of design engineering. However, the manner in which this is addressed in the methodology is not obvious. The (implicit) assumption seems to be that through a systematic approach, these uncertain aspects are sufficiently dealt with. For the role of team members in a project team, great emphasis is put on a sound task description and corresponding planning. Ulrich \& Eppinger, in a comparable systematic approach, even go as far as to claim that a meticulous planning is one of the key contributors to eventually a successful product (Ulrich \& Eppinger, 2015).

\subsubsection{Andreasen}

Based on the work of Hubka and Eder and Andreasen \& Heinz the encapsulated design model as presented in (Andreasen et al., 2015) illustrates a very different approach to design (figure 3-5). Based on a set of design entities that constitute the principle outcomes of a development cycle, the model and its accompanying description of tools and techniques are presented as stepping stones for defining a practical procedure. Exploration as activity is demarcated as the start of a project that lays the basis for all subsequent activities, but might be an integral part of those activities as well. Incompleteness and uncertainties are considered to be a natural part of design work. For a design process to work, there needs to be considerable attention for information flowing between key entities such as product life and product development to prevent from overlooking important aspects. Furthermore, the methodology pays considerable attention to how the proposed model and activities should be tailored towards its user, the organisation and context.

\subsection{ACTOR, ARTEFACT AND ASSETS BASED MODELS}

Methodologies oriented towards the actor are predominantly focused on the knowledge domain and adjacent skills such as decision-making. General Design Theory (GDT) bases its mathematical formulation of design knowledge processes on a distinction between an entity and an entity concept and axiomatic set theory (Yoshikawa, 1987). With 
Figure 3-6 C-K Theory (Hatchuel \& Weil, 2003)

Figure 3-7 DSM Matrix (Browning, 2001)

Figure 3-8 FBS Model of design as a process (Gero, 1990)

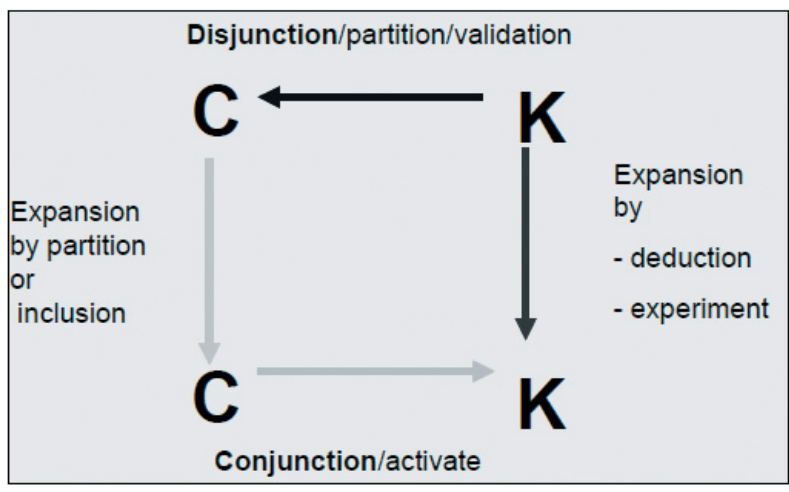

PROVIDE
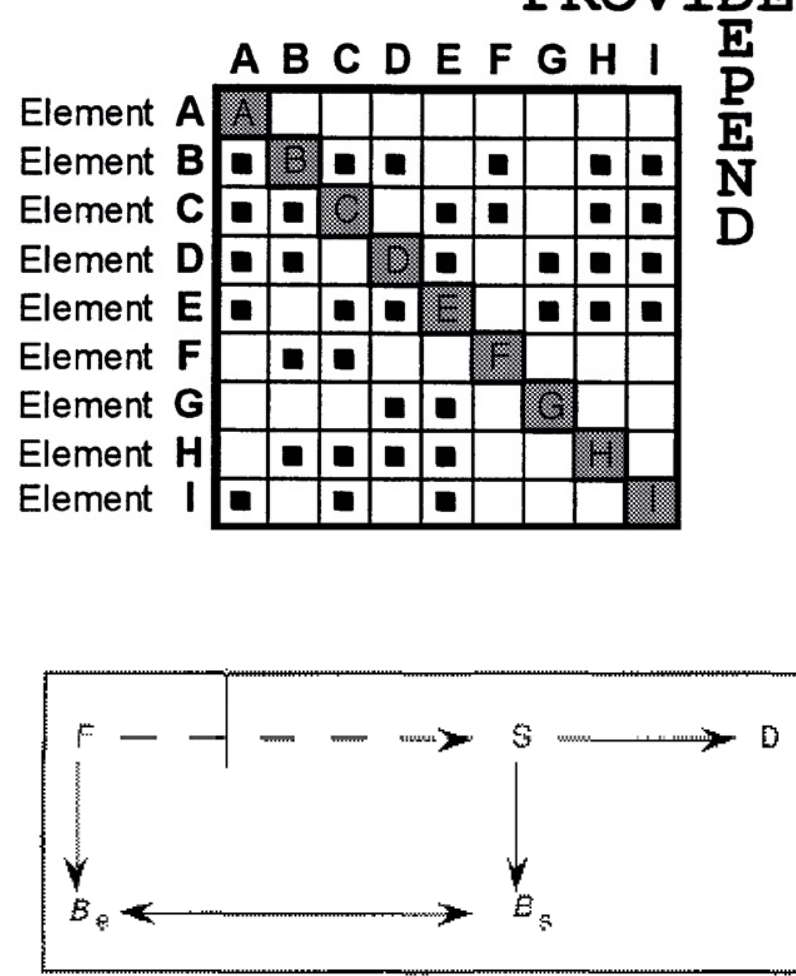

$B_{e}=$ Set of expected behaviors

$B_{s}$ - Set of actual behaviors $D-D$ besign description

$F=$ Set of surctions $\quad 5=S$ Sturture

$\rightarrow=$ Transformation

$m>>$ Occasional transformator:

$\leftrightarrow \rightarrow \infty$ Comparisor 
it, GDT rigorously explains the design process as design knowledge operations. Furthermore, GDT has had major influence in guiding the establishment of CAD-systems (Reich, 1995). Partly based on the mathematical approaches such as GDT, C-K Theory attempts to construct a model of design (Hatchuel \& Weil, 2009) that does not exclude creativity and innovation from design theory but unifies the various views. Similar to the entity - concept entity division of GDT, C-K theory divides the design space into a concept space and a knowledge space, each containing propositions. If these propositions for a designer have logical status, they belong to the knowledge space, if not they belong to the concept space. With this definition, the authors put forward an explanation for the specificities of design reasoning and with it, can map a design thinking process using a so-called design square (figure $3-6$ ).

Design methodologies labelled as assets originated as specific design methods or even design tools, such as the Design Structure Matrix (Browning, 2001) and Quality Function Deployment (Hauser \& Clausing, 1988). Such models are simultaneously considered tools in other methodologies and gradually grow into more elaborate methodologies of their own. This illustrates the before-mentioned lack of clear terminology and amalgamation of terms. The DSM methodology is based on a square matrix representation of a system or process. It can visualise the interdependencies between entities, important patterns and feedback loops (figure 3-7). With it, it is an abstract but effective modelling technique that aids in monitoring and improving a system, especially when that system is complex. In a similar manner, Quality Function Deployment (QFD) uses a visual representation to assign and govern customer requirements to the functions of a product or system. Originally intended as a procedure to govern quality, QFD has developed into a versatile and comprehensive toolbox that is used for various applications in industry. When combined with approaches to systematically quantify subjective components and asessment, the accuracy of QFD is improved (Raharjo, Brombacher, \& Xie, 2008).

Obviously, each methodology or theory recognises the artefact as core of the matter in any development trajectory. As such, one could claim that every design method revolves around this artefact, as it is accepted as the core subject of the discipline: the object that is being designed. However, design methodologies often do not start reasoning from the artefact. This might have to do with the assumption that aspects of the artefact itself would render a methodology with limited scope (Tomiyama et al., 2009). E.g. methodologies developed for planes would logically only be sufficiently applicable to product categories equal or (very) similar to planes. Two examples of methodologies that start to reason from the artefact itself, in generic manner are the Function Behaviour Structure ontology (Gero, 1990) and Axiomatic Design (N. P. Suh, 1991).

Gero constitutes a framework that consists of three principle variables: functions describing what it is for, behaviour describing what the artefact does and structure describing what it is (figure 3-8). Based on this framework Gero recognises eight distinct processes that together form the basis for any design engineering process: formulation, synthesis, analysis, evaluation, reformulation and production of design description (Gero, 1990). Of those phases the reformulation phases are considered to be a unique aspect of the methodology. 
Based on previous successful experiences Suh developed a set of two axioms (the information axiom and the independence axiom) and four domains (customer, functional, physical, process). The independence axiom states that independence of each functional requirement should be maintained (N. P. Suh, 1991). the information axiom states that when all information elements and their corresponding probabilities are calculated, that commonly the alternative with the least amount of information is the best.

In representing the uncertainty, axiomatic design covers an essential part of the non-deterministic aspects. However, simultaneously it does not consider the creative aspect of design in detail. Grounded on the believe that design engineering needed a rigorous scientific base to professionalise the discipline, Suh puts focus on the analytical aspect of designing alone. Besides, the basic assumption is made that a sound approach for the analytical process of design will positively influence the creative process as well. While this might be true, there is no reason to assume that this influence is not reciprocal.

\subsection{TRENDS AND CHALLENGES}

While the majority of the methodologies is currently either process-based or has a strong, important element of a process model, there is growing concerns about the limitations of this process-focus (Albers, Sadowski, \& Marxen, 2011; Birkhofer, 2011). For instance, the skills, intelligence, ways of thinking and the corresponding activities of actors cannot always be described by process-models (P. Badke-Schaub, Daalhuizen, \& Roozenburg, 2011). As such, there is a need to put focus on the other elements of product development.

While the development cycles of physical artefacts already incorporate diverse disciplines, product development increasingly goes beyond the traditional border of the physical artefact into for instance product-service systems (Birkhofer, 2011). Simultaneously, there is an increasing need to incorporate life cycle engineering aspects into DTM in order to educate and prepare design practitioners in sustainable development. These trends results in even more complex multi-disciplinary product (Tomiyama et al., 2009) development which pose a challenge for a large group of methodologies that grew out of one specific discipline. DTM is currently insufficiently prepared for incorporating or merging with such new disciplines.

A second trend concerns the integration of computer, ICT and information technology in DTM (Birkhofer, 2011; Tomiyama et al., 2009). Software tools have become indispensable tools in product development cycles. Consequently, there is both a clear trend in the integration of computer and software tools into DTM and a clear need to further advance this into algorithm-supported design (Birkhofer, 2011), digital engineering, PLM system support and virtual reality applications (Tomiyama et al., 2009).

\subsection{EVALUATION}

The described methodologies vary greatly in background, principles and approaches. Despite fundamental differences, the majority of design methodologies are based on best practices. As such, this base of practical knowledge and experience could be re- 
garded as a common denominator. The overall approach in establishing design methodologies can be characterised as attempts to generalise best practices and (collective) experience in order to objectify and make this knowledge available for a widespread audience of design engineers. Each approach can be considered as a specific language deduced from best practices (labelled as the known), to offer support for future use (labelled as the unknown) (Le Masson \& Weil, 2013).

It is difficult - if not impossible - to determine which of these languages adheres best to the non-deterministic character of design engineering and effectively and efficiently succeeds in enhancing the predictability of the development cycle and the appropriateness of the product definition. It depends on the quality of the application in current practise and how each contextual factor is taken into account (Nieberding, 2010). Moreover, the application is also determined by all factors of the initial, best practises that served as inspiration for the methodology and how each methodology has incorporated, translated or neglected these factors. Therefore, which methodology suits which situation is not primarily a matter of scientific debate, it is more a matter of (collective) taste. In enhancing the reliability and predictability of development cycles, each methodology can thus be seen as a possible useful scenario for successfully governing and executing a product development cycle.

\subsubsection{Process-orientation}

There are abundant methodologies that describe design engineering as a sequential, phased set of activities. As a result, process-oriented models are used - either explicitly or implicitly - as an overarching framework for the majority of the design methodologies. Even design methodologies not starting to reason from the activity itself but from other elements put significant focus on prescriptive procedures, e.g. The process of rational decision making (Simon, 1996), the DSM-Matrix applied to core design processes ((Browning, 2001)) and FBS (Per Galle, 2009).These methodologies are based on optimizing the development process by serving as a reminder for all parties involved at the appropriate moment in the development cycle or by giving guidance in the communication between actors. With such an approach, the methodologic language tends to become the core matter rather than a mean. In setting up such a 'design engineering language', focus is often put on the constructs, rules and structure of the 'sentences' that constitute the methodology. While this has proven to be of indispensable value in explaining and instructing design engineering, this renders some difficulties when applied in practice. To allow for adequate communication on design trajectories such languages are essential, but focussing on the actual denotation of what the communication is about requires more than semantics. Obviously, such a formal language needs to be adopted and compared with reality. More importantly, in using such a language one could easily be absorbed by the grammar, distracting from the actual content. Consequently, the actual meaning of the sentence might become a changeling.

\subsubsection{Doing the things right or the right things?}

Most methodologies are developed in an attempt to adequately integrate the different core disciplines in the development cycle (Oude Luttikhuis, De Lange, Lutters, \& ten Klooster, 2015). The processes function as transmitters between actors in order to efficiently communicate and exchange (product) information. This information about the evolving product definition and its corresponding process is scattered amongst all 
stakeholders involved, making it well-nigh impossible to obtain a coherent overview and status of a product or process under development. An additional problem with such communication is that the information used can easily be misinterpreted, especially when communication partners have different backgrounds and have their own expertise language and jargon. Moreover, in order to maintain control over the relations, the difference between the required information and the employed information is often large. As in most methodologies the processes and information are integrated to such an extent that they cannot be decoupled, this phenomena does not contribute to an efficient and effective product development cycle, but often even severely hampers the process, causing unnecessary halts or loops and costly corrective procedures (Oude Luttikhuis et al., 2015). More important, when control of the development cycle is based on simplified descriptions of the process, one might be tempted to check for the usual, or even worse, check whether the prescribed activities have been performed. With this, there is a considerable risk that the actual outcome of development cycles degenerates into by-products of the adopted sequence of processes. Such a change of cause and effects is obviously detrimental to both the understanding of the development cycle and to its effectivity. The danger in such application is that it can easily lead to a blinkered view on the actual development cycle as it only assures that the 'prescribed' things have been done right and not if the right things are done. This sharply contrasts with the non-deterministic character of design as substantiated from the previous chapter. A focus on 'doing things right', wrongfully assumes that product development is a deterministic process. As such, it seems to unwittingly foster a pedantic attitude towards design, treating design practise as an administrative procedure.

\subsubsection{Who controls the applicability of the methodology?}

Any design method is a simplified description of the intangible and multi-faceted product development cycle. Therefore, labelling any design method as the ideal is illogical, or naive at best. Moreover, if the application of a design method is imposed or an imperative, inherently the product developer will experience limitations in the way the development cycle can be carried out, thus automatically rendering that method flawed. However, these idealised descriptions were based on a collection of best practises, each with their own peculiarities. As such, the generic applicability of methodologies via processes might unnecessarily erect a barrier between idealised or simplified models and current practises. Moreover, product developers are forced to behave according to certain patterns or workflows, thus diverting them from the core of the development cycle. There is a need to take matters more light-heartedly and adjust the methodology according one's own judgement. So, while no ideal process description can exist, product developers do need support in e.g. organisational matters and communication. Design methodologies are on the verge of being straitjackets and friendly advice. From a content point of view, the one that can find the trade-off between the two is the product developer himself. However, in this adjustment much of the added value of established control principles is easily lost or misunderstood. Even in design trajectories heavily influenced and determined by process-oriented models of design, the actual activities of the various stakeholders involved do not automatically adhere to the prescribed activities and regularly deviate from the process (De Koeijer, De Lange, $\&$ Wever, 2017). In practical circumstances, such phenomena are often seen as inevita- 
ble, and product developers are assumed to cope with them at their own discretion. Consequently, such deviations are hardly made explicit, and are therefore not easily captured in best practices for development cycles. Therefore, design methodologies inherently tend to generalise towards that renderings of the design cycle that are correct, yet lack applicability. With that, design methodologies again can easily turn into idealised representations. Relying on such methodologies might create a false pretence of certainty on the course, but especially on the content of a development cycle.

Moreover, there is a significant chance that such models cannot address or incorporate newly gained experiences. Methodologies do not come with intrinsic corrective actions or improvement mechanisms. Consequently, no new circumstance is covered by predetermined process definitions. This either limits the flexibility of the design team using the methodology or limits the applicability, reliability and predictability that the methodology can provide. According to common sense, the applicability of any methodology might alter during its use. However, there are currently no means - other than personal experience - to assess this applicability and to decide whether the methodology could provide for the required level of reliability. As such, there is no ingrained control mechanism for the applicability of methodologies.

\subsection{CONCLUSION}

In enabling design engineers to effectively and efficiently direct the evolvement of a product definition, design methodologies are often embraced as meaningful scenarios, as they describe what to do when and what to focus on when designing. As such, methodologies provide specific approaches to enhance the predictability and the reliability of the development cycle and corresponding product. Yet, the quality of the envisaged route does not vouch for the quality of the resulting product definition. Often, an adaptation of the formal, idealised scenario to own context or practise is required, if only to do justice to the insights, creativity and abilities of the product developers involved. Development cycles are a mix of both deterministic and non-deterministic aspects, with formal methodologies endeavouring to streamline the organisation and course of those cycles. Therefore, product developers have to rely on insights and assessments of instantaneous evolvements of the product definition under consideration in order to concurrently and simultaneously further that product definition and determine the best way to achieve that evolvement. As a metaphor: sometimes product developers need to re-interpret or redefine the rules of the game while playing the game. This observation makes the notion uncertainty an inherent dimension of product development. Here the notion uncertainty is stripped of any value judgement; it is neither positive nor negative, it just belongs to a development cycle in a neutral way that is comparable to how the notion quality is attached to such a cycle.

The product developer is able to consider and reflect on uncertainties in the development cycle, provided he has the autonomy to balance any evolvement of the product definition against the design methodology applied. This in itself implies that external government of the design cycle by means of enforced unyielding design methods may ease management responsibilities, but may be detrimental for the quality of the resulting product definition. Whereas process oriented design methodologies aim to converge to situations with as little uncertainty as possible. However, whenever the 
government of a development cycle intends to make any ruling on uncertainties in the development cycle, it not only interferes with the autonomy of designers, but also pretends to fathom the denotation of that uncertainty, both for the course of the development cycle, but foremost for the resulting product definition.

Many design methodologies implicitly attempt to confine the amount of uncertainty in development cycle; however, as uncertainty is also a symptom of the freedom of choice and creativity of the product developer, the result is an uncertainty paradox. This paradox stresses that product definitions should contain a minimum of uncertainty in order to be practicable, whereas the development cycle itself thrives on uncertainty. In different wording: the product definition benefits from convergence, whereas the development cycle requires divergence to extrapolate on available information.

In a certain sense, this uncertainty paradox articulates the main driver of product development capturing and understanding the current state of the product definition in order to be able to evolve that state. Stating the current state without instigations for evolvement is pointless, whereas evolvement without fathoming the current definition is purposeless - or just risky. With this, the driver of product development emerges from the development cycle itself. This sheds a different light on design methods that aim to command development cycles from an external perspective, relying on logic, experience and best practices. Obviously, these are by no means useless approaches, although their underlying inclination to declare or treat development cycles as being deterministic is a premonition. Moreover, the efforts to align the eradication of uncertainty in the product definition with combatting uncertainty in the development process are not necessarily justified. As such process driven design support always renders two images of a product development cycle: a generalised, idealised depiction and the actual discourse. Although predominantly based on collective past experiences, these methodologies do not take the actual design practise of the organisation as the starting point. This gap in DTM seems to exist for whatever angle on choses - artefact, actor, assets or activities. 


\section{INFORMATION-VALUE AXIOM}

In an attempt to fill the gap as addressed in the previous chapter, this chapter puts focus on the information in product development. Information and its effective management play an important but underexposed role in product development. This alone, is reason to put focus on information for design support. However, the described trends on integration of ICT and software tools in DTM, the inherent connection with uncertainty and the submissive role of process models, makes it an interesting direction for further investigation. Starting from the information-value axiom, this chapter outlines an information perspective on product development. First the terminology of information and related keywords is explored in the context of product development. Based on this exploration, a reference model for information based product development is defined. Together with the subsequent chapter on current and future information usage, this chapter explores the potential of using information (management) as solution direction for design support that is based on (any) daily practise of product development. 


\subsection{INFORMATION-VALUE AXIOM}

The course of product development cycles and the resulting outcome are strongly interwoven and cannot be separated without making concessions to the effectivity and efficiency of the development cycle. Moreover, in many practical circumstances the actual course of the design cycle and the simplified model thereof (as part of the design methodology) are observed as mutually dependent. In a comparable manner, there is an inherent tendency to treat the tangible product that is the outcome of a development cycle and the product definition that underlies the development cycle as synonymous. However, design trajectories do not result in actual tangible products, but rather in delineations thereof. In essence, the produced products are instantiations of the product definition. To allow for such an instantiation, the information that constitutes the product definition must be equivocal and adequate for manufacturing while being appropriate for the perspectives of all involved. Once such a product definition is available, the manner it came into being is of lesser relevance for the manufacturing environment. For the downstream processes, merely the information that captures the essence of the product is relevant. From this perspective, the development processes and the design methodology are just tools to shape the resulting product definition. This implies that the information that constitutes the product definition is essentially independent of the design methodology. Compared to the ingrained process-oriented approach, in which the information is the sheer consequence of the execution of steps in design methodologies, this makes it possible to look at development cycles in a different way: it allows for a paradigm in product development that is based on the information content as being the decisive factor. To further exploit this paradigm, this thesis postulates the following information-value axiom:

\section{"Information is the carrier of all (added) value in and of a product development cycle"}

Whereas in process oriented design support the starting point is a framework of the design process, the solution direction of this research is based on the information state of the development cycle. With this, focus is not on the task itself, nor on its definition, but on the intended outcome of that task. After all, seen from the information-value axiom, this outcome is the sole reason for executing a task. Therefore, this research focuses on the product definition as the key concern, rather than on alignment, logic, completeness and sequentiality of processes as is the case in DTM. Essentially, this implies that the information content of development cycles will get a different significance and role. Given that change, the information content might also require a different structure and stature. After all, the information content will also be the initiator, driver and assessor of development processes. This requires new approaches and a different way of thinking about development cycles. Without jumping to conclusions related to how, where and by whom what information is captured and made available, it is essential to recognise that the information content also needs to encompass the 'why' of product development. It therefore relates to design rationale, as well as to governing the design process itself. In this role, the information content does justice to the interweaving of the design result and the design process. How the information-value axiom will influence the course of development cycles is the topic of the forthcoming 
chapters. However, before the impact of the information-value axiom can be elaborated, this chapter first addresses the basics of what information is and how its essence and usage in manufacturing can be defined.

\subsection{DEFINING THE NOTION INFORMATION}

Information is a commonly used but extremely ambiguous term. The term is so generally adopted that in daily practise it is often used without considering its exact definition. It is associated with communication and is closely related to or even held synonymic for data and knowledge ("CIRP Encyclopedia of Production Engineering," 2014). However, it makes sense to distinguish between these three concepts. Although many different definitions exist, here the following formulations are used (Lutters,E., 2001);

- Data is the representation of facts, concepts or instructions in a formalised manner; suitable for communication, interpretation or processing by humans or automatic systems.

- Information is the meaning that a human assigns to data by means of the known conventions (context information) used in its representations.

- Knowledge is the context that enables the analysis and adaptation of a situation, based on the interpretation of information.

From this hierarchy, information mediates between data and knowledge, in that information is 'meaningful data' and can be interpreted in context to become knowledge. In everyday usage, information is a medium in communication (figure 4-1). Whatever information source is used; the basics of communication will therefore always apply. This implies that in assessing information, there is always a (group of) sender(s), a message, a (group of) receiver(s) and the possibility of noise. In considering information as the backbone for design support, it is important to take into account this scheme and make sure that the structure can cope with the required content, context and state of all the information sources available. As information contains meaning, it can be perspective-dependent; therefore, it is purposeless to carve out a conclusive definition of the notion information. For the purpose of this research, information can be depicted
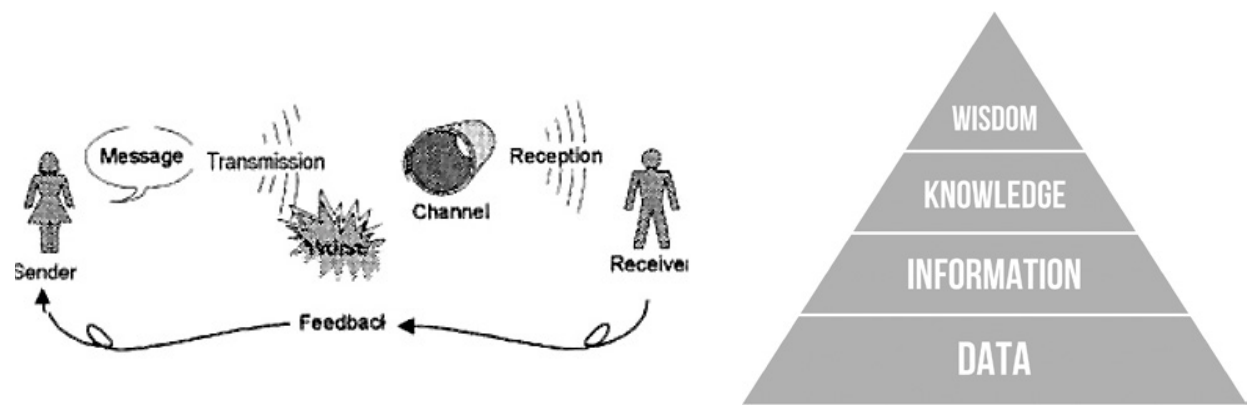

Figure 4-1 Shannon-Weaver model of communication

Figure 4-2 Wisdom hierarchy (Rowley, 2007)

"source: Global communications : opportunities for trade and aid" U.S. Congress, Office of Technology Assessment. (1995). (OTA-ITC-642nd ed.). U.S. Government Printing Office. 
as the entirety of all ideas, facts, and imaginative works of the mind which can be communicated, recorded, published and/or distributed formally or informally in any format (ALA Glossary of Library and Information Science, 2013). Information, therefore, is a means to capture the current product definition. With adding structure to information entities and interrelating them, the meaning and purport of the product definition can be captured. This sets aside the product definition from being an inconsistent collection of factual data. Moreover, it allows for purposeful and contextualised interpretation in terms of knowledge.

The product definition, by means of information, conveys the design intent and design solutions. As such, information then also is the carrier of all indistinctnesses in product development cycles.

The relationship between data, information and knowledge has been a constant subject of study (Boisot \& Canals, 2004). The data-information-knowledge-wisdom (d-ik-w) pyramid (figure 4-2), arranges the terms in a strict hierarchical order in which each term is separated by an interpretation layer. Whereas this model is commonly used and (implicitly) referred to within fields such as information management and science, there is little consensus on the terms (Rowley, 2007). Buckland addressed the ambiguousness in the use of the term 'information' by proposing two views: information as process and information as knowledge respectively (Buckland, 1991). Buckland added a third characterisation in describing information as a thing, referring to documents, books and all other examples of explicitly available information. Nonaka labelled this as the dominant western view on knowledge and criticised it as inadvertently putting focus on explicit, measurable, tangible and quantifiable knowledge (Nonaka \& Takeuchi, 1995). His claim is that product development and the innovations are not only derived from this collection of explicitly available knowledge. Instead, it is fostered by the interplay of tacit knowledge and explicit knowledge. Subsequently, teams and organisation should be guided to use that tacit knowledge and should be supported in regularly transforming tacit knowledge into explicit knowledge and explicit into tacit. Nonaka defines knowledge as 'justified true belief' (Nonaka \& Takeuchi, 1995). Here, knowledge is also implicit; it is not something that can be directly or explicitly put into use. Either way, knowledge is defined as a key enabler in innovation processes(Esterhuizen, Schutte, \& du Toit, 2012). Ahmed et. al. state that it is impossible to define the terms in an absolute manner (Ahmed et al., 1999). As a document with successful interpretation is information for one actor whereas for a different actor using a different context this document remains data. As such, the authors conclude that the notions of data, information and knowledge are relative. Moreover, Ahmed et. al. conclude that knowledge, information and data are often expressed and defined using each other's terminology.

These different perspectives on knowledge and information have rendered two camps on how to manage them (Culley, 2014): based on information (information management) and based on knowledge (knowledge management). The dominant view currently for DTM seems to be knowledge management in which information is commonly regard as a representation of knowledge (Chandrasegaran et al., 2013). There are good reasons to consider this knowledge perspective, e.g. as it puts more focus on the actor creating it (Culley, 2014). However, it also puts information management in line with document and computer management. But information is not always explicitly available. In order to start to reason from the information-value axiom, some clarification is 
needed and communication, information, knowledge and data should be defined in the context of design engineering. After all, having the above described definitions do not necessarily convey anything about the use of the concepts in product development practise.

\subsection{TERMINOLOGY EXPLORED IN FOUR SCENARIOS}

To illustrate the information-value axiom and to contextualise the terminology, four scenarios are established, taking into account the four basic elements: actor, artefact, assets and activities (see section 2.2). The scenarios are derived from the product development situations described in section 2.1. This broad spectrum of practise cases is subjectively clustered into a set of four scenarios, successively increasing complexity. The first scenario starts with a very simple version of a product development cycle. Based on this scenario, aspects of communication, knowledge, information and data are described. In each succeeding scenario, the interdependencies become more intricate, thus requiring a more precise formulation. With this increasing complicatedness, the resulting scenarios approach the delineation of product development as given in chapter two. This exploration results in a model of that combines the definitions of information, data and knowledge with communication.

\subsubsection{Scenario A: One actor}

In its simplest form, one actor can represent every element of a development cycle. In this scenario, the actor is the client, the user and creator all at once. He has the responsibility to represent both the problem space and solution space and find a solution that fulfils his own aspired value. In this situation, there is little need for communication. The actor needs to understand the problem and use his knowledge, experience and skills to come up with a solution and create that solution. Decision-making and alignment comes naturally, it might even be a largely subconscious process that relies on heuristics.

In this bare form, the actor transfers and translates his knowledge into the product definition. There is no collection of documents, no drawings or text describing the product. Yet, even in this simple form, information, albeit in a transient manner, already plays a significant role. For this one actor, there is no need to formally communicate the information, therefore there is no explicit need to distinguish between information and knowledge. This is all the more true, as any information in this scenario is ingrained in one context. Moreover, information is thus not necessarily exclusively linked to an explicit carrier or medium. From this one actor scenario there are already some important aspects to consider:

- Knowledge is personal and implicit.

- Information aids in making knowledge accessible.

- Information is not necessarily linked to an explicit medium.

\subsubsection{Scenario B: Client-creator}

In the second situation, there are two actors, one as creator and one as client/end-user. This obviously introduces the need for communication: the client expresses the design problem, and the creator acts for the design intent. This communication can be characterised as an intermittent dialog between two actors in which information 
about the situation, problems, circumstances and product is exchanged. This exchange of information can be via direct transfer, for instance in a conversation or via signs and hand gestures. Alternatively, the exchange is supported by written text and sketches of ideas; test models and the evolving product definition. Because the latter uses a medium, it is labelled as a form of indirect transfer.

The intermittent dialog between can be characterised as a negotiation in which terms and conditions between the client and the design engineer establishes the veracity of the product definition. Obviously, requirements might be interdependent; also setting a certain condition might logically limit the possibilities on different aspects of the product definition. For instance, a choice of one specific material automatically limits the possibilities for geometry and the processing of that material. Nevertheless, consequences are not always that predictable or logical. Even in this very simplified situation of one product developer working for one client, this negotiation of requirements could already be complicated and difficult to control.

Knowledge is regarded as belonging to the actor. It is personal and therefore subjective. Moreover, knowledge can thus not be directly transferred, it always requires a transformation that explicates the intended meaning. In that transformation process, information, although being volatile and intangible, is considered to be the enabler.

With two actors, there are also two knowledge contexts. Consequently, there are always two, potentially disjointed, interpretations of information. Indeed, it is quite probable that, due to differences in context, background, interests and education, these interpretations differ. As such, there is not only a clear need for communication but also for alignment. The mutual exchange of information via speech, documents or any other medium enables this alignment. Such information-induced alignment is required to allow for mutual understanding and agreement. In addition to the aspects mentioned in scenario one, the following aspects are deduced from scenario two;

- The transfer of information is either direct (via senses) or indirect (e.g. via sketch or text)

- Alignment is required when two or more actors are involved

- Alignment happens via mutual exchange of information

\subsubsection{Scenario C: Client, designer and producer}

With the third scenario, manufacturing is split into two separate responsibilities: defining and making. There are now three actors involved: the client/end-user, one responsible for the product definitions and one responsible for the production of that product definition, bringing this scenario close to the modern-day practice of both design engineering and manufacturing in an industrialised context. With a third actor, in essence there is a multiplication of the issues from the second scenario: with three actors there is even more need for alignment and the overall information exchange will increase as well. Moreover, with an increasing number of actors, the avail of explicitly available information increases. This smoothens the alignment process as one can refer to one document instead of constantly verbally repeating the previously made agreements. Additionally, a document can be the linking entity between multiple actors. The definition of the product is an important example of such a formalised agreement. It can be used as a reference for the producing actor and, independent of the number of discrete products manufactured. With this third scenario, the common form of a prod- 
uct definition expressed in explicit (instructive) information as end-result of a product development cycle has come into sight. As a result, it is important to note that:

- The likelihood of explicit information exchange increases when more actors are introduced.

\subsubsection{Scenario D: Clients, users, design engineers and manufacturers}

The fourth scenario increases the number of actors on every aspect. There is a team of actors stemming from various disciplines responsible for the product definition and a team for manufacturing. The receiving side has expanded tremendously, there is an entire organisation that acts as client and the users are numerous. While this may seem a very complex situation, the essence of communication and information exchange and alignment from scenario two and three still apply, merely at a larger scale. With responsibilities now divided between multiple actors, the chance of information being shared unambiguously decrease significantly. In other words, explicitly available information will be available in fragments dispersed over the various actors. Furthermore, with an increase of actors and disciplines, the chance of misalignment increases significantly. This potentially results in a Babylonian confusion, leading to more efforts being spent on obtaining alignment than on evolving the actual product definition. This is partly caused by the impossibility of having all actors available in one place at a specific moment in time. With a product intended for mass audiences, the group of end-users becomes more anonymous and might be reached only by sample. This leads to a need to, either implicitly or explicitly, make assumptions about the unavailable/inaccessible actors and the missing information. Obviously, such assumptions increase the level of uncertainty about the product definition. When relying on such assumptions for a longer period of time, they might become part of the experience and therefore be treated as self-evident or as dogmatic presumptions. In itself, this does not alter the way in which knowledge is made communicable by means of information, but it does stress the importance of being aware of the fact that knowledge is linked to information by virtue of the context of the actor. With the fourth scenario, the following aspects:

- Making (implicit) assumptions if information is unavailable is a common and necessary aspect in product development cycles

- Without context it is impossible to interpret information and assess the quality of assumptions.

\subsubsection{Knowledge, information and data in communication}

In summary, the four scenarios have led to the recognition of the following aspects:

- Knowledge is personal and implicit.

- Information aids in making knowledge accessible.

- Information is not necessarily linked to an explicit medium.

- The transfer of information is either direct (via senses) or indirect (e.g. via sketch or text).

- Alignment is required when two or more actors are involved.

- Alignment happens via mutual exchange of information.

- The likelihood of explicit information exchange increases when more actors are introduced.

- Making (implicit) assumptions if information is unavailable is a common and necessary aspect in product development cycles. 
- Without context it is impossible to interpret information and assess the quality of assumptions.

Based on these aspects the definitions of information, knowledge and data are reinterpreted in the context of product development. Figure 4-3 depicts the terms information, knowledge and data in a communication process, summarizing the aspects discussed in the scenarios. The model contextualises the definitions as being part of communication and incorporates knowledge as a personal commodity, information as meaning and data as standardised formats for various media.

For this research, information is defined as an explication of knowledge in order to make this knowledge transferable. Context for information as well as knowledge is crucial. This context is determined by personal aspects such as background, interest, experience, mood and skills. This context is also influenced by the environment of actors. Knowledge is understood as being implicit and personal. Therefore, knowledge can only be made available via information using this personal context. Other than the $\mathrm{d}$-i-k-w paradigm, information is not automatically coupled with data as information can also be directly transferred via senses using a temporary medium such as soundwaves.

Information is expressive and meaningful, consequently information is not by definition factual but subjective. As information is at best a partial reflection of knowledge transformation, there is always the possibility that one document is differently interpreted by different actors. In other words, these actors aren't extracting the same information from that one document.

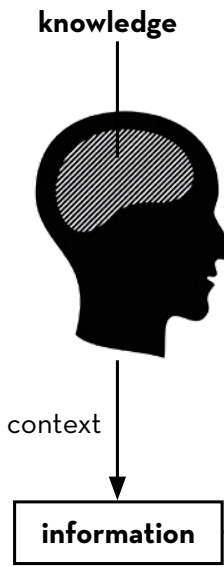

direct transfer

by means of understanding

and senses

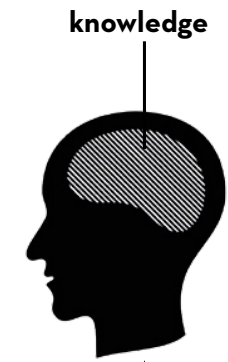

4

context information

indirect transfer

by means of a medium

recorded in a

form of data

Figure 4-3 Information, knowledge and data in context of communication. 


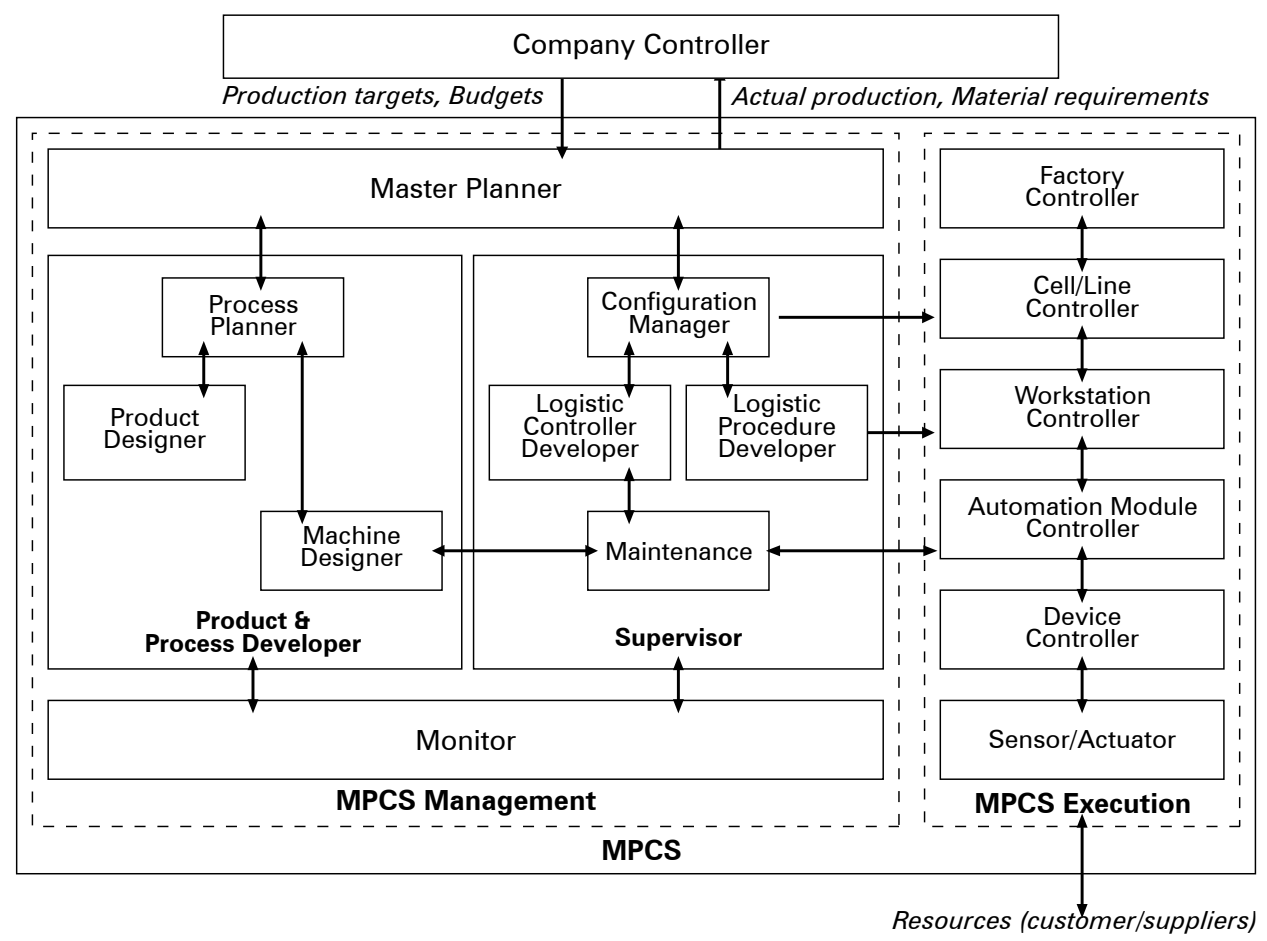

Figure 4-4 Reference model Biemans (Biemans, 1989)

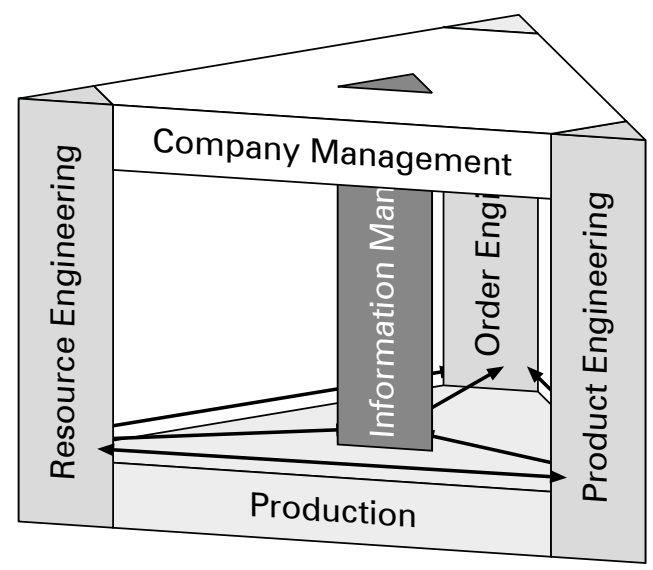

Figure 4-5 Reference model Lutters (Eric Lutters, 2001) 


\subsection{REFERENCE MODELS}

The previous sections explored the role of the different actors, the mutual relations between data, information and knowledge and the way in which information can be the interface between different knowledge contexts. These disquisitions, building on the information-value axiom form the foundation for a different approach for design(er) support. To arrive at a systematic and coherent underpinning of such support, not only the constituents of the support approach need to be defined, but certainly also the control principles that can make such support instrumental for the various actors requiring significant attention. In other words: this research needs a framework to express the design in terms of information instead of processes, without prescribing or limiting the freedom of action of the actors. For this purpose, a so-called reference model can be used.

Reference models give an abstract and more or less factual depiction of a system in which the usability of that model is primarily determined by the ability for humans to understand and use it in managing and controlling a system (Biemans \& Vissers, 1989). A reference model views its subject, whether that is a process, problem, software architecture or organisation, as a system of interrelated concepts in which sequentiality is absent. Definitions of those concepts and relations are used to create common ground for the discipline, field or group of stakeholders involved. As such, it tries to explicate a situation, subject or practice systematically without using activities as common denominator. These aspects conjointly make the concept of reference models the designated foundation for an information-based perspective on product development.

Reference models stem from enterprise engineering and manufacturing. For instance, the PERA (Purdue Enterprise Reference Architecture) framework uses system representations as standards that prescribe generic requirements for Computer Integrated Manufacturing (CIM) that are independent of specific applications. Biemans defined a reference model as an organisational-driven representation of a manufacturing system. With a reference model a system is decomposed into relatively independent functional components (Biemans, 1989),(figure 4-4). For each of these components, responsibilities, corresponding tasks and relations are holistically defined. Interestingly, Biemans only begins describing processes once the system representation is in place. This contrasts with design engineering in which the process descriptions themselves form the representation. A significant part of the work of Biemans is also about processes. However, because of the importance of relative interdependency, emphasis is put on the responsibilities belonging to the individual components instead of the concatenation of processes. A representation such as used in Biemans (figure 4-4) renders a specific level of detail - usually a generic one - to serve strategic purposes. Although the functional task descriptions that Biemans uses are easily misinterpreted as concrete job descriptions, Biemans specifically warns that every reference model needs adequate translation for implementation.

Alternatively, the Manufacturing Engineering Model of Lutters steers away from the rather specific manufacturing components and task descriptions of models such as Biemans. Rather, the model epitomises the manufacturing environment as consisting of three disciplines: Order Engineering, Resource Engineering and Production Engineering (Eric Lutters, 2001)(figure 4-5). Information Management is added as a core to 
enable control and minimise undirected communication between departments. What distinguishes this model from Biemans and PERA is the absence of explicitly defined tasks. This renders a more abstract but also more flexible model that is not limited to a specific type of production or products.

Apart from use in manufacturing, there are different uses in design engineering for the notion reference model. In the Design Research Methodology the term is used for a network of influencing factors to clarify the problem as well as the solution space (Blessing \& Chakrabarti, 2009). Bonnema uses it to clarify solution paths in conceptual development (Bonnema, 2008). Both examples use a reference model to clarify more abstract subjects than the previously manufacturing based examples.

\subsubsection{Requirements specific for product development.}

As the reference models mentioned above have not been specifically developed for a product development context, it is not obvious that any of these models is applicable for design engineering without any adaptations. Foremost, any attempt to copy one of the models would render an obstructed view on product development that does not immediately do justice to its non-deterministic characteristics as discussed in section 2.2.5. For a design engineering environment, the following aspects require attention:

\section{Different system boundaries}

The discussed reference models include product development. However, focus is on the manufacturing environment. For this research, focus is entirely put on product development. It is assumed that the more seamlessly a reference model connects to the application domain, the more effective the proffered support and system definition can become. Consequently, a different system boundary may be useful.

\section{Actors instead of machines.}

Design is in essence a human activity, rendering system components or machinery indominant. Moreover, by addressing actors, the reference model needs to take into account two-way interactions that overtakes the formalised, passive and reactive response provided by hardwired resources.

\section{Multiple levels of detail}

A reference model is an intermediary step in defining a system and its corresponding behaviour. Usually, focus is put on one, strategic level of detail. For product development, one level is not sufficient, regardless of the level of detail. Product development cycles include multiple levels of aggregation simultaneously. Consequently, a reference model depicting and capturing development processes should take this into account.

\section{Uncertainty}

Reference models are not tailored to utilise and exploit non-deterministic processes. Uncertainty, for instance, is a concept not covered by reference models. On the contrary, most models are used to reduce the uncertainty of a system. For this research, a model is thus needed that is suitable to capture the uncertainty of product development cycles. 
With the reference model for information-based product development (figure 4-6, next page) focus is put on the role of information in product development. Other than the intermediary design planning scope of the model of Biemans, here the intention is not to use the model as a blueprint for composing systems of product development. Although the reference model can be used to characterise practise development situations, the main purpose of the model is to explain and define the inner workings of product development from an information perspective.

Other than common process-based models as discussed in chapter three, product information is captured without an explicit focus on the activities or processes. In a sense, the reference model reverses this: instead of assuming information content to logically follow from depicted activities, it is assumed that activities can be logically deduced from the evolving information content and the corresponding interaction with actors. Consequently, with a focus on the information content of the evolving product definition, the reference model in principle does not repudiate any process model, it just accepts that there are a multitude of process models that might be applicable, depending upon the specific context. Therefore, the reference model should not be understood as a full replacement of any process-model, rather it is intended as a complementary model in which the basic mode of interaction between actors and the evolving information content is defined. The reference model thus considers the evolving information content to be the pivot of the development cycle. As such, the reference model can be understood as an attempt to do justice to the information-axiom introduced at the beginning of this chapter.

Instead of iteration loops or progress arrows, each element has a relative status as attribute, signifying or indicating the maturity of that aspect. This status attribute could well easily include a version for instance of a document, and thus referring directly to the number of iterations, but might as well include the probability or level of certainty that that element has within the design project. As such, the progression of a design trajectory is not reflected in a timeline or sequentiality but in the state of these four elements. Statuses reflect the level of confidence a design engineer or team assigns to a (subset of) any of the four core concepts.

Focal point of the reference model is the interaction between any product development team and the corresponding evolving information content. The first is defined in the reference model as the actor demeanour and the second as the product definition. There are two fundamental ways of interaction: via a concept or via a requirement specification. As the information terminology has no progressing dimension and the reference model always gives a status of a situation, the interaction between the four aspects are defined as the interdependencies and not as an activity or iteration.

Product developers continuously aim to extract requirements or concepts from real-world situations or future scenarios and translate these abstract requirements into well-defined solutions. In other words, information continuously transformed from implicit to explicit information, from requirements or concepts into a (subset of) the product definition. In practise, the various aspects could easily amalgamate. For instance, a requirement specification might contain solution-phrased demands, something that ideally should be avoided as it hampers its functionality as a referee. Howev- 


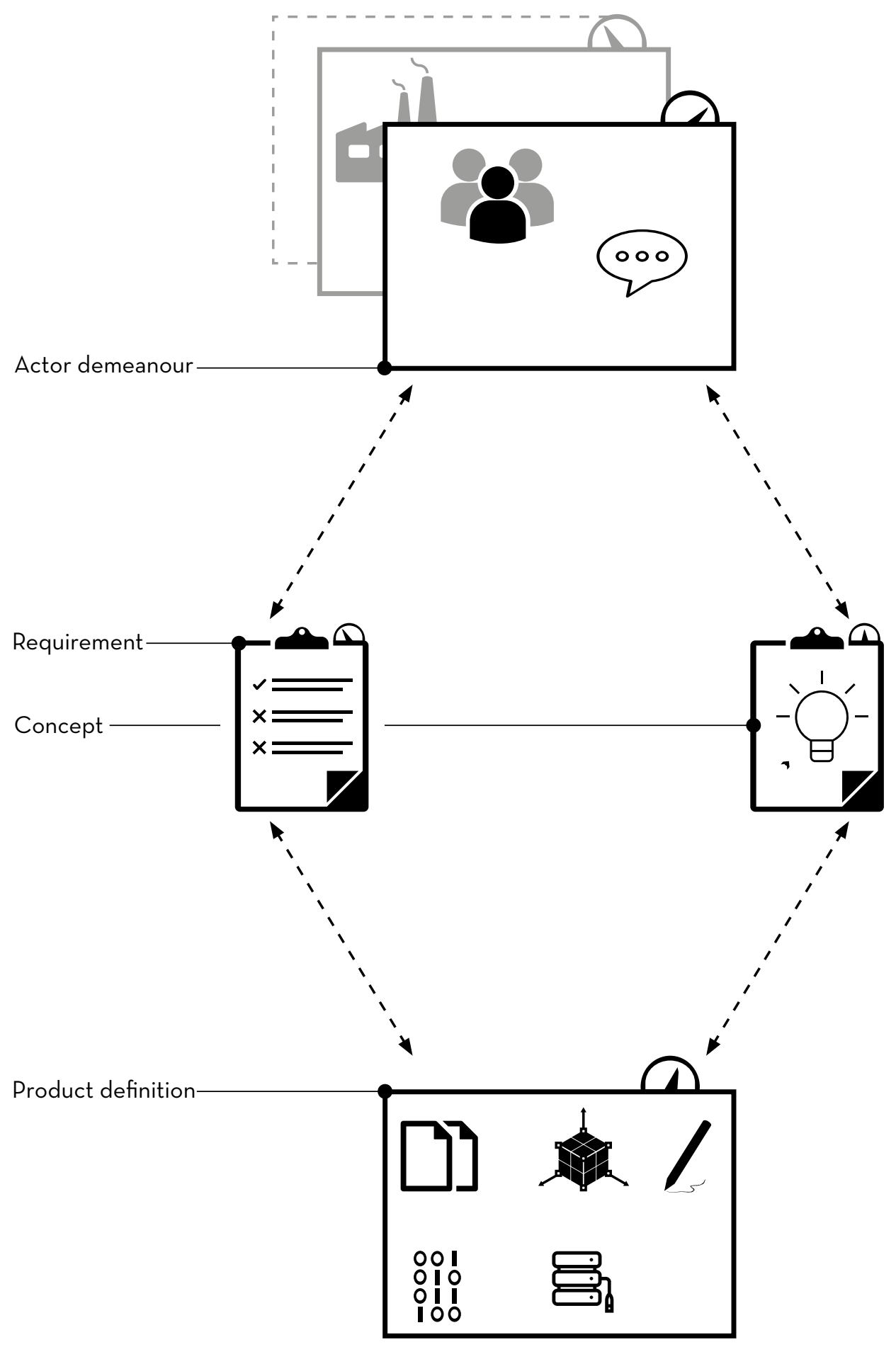

Figure 4-6 Reference model for information-based product development 
er, some requirements, especially technical requirements, can only be based on such solution-phrased requirements and should even explicitly be connected to it, in order to preserve the rationale. As a result, an amalgamation of the three different sources of information is considered as inevitable and even useful in practise. Nevertheless, it is considered as important, if not crucial, to be able to make the distinction between these four core concepts as it touches upon the essence of product development: creating a suitable product definition that adheres to the requirement specification and is predicted to fulfil the pursued overall added value. Each of the aspects: actor demeanour, product definition, concept and requirement specification is discussed below.

\subsubsection{Product definition}

The product that was the reason to start a development cycle does not yet exist during that cycle. To allow for purposeful reasoning during the development cycle, all actors refer to product definition. The product definition is an information model that anticipates the outcome of the development cycle in such a way that the product definition and the final product have a coinciding denotation for all actors involved. In other words: the product definition adheres to the aspired values and allows for equivocal and purposeful materialisation. This collection of information that constitutes the product definition consists of e.g. material descriptions, shape and form definitions and technical drawings that conjointly define the 'class' of the product. A perhaps unexpected, but equally important part of the product definition is the collection of previously dismissed drafts, concepts, considerations, alternatives and ideas. It is a complementary way of defining the product, because by describing what it is not, its definition is also improved. The reason for regarding this as part of the product definition is due to the importance of rejected ideas in relation to the rationale behind a design

In downstream phases, this collection of information allows for engineering analyses (e.g. strength, dynamics), for user testing (e.g. acceptance, buying behaviour) and it allows for ensuring that instantiations of that class can be produced. The product definition can thus be regarded as the principle output of any design engineering process. In practice, the generalised notion of a product definition can take on any form: from detailed bill of materials for PDM-systems to conceptual drawings establishing the principle idea of a new product. Moreover, what is exactly understood as a sufficient product definition is dependent upon the involved actors and context. As the collective of stakeholders involved in a development cycle will beg to differ on the requirements imposed on what a sufficient product definition is, the alignment on establishing an adequate product definition in itself will require development efforts. To add to that complexity, product definitions can span multiple levels of aggregation. For example, when considering the wrapper of a candy bar, the product definition might address the coil of foil for the material supplier, whereas the candy bar and the wrapper conjointly define the complete product for the end-user.

\subsubsection{Actor demeanour}

As indicated in the previous section, a reference model for industrial design engineering should address actors rather that machines. Whichever practical development situation is addressed, the combination of actors that conjointly form and/ or influence a product development cycle, strongly characterises both the expected approach as well as the potential of a development team. Moreover, actors are also the senders and 
receivers of information, and holders of knowledge as indicated in the communication model (see figure 4-3 ) As such, knowledge of the involved actors is understood to be a crucial element in understanding the context in which information can be interpreted in a purposeful manner.

As such it is crucial to incorporate actors in a reference model that is based on the information-value axiom. However, directly including any set of actors would make little sense, as there is no coherent generic applicable set of actors to be made that covers all the various disciplines for all product development trajectories that fall within the industrial design engineering scope of this thesis. The diversity in involved disciplines alone, is enough reason not to classify a certain set of actors as being a definitive part of the reference model. Moreover, such a classification of actor types unnecessarily limits the applicability of the reference model for future development cycles. More importantly, such a classification would give cause for stigmatizing and does not focus on the essence of why an actor is considered such an important aspect of the reference model. Therefore, focus is put on the demeanour of the involved actors. Demeanour includes both the conduct and stance of actors with respect to product development. Actor demeanour therefore conveys the reason and rationale for which activities are performed, and which type/scope artefact are considered and which assets might be expected or should be considered.

This actor demeanour is applicable beyond the traditional boundaries of product development teams. It is intended to capture actors and their context for all relevant parts of the product life cycle. This includes actors stemming from adjacent disciplines such as maintenance, procurement or manufacturing

\subsubsection{Concept and requirement specification}

There are two principle ways how actors can contribute to a product definition: either via a concept or via a requirement specification. Although in practise an apparent amalgamation between these two concepts often exists, e.g. stated requirements that contain solution-phrased definitions or concepts that seem to initially add to the product definition but later turn out to the discovery of additional requirements instead. However, there is a strict delineation between concept and requirement specification. (in shape of: new concepts that come with assumptions) With a concept an actor directly contributes to the evolvement of a product definition itself, whereas with a requirement specification the frame of reference for the product definition is addressed.

Obviously, concept addresses any drafts and design proposals for the product definition. However, concept as intended in the reference model extends beyond this designerly denotation and is expressed as any generic idea about the (evolvement of) the product definition, whether this involves concrete drafts, a generic solution direction, or the formation of new ideas.

The requirement specification demarcates the pursued value (stated purpose) and both the solution space and the problem space of any development cycle. As such, the requirement specification is understood to be a part of the constantly evolving information content, rather than a fixed list of demands and wishes that is devised after thorough analysis and only revised when needed afterwards. The requirement specification is thus a live document that serves as an intermediary between the various scenarios and product definition. The essence of a requirement specification is that it 
describes the desired behaviour of the product under development while adhering to the scenario descriptions. In design teams, the requirement specification forms an explicit, consolidated control mechanism, it offers common ground and formal check that counterbalances the inevitable subjectivity that is involved in any design trajectory. Often stated and stressed criteria for requirements (Roozenburg \& Eekels, 1995) such as sound formulation, measurable criteria and avoidance of redundancy are important but nevertheless inferior to the steering and mirroring role a requirement specification plays in design. In other words, by considering requirement specifications merely as the 'law book' of a development cycle, much of its added value is lost. Next to acting as the conscience of design cycles, the requirement specification can additionally be the marketplace where supply and demand meet. Therefore, it is on this requirement specification that the actual, profound and determining considerations are made.

$A$ requirement specification includes a stated purpose, function descriptions and technical requirements (see section 2.3). Similar to the actor demeanour of involved actors, scenarios in requirement specification capture context, characteristics and behaviour of prospect users of an artefact. As such, these scenarios also represent the future environment/ context in which the artefact is going to function and is therefore considered to be a crucial component in requirement specifications.

Scenarios offer the context in which the rationale of those requirements are made understandable. Consequently, there is (and should be) a clear definition between scenarios, purpose and requirements. In fact, if such a relation cannot be established, this indicates that some element is missing or the requirement is superfluous.

\subsection{CONSEQUENCES OF ADOPTING THE REFERENCE MODEL}

The reference model addresses design engineering in terms of four aspects. Based on the axiom, information in this model carries the added value of the product development cycle, whether this information is explicitly available in documents and models or is only transferred in direct communication. As such, the reference model allows the product definition to offer a snapshot of all results at any given moment in the development cycle. In this, focus is on the balance between the evolving status of a product definition and that of the actor demeanour. Here, the requirement specification is specified as the reference for regulating this balance. Interestingly, this requirement specification is in itself evolving as well; this renders all components of the reference model dynamic, with the mutual relations being defining features for the development cycle. In essence, the fact that the requirement specification connects the product definition to the 'actor demeanour' in an equivalent manner, thus not prevailing the one over the other, again substantiates the claim that the development cycle thrives on the information content rather than on process descriptions. The evolving character of the requirement specification emphasises that as well, as a process oriented evolvement would require extremely intricate process descriptions, with demonstrable complete understanding of all aspects of the development cycle.

With an information perspective, focus is not put on the activities but on the results of those activities as it models design engineering as evolving information content. This renders a view on the design process in which the actual progression seems disconnected from the information content. Design engineering in the reference model is 
viewed as a system with a specific focus on information. As a result, there is no explicit depiction of a sequence of activities or processes in the model. Rather, any sequence is deemed possible.

With this, the perspective on development cycles changes to such an extent, that two subservient aspects of development cycles can become determinative factors in such cycles: decisions as common denominator and uncertainty as driver. Previously chiefly seen as consequence rather than as instigators, the information based paradigm allows them to become instrumental and directional in development cycles.

\subsubsection{Decisions as common denominator}

Decision making is the activity that determines the preferred course of action. Simultaneously, there is an important aspect of consolidation in decision making: determining which available option is currently best and which alternatives are abandoned. Consequently, decision making can be understood as the design activity that fosters and consolidates both the product definition, the requirement specification and the design rationale. Decision making can be objective or subjective, stressing the balance between deterministic and non-deterministic aspects of development cycles. Unlike design methodologies in which the entire development cycles is modelled as a sequential process to foster understanding, this research views the process component as a network of decisions that have logical dependency but which are not necessarily have to be sequentially organized in time.

As such, there is a clear relation between decision making and the information content in a development cycle. Even more, if designing is understood in terms of creating (new) information content, rather than as a predefined course of actions, then decision making is the elementary activity in establishing that information content.

In regarding decisions as the common denominator of development cycles, each decision is assumed to potentially affect the (evolvement of) the product definition. Regardless whether this decision is a minor change of a technical drawing made by one actor or a strategic new solution direction involving multiple actors.

Consequently, the coherent set of design decisions is seen as the scaffolding that enables a design team to initiate, substantiate and assess the evolvement of development trajectories against the context and requirement specification. Decision making should therefore be understood as a value adding activity (De Lange et al., 2016). In extrema: decision making is no longer seen as the activity that leaves behind a trail of information, it rather becomes a tool to allow for purposeful evolvement of the information content.

A multitude of actors, often with different perspectives and interests, are involved in decision making processes during the product development cycle. They continuously influence and decide on all aspects of the product under development. Whereas the rationale of a design decision might be perfectly valid from one specific viewpoint, this might not be inherently true for all other perspectives involved. For example, a packaging concept that is perfect from a marketing perspective, may be infeasible from a production point of view. Decisions influence the solution space of other decisions via the information content. In most cases, it cannot be foreseen which other decisions need to be made, changed or are invalidated in making a decision. This applies both internally (within an organisation) and externally (over different organisations). 
It is assumed that the effectiveness and efficiency of decision making together influence or even determine the success and quality of a product development cycle. The combination of these aspects convey the balance the result of a decision and how much resources it will cost to reach that decision. Due to this balance, the ratio between the two is regarded as more important than putting exact numbers on effect and efficiency. The effectiveness and efficiency of decision making together is regarded as an important aspect. However, the actual interpretation of what effectiveness and efficiency entails is not addressed. This interpretation is heavily dependent on the specific context and this definition includes a significant component of subjectivity, it is therefore well-nigh impossible to quantify or precisely determine the effectiveness or efficiency of decision making in general.

Decision making has both expected and unexpected impacts. Even a straightforward, simple choice may lead to unforeseen consequences, with a snowball effect as extreme. Next to such aftereffects, the elusiveness of decision making in itself will also affect its predictability. In process oriented development cycles, designers are not aware of this elusiveness, or lack substantiated means of incorporating it in decision making. Therefore, their only option is to ignore it altogether by entirely focusing on decisions that rely on information that is explicitly available. As a result, this information might be mistakenly perceived as correct, certain and unfaltering, resulting in situations where decision processes convert potentially unreliable information in outcomes that are presented as sound. This brings a false sense of exactitude to evolving product definitions and development cycles. With the information-value axiom, these normative decision making processes become tools to change the information content; therefore, the evolving information content is leading. With this, individual decisions can be judged on their merits, in which the value they add to the information content is the main criterion. Consequently, decisions become tools to connect the evolving information content, the requirement specification and the actor demeanour.

\subsubsection{Uncertainty as driver}

Traditionally, designers have adopted to becoming experts in following two paths at the same time: they can follow the designated route, established by for example a design method or a stage-gate process while simultaneously they can leave the beaten track by dealing with the uncertainty, ambiguousness and unpredictability that characterises the development cycle. It is the problem solving focus, creativity and the ability to make decisions under uncertainty that allows a designer to create new ideas and materialise the pursued added value (Kees Dorst, 2011). Uncertainty is present on all levels and in all aspects of the model and the design practise it tries to explicate. However, if not seen from a process oriented approach, uncertainty is not always an undesired quality. Where such process-oriented approaches aim to converge to situations with as little uncertainty as possible, the information-value axiom allows for an approach in which uncertainty can be anything from an annoying disturbance, via a neutral appearance to an actual challenge and initiation for steps in the development cycle. As such, uncertainty has an important and indispensable role in design; in essence, it can be the sheer reason to take the next step in a development cycle.

At the same time, in order for a product to be instantiated based on its product definition, the uncertainties present must not obfuscate the design intent. With this, a 
tendency is explainable to confine or reduce the initial uncertainty to such an extent that the resulting definition of the product is sufficiently ready for realisation of the actual products. However, this reduction must be a logical consequence of the evolvement of the product definition instead of a core means that has a prevailing role. With the relation between the uncertainty and the evolvement of the product definition, as well as the observation that product development can indeed thrive on uncertainties, consorting uncertainty can actually be a value adding activity. Moreover, uncertainty is an information condition, which aligns with the information-value axiom. Combining these observations result in depiction of development cycles where the requirement specification, the product definition and the actor demeanour should balance each other. At the end of the development cycle, this balance should be quite stable, but during product development any misbalance will lead to next steps in the development cycle. Here, uncertainty is, for example, a means to test the stability of the current state. Therefore, uncertainty in itself can be the pro-active onset for development initiatives; i.e. uncertainty can drive the development cycle, thus fostering progression.

\subsection{CONCLUSION}

Within the domain of design engineering, many well-intended, adequate and effective process oriented approaches are available as design methods for development cycles. Irrespective of their successful application and implementation in industry and their valuable role in educating product designers, this research claims that process oriented approaches are actually circumferential ways to arrive at the end result of product development: an adequate product definition maintained communally by all actors. A more direct, or purport driven, development approach is to aim for the purposeful evolvement of the product definition. With this, the aim is to directly capture the added value engendered by the development cycle in the product definition. The information-value axiom claims that in this, processes are mere means or tools rather than being carriers of added value themselves. When viewed from an information perspective the essence of product design is not modelled in stages nor is it captured with analysis, synthesis and evaluation. It revolves around understanding real world situations, envisioning promising future scenarios, precisely capturing issues, around converting aspired values and context into a usable requirement specification and creating a sound product definition that can add value to when produced.

At first sight this seems a rather peculiar way of describing the design practise, as the usual timeline, important decision moments and the actors involved are not primarily addressed. However, the artefact is the key element of product design practise; design engineering revolves around the product. The usual result of a design project is a definition of that product. With the proposed reference model, every other element of the design practise logically follows from the artefact. As such, it complements models that focus on the process, and models that focus on the actor. Even more, when reasoning from the axiom, it seems that a rather neutral depiction can be acquired from which several methodologies could be deduced. 


\section{EXPLORATION \\ OF}

\section{INFORMATION USAGE}

The previous chapter outlined the axiom that states that in development cycles, information is the carrier of all (added) value. Even if the interpretation and impact of that axiom are fully clear, the way in which this axiom in itself can become instrumental in product development is not necessarily obvious. The different paradigm is clear, and the advantages of the information based approach are substantiated; however, at the same time the way in which this will allow for changes in development cycles is not yet elaborated. In other words: the tools, methods and techniques required to allow information to carry the added value need specification and fundamental underpinning. This chapter therefore starts with an exploration of the current structuring and use of information, from which challenges with that usage are identified. From that, an analogy is developed that allows for the support of adequate decision making. 


\subsection{INFORMATION MODELS AND STRUCTURING PRINCIPLES}

This paragraph introduces three perspectives on information management: a system perspective concerning data and information models; a user's perspective on clustering and classifying information; and a product development cycles perspective. Relevant aspects of information management are introduced and briefly discussed using these three perspectives. The next section will review current information usage practises in product development in depth.

\subsubsection{System perspective: data and information models}

Countless models of data and information depict the manipulation, storage and exchange of sources of information. To allow for these desired functionalities, applications and frameworks for software systems rely on data or information models that have a predetermined, usually hierarchical, structure. ERP systems are good examples of systems that are predominantly based on an a priori-determined structure. Data input is controlled via strict forms that allow for little to no flexibility. Important business activities such as purchasing, supply chain activities are dependent on a reliable source and input of data and partially base this reliability on the predetermined structure these systems adhere to. This strictly controlled input is understandable and logic. However, these data and information models result in hierarchical structures for information sources that only allow for a limited perspective on the information sources. If this perspective aligns with the intended purpose and domain, this limitation is of no concern. However, in product development, these systems are often applied for different purposes or are used in varying settings. Within such different contexts, this causes difficulties in understanding the meaning of, but foremost in making purposeful use of these a-priori determined, rigid structures.

Product development teams are supported by systems for various and diverse functionalities. Apart from software that is tailored towards specific processing and editing of data there are systems specifically aimed at integrating many of the managerial functionalities needed during product development. This need for project management has caused several complex software systems/approaches from very different domains to move closer together. As such, ERP, PLM and PDM systems, Project management software and on-line collaboration initiatives are gradually becoming alternatives. In this range of approaches, the impact of considering information as the workpiece is nevertheless rather diverse. Where some approaches have a bookkeeping background, the more engineering oriented approaches such as PLM centre around a 3D-model of the product definition. The obvious example in this context is the domain of CAD/ CAM software. The traditional functionality of a CAD/CAM system allows a user to define geometry, determine properties and analyse consequences in interrelated models. In establishing such models there is abundant freedom and the level of detail can be gradually built up. Based on this core functionality, CAD systems are embedded in Product Lifecycle Management (PLM) systems that offer a wide range of abilities offering instruments for well-nigh every phase of both development and realisation. In such systems, product development teams can simultaneously work on models, communicate and control versions. Even file exchange between various applications and systems is attempted by using standards: in essence agreed upon languages to express the information. 
Figure 5-1 An example of an early graphical user interface using the physical desktop as reference: Apple Macintosh (1984)

Figure 5-2 Examples of hierarchical structuring principles applied for interaction in software systems: Operation system file explorer (a), ERP system (b), CAD System (c)
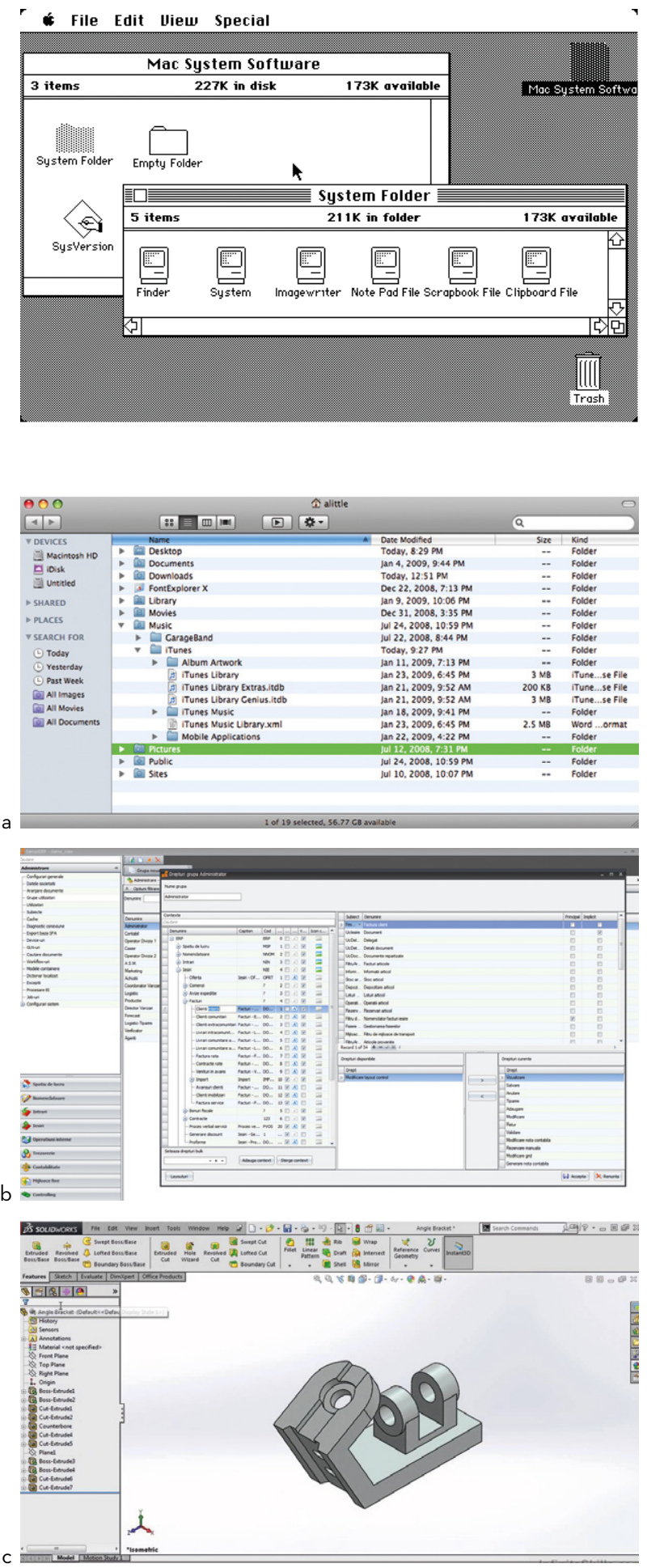
The ISO 10303 standard 'Automation systems and integration - Product data representation and exchange' (Standardization, 2014), informally known as STEP (Standard Exchange of Product Data), is exemplary for this type of standardised information models. The initial purpose of STEP was to base the standard on a generic product information model that was independent of any implementation and could serve as standard to neutrally exchange files (STEP - The grand experience, 1999). This powerful idea has grown the application range of STEP in a broad domain, covering design, manufacturing and engineering. Each domain is sectioned and served by so-called application protocols (AP) that offer prescriptions or working approaches on scope and requirements (Zheng, Bricogne, Duigou, \& Eynard, 2014). APs are standards that do not directly influence the structuring of information by users; they are rather powerful mechanism that should allow for a smooth transition of product data between various applications, without allowing the user to directly impact the structuring of the information itself.

The STEP standard is just a tip of the iceberg in surveying all systems that play a role in a typical product development cycle. Figure 5-3 in the section 5.2 below illustrates a typical use scenario of CAD systems and various other programs and software systems that are used to create, manage and communicate (product) information. It would make little sense to review all data and information models underlying these systems. Instead, for this research a pragmatic attitude towards these systems and information and data models is chosen. It is assumed that all of the models can contribute to the creation, storage and/ or retrieval of information sources. As such, any file stemming from such a system potentially contains valuable information about the product definition.

\subsubsection{User perspective: hierarchical structuring principles}

Ever since the first Graphical User Interfaces were based on an analogy with the typical office surrounding at the time (figure 5-1), users structure information on computers just as any non-digital filing system would do. This (intentionally) has a strong resemblance to a physical filing system. Obviously, the digitalised version has additional advantages over this old archiving principle such as ease of storage, ease of access, ease of search and categorisation based on data, file type, date etc. But the overall and underlying functionality is still similar. From a user point of view, the archetypal organisation of files is using an archiving system of files and folders. Regardless of powerful search functions, tagging systems, sorting options and file type recognition, this hierarchical way of classifying information files is the dominant way of structuring information for users (figure 5-2).

However, people make sense of the world by interrelating concepts. That simple observation implies that the relation between 'files in a cabinet' can bear a denotation that is much more relevant than the information contained in a file. Especially for the contextualisation of information entities, the ability to connect entities in a meaningful manner is essential. Inherently, humans rely on that ability; even young infants start to understand the world around them by finding and exploring such relations. Interestingly enough, humans also tend to understand information content by assessing the mutual relations between the information content. However, for sheer reasons of efficiency - and in preventing from reinventing the wheel over and over again, humans also tend to automatically cluster information that has similar properties. As such, this is an extremely useful skill, that, under influence of the urge to communicate the infor- 
mation content together with its underlying structure, slowly tends to adhere to more explicit and formal standards. In other words, out of these clusters, more stringent classifications emerge that are less flexible than the original clusters but work effectively in a certain setting for a specific purpose. To emphasise the difference between the notions clustering and classification: in clustering the structure tends to follow the information content; in classification, the information content is required to follow the preconceived and agreed upon structure or taxonomy. This difference is relevant, as clustering can adhere to changing denotation of the information content, whereas in classification the potential denotation precedes the actual content. This explains why no classification system is perfect; after all each such a structure usually has the inevitable category 'other'. In sorting, clustering and in classifying information, people try to make sense of it by applying logic, to retrieve information and to be able to find it again. In other words, people attach denotation to the structures themselves, for example to be able to communicate more efficiently about the information content they index. In any product development trajectory there are many of those structures that are each useful - at the same time.

\subsubsection{Perspectives on information in product development}

During any product development cycle, there are multiple disciples involved in establishing the product definition. Each discipline has a specific perspective on the matter, formed by the responsibilities, background and/or specialism of the actors involved. This renders different views on the same matter. For instance, a product designer might be concerned with the product in relation to users, problems, requirements, solution principles, CAD-models and the products overall appearance. A marketer might also be interested in the overall appearance and product but then in relation with the brand, proposition value, retailing, the markets and consumers. Contrastingly, a manufacturer would also view a product as an important part but presumably in relation to production lines, batch sizes, planning and supply. For a typical development cycle, such views are active simultaneously, regardless whether these reflect the perspective of an individual, a whole department or is embedded in important software systems. Each specific view on information has its own place and functionality in the overall development cycle. When reflected or expressed in information, such perspectives render classifications or structures that are often hierarchical and more or less predetermined. Each view potentially implies different classification criteria resulting in different (more or less rigid) structures of information.

Comparable to the usefulness of different perspectives on the product definition, each of the information structures is regarded as potentially meaningful and helpful as it aids in establishing the information content in a certain context and with that with a certain meaning. Examples of such information structures are the forms in ERP systems that define how information is inputted in the system, the typical file-folder structure on a personal desktop computer or a shared drive. In such a predetermined, hierarchical structure, any information entity that does not suit the current classification would either end up in the remaining folder or would disprove the taxonomy and would lead to a reconsideration of the classification criteria. In other words, if any predetermined relation between information entities is falsified, this causes a need to reconsider the entire taxonomy of information. 
Information management in product development has a multitude of structuring principles, data and information models that enable intended usage and processing of information. For users such models are often not directly visible, the focus of information management here is to cluster or classify information. In the meta-perspective of a product development cycle, involving a multitude of systems and actors stemming from various backgrounds, each cluster or classification represents a certain view on information. The important aspect here is that most systems and usage principles do not cater for the recognition and usage of these various views. When views are explicitly addressed, e.g. in PLM systems, this is often in the form of predefined roles. However useful, this principle solution does not leave room for any flexibility in recognizing or purposefully using emerging clusters and structuring principles. As such, information management for product development seems to lack an important dimension. The next section reviews this information usage in more depth using literature on information and knowledge management and examples derived from the practise situations described in section 2.1.

\subsection{CURRENT INFORMATION USAGE}

Abundant empirical research exists on information and knowledge usage in relation to the needs of design engineers. Together with the cases used in this research (see section 2.1), this literature is used to obtain and overview of information usage in design engineering. Figure 5-3 (next page) gives a synoptic overview of this information usage scenario. A significant part of the literature reports on research methods that result in a thorough classification of the information and knowledge needs e.g. (Heisig, Caldwell, Grebici, \& Clarkson, 2010), the cognitive skills used (Robinson, 2010) and the time spend on information (Allard, Levine, \& Tenopir, 2009; Reed, Scanlan, Wills, \& Halliday, 2011; Robinson, 2012).

Based on a survey amongst 137 design engineers, Heisig et al. (Heisig et al., 2010) identified 69 overall categories that reflect the expressed information needs, spanning the entire development cycle (e.g. drawings, decision and requirements) as well as the entire product life cycle (maintenance, product life end, supply chain). Although the categories are not mutually exclusive, they do give a solid representation of how design engineering practitioners express their information and knowledge needs. Consequently, it gives an insight in the terminology used.

For the overall time spend on information usage the results vary significantly. Whatever figure is used or reported, information usage is considered an important and significant aspect of the work of design engineers. The differences may be partly explained by the influence of different organisations and industrial background, used methods and number of participants. However, there might be a more fundamental issue that is causing this variance. There is no commonly accepted set of definitions used for information. In fact, most publications do no devote any space to terminology or definitions. As a result, each research has a slightly different perspective and corresponding different (implicit) definitions of information. Although collectively this offers a rich view on information usage, this lack of common terminology might also contribute to the variance. 


\section{HOW PRODUCT \\ DEVELOPERS \\ AND DESIGN \\ ENGINEERS USE INFORMATION}
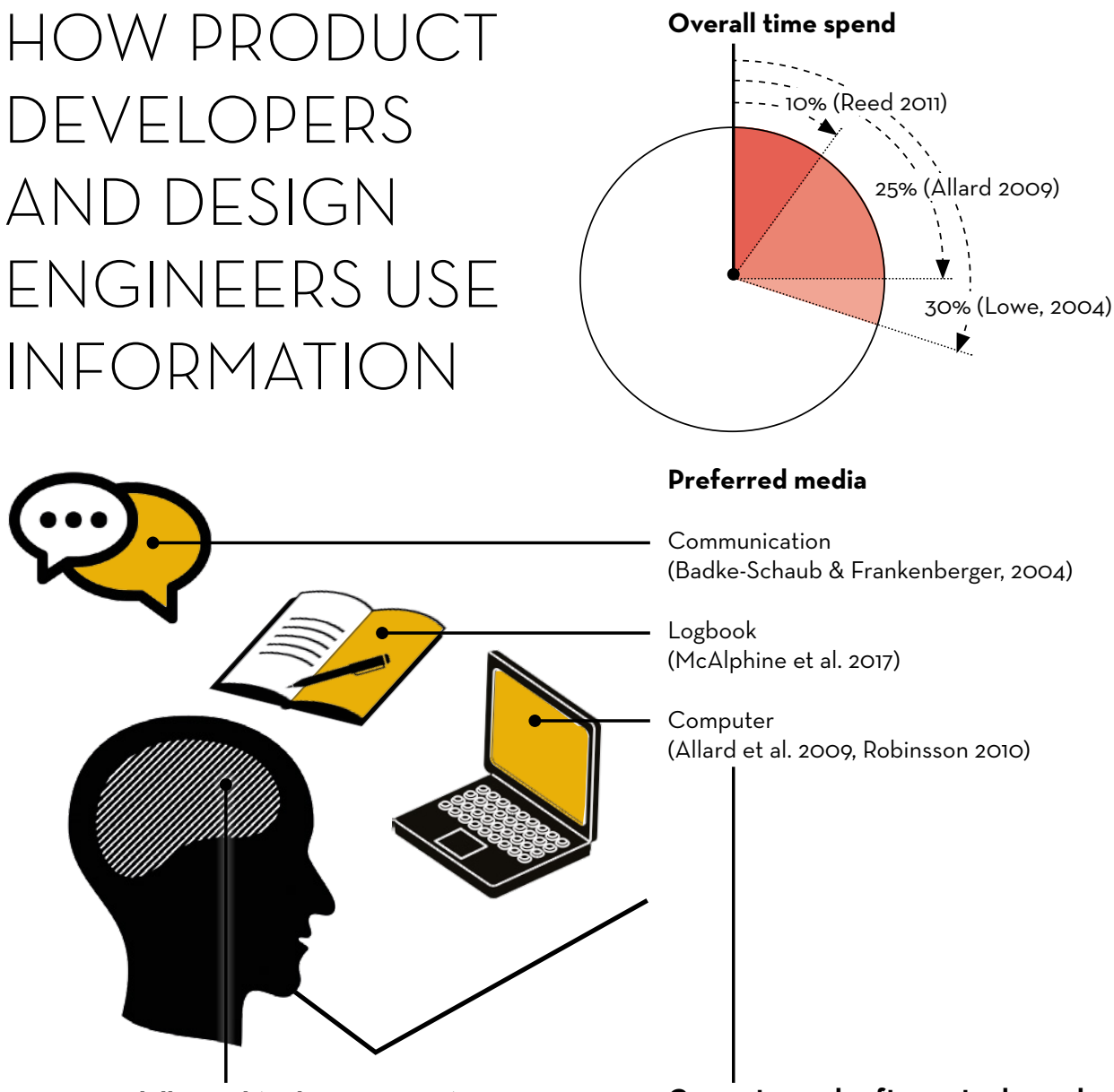

Preferred media

Communication

(Badke-Schaub \& Frankenberger, 2004)

Logbook

(McAlphine et al. 2017)

Computer

(Allard et al. 2009, Robinsson 2010)

\section{Cognitive skills used (Robinsson 2010)}

Computer and software tools used

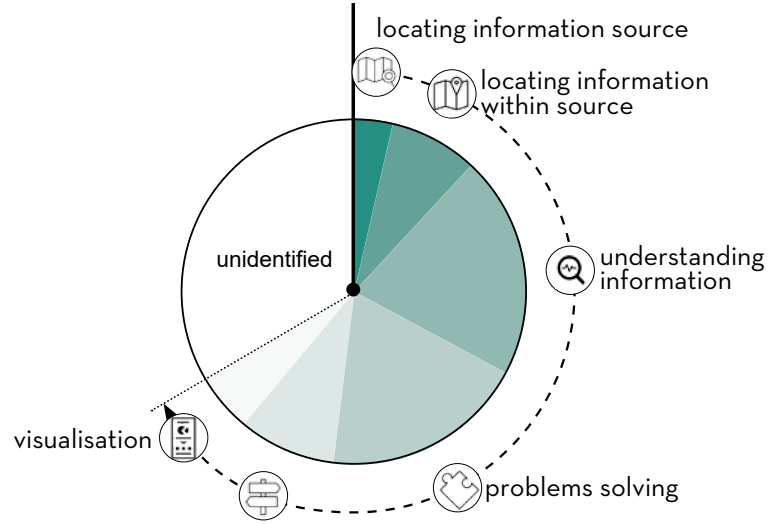

decision making

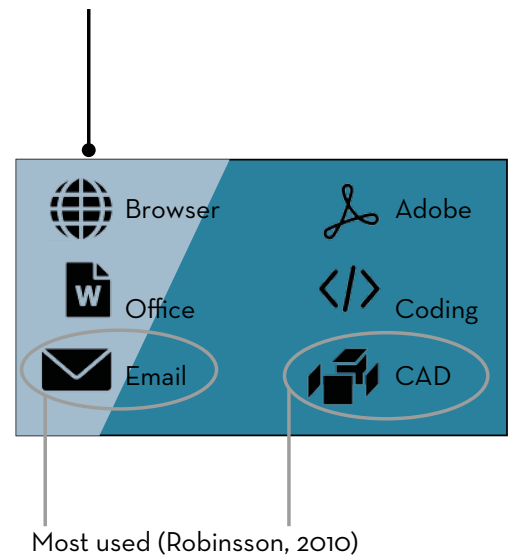

Figure 5-3 Overview of information usage in design engineering practise 
The study of Reed et al (Reed et al., 2011) focuses on the information behaviour of design engineers that are supported by knowledge-based systems (KBS) developed by the authors. In evaluating the effectiveness of the KBS, they found that $10 \%$ of the overall time was invested in accessing or supplying knowledge and information. However, the communication activities recorded by the participants are not taken into account in this number. At the same time, however, communication is described as being the transfer of knowledge and information.

Allard et al. (Allard et al., 2009) report that $25.6 \%$ of the time is devoted to information events during a working day, making the same distinction between communication but with no explicit focus on knowledge.

Combining rigorous statistical analysis with a characterisation of social and technical work, Robinson (Robinson, 2010, 2012) also puts focus on the cognitive abilities used with information. Based on the dataset and coding scheme, six categories could be extracted, accounting for almost $66 \%$ percent of the cognitive skills used (figure 5-3 bottom left)

\subsubsection{Information sources}

In accessing and supplying information, different types of media are used. With communication and capturing as main goals these media encompass anything between informal documentation and the usage of various software systems via computers. As an example, the development situation based on marketing involved a case for new product development that shows an amalgamation of process documentation and personal informal sources from which no coherent image can arise, thus rendering structured and effective control and communication impossible. A completely different image arises when routine development cycles are considered within the same organisation. Driven by the same, imposed, stage-gated principle, one document specifies and standardises the entire process. In such approaches, developed in an attempt to adequately integrate the different disciplines in the development cycle, information and processes are vigorously interwoven to such an extent that they cannot be decoupled. As the focus in practice often is on the processes that transmit the information between disciplines (often communication), the balance between information and processes is instable (Oude Luttikhuis et al., 2015).

Lowe et al. (Lowe, McMahon, \& Culley, 2004) put focus on the types of information (words, numbers diagrams or geometry) that are transmitted and received in both early and later design stages, capturing the change in dominantly used types. Whereas in early stages 'words' is found to be the dominant type, in later stages 'geometry' is the prevailing type of information that is being used. Reinforcing and enriching this transformation of information types, Chandrasegaran et al. use the development process of Pahl \& Beitz and - based on their experience - map what information and knowledge representations are used throughout the design process (figure 5-4) (Chandrasegaran et al., 2013).

When focusing on the explicitly available documentation, there are two primary sources: information on the current project and contextual information on e.g. previous projects or generic subjects. There is no strong consensus on which category product developers rely on more, with indications ranging from 82/18\% (Aurisicchio, Bracewell, \& Wallace, 2012) to a more balanced 50/50\% (Vijaykumar \& Chakrabarti, 2008). In ad- 


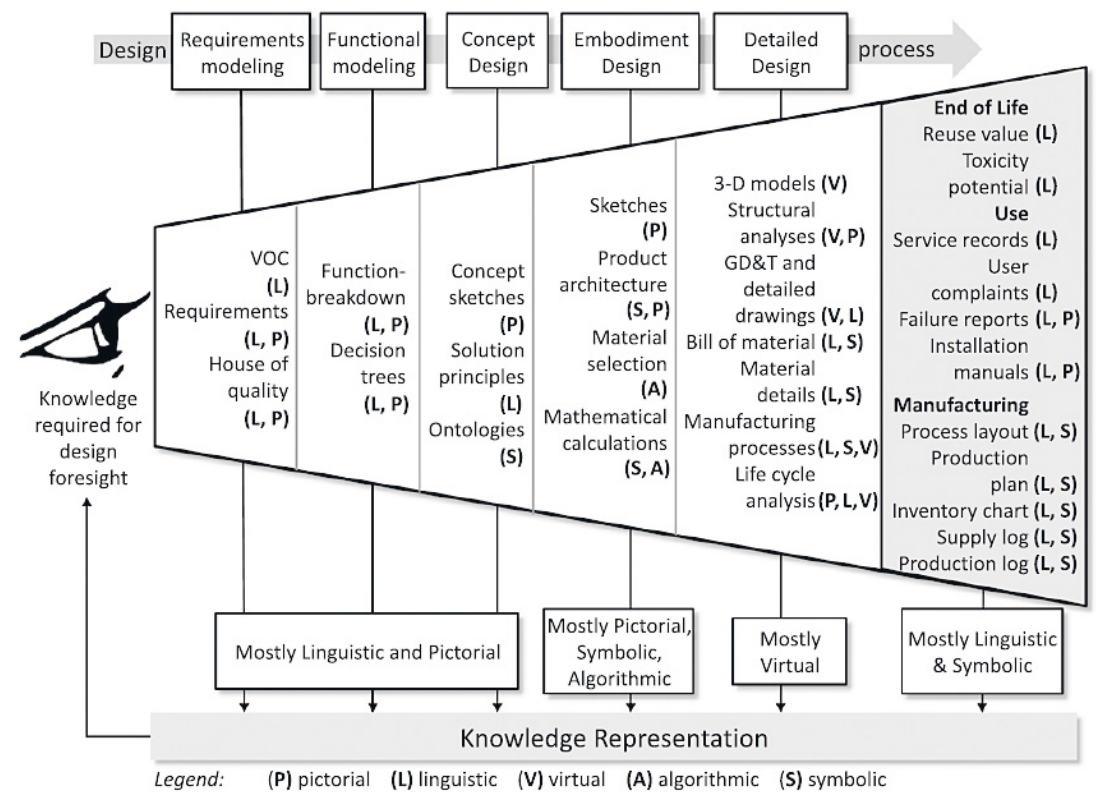

Figure 5-4 Overview of used media, in product development (Chandrasegaran et al., 2013)

dition, Vijaykumar and Chakrabarti (2008) found that the need for "product related information or knowledge was much higher than that for process related information or knowledge that is, designers focused more on the artefact being designed than on how to design it. Documentation is often not found due to unawareness of the existence or availability (Salzberg \& Watkins, 1990) or the required effort in time and money (Allard et al., 2009).

In information sources, there is informal and formal documentation. The latter being of significant value for ERP and PDM systems and for reaching agreements with external contacts (De Koeijer et al., 2017). For informal information, personal scribbling, mail and informal meetings, there is no adequate management possible from a product development perspective (Lowe et al., 2004).

In a case for development situation based on material development and manufacturing (see section 2.1.3) information is predominantly made accessible by means of actively sharing it via informal and formal communication. For example, project management information and test updates are shared via email, in meetings or via informal contact moments. This culture of quick updates, informal contacts enables the team to respond quickly to changing circumstances and results in a lean and flexible approach. However, the (implicit) focus on communication as the primary way to access information has some considerable downsides, especially regarding the reuse of 
information, its traceability and the rationale of the development cycle. In using mail conversations as the dominant access to information as well as the (personal) project management system, documentation is fragmented and repeated amongst all project members, with many risks of versioning issues. This hampers maintaining a coherent overview. For instance, test results from external parties appeared to contradict internal tests. However, with the little documentation available on these internal tests, no verification of analysis between the different results was possible, leading to corrective loops and rework. In Scenario Wessanen a similar approach is used, although the process is completely differently structured. Here, exchange of information is primarily via meetings, informal contact and email. The primary used software package for this organisation are presentation, spreadsheets and text-files. In both cases, accessing information seems to premise communication and thus 'information on the move'. This adds a considerable risk of information incompleteness: if a product developer is not involved in a specific communication, he might not be able to maintain an overview of the information that is relevant for him.

In a study focussing on the role of logbooks, McAlphine et al. (McAlpine, Cash, \& Hicks, 2017) indicate the different types of information and amalgamation of these types as an important reason why a (paper-based) logbook is still a preferred medium amongst design engineers. Software that provides an electronic alternative for the paper-based logbooks, such as Evernote or Onenote were not explicitly taken into account in these studies. However, the research does show a significant difference between the 'informal' information that is captured by logbooks or other personal information management tools and the more structured, formal type of information that is captured via e.g. standardised minutes, technical reports and drawings and cad-files. In contrast with most mono-type focused software, the use of logbooks, they argue, is a relatively fast way of documenting that supports the various mediation needs of the design engineering, while remaining completely free-form. Nevertheless, to arrive at the current state of information, the entire log needs to be reassessed in order to compile the overview at any given time.

\subsubsection{Human aspects}

Apart from explicitly available documentation, direct colleagues are an important source for information, especially when in search for input on vague or difficult problems that are not yet thoroughly defined. The interaction, shared context and ease of access and relative ease of understanding foster an efficient and effective way of finding the right sources. This does not mean that it replaces the explicit information sources completely. On the contrary, both ways of finding useful information influence and potentially reinforce the short-term efficiency. For instance, company archives are used to find knowledgeable colleagues on a specific subject and colleagues are used to find right documentation spot in archives (Hertzum \& Pejtersen, 2000). However, such archives are not always tailored towards this type of usage and organisation could benefit from different structuring and more flexible approaches in structuring such as the two dimensional stakeholder-level of detail model of Hertzum (Hertzum, 2014). Moreover, it is also questionable if peer-generated information generally becomes part of the more formal information sources. Whereas product developers are often keen on discussing, sharing and brainstorming, formally reporting on the outcomes of such 
activities does not seem to be their favourite pastime (Robinson, 2012). Another important reason for communication amongst colleagues is the experience they have built up in previous projects. The knowledge and information stemming from those previous experiences is hard to capture in explicit documentation but is nevertheless considered as invaluable and even indispensable in design engineering work, especially in design reviews and with important decisions (Lowe et al., 2004). Allard et al (Allard et al., 2009) summarise these aspects as "a prevalence for internal communication and reliance on colleagues for information, quality and trustworthiness" and signifies it as recurring themes throughout the empirical research on information and knowledge usage in design engineering. Badke-Schaub and Frankenberger highlight the importance of such communication in decisive moments, being the preferred mode of design representation in such decisive moments (Petra Badke-Schaub \& Frankenberger, 2004). Complementing this customary behaviour, researchers also describe a trend towards Internet and web-based search engines as primary consultant for generic information (Robinson, 2012).

\subsubsection{Software and Supporting systems}

In a study focusing on the knowledge use by design engineers, Robinsson found that almost half of the time is spend working on a computer (Robinson, 2010). The used software is as diverse as this study and the study of Allard et al. indicate. Robinson found that the majority of that time is spend either on email or on CAD-systems. Computers thus play a crucial role in the work of design engineers and in expressing the information and knowledge needs, participants in various studies express important requirements for such supporting systems. According to Lowe, support systems should be capable of providing access not only to formal information, but informal and other, less structured information as well (Lowe et al., 2004). Heisig summarised the expressed requirements as "one single place from which to retrieve knowledge and information; visual aids like maps to support navigation from the 'big picture' as high-level overview to component-specific details; multi-format importing; and applications supporting the traceability of information and the evolution or history of the design." (Heisig et al., 2010)

There is a diverse set of tools used for searching, creating and documenting information. Tools range from generic software packages such as text-processing programs and email software, to design engineering specific tools covering CAD and elaborate PDM suites. Internet and cloud-based services, especially for searching information and collaboration has become to play a significant part in information management for product development cycles. Most of these tools and software packages are based on predetermined data- and information models. And for good reason. Much of the advantages, especially the coulee of possible simulations and calculations become available because of these models. However intricate and diverse these functionalities are, the use is built for specific or tailored purposes and applicable for a limited set of models. Logically this limits each tool to a certain type or specific subset of information. This might be a reason why 'analogue' information tools such as paper logbooks are still also commonly used. These simple and straightforward tools do not offer the sophisticated advantages of computer-based tools. However, they do allow any type of information to be recorded in whatever state. On the contrary, most software programs seem to 
presuppose a sense of absoluteness and completeness in the required (information) inputs. In other words, such programs assume information to have a high degree of certain or absoluteness.

The use of systems such as ERP (Enterprise Resource Planning) and PLM (Product Lifecycle Management) are common. These systems are invaluable in establishing a 'paper trail' and enable the management and realisation of products, fostering efficient and effective flows of information and resources. The implementation of data on the finalised product definition often demarcates the end phase of a development cycle. For development trajectories, especially in the early stages and the final stage, such systems can also negatively affect the efficiency and effectiveness. It can be difficult to extract the required information from formalised systems, as the example from the Scenario Heinz illustrates. For the early phase of development in re-design work, a feasibility study is mandatory. Data from the ERP-system is required as input for such a study. However, there is no easy way of accessing this data. The formalised workflow dictates a reliable but lengthy process involving multiple actors and approvals. However, it is much faster to extract the data yourself. In order to do that, significant experience with the ERP system is required, involving remembering numeric codes. These codes provide the access to details about production locations, articles and specifications. Search entries on the name or coordinates of the production locations either return no results or are not possible to enter into the ERP. For design practise situation based on design engineering (section 2.1.1) there are several systems in use that need to be filled with information on the final product definition. Inputting and updating data in these systems requires substantial effort involving not only project members but a specialised department as well. More importantly, the various systems in use do not seem to interact, causing different versions of documents. Consequently, this causes confusion and ambiguity on status.

\subsubsection{Reuse and rationale}

Heisig found that the most important reason to (re-)use information is to understand the rationale of a design but that this is also often hard to find (Heisig et al., 2010). Justification, decisions and reasons for design are not that easily captured in explicit documentation. For the reuse of information, Silventoinen et al. point out that both information systems and human aspects such as communication are important (Silventoinen, Denger, Lampela, \& Papinniemi, 2014). The human factors are even deemed crucial in understanding context, background and possible applications of the documented information.

\subsection{SUMMARY OF ISSUES}

Obviously, the sources of information and corresponding (digital) systems play an indispensable role in modern-day product development. Digital systems provide numerous advantages. To name a few: trustworthy data storage, relative low cost of altering information and the ease of sharing information sources. However, the use of these systems in product development cycles also has its caveats, as described in the previous section. This section summarises these issues. 


\subsubsection{Available but not accessible or findable}

There is no strong consensus on how to store and share information. There is a mixture of personal filing systems, shared directories and intrusively dominating software systems. As design work is done in (large) projects and multiple actors working concurrently, communication is an essential part of project work. A lot of information can be found in email. As such, product information is scattered all over these systems, making it hard to access information. An indispensable source of information is therefore (direct) colleagues, especially those with abundant project experience within the organisation. It is often reported that consulting a colleague is more effective and faster than searching for information yourself. As such, explicit, sharable information although available is often not readily accessible.

\section{Unstructured and fragmented information}

Information plays a crucial role in the development process. Although many companies have formal systems in place, the larger part of the information that is actually available within a company generally does not adhere to the requirements of such systems. This so-called unstructured information can, for example, be found in reports, minutes or e-mails. Although the documents that contain this unstructured information can be stored in formal systems, it is difficult to retrieve the information itself at a later stadium in the development cycle. Furthermore, the information is often stored decentralised, accessed by various software tools, different computers and even different networks causing fragmentation of information. These effects are potentially increased when multiple organisations are involved. Consequently, it is often difficult to adequately retrieve information and to maintain an unequivocal overview. In everyday practice at the company, many tasks, questions or updates are communicated by e-mail. In this accumulating flow of e-mail correspondence, valuable information is easily overlooked or lost in the flow of new, emerging messages. Additionally, the e-mail correspondence is stored separately in many different mailboxes. Consequently, all stakeholders of a project have their own source of information, but they lack the possibility to estimate its accuracy, validity and actuality. Furthermore, the fragmentation of information causes the information to become detached from its context and background, making it even harder to understand and interpret the information.

\section{Rigid structures}

The storage of available information in document management systems is often dictated by predefined, rigid and hierarchical tree-like structures. These structures, however, are only appropriate for a certain view on the information; other perspectives, in which the same information is needed, are disregarded. Moreover, the imposed structuring might not be able to cope with new types of information. When, for example, looking from a production point of view, it might be suitable to classify packaging material primarily based on supplier, subsequently on type and finally on technical specifications. Initially, there's nothing wrong with such a classification; it might even be considered a standard classification within the domain. However, problems arise when the structure dictates the way in which information is retrieved. If, for instance, a graphical label design is to be checked as concerns correct dimensions with the technical specifications of a pouch, it might not be obvious to first look for the correct supplier. In fact, a 
specific supplier might not even be known yet at this stage. Although the information is available, it cannot be used.

\section{Predominance of software systems}

At most organisations, product development would be nearly impossible without for example enterprise resource planning (ERP) software. Various departments, such as purchasing, sales, quality assurance and production, heavily depend on the information that is captured in this system. However, to include project information in the ERP system, this information has to be 'translated' to adequately capture its denotation in the system. In practice, this translation does not occur in a natural manner. Instead, the information that is stored in the ERP system is re-engendered, as if no preceding project were executed. Moreover, the information directly stemming from the project often is incompatible, or not complete enough to add value to the content of the ERP system. When an organisation endeavours to keep the information in the ERP system actual, more often than not, the project execution itself is influenced by constraints and quirks of the dominant software. In extreme, development projects might rather focus on gathering information for the ERP system than on developing product/packaging combinations that optimally meet the requirement specifications.

\subsubsection{Absence of information, abundance of data}

There is simply too much data to allow for adequate judgements on if the data represents information. We are so accustomed to information and data being a part of daily lives it is no longer a scarcity but a commodity. As the digitalised working environment has brought great advantages, it also led to an ever-growing collection of data. As a result, the sheer amount of available data is potentially diminishing the usefulness of information. What results is a cluttered, complex and contradictory collection of 'data that potentially is information' that by sheer size alone is too big to take into account.

\section{Misunderstanding by missing context}

Without context, a correct or useful interpretation of information is well-nigh impossible. Unfortunately, crucial information is often not documented or it is lost in the process, severely hampering effective communication. An additional problem with such communication is that the used information can easily be misinterpreted, especially when communication partners stem from different backgrounds and have their own expertise language. This is often the case with different disciplines within an organisation as well as between different organisations. A question in one domain can be answered adequately in a way that is completely irrelevant in another domain. Moreover, the difference between the required information and the employed information is often large. In its mildest form, this phenomenon does not contribute to an efficient and effective product development process, but often even severely hampers the process, causing unnecessary halts or loops and costly corrective procedures. Information is predominantly available without the necessary context due to the fact that most systems used do not allow to record context other than meta-data and that what is predefined by models and the software. As such, information easily gets detached from the context in which it could effectuate its meaning. Moreover, this context-less information may be available, but cannot be interpreted in a meaningful way. 


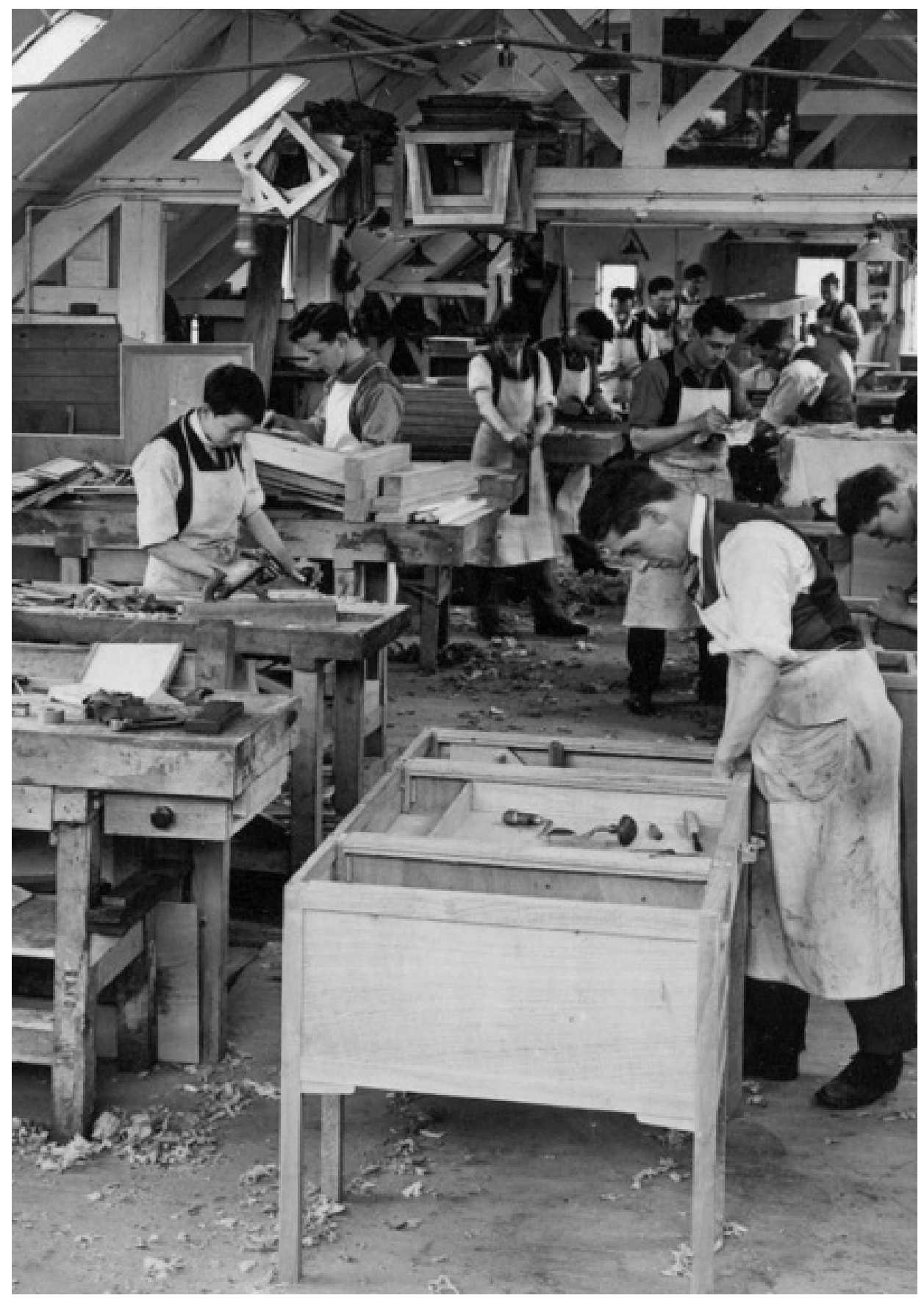

Figure 5-5 Workpieces in workshop setting, historic

'Furniture making at Russell \& Sons workshop, Broadway in Worcestershire, about 1926 via: http:// gimson.leicester.gov.uk/ernest-gimson/gimson-as-a-maker/handiwork-versus-machine-production/ 


\section{Difficulty of externalising (tacit) knowledge}

The efficient availability of knowledge, experience and information throughout the organisation is an important prerequisite for designers to be able to do their work. On a personal level valuable experiences and knowledge are gained during a project. On an organisational level, however, 'reinventing the wheel', or maybe worse, 'making the same mistake twice', might occur more often than companies would like to admit. For example, knowledge on material selection gained from past experience is certainly available in the company. However, often the required information is not accessible at the right place and at the right time, because it is merely present in people's minds. Externalisation of (tacit) knowledge is difficult to realise, which results in a knowledge drain when employees leave the company.

\section{Difficulty of capturing rationale}

The type of information that is stored is heavily influenced by software systems in use. Therefore, information on e.g. technical drawings, bills of materials and technical specifications are almost always carefully documented. However, the rational that led to these (final) documents is either hidden or implicit in email-conversations, stored in (personal) logbooks or not recorded at all.

This section listed the issues around current information usage in product development cycles. Despite new emerging technologies, information here still predominantly fulfils a necessary but passive archiving and documenting role rather than being at the centre of activities. Although information and knowledge management is widely recognised as being an important if not decisive influencer of development trajectories, information itself seems to be (implicitly) considered as either a given or a logical by-product of product development. This contrasts with the value this information carries. In an attempt to reiterate this role of information in product development an analogy between information and discrete workpieces is made.

\subsection{WORKPIECE ANALOGY}

In chapter two the artefact was characterised as being the most typical element of design engineering projects for which a form of documented information carries the definition. However, documented information has not always had the value it often has in modern development trajectories. This is a result of the effects the industrialisation has had on design engineering. Whereas in pre-industrialisation artefacts where predominantly created by skilled craftsmen in small workshops (see figure 5-5 for an example), such as potters, glass makers, and blacksmiths, nowadays artefacts are predominantly mass-manufactured through which a considerable part of those artisanal skills have been transferred to the production environment. This transformation process was commonly referred to as "de-skilling" by the labour force. However, that de-skilling is inherently accompanied by conveying instructions to the production environments. The need to formalise these instructions is, in a certain sense, the initial occasion to capture the product definition in an explicit manner. Previously, this was not a necessity, to say the least. Centuries had passed in which the creation and definition of artefacts had not necessarily been divided in two separate parts, because next to drawings, note- 
books and scribblings, the unfinished artefact itself had an important role. Although this craftsmanship is no longer the standard (nor possible) way of working for industrial product development, modern-day examples of such artesian development cycles can still be found. For instance, a potter, sculptor or blacksmith still has the ability and possibility to amalgamate the requirements, the resources and the (informal) product definition without the obligation to make the coherence explicit. This also means that, for the artisanal approach, iterations are implicit; moreover, iterations do not require formal communication nor procedures or formats for information exchange (compare scenario $A$ in section 4.1). Design rational is entirely owned by the artisan, directly contributing to experience, but well-nigh impossible to convey. In a post-industrialisation era the situation has changed to such an extent that in every development cycle the presence of some actors is inevitable or mandatory (i.e. government or legal bodies) enforcing more formal communication and the explicit formulation of information content.

In returning to the artisan that need not separate the evolvement of the product definition from the means to achieve such evolvement, obviously, a workpiece in itself is an evolving, intermediary result of a design engineers' actions. Even more, this workpiece has a great - albeit passive - influence on its own, simply by being the subject of the development activities. For an artisan, if his workpiece is unruly, for example by showing unexpected deficiencies for instance, he will think of and perform corrective actions. Artists and craftsmen identify interrelations between their mind, hands and the workpiece (Crilly, Maier, \& Clarkson, 2008) or report of "reading" a workpiece in order to determine either the manufacturing strategy or the next step in that strategy. In these examples, it is clear that any process selected by an artisan is a choice that follows the change intent for the workpiece. In other words: the workpiece can lead or might even dictate the process.

Needless to say that the situation of the artisan working on one individual product cannot be plainly translated to post-industrialised manufacturing environments. At the same time, however, there is no reason for the actual workpiece in manufacturing environments to be deprived of all its impact. Based on the workpiece, a production engineer can determine whether or not things have worked out the way it should have, whether this is done via formalised technical drawings using tolerances and specifications or via experience, common sense and an accurate eye. Even if only to identify differences between the product definition and the instantiated product, the product definition can be improved based on the observations.

More and more, the product definition is seen as establishing the 'product type', where the individual resulting products are the 'product instantiations', thus aligning the product definition and the resulting products. This implies that behaviour (in its broadest sense) of the product can also be allotted to the product definition. Like a physical car can be exposed to a crash test, its product definition can be exposed to a simulation of the same crash. This stresses the role of the product definition as a mediator between the requirement specification and the actor's demeanour. In a social-technical treatise on the Actor Network Theory, Latour labelled entities that have such a mediating role as objects having agency, but lacking intention (Latour, 2005). For Latour, it is a way to describe the effect objects can have in social interaction between 
humans, but there is no limitation in applying the theory also to technical interactions. While being controversial at its time, for exactly this agency characterisation of objects, its strength is not the theoretical aspect - this is heavily debated - but its adaptability (Mol, 2010).

In a similar manner, workpieces have agency in the environments they are part of. Although a workpiece occupies a central role in a development or production cycle, it does not have a dominant, overpowering or decisive influence. Rather, it has a passive presence. However, it is this simple fact, its sheer presence that enables designers to determine what to do next. In that sense, workpieces do have a very important influence: a role as continuously available starting block for the next stretch.

It is exactly this passive, but essential influence that makes discrete workpieces an interesting analogy for a revaluation of the role of information in product development. After all, if a design engineer could continuously rely on the availability of an information content having agency, that design engineer could purposefully and carefully focus on determining and using the appropriate tools to cause effective and efficient evolvements of that information content. This might tend towards the image of the artisan, autonomously working on a product. This by no means implies a taste for nostalgia, but rather does justice to the treatise in section conclusion of chapter two (section 2.4) that outlined a certain autonomy for the design engineering as an important precondition for design support aimed at non-deterministic design engineering processes. In itself, a workpiece (or product definition) neither dictates nor prescribes any process, 'next step' or specific toolset to be used. Rather, it shows the other end of the spectrum. In the interplay between workpieces and actors, focus is put on the effect or outcomes of using such tools or performing the activities, rather than the activity or sequence itself.

Because for product development cycles, the product definition and the instantiated product are aligned, for these development cycles, the workpiece and the information content coincide. After all, all characteristics of the workpiece are captured in information, predominantly in documented, explicit form. So, in development cycles, the product definition or information content could have the same role as the workpiece has for the artisan. Nevertheless, generally, information plays an important role, but is hardly regarded as a centrepiece of development cycles. It is beyond the scope of this thesis to designate the origins of that, although there seems to be a link to Taylorism in which introduction of workers having explicit contributions to production cycles called for accurate and clear-cut prescriptions of what these workers had to do. In other words, the introduction of mass-production inherently and implicitly seems to have created a penchant for process-oriented thinking.

In an attempt to re-establish the role of information in product development cycles from different perspectives, the analogy with discrete workpieces is elaborated. For this reason, three specific characteristics of workpiece usage are addressed:

- Reference

- Reciprocity

- Incorporates uncertainty

Each of these aspects is briefly discussed using examples of discrete workpieces from both production as well as non-industrialised practices of design. 
Figure 5-6 Communication with a workpiece

Figure 5-7 Sculpture as workpiece'

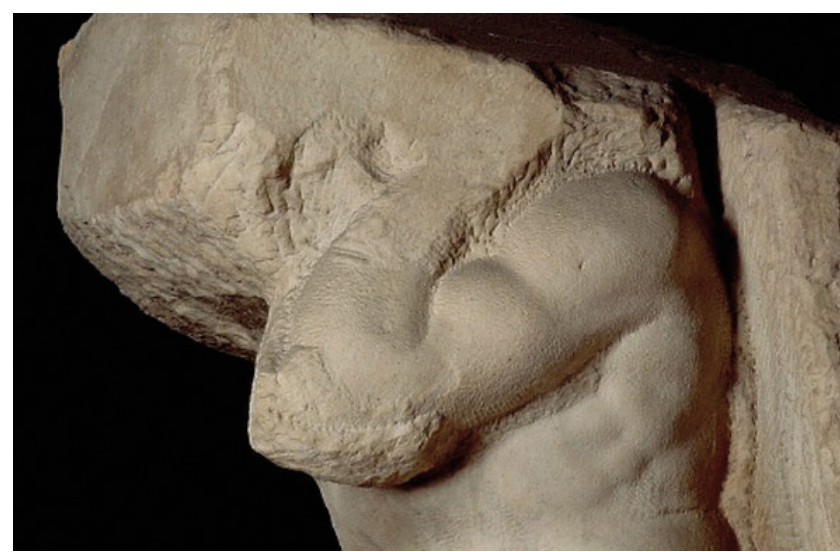

'A part of the atlas slave by Michelangelo. By Anonymous Public Domain, https://commons.wikimedia.org/w/ index. php?curid=10870794 


\subsubsection{Reference}

In general, a workpiece is the result of collaborative effort. It is the tangible, artificial result of all labour. As such, a workpiece offers a common reference for all stakeholders involved. It offers a materialised snapshot in time that reflects the status of a design or realisation process. No matter what the predefined plan of action was, the workpiece offers a reality check: it always has a neutral status. Although there might be clear differences between a status and the desired one, there is no discussion possible on its current factual state. This offers a useful anchor point as different perspectives might render very different assumptions or views. Although such discussions cannot be completely avoided by using a workpiece, it does offer a reference point upon which the discussion can be consolidated and decisions can be based.

\subsubsection{Reciprocity}

Quintessential for the craftsman is the direct interplay between the definition of the artefact and its realisation. For instance, in shaping a statue, a sculptor immediately experiences the consequences of his actions and can directly respond to that by altering the shape (and therefore the definition of the artefact) or use a different technique (and by that altering the realisation process). This process can impossibly be executed without the artefact itself.

This reciprocity is enabled through an almost instantaneous manifestation of the consequences of the artisan's decisions. With explicit information in product development trajectories this direct interplay is hard to achieve or even impossible. To view a change of information in the context of the entire evolving product definition is wellnigh impossible due to the amount of available information alone, let alone by the multitude of stakeholders involved.

In this example, the decisions of the sculptor have two important influencers: the purpose (which is a decision in itself) and the workpiece. From its purpose, for instance to shape an arm of a statue, myriad decisions follow each other in rapid succession or probably even concurrently. By far, not all of those decisions are made explicitly, for instance how to position the chisel might be more a matter of experience and skill that is determined subconsciously. The results of these decisions are directly visible in the workpiece and the (evaluated) result might alter the course of actions of the sculptor, influencing the decisions made by the sculptor and even adapting his original purpose.

Inspired by the human-product interaction model of Dirken (Dirken, 1997) and the previously introduced communication model (see figure 4-3 in section 4.2.5), figure 5-6 illustrates this reciprocity. In essence, this direct interplay is made possible by the manifestation of the consequences of each decision in the workpiece. For every tap of the hammer, the effect is almost immediately visible. With every tap of the hammer, the artisan aims to better approach the purpose.

\subsubsection{Reflect uncertainty}

A workpiece is unfinished by definition. Therefore, it not only reflects the outcome of what already has been done, it also reflects the future work looming. This is best illustrated by an unfinished sculpture in which it is immediately clear which part is finished and which part needs work (figure 5-7). 
With that, a workpiece also gives a sense of that what needs to be done in order to finish the artefact. However, the current state can be subject to different assessments from different perspectives, much like how the estimates for the future amount of work, required tools and techniques, required actors and foreseen end-result may vary considerably amongst the actors involved. With this, the nascent workpiece expresses different types of uncertainty. Firstly, every workpiece has inaccuracies or deviations from the nominal shape, so the current state has uncertainties; secondly, the way in which future work will influence the outcome, the process and also the purpose of the project is uncertain; thirdly, it is uncertain if and how the artisan will be able to actually achieve the foreseen result; fourthly, there are uncertainties about how the artisan will succeed to balance the quality of the work against the speed of the process. Obviously, there are other sources of uncertainty, for example caused by influences of (un)anticipated external stressors. Being uncertain, in itself causes (the need for) decisions (see section 4.5.2), which each involve risk assessments, assessments of possible benefits and ways to avoid or achieve them respectively. With that, uncertainties in a sense define the part of the solution space that an artisan currently has to his avail with the long-term impacts of utilizing that solution space in a specific way as merely directional. Nevertheless, the current state of the workpiece is the starting point for whatever utilisation of that solution space. In this, the workpiece is not only the carrier of that current state, it also reflects the uncertainties that come with that state.

Linked to discrete workpieces, the very core concept of tolerance as it is standardised in production engineering is a useful concept of allowing uncertainty. The inevitability of geometric inaccuracies in workpieces is a subject of study of an entire scholarly field on tolerance and uncertainties (Morse et al., 2019 (tbp)). In essence, a tolerance is an acceptable bandwidth of e.g. dimension or quality that has been incorporated in the design. Anticipating on the inevitability of inaccuracies, these tolerances provide boundaries on what is acceptable or not.

In product design, largely two types of acceptability exist: quantitative and qualitative acceptability. Quantitative acceptability encompasses all phenomena where the current state and its inaccuracies can be expressed on a deterministic scale, as is the case for tolerances/accuracies/measuring errors etc. For, qualitative acceptability, no equivocal scale or dimension of assessment can exist; in these cases, concrete tools for directing uncertainty and anticipating on the inevitability of that uncertainty are hardly available. To mention just one example: the extent to which an entry in the requirement specification is met, is commonly impossible to indicate if multiple actors are taken into perspective and if a sincere assessment of the mutual interdependencies between the entries is made. This results in a situation where quantitative acceptability is confined in standards - albeit sometimes subject to heated discourses, but where dealing with qualitative acceptability is often left to the discretion of the product developer - implicitly accepting a certain degree of subjectivity. In product development often quantitative tools are used to support such qualitative discussions. Although such quantitative measures - e.g. weighing of requirements or calculating quality - have great potential, one runs the risk of focussing on this quantitative aspect instead of the rationale behind it. 


\subsection{CONCLUSION}

This chapter has reviewed information usage in design engineering. First, the current usage is described based on a sketch of the status quo derived from literature on information usage in design engineering and empirical evidence from the case studies (sections 5.1 and 5.2). It results in a list of issues (section 5.3) focussing on two core problem areas themed as 'available but not accessible' and 'absence of information, abundance of data'.

These issues illustrate that information is not necessarily logically linked to decisions and uncertainty. As a pendant to this scenario, an analogy with discrete workpieces has been used to explore a different functionality for information, defining it as the pivot in governing product development cycles. This analogy has led to the definition of a list of desired characteristics of information usage that seem to do justice to the importance of information (as expressed in the information-value axiom in chapter four) and delineate a different functionality of information in product development cycles.

For a design support system, the difficulty lies in a sensible marriage of the analogy and the current usage issues. A solution based only on the current state would not allow for a real function change and would leave the reasoning path based on the information value axiom (see section 4.1). A solution based only on the desired state would not have this disadvantage. However, this would render a too simplified model of reality that might be of no practical use. Consequently, the challenge is to try to realise the desired functionalities expressed in the analogy while simultaneously bearing in mind the issues of the current information usage. 



\section{PRODUCT DEFINITION AS A WORKPIECE}

In combining the information-value axiom with the explorations on design methodologies, the scenarios in practice and the delineation of the meaning and role of information as a workpiece, the reference model in section 4.4 can become the basis for a type of design support that is not rooted in process based ways of working. Rather, it aims to support product developers based on the information content that evolves during product development. To arrive at a means of support that is founded on the information content rather than on whatever way of depicting the design process in terms of its activities, management and control, the image of how developers are adequately facilitated has to be adjusted. After all, design(er) support rooted in the information content cannot logically be expressed in terms of process definitions. This chapter focuses on a formal outlining of what information-based design support requires and what it entails. Because this information-induced support does not yet exist, creating that outline is considered as if it is a design problem in itself. For that reason, the development starts with deducing a requirement specification, foremost in terms of a stated purpose. As this requirement specification leads to the designation of a number of principle solutions that conjointly can build that information based support, the cohesion and alignment of those solutions is addressed. Subsequent chapters will elaborate on the individual components, chapter nine brings them together in an architecture for information-based design(er) support. 


\subsection{STATED PURPOSE}

From the discussion in sections 5.3 and 5.4, it is clear that in product development, the role of the 'workpiece' has been subordinated to the control of the development process. Moreover, it has been substantiated that product development cycles could benefit from having such a workpiece to its avail. However, as a self-fulfilling prophecy, the focus on the processes in development cycles distracts the attention from establishing such an unambiguous and accessible workpiece. Rather, the non-connected collection of (partial) models, prototypes, (technical) drawings, sketches, texts, data, test results or any other type of container seems to constitute the shattered results of the prevalent design processes. To bring some structure to this collection, generally, (control) processes are established and enforced. Although such an approach does not do justice to the information-value axiom, it neither denies the fact that the added value is indeed in the information. The main assumption seems to be that the value in that information is merely accessible via structured development processes, i.e. the value of the information content is made subject to those processes. With that, it is clear that for product developers, currently, the information content is not available and accessible in a way that resembles the workpiece for e.g. a sculptor or an artisan.

Based on the information-value axiom, the approach that this research advocates is that design(er) support can focus on the information content. So, comparable to tangible objects under construction, where the status is evidently visible and accessible, the information content (i.e. the product definition) should be regarded as a workpiece in which the consequences of design decisions are made explicit. As such it should provide the (already available) information a different role: it not only serves as the main outcome of the design process, it also serves as the base for controlling and managing the project. Information as workpiece is instantly assessable, making the progress of a development available at any time, for all stakeholders involved. This fosters efficient workflows and instigates actions based on the actual progress, content and issues. Moreover, it concurrently becomes the output of the development cycle and the driver of that same cycle.

To allow for design(er) support to focus on the value of the information content, a framework is required that brings together the functionality that such design(er) support consists of. Moreover, in order to allow for effective implementation of that support, an architecture is required that brings together all components that can shape the required functionality envisaged. In a sense, architectures are the logical sequel to the definition of reference models and the analysis of the functions and the information entities that act in an environment. They interrelate these aspects of product development systems and give a directive for their harmonious co-operation and interrelation.

In anticipation of the design(er) support system that will be the result of actually implementing the architecture, it is evident that the 'workpiece' in itself can indeed be the carrier of all information in a development cycle, but that merely 'carrying' that value is insufficient. After all, any workpiece belaboured by an artisan requires a sturdy foundation, which also allows for e.g. storing tools. To elaborate on that: the workpiece 
can better be accessed if an adequate workbench is available. In assuming that this comparison holds true for 'information as a workpiece' as well, this implies that, next to defining the requirements on the information-workpiece, the requirements of the information-workbench need specifying.

At the highest level, this implies that a design(er) support system based on the information-value axiom has two main constituents:

- The actual, structured and accessible information content of the development cycle, that acts as the 'workpiece' for product development.

- Interfaces or leverage points and instruments that allow for purposeful evolvement of the information content, that together shape the 'workbench' for product development.

More directly, the basic stance is that the support system renders the product definition accessible in a meaningful way and simultaneously allows for purposeful evolvements of that product definition, while being able to judge the virtue of all evolvements. Especially the introduction of this judging aspect stresses the consequences of adopting the information-value axiom: rather than adding to the product definition in a process oriented manner, the product developer is challenged to assess the quality, impact and value of the proposed contribution. Therefore, focus is on furthering the product definition, with clear opportunities for weighing alternatives and making considerations. This implies that every change to the product definition requires one or more independent reflexions, and that every such change might lead to subsequent reflexions based on the changed content. In this way, the reflexions become repercussions of the changed information content, for example to find a compromise, find a new equilibrium or to explore new opportunities.

In any case, these reflexions directly relate to decisions made by the product developers and other actors involved. This positions decisions as part of the tool-set of the product developer. Although it need not necessarily and exhaustively be defined when and how to reach decisions, these decisions become an explicitly controlling factor in capturing, driving and assessing evolvement of the product definition. Obviously, decisions relate to the development cycle under consideration and especially to the aim of that cycle. However, additionally, what and how decisions can be reached is also determined by the potentialities ingrained in the product definition and in what is deemed possible in the context/environment of the development cycle. In other words, the decision-maker has a certain freedom-to-act and a certain scope in which a decision potentially makes sense or potentially is purposeful. This scope is referred to as the solution space for a decision or for a development cycle. This solution space is continuously subject to change and dynamics, for example due to path dependency, external stressors or simply due to other decisions influencing the product definition. Consequently, this solution space simultaneously facilitates and limits product developers; at the same time, the solution space comes with many indistinctnesses, due to its changing and temporal character. 
To bring together the two constituents of the design(er) support system based on the information-value axiom and the role of decisions, the requirement specification for such a system can be based on the following stated purpose:

\section{Employ the evolving information content to explore the uncertain solution space and explicate possible consequences of development decisions in order to initiate, direct and facilitate effective and efficient decision making.}

This stated purpose tries to do justice to the information-value axiom and in that sense has a range well beyond the scope of this thesis. Consequently, this thesis does not aim to entirely fulfil the stated purpose all at once. It puts focus on the first, elementary components of what is regarded as a new direction/ branch in offering designer/ support. The above-mentioned architecture that should function as a blueprint for building and implementing design(er) support systems, is therefore the final stage for this thesis.

\subsubsection{Basic assumptions}

Elaborating this stated purpose into a depiction of a support system is only possible in a certain scope and context. Next to the remarks already made in section 2.2.5 (key characteristics of product development, combining deterministic and non-deterministic aspects), there are a number of additional aspects - either implicit or explicit - that will become consequential in developing an architecture for such a system. This section aims to frame the environment in which such a system can be used. To allow for making such assumptions explicit, some overlap with and repetition of earlier observations is inevitable - or even purposeful.

A design engineer ultimately wants to know the effects of decisions as well as an indication of the reliability of the decision and an indication of the firmness of the impact of the decisions. In order to foster this basic pattern in designing without hampering creativity or intuition, focus needs to be put on making the consequences and dependability of these decisions insightful for all actors involved. As a consequence of the information-value axiom, the basis for this goal is the evolving product information.

By making the consequences of decisions insightful by means of information, this research aims at a type of design support that - aberrant from design methodologies - is generically applicable but always offers support based on the specific and actual situation at hand. After all, there is a clear relation between decision making and the information content in a development cycle. Even more, if designing is understood in terms of creating (new) information content (Culley, 2014), rather than a - more or less - predefined course of actions, then decision making is the elementary activity in establishing that information content. Consequently, the coherent set of design decisions is seen as the backbone that enables a design team to initiate, substantiate and assess the evolvement of development trajectories against the information content, the context and requirement specification. This offers common ground for every stakeholder involved, but it requires that the information should provide an indisputable status quo of the project. Although this is a logical deduction, which implicitly, generally and 
unquestionably is assumed to be true in product development cycles, it poses a significant challenge. The reason for this is that currently, having avail of such an adequate and purposeful status quo is well-nigh impossible to achieve, due to e.g. the process oriented approach (as discussed in section 3.5) and the current issues in the use of information as an archive rather than as the core of a development cycle (as discussed in section 5.3).

Moreover, the inevitable differences that do exist between the anticipated status quo and the actual status quo that is expressed in information can foster alignment between the actors involved. Any dispute or difference that might arise, and that consequently challenges the explicit status quo, might point at consequences of design decisions that have not yet been processed in information. In signifying such differences, inconsistencies, internal stress, incertitudes or contradictions become sources for support as they are instrumental in initiating, controlling, aligning and assessing development activities based on the actual content of a development project. A specific role can be designated to that part of the information content that is incomplete. Not only is the information content as such incomplete by definition during the development cycle, but especially observable incompleteness is a clear instigation for development activities. Incompleteness also has an impact on the solution space as mentioned in the stated purpose; next to influencing the solution space in itself, it additionally stresses the uncertain characteristics of that solution space.

To summarise these considerations and the framing of the development environment in terms of the information-value axiom, the following basic assumptions are relevant for the development of a support system based in the information content:

- The information content is always incomplete

- The information content has a level of uncertainty/unreliability

- Decision making is the elementary activity in establishing the information content

- Decision making is the common denominator in every activity of any actor.

- Making the consequences of design decisions explicit (indirectly) improves theproduct definition and the development cycle.

With this, the stated purpose essentially claims that the product developer ultimately benefits from being able to adequately reach decisions. However, coming from a process oriented approach in which deciding is an act - either consciously or implicitly, an information based approach requires a reassessment of the essence of decision making. This reassessment can be based on the reference model (see section 4.4), firmly focusing on the relevance of information. At the same time, the decision making can no longer be separated from the existence and relevance of uncertainties in the information content. After all, decision making can become more than the act of cutting the knot, it rather becomes a tool to initiate, implement, ratify, assess and even plan evolvements of the product definition. 


\subsection{DECISION IMPACT MODEL}

Being the common frame of reference for all actors in a development cycle, a transparent depiction of what it means to reach a decision is essential. Not only will an adequate decision model add to the way in which a design(er) support system can be established, but, even more relevant, the model and the product definition are interwoven to such an extent that actors cannot afford to have different interpretations of what a decision and its impact entails. This section introduces the decision impact model that describes the relations between decisions, information and the product development environment (De Lange et al., 2016). Based on the stated purpose, this section reiterates the generic product development engineering reference model.

Given the fact that decision making is traditionally seen as an inherent component of design processes, there is not one conclusive approach for decision making in design engineering (Krishnan \& Ulrich, 2001). Therefore, a generic model (figure 6-1) is presented here, addressing decision making as an independent activity that meets the urge to transform the currently available information content. It does not put focus on the decision process itself, but on the effect that this decision potentially will have on the product definition.

Each component of the model as illustrated in figure $6-1$ is discussed in the following sections.

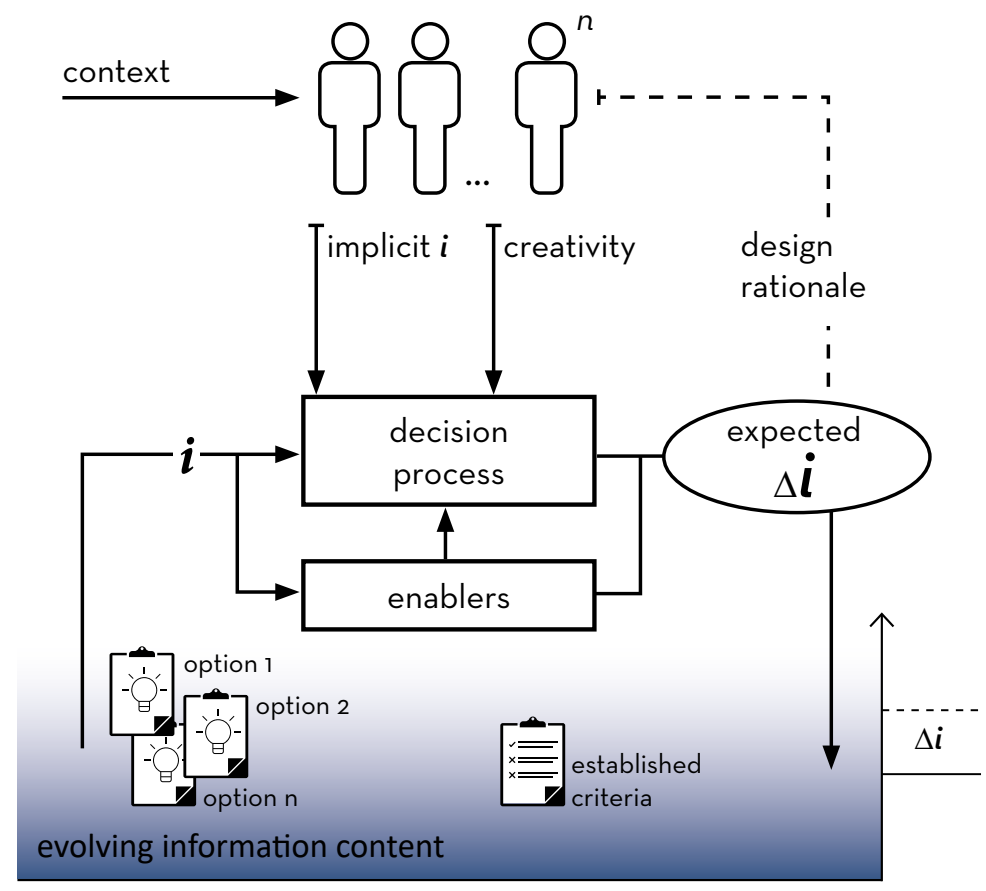

Figure 6-1 The decision-impact model: decision-making explained in terms of information transformation 


\subsubsection{Evolving information content}

As the transformation of the information content is the main aspect of the decision impact model, the basis of the model is the information content. This content represents the common reference of the design process, including all explicit sources of information, e.g. the current product definition, various change proposals/options and previously established decision criteria. It is important to denote that this common reference is thus reflecting the current status of the development cycle. It entails all already consolidated results of the development cycle, including ideas or aspects that have previously been rejected. In essence, the information base of the decision model is regarded as the information workpiece of the development cycle.

An important feature that this information workpiece has over a physical workpiece is that it cannot only depict the current state, but also previous states as well as the way in which a state came into being. With that, a product definition is not only a snapshot in time, but it can also be accompanied by reasoning and rationale.

\subsubsection{Explicit and implicit information}

Obviously, not everything in a development cycle is available as concrete, tangible and readable information (see the definition of information in section 4.2). A distinction is made between explicit and communicable sources of information (like models, facts, data, images, text, correspondence or software) and implicit information that knowingly or unknowingly is embayed by the actor(s) involved in the decision process. Both sources of information provide the prerequisites (goals, alternatives and consequences) for a decision to be made, although there is a clear distinction. The explicit sources of information together are defined as the common reference for the development team constituting the information workpiece, all other sources of information are regarded as implicit or intangible (even if that information in itself is potentially available as explicit, communicable information).

\subsubsection{Decision making}

As stated before, the aim of the decision process is to transform an available information state into an evolved information state, influenced and controlled by decision makers in a specific context. With this, the middle layer of the decision model in figure 6.1 relies on the information $i$ being obtained or deduced from the information content. Moreover, also the explicit criteria for the decision are retained from the information content. These criteria are part of the information content as they in themselves are inherent information entities in the development cycle, but also because - according to the reference model - requirements connect the product definition to the actor demeanour in terms of information. The outcome of the decision process should be evaluated in context of the entire collection of explicitly available information. As such, each decision does not merely add new information content or alters already existing sources but this implies that decision making leads to an enrichment or fortification of the information content - even if the design team decides to mercilessly kill a concept. In the model, the decision process is the formal converter of the available information $\boldsymbol{i}$ into a foreseen or expected change of the information content $\Delta \boldsymbol{i}$. The model does not prescribe how the decision is reached, to allow for flexible application of the model as a whole. 


\subsubsection{Actors as decision makers}

The more singular and intangible influencers of decision processes are represented in the figure by the assessors of the explicit information, the so-called actors. These actors are considered the he primary sources of information in product development trajectories - either directly, via formal meetings and informal chats or indirectly as the authors of the documents and creators of information. In establishing a context of daily practise, it is essential to have a clear notion of the actors that are directly or indirectly involved in the product development project.

Actors not only bring (in)tangible control factors into a decision process, actors also introduce creativity (as introduced in section 2.2.2). This implies that actors in a decision process act as a kind of referee while simultaneously participating in the game. The complexity of this role is emphasised by the fact that actors are subjective to contextual factors, for example, their judgement is dependent on the mutual relations they have with other actors. In other words, more often than not, it is not clear if efforts to establish the information content are predictable, straightforward, or unequivocal. This actor demeanour (as introduced in section 4.5.2) is a significant aspect of the non-deterministic character of product development. As such, it is important to not only put focus on the actual outcome a decision process, but to the rationale behind this process as well. This is depicted as the design rationale in the figure. In reaching a decision, this design rationale entails the reasons why a decision is made. As is to be expected, this design rationale influences the way in which the expected $\Delta \boldsymbol{i}$ becomes part of the information content.

\subsubsection{Enablers}

The assets required to establish this information are defined as the enablers. In its broadest sense, enablers transform information input into output according to a predefined and well-established set of operations. These can range from algorithms for e.g. strength analysis or workflow assessment, to process descriptions for risk assessment.

\subsubsection{Decisions and the consequences}

The outcome of the decision is labelled as the expected $\Delta \boldsymbol{i}$, because this outcome is an attempt to change the information content. To mention a simple example: in a decision process about selecting a supplier for a material the expected $\Delta \boldsymbol{i}$ would not only entail the advice on which supplier is best. The expected $\Delta \boldsymbol{i}$ would also entail the possible impact and consequences involved for accepting the proposal, e.g. an audit of the selected suppliers. As such, the expected $\Delta \boldsymbol{i}$ entails the outcome (decision) expressed in information and the expected impact (possible consequences) that are assumed that the decision will effectuate once processed in the evolving information content.

The decision impact model explains the core concept of how information should function as a workpiece. It relates an interconnected system of information sources with decision making processes in a context that are fundamental to product development. The model separates the information content from the instruments that can influence that content. This implies that the information content needs to provide an unequivocal, reliable and accessible basis for decision making. However, incompleteness and uncertainty are inherent characteristics of a product definition under consideration. Also the decision processes are not necessarily deterministic, given for example, the subjectivity and implicit constraints of the actors involved. 


\subsection{CONSEQUENCES OF DECISION MAKING}

The connection between the decisions and the information workpiece lays at the heart of the information-based approach in design support and is expressed as expected $\boldsymbol{\Delta} \boldsymbol{i}$. As such, the $\boldsymbol{\Delta} \boldsymbol{i}$ should not be seen as a mere factual change to the information content, it rather acts as a force on the existing information content. With this, $\Delta \boldsymbol{i}$ is an external stressor to the information content, that calls for reaching a new equilibrium in the state of stress that characterises the information content. Obviously, some decisions hardly have an impact, as the stressor they represent is either small or impacts a part of the information content where the internal stresses are quite stable. In other cases, apparently small decisions may completely bring the information content out of balance, predicting an avalanche of subsequent and dependent decisions. In such cases, it is may be wiser to reassess if enforcing the expected $\Delta \boldsymbol{i}$ indeed justifies the consequences. Interestingly enough, the assessment of how the information content may respond to the expected $\Delta \boldsymbol{i}$ is in itself subjective, as it heavily depends on the perspective of the assessor. After all, whereas a certain proposed change may, for some stakeholders have no impact at all, for some stakeholders the same proposal might cause blind panic, whereas as for some stakeholders it may come as a solution to other issues. Even for 'rational' decisions, e.g. choosing a material based on predetermined specifications, this subjective component can be present, albeit in a more abate manner, for instance via the experience of the involved actors.

Although any decision process in itself will require time and effort, effectuating the consequences of the decision - i.e. implementing an expected $\Delta \boldsymbol{i}$ will also take considerable time. Unfortunately, even in non-complex environments, many stakeholders will be involved in multiple decision processes concurrently. This implies that the explicit information and criteria as well as the implicit criteria are subject to change while the decision is made. Consequently, the actual $\Delta \boldsymbol{i}$ of one singular decision is extremely hard, if not impossible to determine. In other words, the product definition evolves over time, but not necessarily as imagined or predicted when the decision was made. In any case, if an expected $\boldsymbol{\Delta} \boldsymbol{i}$ indeed becomes part of the information content, the repercussions of the decision will indeed lead to an evolvement and new equilibrium state of the information content by $\Delta \boldsymbol{i}$, influencing the content, the criteria, the completeness and the uncertainty of the information content.

Decisions are tools to belabour the information content. More specifically, given the consequences of the decision process as described in the previous section, decisions propose influences, to which the information content reacts by triggering other decisions when required. In coming back to the metaphor of the artisan and the workpiece, decisions are the tools that, in the hand of the artisan, impact the workpiece. However, there is an essential difference: in the case of the information content, the product definition need not unremittingly and irreversibly be impacted by decisions. Contrarily, product definitions in the-make have the ability to allow for potential variants, for testing possible consequences and for weighing alternatives before residing to a well-founded solution. In short: the combination of a product definition and decision making provide a level of 'undo' functionality that is unavailable to artisans. Obviously, this is especially advantageous in situations where uncertainties play an important role. As it already has been recognised that during each process myriad decisions are made, each influencing other processes, it is of great advantage if all these processes can 
be involved in every stage of the design and engineering processes. This implies that (inter)dependencies between decisions can be taken into account, without necessarily having a sequential dependence. In substantiating this approach, the following sections elaborate on how the consequences and corresponding uncertainties can be utilised.

\subsubsection{What-if as principle solution direction}

This approach facilitates so-called 'what-if' design (Winnie Dankers, 2014; D. Lutters, Vaneker, \& van Houten, 2004; van Houten \& Lutters, 2006), where decision dependencies are applied, not only to analyse a certain reasoning, but to process the consequences as well. What-if design focuses on the reformulation of design and engineering problems in such a way that an equivocal question with a formal structure can be found as a synonym for the problem. This not only helps to map the range of the problem, it also aims at creating an interface between the designer and a design support system. Based on such a formalised synonym for a problem, design support systems might be able to actually understand and (help to) solve the problem. In everyday practice, whatif questions may become very effective and efficient ways of investigating the consequences of decisions, and of generating alternatives. In other words: what-if design is a way to extrapolate based on the current information content, with the 'undo' function as a reliable safety net.

\subsubsection{The role of uncertainty}

Already in the second chapter uncertainty was characterised as being one of the defining aspects of the non-deterministic nature of design engineering. Whereas attaching a negative connotation to uncertainty might seem obvious or even required, from the elaboration of the information-value axiom into the reference model, the conclusion was drawn that uncertainty is by no means detrimental or undesirable by definition (see section 4.5.2). Rather, all elaborations indicate that uncertainty is hardly more than a characterisation of every piece of data/information and of every activity. Setting aside one's ingrained inclination to nullify uncertainty, it simply makes sense to observe any information entity or activity as not entirely fathomable and therefore possessing uncertainty by definition.

These considerations can lead to a different approach in supporting design engineering practice based on the information-value axiom. Based on the previously introduced decision impact model the notion uncertainty is elaborated upon in terms of the VUCA framework (Stiehm, Hicks, \& Townsend, 2002). This leads to the delineation of different types of uncertainty. However, as mentioned before, if a product is actually instantiated, there usually is an upper threshold on the uncertainty allowed to render a product without too much risk. This is comparable to transferring a design drawing to a manufacturing department: whereas the designer sees a dimension with a certain (functional) tolerance, the machine operator can merely attempt to manufacture the product with an accuracy that lies within the bandwidth specified by that tolerance. With that, it becomes essential to address uncertainty in terms of the way in which the entire product definition responds to it. In other words: it becomes important to define the response to a change in, or an addition of, uncertainty. Based on the concept of antifragility, the potential responses of the information workpiece on the various types of uncertainties is established. 


\subsubsection{Fragility, robustness, resilience and anti-fragility}

The theory on antifragility offers a vocabulary as to how the product definition as a workpiece might respond to a $\Delta \mathrm{i}$. This advice is based on the philosophical debate on how systems respond to chaos. Each system could respond being either robust, resilient or fragile. Taleb adds a fourth concept on antifragility (Taleb, 2012). It is argued that in describing these responses not robustness or resilience is the inverse of fragile, but antifragility. The following paragraph describes these various system responses. For systems and organisations, antifragility offers new concepts of how to respond to unexpected events and how to learn from it. Based on measuring antifragility, an organisation can identify improvements (Kennon, Schutte, \& Lutters, 2015).

Imagine a glass bottle, if this product is introduced to a stressor in the form of a moving projectile, this projectile could cause the bottle to shred into pieces, or in other words, the bottle would be considered fragile. To prevent such unwanted events to happen, one could adjust the system, determining between which boundaries the system should be fragile or robust. A common measure is to make the system robust, or in other words to shield the system from the impact of the stressor. This is what commonly happens in glass bottle design in which after the annealing phase a lubricant layer (polymer, wax or oil) is spread on the glass surface to protect the glass from scratching and other impacts during transport, filling and packing operations.

A second response type is often referred to as resilience. A system is considered resilient if it can absorb the impact but, in time, recover from that impact. For instance, nature's ability to recover from human impact is referred to as being resilient. For the glass bottle this would mean, allowing the impact on the material instead of shielding the system against it and somehow allow the bottle to recover from the impact, as if nothing has happened. This might be hard to image for glass bottles. However, the same stressor on a rubber bottle could be labelled as an example of resilience: the shape of the bottle is temporally impacted but the material properties allow the bottle to spring back into the original shape.

A fourth concept is labelled as anti-fragility, defined as being elements or systems that could gain from and improve upon disorder (Taleb, 2012). As such, this concept seems to define the potential positive effect aspects of uncertainty might have in a development cycle. Together with the more risk-focussed concepts, the anti-fragility concepts offers a vocabulary that enables to address the influence of uncertainty in a (more) neutral manner. When translated to the information as a workpiece, the vocabulary allows to (purposefully) determine the manners in which a workpiece might or should respond to different types of uncertainty. In summary:

- Fragility describes a system that fails when introduced to the various types of uncertainties.

- Robustness describes a system that is sufficiently shielded against known uncertainties

- Resilience describes a system that can absorb the effect of uncertainties and in time - return to the original functioning.

- Anti-fragility describes a system that not only absorbs the effect of uncertainties but gains in functioning as well. 


\subsubsection{Volatility, uncertainty, complexity and ambiguity}

This section describes the elusiveness of decision making in terms of volatility, uncertainty, complexity and ambiguity (VUCA). The acronym 'VUCA' describes the dynamics and indefiniteness of realistic situations while serving as a framework for strategic decision making (Stiehm et al., 2002). The holistic view and the inherent appreciation of lifelike decision processes and the focus on the indefinite aspects thereof makes VUCA an appropriate backbone for describing the elusiveness of decision making in product development.

There is a dichotomy in VUCA when it is used to indicate the indefiniteness of the design process. Uncertainty and ambiguity are attributes of the information that is defined and evolves during the development cycle. These aspects originate directly from the work of product developers and are therefore directly influenceable. However, volatility and complexity operate at a different level of aggregation, emphasising the potential external influences that - more often than not- our outside the influence of the product developers involved.

\section{Volatility}

Volatility addresses the nature of change. A volatile situation is subject to change, in which timing and the magnitude of events are not necessarily related to the significance of the impact. Oftentimes, a situation is labelled volatile in hindsight, making it a qualitative measure for the instability of a process or situation.

In the decision model of figure 6-1, the basis of the volatility of a process is represented by the context in the upper left corner. It characterises the change of contextual factors that influence the actors involved. The causes for a volatile situation in a design cycle generally stem from instability. An example is the unanticipated launch of a competitor's product, thus altering the stated purpose of the current project. Volatility can also be seen as a characterisation of inexplicable actor behaviour. Here, the cause of that behaviour stems from a context different than the development environment of the current project.

By means of e.g. risk assessments, volatility of processes can be characterised. However, the step to controlling volatility of processes is well-nigh impossible. For the information content, however, volatility can more adequately be addressed. Here, volatility has everything to do with validity. Even highly volatile information, such as prices for raw material, can be encapsulated by explicitly addressing the validity of information.

\section{Uncertainty}

Habitually, design decisions are regarded as a means to limit or reduce uncertainty. Uncertainty is typically regarded as one of the main causes of hesitation and instability in design cycles. While these adverse effects are undeniable, uncertainty also has a more efficacious influence, as it creates design freedom and enables designers to explore new ideas and create new value. In other words, the absence of uncertainty in a design cycle would disclaim the need for the creation of new products.

When expressed or put into estimates, uncertainty conveys the assessment of the unknown but necessary parts of a development cycle. However, uncertainty is not an allocable, delimited area in a decision process. It is so intertwined with the essence of design that it is in fact ubiquitous. Indefinite product definitions, hesitation about previously established criteria or the unsettled future course of actions: uncertainty is 
literally present in every aspect of decision making. When expressed in terms of the decision model: literally every arrow and delineation is vague rather than fixed. While this may seem to be an unworkable assumption, it does justice to the reality of decision making in design.

In an attempt to purposefully take into account uncertainty in decision making, a practical divide is proposed between ingrained, uncontrollable uncertainty and uncertainty that is considered to be manageable. The latter is regarded as the probability that a designer can, with some effort, be a little more certain about something.

Although commonly regarded as an inherent part of design, uncertainty is not explicitly reflected in the information that is used during decision making. The available information, especially in digital form, seems to claim a certainty that is not congruent with the uncertain nature of design. Additionally, many decisions are not solely based on explicit information, but are supported by heuristics or gut-feeling (Gigerenzer \& Gaissmaier, 2011). Subsequently, the outcome of decisions is often documented as univocal and objectively valid, if documented at all. This renders a sense of certainty that is not justifiable.

Explicit, exchangeable information and implicit, tacit knowledge used in decision making are mutually dependent, the information employed should therefore also bear the signs of the uncertainty that was or is at play. As such it can not only convey the content but needs to simultaneously address the sensitivity of that information.

\section{Complexity}

Complexity addresses the intricate, entangled systems and situations inherent to design. A complex situation or system consists of many interrelated parts, where the relations between those parts can be unclear or unknown. Moreover, such relations can also bear relevance for other products or projects. To mention just one example of complexity, what starts as a singular stakeholder can appear to be a cohesive network of multiple actors. This punctualisation effect postulates that each entity might be a network of different entities when the context or the environment changes (Latour, 2002). Consequently, it is impossible (and meaningless) to aim for a univocal consideration of the complexity of a system or a situation.

Moreover, in adding value, designers constantly create new artefacts; in other words, they are used to addressing the undefined while attempting to simultaneously addressing relations between undefined aspects. Complexity is considered to be a rudimentary yet fairly uncontrollable aspect of design. With this, addressing volatility, uncertainty and ambiguity seems an appropriate way to limit the effects of complexity on the consistency of a product definition.

\section{Ambiguity}

Whereas uncertainty is depicted by a range of known and (yet) unknown possibilities, ambiguity characterises situations in which the uncertainties are not knowable ( $D$. Lutters \& Van Houten, 2013). Distinctive ambiguities are predominantly found in the earlier phases of product development, when possible routes are considered and the denotation and impact of processes and entities are unknown or are questioned in the evolving development context.

Ambiguity is a downright consequence of the inevitable differences in interpretation when multiple stakeholders are involved. Even the most obvious, strictly defined 
entity could still be assigned different meanings by different actors in relating it to, or deducing it in, the actors' real-world context or knowledge. This renders ambiguity as a characteristic of the relation between an entity and an individual actor. Each actor has a unique frame of reference that is not only determined by the current status and development cycle, but is also influenced by expertise, interests, previous experience, education and factors such as mood. Joint procedural agreements, ranging from making minutes of a meeting to adopting industry standards can reduce this equivocality, but it cannot banish it. It goes without saying that the burden of ambiguity increases exponentially with the number of stakeholders involved, especially if the stakeholders are only loosely connected to the project.

In design, ambiguity is influenced by the state and condition of the resources used. Information related to such resources (ranging from documents to equipment) is often incomplete and indefinite. Moreover, stakeholders only might have access to partially overlapping information or even separate, detached information on the same resource. Even a difference as simple as having two versions of the same document could cause misalignment and obfuscates mutual understanding. Given the contexts of the actors, even explicit and exchangeable information in a design project does not necessarily allow for univocal interpretation. Although scrupulous and controlled processing might case the manifestations of ambiguity, that is not the encompassing answer to deal with ambiguity. Moreover, the design process might be frustrated, particularly because it is the discrepancy in itself that can be instrumental in fostering new ideas, better comprehension of the design problem and better decision making. Rather than preventing ambiguity, this research aims at purposefully embracing the various denotations of information. This is not done by pointing out the emerging indefiniteness of information, but by explicitly taking into account the different perspectives on the information content.

\section{Summary}

- Volatility describes the variability of situation. A situation subjective to change in which timing and magnitude of events not necessarily relate to the significance of the impact. Volatility addresses the validity of information.

- Uncertainty is divided into ingrained and uncontrollable part and manageable uncertainty. Manageable uncertainty is considered to be the probability that with effort an actor can be a little more certain about a decision or a certain topic. Manageable uncertainty addresses the probability of information.

- Complexity is considered to be a rudimentary and ingrained part of any system that has no base to allow for instrumental use.

- Ambiguity is considered to address situations in which any concept, information entity or decision outcome has more than one meaning. Consequently, ambiguity delineates situations in which it is - by definition - not knowable to determine which uncertainties are at play. Ambiguity addresses the meaning of information.

The VUCA framework offers a way of how different types of uncertainties in principle could be expressed in terms of information aspects. In that sense, it offers a first step into addressing uncertainty in a neutral way and explicitly addressing it when investi- 
gating the consequences of decisions. The ant-fragility theory offers a basic terminology to discuss how the product definition responds to these uncertain consequences of design decisions.

Together with the decision impact model, this section has delineated the basic concept that underlies the design(er) support that is based on the information-value axiom. The following section illustrates the usage of this concept in scenarios of usage.

\subsection{SCENARIOS}

To illustrate the potential added value of the design(er) support system, some examples of usage in the form of scenarios are given. In correspondence with the concept of requirement specification as described in section 2.3 these scenarios are considered to be a fundamental part of the specification that is the thread of this chapter. Besides illustrating the overall functioning and corresponding added value of a designer support system based on information-value axiom and the stated purpose, the scenarios serve as a source to deduced functionalities and prerequisites.

While these scenarios depict potential and or desired future situations, they are rooted in the practise situations as described in section 2.1. As such, the type of work and decisions that are part of the scenarios are assumed to be part of daily product development work. The scenarios are divided amongst three categories - facilitate, direct and initiate - in which the functionality of the system and the corresponding added value gradually increases (figure 6-2). Each category will be briefly discussed.

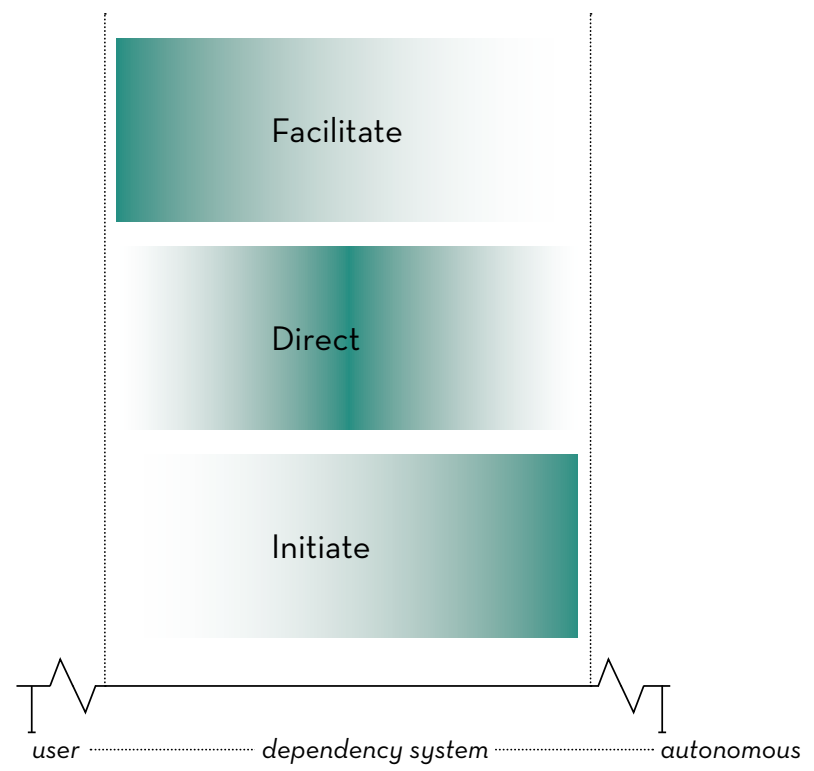

Figure 6-2 Three functional categories of the design(er) support system 


\subsubsection{Scenario facilitate}

The system should offer support in multi-stakeholder decision processes, it should enable to research the consequences of decisions and aid in finding the optimal solution. This involves complicated decisions in which not all information is explicitly available and the information that is explicitly available is incomplete and presumed to be biased according to (implicit) assumptions. For instance, to investigate the effect of a concept choice on the already established product definition and the corresponding requirement specification while full details are lacking. This also involves investigating the various perspectives on a decision, making differences explicit, comparable and discussable. Examples are:

- Given a new directive on sustainable manufacturing, what are the most sensitive parts of my design?

- What part(s) of the product definition is affected when the production method is changed?

- What is the sensitivity of the most important client requirement on brand image and how might this affect the product definition?

Facilitating effective and efficient decision making is offering basic functionalities to support decision processes that might involve a significant amount of information that is not explicitly available, such as the design(er) support system in its simplest form: with facilitate the impact of one or a small number of decisions are evaluated (figure 6-3). The users are not only in control of the evaluation, but do most of the work. Facilitate could be regarded as the more singular use of the system supports e.g. multi-actor decision making.

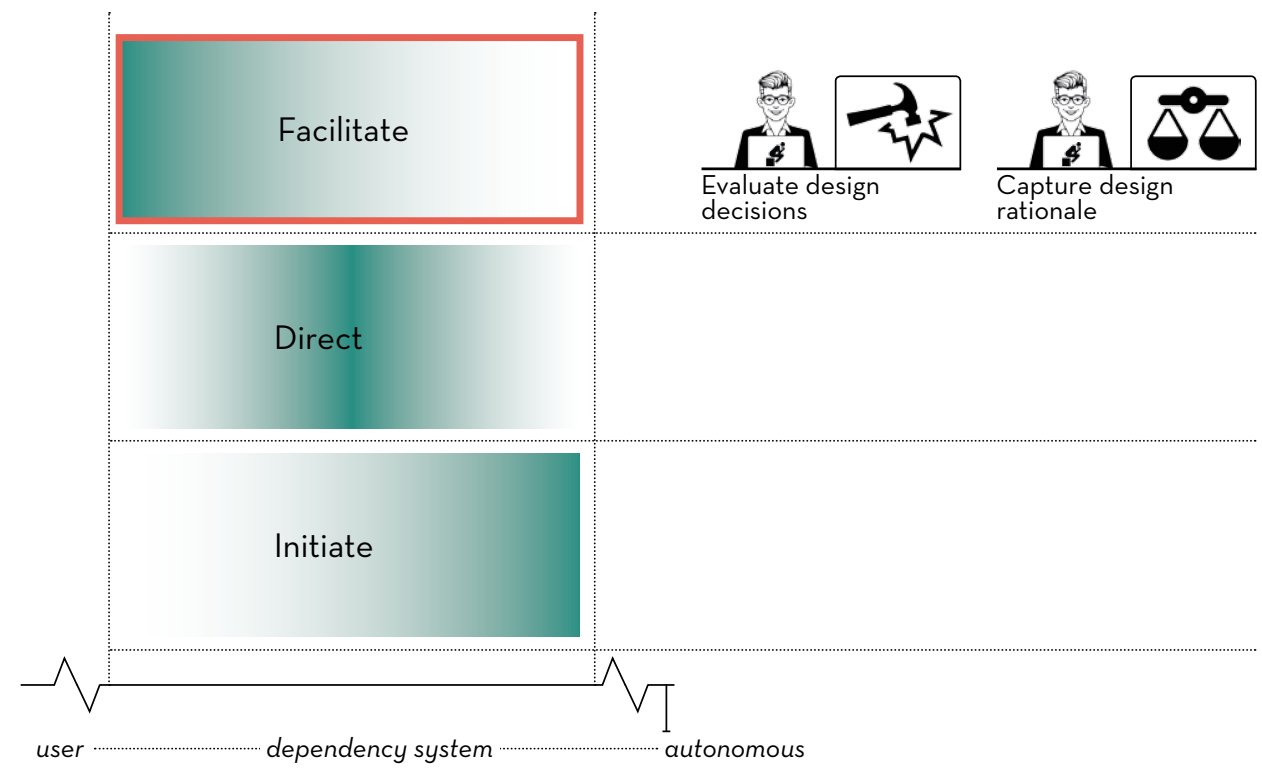

Figure 6-3 Synopsis scenario facilitate 


\subsubsection{Scenario direct}

For the scenario direct, (figure 6-4) focus in functionality is not put on one complex decision but on a collection of relatively simple decisions that could be (partly) performed by the system. Such decisions involve relative simple and straightforward activities such as determining the weight of a cad-model or calculating distances. Dependant on the specific user demands and the implementation context, such tasks could be automated to a great extent, see for example automated design synthesis. Whereas one such a (semi-) automated task does not offer a great deal of support, the combination of large or even innumerable amount of such tasks does have the potential to perform more routine development tasks. The first benefit here is obviously to relieve product developers from work. Moreover, it cannot only be used to create tasks, with such workflows the system can also perform control and consistency checks in the background, assessing information completeness and potential gaps. As such, a collection of these relative simple decisions can direct product developers to potential information gaps and as such can also play a vital role in the enablers of more complex decisions. Based on the information workpiece, the system enables semi-automatic workflows that perform these more or less routine tasks:

- Calculate aspects of an assembly such as costs or weight of an assembly.

- Gaps: material change, scavenge the workpiece in the background to evaluate recent changes

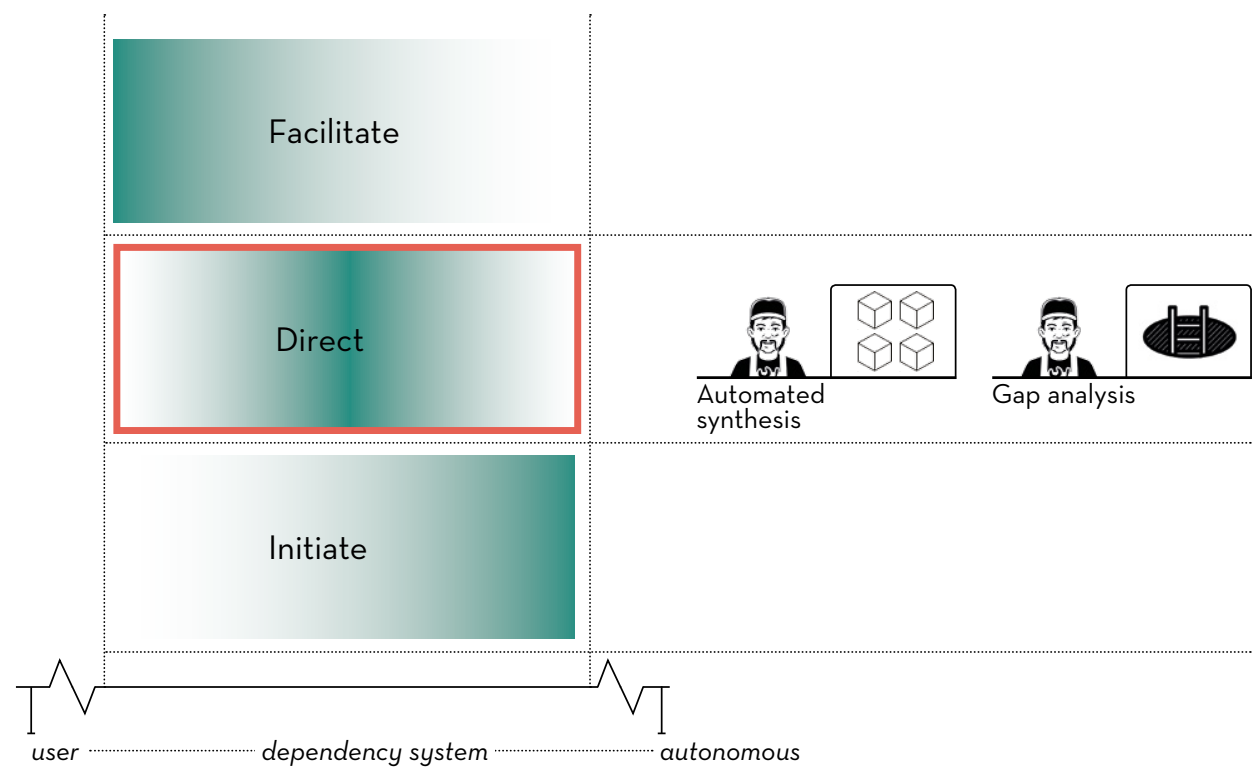

Figure 6-4 Scenario direct

\subsubsection{Scenario initiate}

Scenario initiate (figure 6-5) combines the two previous scenarios and puts focus on the more managerial functions of the envisioned system. Based upon the information workpiece, the decision support and automated workflows the workpiece can act as the base upon which project management, communication and control are fed with both current and potential future states of the workpiece. Overviews to either quick- 
ly see who is working on which information subjects or comparing the current state with external scenarios. As such, this offers to capture best practises. The neutral assessment of uncertainty here becomes important to predict future information needs based upon the workpiece. This enables control that is not only based but also induced by the information.

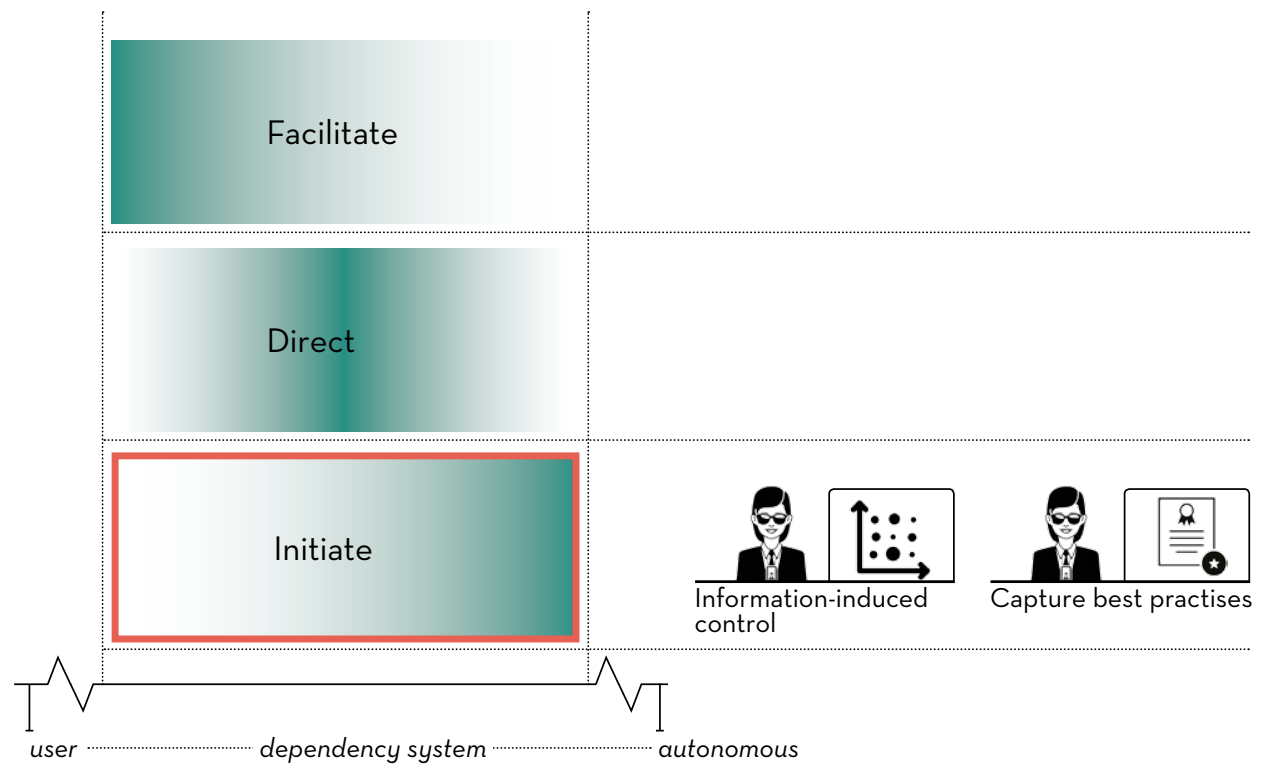

Figure 6-5 Scenario initiate

\subsubsection{Summary and added value}

The design(er) support system described in this chapter is based on two principal components:

- A workpiece: Establish one source of interconnected information.

- Tooling: Establish an interface that allows for purposeful evolvement of information

The future use scenarios aim to illustrate how design support based on the information axiom and the two components mentioned can actualise the stated purpose defined in this chapter. Collectively, the scenarios illustrate the variety in potential future usage of the decision impact model and they highlight the most relevant added value of the intended support approach: being suitable for any daily practise, respecting the autonomy of stakeholders involved and making uncertainty instrumental.

The workpiece comprises of information entities that are formulated, used and revised by the actors involved. With this, the design support is inextricably linked with the daily practise of product development cycles. As opposed to the formal approaches discussed in chapter three, this has two advantages. First, it makes this support purposeful and feasible for multidisciplinary product development teams. Second, since it does not start from an aggregated model or approach of the development process, it 
does not create a potential or implicit language barrier between theory and practise. Rather, it integrates all languages and dialects used in the information that underlies the actual product development cycle.

The intended design support thrives on the autonomy of involved actors. In comparison to prescriptive approaches, it does not instruct a project team what to do, nor will it put focus on any prevalent sequentiality of actions or processes. Rather, it goes along with the actors by means of the decisions made. This offers a different type of support with new functionalities. This support should become a logical complement to the product developer, instead of being a dominant formal approach that dictates a certain path, preference or perspective.

Habitually, uncertainty is conceived as a ubiquitous yet undesired aspect of product development. In recognising both the deterministic and non-deterministic aspects of product development, the approach chosen here does not put focus on only mitigating these negative effects of uncertainty. Rather, uncertainty is considered to be a neutral element that has both undesired and desired consequences. Uncertainty is not only ubiquitous, is it now also regarded as an indispensable and defining characteristic of product development. By avoiding a prepossessed attitude towards any form of uncertainty, the approach advocated here tries to make uncertainty instrumental in the government of product development cycles.

\section{Make the current and future status explicit}

The evolving product information can be used to reflect the status quo in a design trajectory in a structured and systematic manner. This allows all stakeholders to rely on the explicit availability of the information content, implying that the workpiece indeed represents the current state of affairs. With this, the workpiece can also become the unambiguous and unbiased starting point to allow stakeholders to explore future scenarios from different perspectives. The explicit availability of the information content also gives a purposeful backbone for aligning and sampling design decisions and their outcomes. For the context of product development, the ability to explicitly interrelate the current state of affairs with the foreseen, simulated or assessed consequences of scenarios is of added value. Moreover, this interrelation provides stakeholders with additional and structured insight in the design project they are working on.

In the following chapters, the scenarios will be used to determine specific requirements for the two principal aspects of the envisioned system.

\subsection{CONCLUSION}

Based on the exploration of information usage in the previous chapter, this chapter has outlined the design briefing of this research for which the following statement is the stated purpose:

\section{Employ the evolving information content to explore the uncertain solution space and explicate possible consequences of development decisions in order to initiate, direct and facilitate effective and efficient decision making.}


A direct consequence of this stated purpose (and the reference model it is based on) is that decisions are seen as the common frame of reference for actors involved in product development. With this, these actors need to consent on the role, purport and employability of decisions and especially on what the consequences of reaching a decision are. For this reason, a decision impact model has been presented, that outlines decisions as a specific interface between the information content and the actors.

The decision impact model explains the core concept of how information should function as a workpiece. It relates an interconnected system of information sources with decision making processes in a context that are fundamental to product development. It emphasises the importance of the relation between the decision output and corresponding set of potential consequences, together defined as $\Delta \boldsymbol{i}$, and the information workpiece.

The model formalises the interaction, but at the same time allows for what-if design. With this, it allows for weighing and pondering over design options/variants. More important, however, is the fact that the decision impact model separates the information content from the instruments that can influence that content. This implies that the information content needs to provide an unequivocal, reliable and accessible basis for decision making. However, incompleteness and uncertainty are inherent characteristics of a product definition under consideration. Also the decision processes are not necessarily deterministic, given for example, the subjectivity and implicit constraints of the actors involved. Needless to say, decisions involve taking a certain amount of risk and therefore involve potential uncertainties. With volatility, uncertainty and ambiguity a basic terminology to address the various types of uncertainties that are at play in any product development cycle. With robustness, resilience, fragility and antifragility a basic terminology is established that could characterise the response of the information workpiece on these uncertainties.

With the decision impact model and uncertainties at play, product development is expressed in terms of information transformation in which new information is not merely added to the already established information content but is purposefully evaluated taking into account the various uncertainties. The scenarios sketch the bigger picture in which this concept is used to achieve design(er) support in facilitating, directing and initiating effective and efficient decision making. These scenarios are used to deduce the functional requirement specification for the two constituents of the design(er) support system. In summary, figure 6-6 (next page) shows the design brief established in this chapter.

Before the approach advocated here can possibly lead to a feasible design(er) support system or an architecture for such a system, the role of the information content, of the instruments that influence that content and of the uncertainty connected to both the information content and the instruments must be fully separated. Therefore, the following chapters independently elaborate on the information content (chapter seven) and the instruments that allow for changing that content (chapter eight) while taking into account the uncertainties. Chapter nine will combine these basic constituents of the system in an architecture. 
Develop a design(er) support system based on two principle aspects:

A workpiece: Establish one source of interconnected information.

Tooling: Establish an interface that allows for purposeful evolvement of information

That is aimed at enabling the following stated purpose:

Employ the evolving information content to explore the uncertain solution space

and explicate possible consequences of development decisions

in order to initiate, direct and facilitate effective and efficient decision making.
Figure 6-6 Synopsis design brief
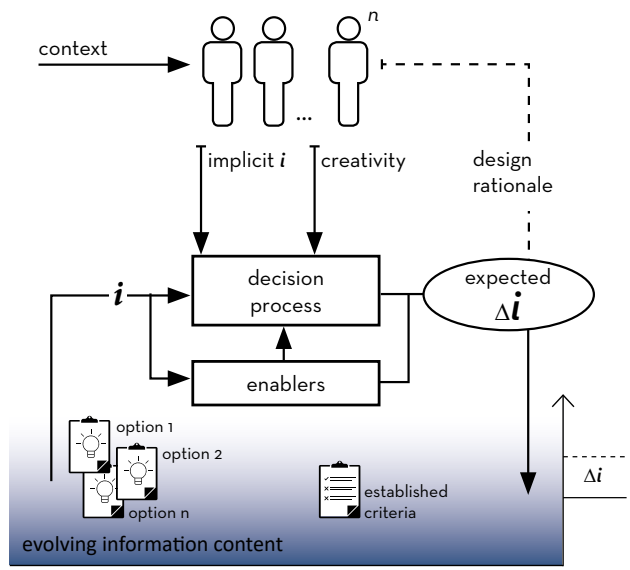

Decision impact model

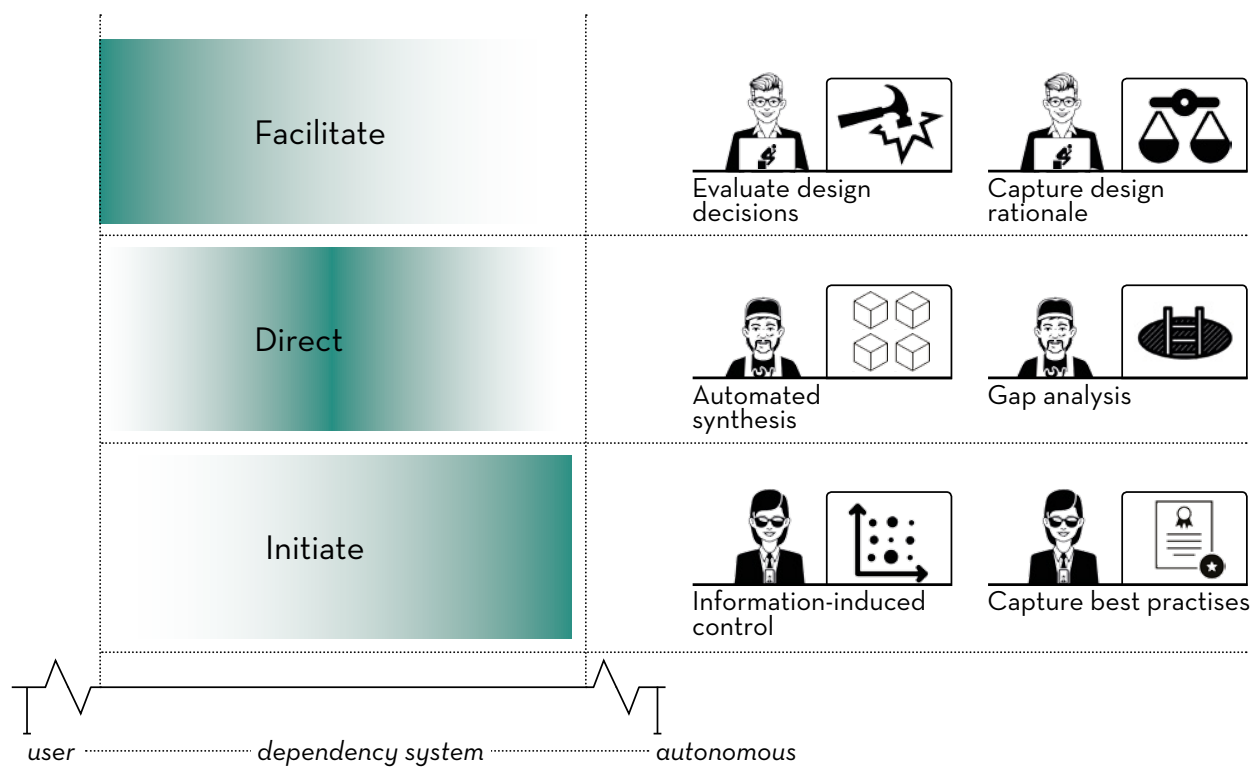

Overview future usage scenarios 


\section{ACTOR NETWORK AS WORKPIECE ENGINE}

The topic of this chapter is the establishment of a framework for information content that does justice to the role of that content in the decision model as defined in the previous chapter. This chapter defines one possible setup of information storage and retrieval that allows for the envisioned workpiece usage. In order to enable this usage, first the information usage situation as described in section 5.2 is revisited, taking into consideration the issues while devising requirements to enable the definition of the functionality related to the information content. The principle solution is to create this system using and extending upon all explicitly available information. Based on the reference model introduced in chapter four, this information - when connected and put into context - can be used to give a representation of the current state of the development cycle, establishing a base for common reference. The so-called actor network approach is used to connect all available sources of information while simultaneously allowing for meaningful access for all actors involved. The actor network should not be understood as a replacement of any of the existing information management systems, rather the approach is to use the actor network as an intermediary using the available sources while simultaneously creating a context in which the information content is embedded. 
In chapter five two main problem areas are identified with regard to the establishment and usage of information: in principle existing and available information that cannot be found or accessed and the lack of context that causes information to degrade to data. Chapter six has defined a new way of information usage that is based on a so-called information workpiece.

However, a solution for such a workpiece does not automatically entail that all identified problems are solved or avoided in this new usage of information. Therefore, this section researches the requirement specification in more depth. Based on the practise situations in chapter two (see section 2.1), the problem areas as described in chapter five (see section 5.3) and the future usage scenarios as outlined in the previous chapter (see section 6.4), this section deduces and defines the perquisites and requirements belonging to the two man functional requirements.

During the early stages of a design and development process, information about the product definition is often incomplete, missing or uncertain. In design engineering, the need for additional information often becomes paradoxical: the needed information simply cannot be known because the decision, for which the additional information was needed in the first place, has not yet been made. Seemingly simple answers are to either estimate the consequences or to substitute the missing information with similar information from another product or life cycle that is already instantiated. While these principle solutions are powerful instruments in decision making, assessing the corresponding context of information is a crucial but often overlooked element. Without it, information runs the risk of losing its intended meaning and value (see section 4.3.5). Without context, a clear distinction between the for a product development cycle specific information and other, 'general' information cannot be made, obstructing the verification of that information and thus leading to an ostensible sense of certainty in decision making. In order to establish an interconnected system of information sources it is crucial to incorporate the context of that information.

Many different actors are involved in both the development cycle and the life cycle of a product. The inevitable differences in working methods, background, knowledge and organisation are potential impediments in facilitating unequivocal decision support throughout those cycles. For instance, the level of detail in the various product development cycles can range from a coarsely-woven chain of decisions taken with 'seven-league strides', to a long-term engineering project of a specific compound used in a metal lid. In applying life cycle engineering, the relative importance of various aspects like social impacts or delivery times might also be different. Moreover, these aspects cannot always be determined on beforehand. Consequently, a tool supporting such a wide range of actors and corresponding decision criteria should incorporate the needed flexibility. With the inevitable differences also comes a different development "language". For the different actors involved in a product life cycle, the notion of the term product can differ. While a manufacturer of plated steel might consider the coils to be its final product, for the producer of the steel cans, these coils are a semi-manufactured article needed to produce their final product. These differences only grow when the relative 'distance' of two actors in the life cycle grows. Furthermore, these differences might have drastic consequences when interpreted in the wrong way. Therefore, a solution fostering the decision support for such a diverse set of different actors 
needs to adhere to the different standards, repositories and types of information used throughout the development cycle. Moreover, the information workpiece should not limit to one specific view on this information, rather it should allow all perspectives.

In establishing an interconnected system, none of the standards is assumed to be suitable as it would immediately exclude other types and perspective of use. For instance, most product information models would not be suitable for the earlier phases of design in which there is not yet any geometry as a reference, but only rough ideas in text or sketches. As such, the solution should be able to cope with any data or information model, irrespective of the scope or perspective that uses the model. Ultimately, the way in which the data or information are organised in a model should be of no concern for the user - provided that the structure can cater for the needs of the user. Nevertheless, users seem to feel more confident if they understand the structuring principles in the models used. Unfortunately, this implies - for sheer historic reasons - that the overwhelming part of structuring efforts is based on tree-like hierarchical approaches. Undeniably effective and efficient in the scope for which they are developed, these hierarchical approaches usually form barriers in allowing for effective communication amongst different perspectives. Nevertheless, based on century-long engrained traditions in for example libraries, museums, archives and other non-digital filing systems, regardless of which underlying data models, repositories and file types are at work, when users have the ability to structure information sources, the preferred way of structuring seems to involve putting files in folders.

This renders a challenge for a multi-perspective system: in any multi-stakeholders setting, not only the information content should be shared, but also multiple of these view-dependent structures should be able to co-exist without one of them being (explicitly nor implicitly) leading or predominant.

In summary, without proper context, potential information resources may remain mere data; or even worse: they might not even be found. Consequently, meaningful information cannot be interpreted without the context. This however, presents a contradiction: on the one hand this implies that the context must be stored with the information content in order to allow for interpretation; on the other hand, it implies that if context becomes part of the information content, the information content is extremely difficult to access if the pre-structuring is not explicitly known. Therefore, the fundamental problem in the latter way of structuring information is that the context is transferred into a maze that can only lead to the information if the rational of the maze are known. One needs to comprehend the context and corresponding perspective in order to find the information source. It is important to note that such information structures are only meaningful and thus logical to those that fully comprehend its rational. In the complex, multi-disciplinary, uncertain and ever-changing context of product development this is a fundamental problem, regardless whether this concerns a collection of files and folders on a shared drive or a data structure underlying an ERP or PLM system.

This illustrates the difficulty in meeting both requirements in establishing a system of interconnected information sources (connect all available information sources and allow for meaningful access). Technically, it is probably not hard to combine all available sources in one place or portal but this would hardly allow for meaningful access. The other way around also holds true: it is not that hard to provide meaningful access to a structure, but it is hard to maintain such a structure if a wealth of diverse information sources is introduced. 
It is assumed that in principle this understanding is not possible for all potential users of the system. In other words: following a worst case scenario: principle actors are likely not to fully comprehend all information structures used and maintained in the system. It should not (nor could) therefore be a responsibility of the users to capture and comprehend the meaning of such a structure and all its perspectives; it should be an inherent task of the system. Rather than only offering the structure, which could potentially become a maze, the system should also capture the essence of the structure - providing any user with a guide to successfully navigate in the maze. Consequently, none of the meanings and structures should dominate, and no structure should be neglected, no matter what practical benefits or concerns there are. In order to integrate all potential information sources, an approach is needed that can cope with all the existing data types, information structures and repositories that are used. No matter what information source and systems are in use, the information needs to be accessible in context and as a system of interconnected sources of information to be able to create an information workpiece that can digest the consequences of design decisions. In other words, every piece of information should be connected in order to together form the workpiece without affecting the ability to provide for meaningful access. The integration (addressing both overlap and dissimilarities) of all possible views should be leading instead of using one view as the dominant one. In allowing these multiple views to co-exist it is assumed that there is a greater change that significant differences and oddities come to the surface and can be made explicit.

\subsubsection{Connect all explicitly available information}

It is needed to be able to handle all relevant information as one collection of information, regardless of the origin or repository of that information. All information regarding a project should thus be accessible as one piece. That access is flexible, attuned to the user and in no way altering the original pool of information.

\section{Compatibility with all existing and future information sources}

In development cycles, there are numerous different structures already in place (as illustrated in section 5.1). Consequently, for an information structure to be able to connect (to) these various sources of information, maximum adaptability and flexibility is required. Each existing information structure has a purpose and explicit reasons to exist, so it is assumed that these or similar systems will continue to be used. Any solution for a workpiece should be able to interact with sources stemming from or residing in such systems. Moreover, as information structures evolve over time and one cannot rule out any (future) source on beforehand, the information structure should be adaptable in order to cope with any (existing and future) information source or system possible.

\section{Structure and guide to structure}

As discussed in section 5.1, with any classification of information, meaning is not only derived from the content of a source but also from the structure it is stored in. When using such an existing source, related to a meaningful structure, the information structure should impartially and objectively capture the intended meaning. To be able to connect all those structures, it is absolutely crucial to have absolute neutrality as such that it captures any (possible) meaning attached to a structure and does not, intentionally or unintentionally add any meaning to it. 


\subsubsection{Allow for meaningful access}

In order to not unnecessarily obfuscate the user there should be no dominance in using a certain type of information or structure. By contrast, it should focus on urgency and importance of information. Access is flexible, attuned to the user and in no way altering the original pool of information.

\section{Capture context}

The information structure should be able to distinguish between e.g. information content, structure and state information without separating them. In other words: the information structure should capture content and meta-information alike. As such, the information structure should identify parts of the elements that establish a product design such as actors, date, version, intended audience, etc. Based on this meta-data, the information structure should provide so-called 'hooks' or leverage points (see section 6.1) to the actual situation.

\section{Multi-perspectives system}

With meaning, the information structure will also capture certain perspectives on an artefact. The information structure should be able to capture, define and represent these perspectives without adding meaning to it. As such, the information structure is multiform and has a neutral stance that should be capable of capturing any perspective.

In summary, together with the already established functional requirements (see section 6.5), this section has discussed the relevant problem areas in more depth in order to deepen the requirement specification (Table 7.1). This leads to the identification of a number of additional requirements to allow for establishing an approach that integrates all available information sources while allowing for meaningful access.

Table 7-1 Overview requirement specification for the workpiece placed in the design brief format set in chapter six and related to the current issues of information usage as defined in chapter five.

\begin{tabular}{|c|c|}
\hline Functional requirements for the workpiece & Related issues of information usage \\
\hline $\begin{array}{l}\text { The actual, structured and accessible } \\
\text { information content of the development } \\
\text { cycle, that acts as the 'workpiece' for } \\
\text { product development as the following } \\
\text { functional requirements (section 6.5) }\end{array}$ & $\begin{array}{l}\text { These functional requirements relate to } \\
\text { the following current issues of informa- } \\
\text { tion usage (section 5.3): }\end{array}$ \\
\hline $\begin{array}{l}\text { Connect all explicitly available } \\
\text { information } \\
\text { - Compatible with all existing and } \\
\quad \text { future information sources } \\
\quad \text { Structure and guide }\end{array}$ & $\begin{array}{l}\text { Available but not accessible or findable } \\
\text { - } \quad \text { Unstructured and fragmented infor- } \\
\text { mation } \\
\text { - } \quad \text { Rigid structures } \\
\text { - } \quad \text { Predominance of software systems }\end{array}$ \\
\hline $\begin{array}{l}\text { Allow for meaningful access } \\
\text { - } \quad \text { Capture context } \\
\text { - } \quad \text { Multi-perspectives system }\end{array}$ & $\begin{array}{l}\text { Absence of information, abundance of } \\
\text { data } \\
\text { - Misunderstanding by missing context } \\
\text { - Difficulty of externalising (tacit) } \\
\text { knowledge } \\
\text { - Difficulty of capturing rationale }\end{array}$ \\
\hline
\end{tabular}




\subsection{INTERCONNECTED INFORMATION AS PRINCIPLE SOLUTION}

In accepting that any information structure or taxonomy could contribute to the product development cycle, all structures should be able to simultaneously exist as part of the information workpiece. Once multiple information structures simultaneously co-exist, the overall structure logically becomes a network.

The basic construct of any network is based on relations between entities and as such has a direct relation with the entity-relation diagram as defined by Yourdon(Coad \& Yourdon, 1990). Figure 7-1 illustrates such a basic diagram. With it, systems can be defined and represented. Entity-Relation Diagrams are widely used for structured system analysis, for instance in the STEP standard that was discussed in section 5.1.1.

Figure 7-1 An example of entity-relation construct (Eric Lutters, 2001)

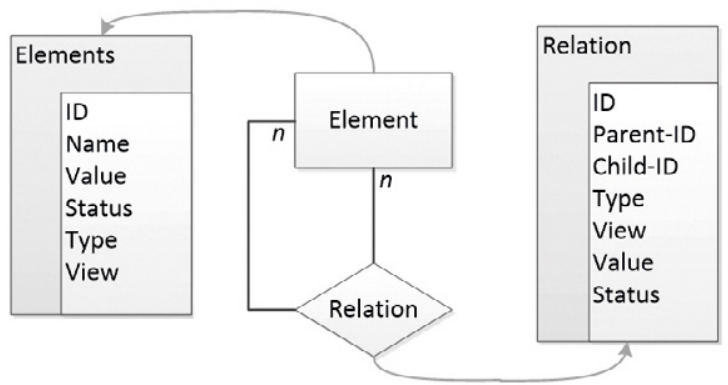

A similar but more flexible approach is used to represent knowledge and information using networks or graphs. Sowa defined conceptual graphs to represent knowledge an information in such a way that its inherent logic can be interpreted by both man and machine (Sowa, 1984). The conceptual graph theory used it to establish a language for representing knowledge with semantics. This language is suitable to perform graph mathematics, laying a basis for artificial intelligence and modern-day so-called knowledge graphs.

Using two concepts, entities (often represented as nodes) and relations (often represented as lines), a network can represent any hierarchical structure, taxonomy, classification or clustering of information sources. Networks offer a way out of the hierarchy and rigidity of tree-like information structures as it simultaneously allows different relations between any two given elements. This offers considerable advantages as compared to other, more rigid structures. A network can 'accept' or mimic any structure. A network structure can also accept any new element or relation that does not fit a predetermined taxonomy. As such, it takes little effort in updating the structure without revisions, e.g. introducing a new classification criteria or an opposing taxonomy. Any hierarchical structure in a network is simply a specific path via specific (types of) entities and specific types of relations. In other words, if an information entity 'disproves' a pre-determined classification, no reconfiguration is needed, it is just assimilated in the network. As a result, the network structure allows for a posteriori structuring instead of a priori structuring. So the structure - or any structure for that matter -, can be determined after it has been stored in a network. This is the key advantage of using a network, and it is the key reason why networks are considered to be a suitable technique of setting up the information structure. 


\section{a. Economic control structures}

(Vitali, Glattfelder, \& Battiston, 2011)

This research uses a network topology to map the interrelations and as such assess corporate control structures on an international scale. It reveals a so-called 'bow-tie structure' in which a relatively small set of highly interrelated financial institutions form an economic powerhouse (Vitali et al., 2011). The image shows a small section of this core knot. The approach that enables such analyses is based on a methodology to determine the backbone of large, complex networks based on the characteristics of the relations between nodes (Glattfelder \& Battiston, 2009).

\section{b. Interrelations in ecological communities}

\section{(Eric L. Berlow et al., 2004)}

Here network analysis and more specifically determining the characteristics of interactions between species (Eric L. Berlow et al., 2004) enable to represent the biodiversity in ecological communities (as depicted in the figure). More specific, it enables enhanced and deep analysis of data. For instance, it revealed how indirect and weak interactions in ecological communities, often considered to be noise in large data collections - have a stronger impact on the prosperity of the ecological community (E. L. Berlow, 1999).

\section{c. Network modelling for search engines}

("The Knowledge Graph,")

The google knowledge graph ("The Knowledge Graph,") uses a network of nodes and relations to offer more contextualised and rich search results, enhancing search results with semantics. The nodes in this graph represent actual objects, as such the graph offers search options that have similarities in how people search and identify things (Singhal, 2012). The knowledge graph enables Google to interpret strings as objects and represent synoptic information about those objects. Using the same concept of a graph, knowledge networks are used to manage innovation projects (Schutte \& Preez, 2008).

d. Mapping cognitive performance and network efficiency (Tuladhar et al., 2016)

This research uses network modelling to create a weighted structural connectivity network that aids in understanding the cognitive impairment related to the cerebral small vessel disease (SVD) (Tuladhar et al., 2016).
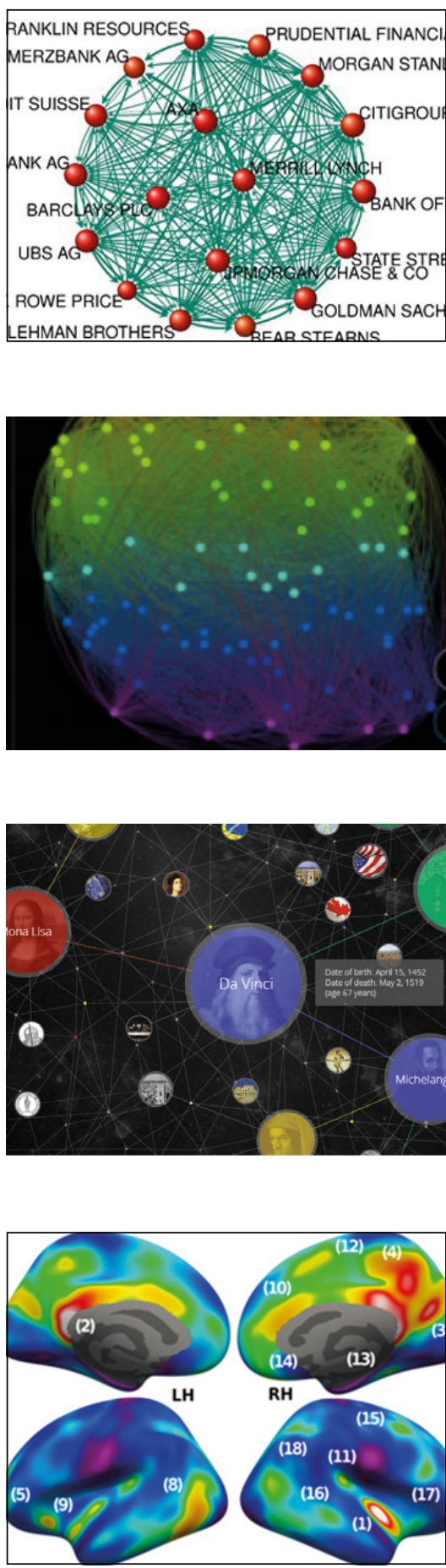

Figure 7-2 Examples of network modelling 
This entity-relationship construct underlying networks thus potentially enables to connect and represent every source of information and to create a structure that forms a basis for a workpiece setup. However, there are some apparent disadvantages to network structures. Any network structure with a reasonable amount of entities and relations grows into a 'hairball' in which it is hard to visually seek information. Furthermore, by incorporating multiple structures, one runs the risk of losing the individual meaning assigned to those structures. As a modelling technique, networks are used to represent a wide variety of phenomena that covers a broad domain: determining the power distribution and connectedness of organisations in a global economy (figure 7-2 a), modelling the biotope and specific relations of species to answer and validate species danger to extinction (figure 7-2 b), capture and link objects that people search for on the web (figure 7-2 c) and model capacities of the human brain (figure 7-2 d). In all these cases, there is no determinant structure that might dictate a preferred hierarchy.

The information structure employed in this research is based upon the work of Lutters (Eric Lutters, 2001). In his work, Lutters uses the conceptual graph concept to establish an information structure that is fundamentally flexible. While most usages of network structures usually involve some classifications, labelling or use of specific ontologies, here the network concept is based upon combinations of entities and relations, allowing any composition to be stored in the network and while its meaning extracted and stored in the ontology. This renders a so-called autorarchic structure that allows for temporary hierarchies to be represented in views (Kals \& Lutters, 1998). A such, it fosters the use of information management as integrator in manufacturing processes, ranging from product development, to production and order preparation.

\subsection{ACTOR NETWORK}

Interestingly, the key factor in establishing a workpiece of information does not start at the myriad of (digital) files that potentially contain useful information for the development cycle. It starts at the creators, users and assessors of these files: the actors. In providing context, actors are considered to be the key factor. If actors are known and can be characterised in specialty, responsibilities and contributions to the product definition, then it provides a start in offering a rich context for which the interpretation is made easier (not necessarily better or more correct). As such, actors are considered the starting point in establishing an information workpiece.

To achieve awareness of the entire product development cycle and the subordination of individual interest to a higher purpose, a non-hierarchical overview is required that provides insight in the entire set of decisions, alternatives, justifications, trade-offs and interrelations. In this, it is the relation between these elements and the different viewpoints involved that will provide additional context to the information. In employing these relations, the information that is required to adequately reach a decision can be identified, variants can be considered and consequences of decisions may be predicted. Such a non-hierarchical structure can also simultaneously adapt to different viewpoints, doing justice to all actors involved. Based on the previously introduced node-link construct of graphs, with actors a basic building block can be constructed that can be used to purposefully deploy the graph modelling language in establishing an information engine. 
Figure 7-3 Basic

building block

Figure 7-4 Illustrative visualisations of actor networks made for IOP project (see appendix D for info on this project).
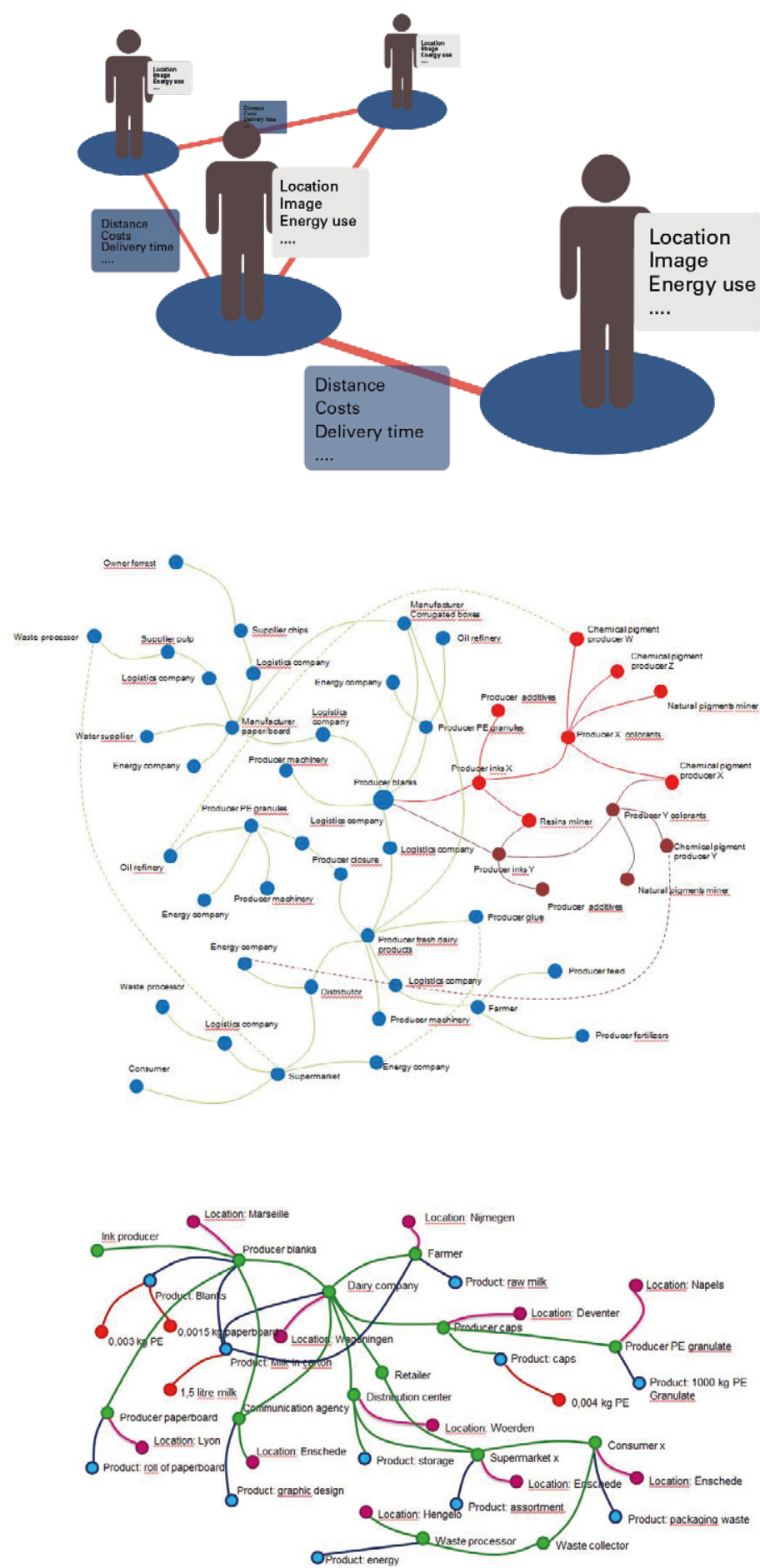


\subsubsection{Basic building block}

The basis for actor network is a graph modelling principle of actors and relations between these actors. This so-called basic building block is an applied construct of the entity-relation diagram (figure 7-1) and allows any relation between any actor. Moreover, multiple relations are allowed between actors. In relating each potential information entity with the corresponding actor, a base for contextualizing information and data sources is created. Figure 7-3 shows a representation of such a basic building block for the information structure. Both the actors and their relations have several aspects and values for these aspects. A collection of such aspects gives a blueprint for characterizing a relation or an actor. Each aspect can be given a value, either quantitative or qualitative, representing the actor or relation under consideration. The fundamental difference between an actor and a relation is reflected by the dependency of aspects. Those of an actor are solely dependent on the actor whereas the aspects of a relation are dependent on both connected actors. For instance, if a location is an aspect that is related to one actor, whereas a corresponding relation aspect such as transport distance is dependent on two sources.

The basic building block can be used to map out all actors that relate to the product definition. The resulting actor network represents the project context, the actors and the readily available information on concepts, requirement specifications and the product definition. As such, it can render an instantiation of the previously introduced reference model (see section 4.5) based on the available information. In the actor network, actors, products and processes are represented by elements (nodes). The elements are connected to each other by different types of both directed and undirected relations (edges), see some preliminary examples in figure 7-4.

Actor networks are non-hierarchical information structures based on the information structure of Lutters (Eric Lutters, 2001) and the conceptual graphs of Sowa (Sowa, 1984). Actor networks allow for the meaningful description of relations between all actors. Consequently, the resulting structure is a network in which individual hierarchical relations - by definition - lose their dominance in the bigger picture. As such, the flexibility of the network prevents the enforcement of any presupposed, domain specific meaning. Merely connecting the actors that are present in a network however, makes little sense; it are the different types of relations between actors and connections of actors with descriptive information (e.g. requirements, product definition, cost, time, quality, logistics etc.) that allow for establishing a context in which the individual elements effectuate their meaning. Including the descriptive information allows for simulating the influence of (the outcome of) decisions on the development cycle and life cycle of the product under development. Different paths/alternatives should be assessed and compared based on criteria that emanate from the descriptive information. In this, strategic considerations can explicitly determine the appraisal of these criteria. These considerations exceed the dependencies for one product: because many actors are related to multiple products, also the interrelations of multiple product life cycles become visible. In this respect, also the non-hierarchic nature of the actor network is substantial: the different life cycles are interrelated in multiple ways, for example by actors (from suppliers to end-users), re-used components or sub-assemblies, shared marketing, mutual cost price determination, logistics etc. 


\subsubsection{Ontology}

Any representation of a network structure containing a significant amount of entities and relations (without filtering) eventually becomes an unreadable 'hairball'. Moreover, if a network contains several different hierarchical structures, the rationale behind such individual tree-like structures is lost, causing not only a 'hairball' in representation but in structure and potential meaning as well.

In building up the network, the ontology of that network keeps track of the various elements and relations. The ontology of the network captures the structure of any information that is added to the network and aids in 'reading' or descrying the structures and corresponding meanings that are represented in the network.

In design engineering, there is a large body of research involved in the development of ontologies specific for design engineering. Such ontologies define the essence of a concept, process or model (Chen, Zhao, Xie, \& Zhang, 2015; Khan et al., 2016; Kitamura \& Mizoguchi, 2004). As such, these ontologies offer powerful mechanisms for knowledge management. However, in most network applications the inherent flexibility of the structure is hampered or even lost due to these predetermined ontologies. Consequently, for the actor network such applications are not of primary concern and in fact impede the flexibility and multiformity of the network.

Consequently, the ontology of the actor network is not a predetermined structure or model. Rather, it deduces its descriptions from the network structure itself based on core aspects of an entity or relation such as 'type' and 'view'. As such, the ontology of the actor network is determined a-posteriori by definition and is - and always should be - a derivative of the actual network. The resulting model offers a base on which the semantics of the corresponding network can be determined. While the network itself might seem a hairball, the ontology thus provides a guide to descrying the structures and meanings of the network that allows the user to understand and 'read' the structure of the network. Next to being the guide to the network, the ontology is an important starting point when information is not readily available. In case of incomplete information, the ontology of a well-established and used network can offer suggestions of similar 'frequently occurring structures' that are already captured by the ontology. As such, the ontology can be used to efficiently re-using already available information or underlying structures without the suggestion becoming a straightjacket that could transform the network in a - complex but still rigid - structure. On the contrary, such suggestions are by definition 'merely' an advice and never should become a law.

\subsubsection{Views}

A typical view on entities in a network representation is that of nodes/circles whereas that of relations are links/lines, as has been used in the figures of this chapter so far. However, the entity-relation concept together with the ontology form a base that allow for any perspective on information. Views represent a specific perspective- or meaning - on the information in the network. In recognizing that this meaning is subjective by definition, this structure is not influencing the network principle but can be reconfigured using views. The flexible entity-relation modelling language together with the ontology-as-derivative concept allow for versatile, scalable and flexibility in usage. Moreover, it prevents the enforcement of any presupposed, domain-specific meaning attached to (parts of) the product definition. Simultaneously, these concepts allow for 
a flexible representation of information that can be tailored to the user and the development domain.

The ontology can be used to search and filter the network. It allows to put focus on a certain part of the network in filtering on certain types of actors or artefacts, while in the background the entire network is still available. Together with the 'views' aspect of entities and relations, the ontology thus aids in constructing and capturing different perspectives on information, laying the base for the views.

With this, the actor network as described and illustrated above becomes the base layer of a stack of layers (see figure 7-5). In this, the individual actors behave like entities according to SADT (Marca \& McGowan, 1987): having input and output, requiring resources and be subject to control. Each of these four interfaces relate to elements on one of the stacked views. For example, a requirement can be the output of an actor, and the control of another actor. Likewise, the output of an actor may be a contribution to the product definition, whereas that same contribution is an input or resource for another actor.

\section{Figure 7-5 Views represented as layers}

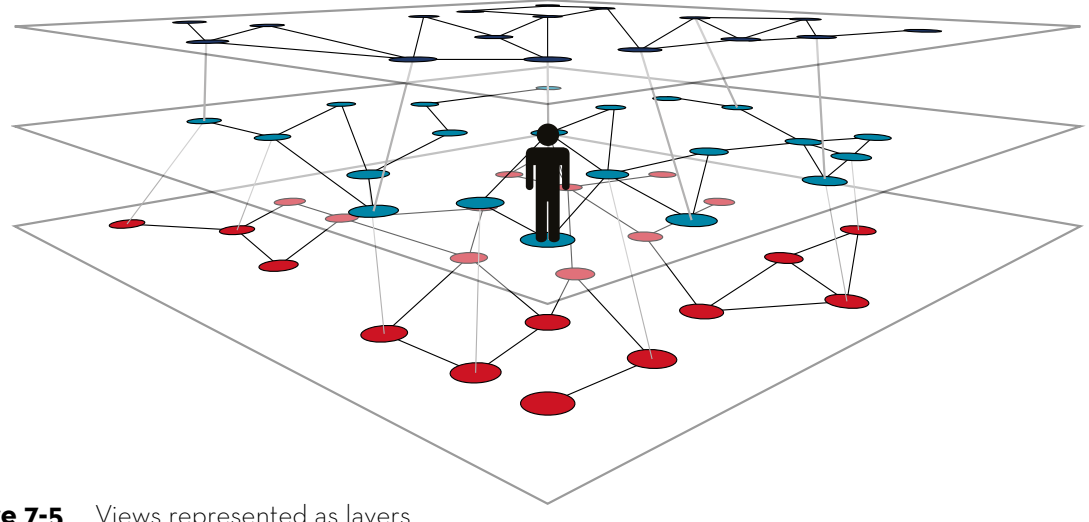

Whereas multiple views are possible, here, the three views - represented as layers that are discerned in relation to the actors are the requirement specification layer, the concept layer and the product definition layer.

Other views in the network might include for example layers that determine the performance of the product definition and requirement specification in terms of for example cost, lead times, quality or sustainability. Such layers aim to assess the quality of the solutions provided in the product definition, in relation to the requirement specification, in terms of specific criteria. This immediately demonstrates that an excellent solution may score considerably less if observed from another perspective. Therefore, the layers conjointly render a balanced, yet subjective, evaluation of the product definition.

Meaningful access to the information can be enabled by using these views as steppingstone for the representation. For instance, as a product engineer is responsible for the formulation of the function fulfilment and the configuration of the product, the corresponding perspective could revolve around the product definition. Within the production domain, that same information will need a different representation in which the configuration of the processes and corresponding key measures form the foci. 


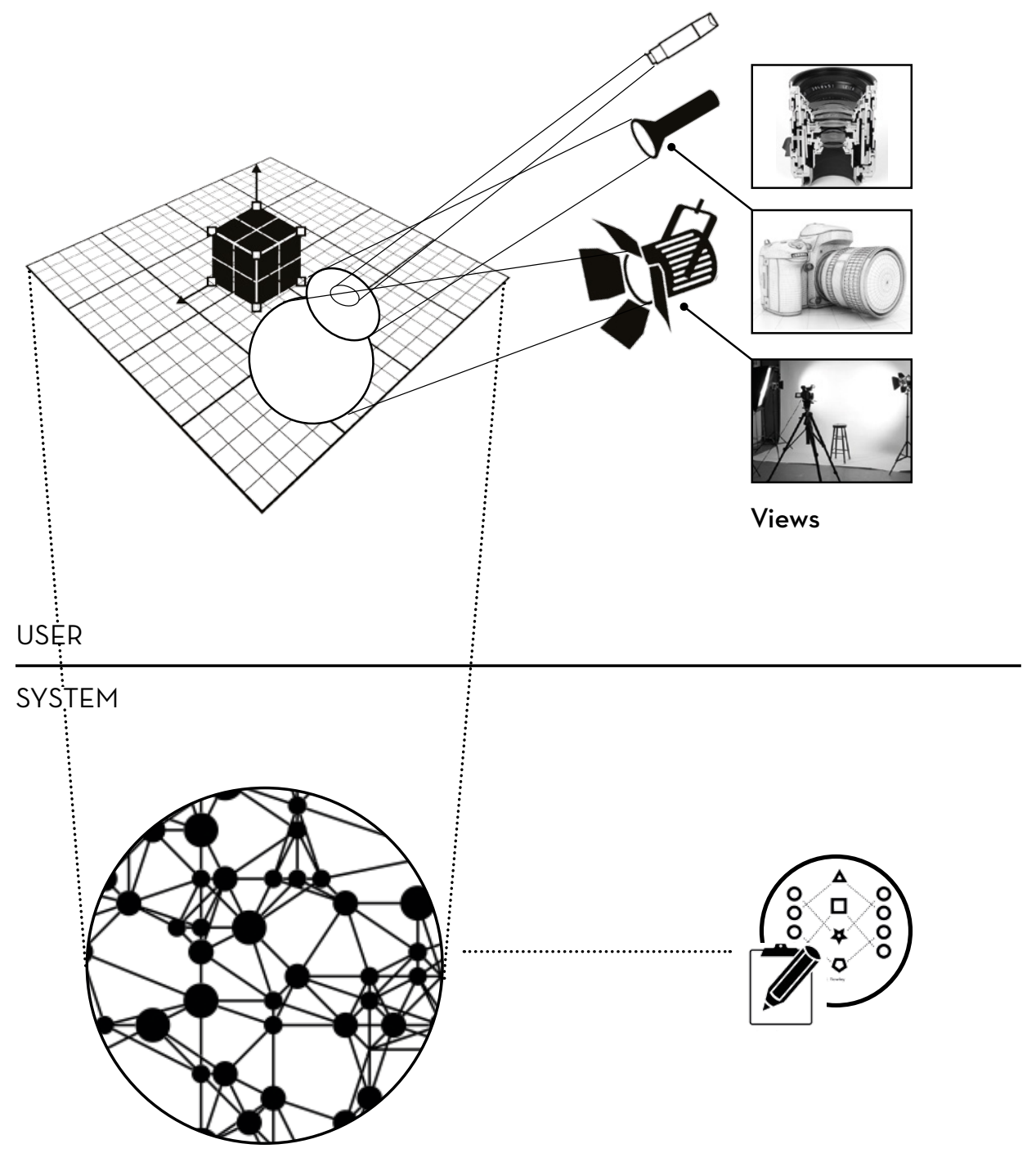

Network

Ontology (guide)

Figure 7-6 Overview actor network concept 
Switching between these different perspectives or views allows a versatile assessment of the information content that is represented in the network. As the network structure is used to prevent bias, it is important to realise that the network is always approached with a certain view. In enabling the use of the flexible structure, so-called autorarchical structures are deployed (Kals \& Lutters, 1998). These structures are temporal hierarchies that depict a certain viewpoint and enable meaningful access to the information for its user. Autorachic structures thus allow any hierarchy to be temporarily retrieved from the network, providing users meaningful access to the information based on e.g. their viewpoint and the case at hand. An autorarchic structure prevents any hierarchy in becoming dominant in the structure and ensures the resilience needed for future changes.

\subsubsection{Summary}

The development of a 'workpiece' of information as mentioned in the previous chapter should not be hampered or biased by imposing a priori viewpoints; therefore, a non-hierarchical way of information structuring is required. For this reason, a so-called 'actor network' is applied, to map out all assignable entities (the 'actors') that relate to the product under development (De Lange, Oude Luttikhuis, ten Klooster, \& Lutters, 2013; E Lutters et al., 2014). An actor network consists out of three parts, the network that stores the information, the ontology that serves as a guide and the views that represent various perspectives on that information (figure 7-6).

Actor networks allow for the meaningful description of relations between all actors. Consequently, the resulting structure is a network in which individual hierarchical relations - by definition - lose their dominance in the bigger picture. In the actor network, actors, products and processes are represented by elements (nodes). The elements are connected to each other by different types of both directed and undirected relations (edges). The actor network enables to construct a workpiece based on the often incomplete, uncertain and scarce information sources that are available in product development cycles. Both structured and unstructured information sources that already play a crucial part in this daily practice can form the starting point for the network, ranging from first drafts for a new production line to complete bills of material from ERP or PLM systems in use. The network principle allows to store such different information formats, while keeping unity.

While any network structure without filtering eventually becomes an unreadable 'hairball', the actor network structure provides for flexible filtering and temporary structuring the information. As such, it allows for a flexible representation of information that is tailored to the user and the development domain. Meaningful access to the information can be enabled by using the dominant perspectives within such domains as steppingstone for the representation. Switching between different perspectives or views allows a versatile assessment of the consequences of design decisions and aid in finding the optimal solution. Different views can be grouped in so-called (temporary) views. With different viewpoints and interests involved, actor networks are instrumental in making these interests explicit, quantifiable and discussable. At the same time, the actor network addresses the actual information content instead of the related processes. As such, the actor network remains extremely flexible and allows for constant reconsideration of the entire set of aspects. 


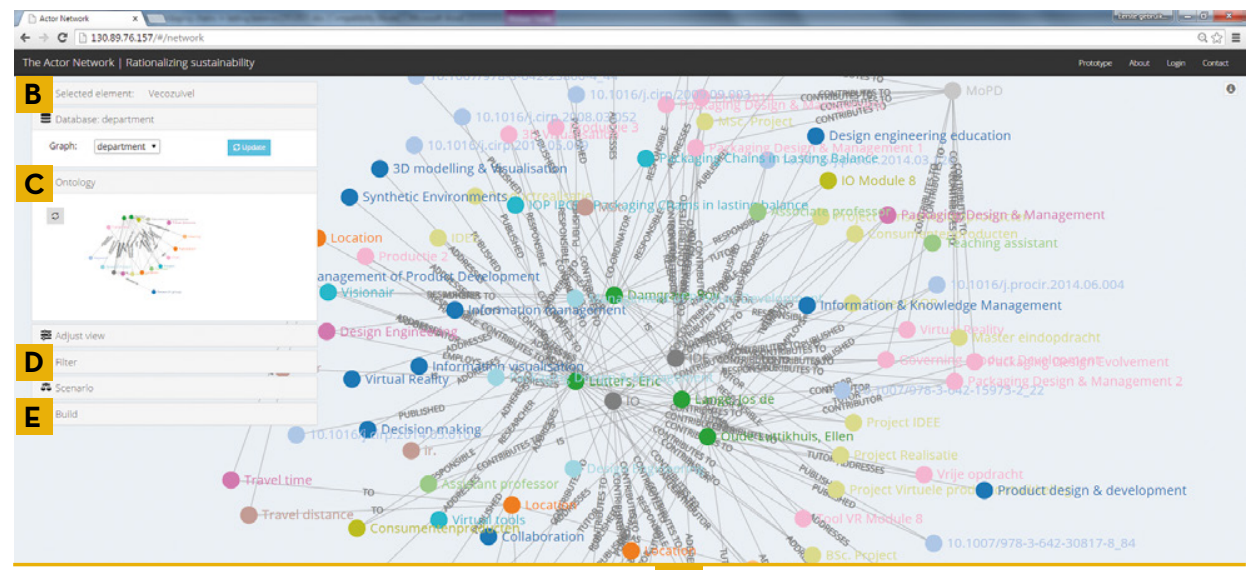

A Actor network

\section{B Information panel}

\& Selected element: 1 I gable top milk Name: 1 I gable top milk

Type: ProductPackaging combination

Value: 1 litre

Name: Product

\section{Ontology}

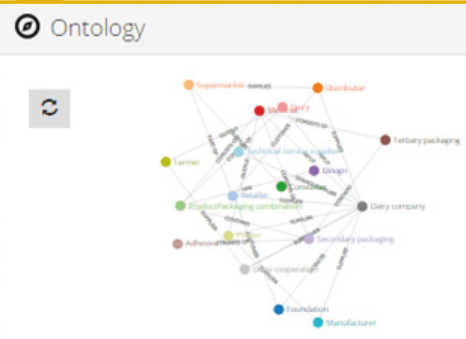

\section{Filter options}

\section{$\overline{\boldsymbol{p}}$ Filter}

\section{NETWORK TYPE}

\begin{tabular}{c|c|c|} 
Star $\quad$ Star $2 n \quad$ Network & \\
\hline
\end{tabular}

\section{FILTERS}

\begin{tabular}{l|l|l} 
Element & Relation \\
types & types
\end{tabular}

\section{E Adjusting the network}

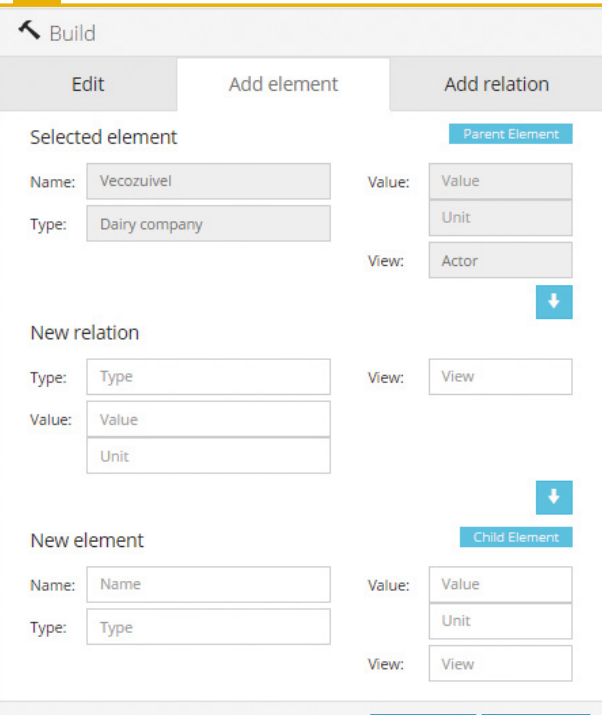

Figure 7-7 Interface of the prototype : the actor network, the information panel, ontology, filter options and building options. The scenario section is described in the next chapter. 


\subsection{USE CASE}

The principle approach described in this chapter has been partly developed and applied in research project "packaging chains in lasting balance' (see appendix D and (De Lange, Oude Luttikhuis, \& Lutters, 2014)). As the core question of this project revolved around finding a solution to integrate sustainability considerations in the daily practise of product development, the actor network was not only used to map out a product definition but the corresponding (future) life cycles as well. The primary goal in this use case is thus to integrate various perspectives on the product definition, in this case a product/ packaging combination, from different parts of the life cycle. As such, it offers a simple enough test case while all principle aspects of the actor network approach are put to use. To validate the theory and evaluating these key functionalities of the actor network, web-based prototype is developed. It is important to note that this prototype has limited possibilities in representing the information contained in the network. A graph representation and a tabular view were predominantly used. As this test case was done with expert users from the consortium, this is considered an accepted limitation of this first 'proof-of-principle' prototype. Figure 7-7 shows an elementary version of the interface. Figure 7-8 shows a representation of the basic elements of this prototype, the database representing the flexible information structure, the server that interacts with this database and the interface that allows interaction with the actor network. The relevant components of the interface are the view containing representation of the network, the ontology and the actor information pane. The actor network view gives access to the network in its full complexity. It allows for navigation through the network. Details on a selected entity are summarised in the actor information pane. The underlying structure of the network is shown in the ontology view. Here, the way in which different types of information are related is depicted, rather than all individual information entities; this ontology thus reflects the inherent backbone structure of the overall network.

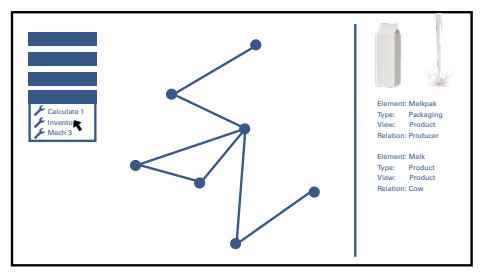

Graphic User Interface

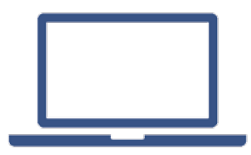

Client
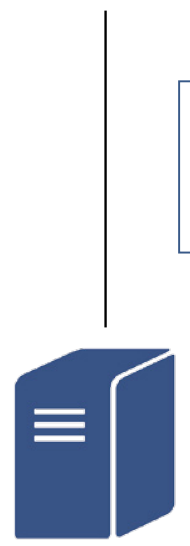

Server
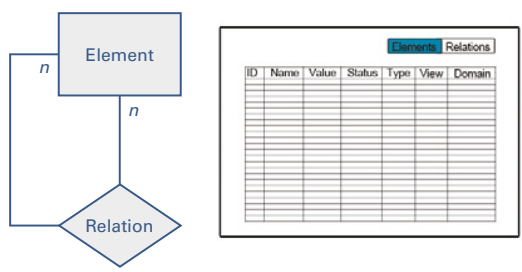

Structure
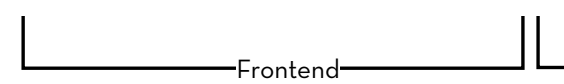

Backend-

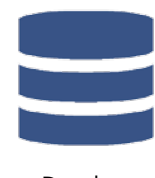

Database

Figure 7-8 Basic elements of the web-based prototype of the actor network 
In building up the network, the ontology of that network (figure 7-7 c), keeps track of the various elements and relations. In figure 7-7 a relative complex network is shown. The ontology of that network gives an overview in the current types of elements and types of relations. As such, the ontology is an important starting point when information is not readily available. While the specific information about a new packaging material or a new supplier might be unknown, the few details that are known - a principle material group or product catalogue - can be used to find similar structures in the ontology. These structures can then serve as a general template that outlines a certain part of the product or life cycle. Furthermore, the ontology serves as a legend that allows the user to understand and 'read' the structure of the network. It allows to put focus on a certain part of the network in filtering on certain types of actors or artefacts, while in the background the entire network is still available. The filter options (figure 7-7 d) can be employed in switching between perspectives and navigating through the network.

The figure shows a part of all actors and corresponding elements of a product-packaging life cycle. A force-layout algorithm is used to dynamically map the network in which entities are represented as circles and relations as lines. While in principle any representation can be configured, the prototype is limited to this force-layout representation. This obviously limits the applicability to more expert users capable of analysing networks. However, while it is a rudimentary representation it already illustrates the ease of how representation can be constructed without altering the underlying information structure. For this purpose, the prototype incorporates filtering and search options through which the user can define a view and save this as a template.

The network modelling approach as implemented in the prototype does not prescribe any rules or procedures on how the network is constructed. Entire graphs can be uploaded at once or a user can manually alter or add elements and relations. The ontology captures the overall structure of the network and can be read as a legend. In figure 7-7, the ontology is programmed to indicate different types of elements using a different colour. Such basic functionalities already offer primary contextual information to better understand the information in the network. The same flexibility in combination with the ontology ensures that no configuration of entities and relations is enforced to capture and represent information sources. Consequently, the actor network allows to capture similar information sources in multiple possible representations.

The entities are described by properties that together define the singular character: id, name, value, type, view and status. For relations a comparable set of properties is available, except for 'name' which is replaced by a source-id and a parent-id. This reflects the bilateral dependency of the relation and enables to give direction to the relation. For example, an element steel producer can have an input/output relation with another element can-producer while a directional relation with an aspect-element helps in characterizing the steel producer. By explicitly adding 'type' and 'view' to both an element and relation, their origin can always be ascertained. Furthermore, such properties provide the so-called hooks for descrying the current structure. Based on the provided information about the properties, an ontology of the current information structure can be made at any time. This way of a posteriori structuring ensures maximum flexibility without losing too much information or violate the situation it captures. As such, it provides the framework that allows for meaningful access to the information. 
The actor network is tested in three organisations with a similar market (fast moving consumer goods) and product portfolio (dairy), yet vary in scale (boutique farm, SME, multi-national). The supply chains were mapped from different viewpoints, including requirement specifications, criteria and product definitions. The outcomes show prominent matches in actors involved and identify unanticipated parallels in key decision criteria with analogue ontologies. In merging the resulting actor networks, a meaningful amalgamation is obtained, demonstrating the structuring capability of the actor network.

The chosen actor network approach for modelling life cycles seems to appropriately model and, more importantly, understandably model the life cycles involved in the development and realisation processes of a product. Actors have different views regarding the life cycle. Furthermore, organisations have different attitudes towards the decision making caused by differences in working methods, backgrounds, organisation, product types, or consumer preferences. These different views have to be included in the actor network application and are the main driver for the flexible setup of the information structure. This structure is not hierarchic, as most file systems often are, but autorarchic.

\subsection{EVALUATION AND DISCUSSION}

The network modelling approach enables to (re)model any information structure. Whether this is a relative simple file-folder structure that represents a certain user's collection or the entire internal structure of e.g. a word-file; the entity-relation construct allows any representation of information, as long as this information allows to be modelled in a form of a network. Moreover, the network modelling approach does not dictate one particular modelling of one specific type of information. For example, a CAD-file can be represented by only one element that offers access to the file or can be represented by an entire subgraph of entities and relation. Both representations - or any representation for that matter - are allowed. Moreover, the actor network allows these various structural representations to co-exist. If one structure is already available this will thus never violate another structural approach for the same information. The ontology, as derivative of the network can be used as a guide to untwine these various meanings. Consequently, it is assumed that this modelling approach suffices for not only all existing information models, but can also be used to represent new models and the standards of the future.

There are some potential disadvantages to this flexible approach. For instance, practical aspects such as predictability of results or processing speed could lead to consider more rigid or even hierarchical approaches towards establishing the interconnectedness. While for implementation, there seemingly might be more (initial) effort involved in establishing a non-hierarchical network such as the actor network, however the (long-term) advantages outweigh these implementation quirks by far. If such flexibility in use is in allowed, one runs the risk that - in implementation - certain standards for certain sources of information become preferred. Certainly, when the ontology is used to temporary fill in information gaps with placeholders for instance, this could cause the suggestion of the above mentioned rigidity. However, there is a subtle difference. Such preferred structures do not violate the flexibility and adaptability of the actor 
network in principle as long as such preferences are not used as a straightjacket. In summary, for the actor network to fulfil the stated requirements on connecting all available information sources, compatibility and allow for multiple perspectives it is of utmost importance not to hinder the flexibility of the network modelling approach. Consequently, dictating a structure or format is prohibited. This holds true for the network itself and the ontology. In allowing for meaningful context the ontology also has a significant part to play. The ontology offers a model based upon which the semantics of (a certain part) of the network can be determined. Consequently, information is structured in the network whereas the rational of that structure does not cause any rigidity in the network itself (as would happen with tree-like structures, taxonomies or strict classifications) but is captured by the ontology. As such, this network-ontology concept offers a structuring mechanism and a separate guide to this structure without violating the flexibility and multi-perspectives requirements.

In essence, this also allows to create rich contexts. But the actor network does not start at these information entities, but it starts with actors as principle starting point for enabling context. In structuring actors and aspects of actors and by connecting actors with each other and with the available information, a framework for 'information-induced' context is created. Consequently, the interconnected sources of information constitute a common reference for everyone involved. More importantly this reference forms the base upon which meaningful access can be constructed. Based upon the actor network and its ontology, multiple views can be constructed in which the interpretation of information is fostered and that aims at avoiding potential rich information sources in becoming data - information without context. As such, it is of utmost importance that the establishment of the information is solid and predictable. Whereas the actor network allows for versatile use in both information structuring and representations, it does have a strict logic and solid base that allows for a controlled establishment of information. With that, the actor network approach in principle adheres to the requirements as defined in this chapter.

\subsection{CONCLUSION}

This chapter has resulted in a set-up that allows for accessing any explicitly available information content of the development cycle, that acts as the 'workpiece' for product development (see section 6.1). A network structure is deployed to integrate all explicitly available information. This network structure allows any (hierarchical) structure to purposefully co-exist with other, potentially contradicting, structures.

The actor network should not be regarded as a singular solution that has the pretence of replacing all information management systems in engineering. Rather, it should be regarded as a minimum viable solution that enables the establishment of a system of interconnected sources. With the actor network the aim is to build upon (proven) systems already in use and put the focus on a versatile approach in associating and representing all information regarding the product development cycle.

The actor network allows for the meaningful description of relations between all actors. Consequently, the resulting structure is a network in which individual hierarchical relations - by definition - lose their dominance in the bigger picture. In the actor network, actors, products and processes are represented by elements (nodes). The el- 
ements are connected to each other by different types of both directed and undirected relations (edges). Using network modelling, ontologies and views, the actor network enables to construct a workpiece based on the often incomplete, uncertain and scarce information sources that are available in product development cycles.

These concepts set the stage to allow for using information as a workpiece. While this setup has far-reaching implications for information and data management, for the user not much has changed yet. In fact, it is assumed that an information set-up based on the actor network could function in any setting without the user noticing it. With this, the actor network can be seen as the engine under the hood - extremely relevant, but hardly directing the driver in determining a route.

Nevertheless, such an engine, independent of its quality, cannot achieve any results on its own - like a car (still) needs a driver to reach its destination. This implies that although the actor network may be adequately capable of capturing all potential information content while effectively representing that content in different perspectives, the actor network will not autonomously or pro-actively evolve the product definition. It is the influence of stressors (see section 6.3) on the actor network that causes changes to the network. With this, the actor network meets the requirement of the information content to be separated from the instruments that change it (see section 6.2). Moreover, this implies that the actor network can not only cater for different (hierarchical) structures at the same time, it also implies that the constitution of the actor network can cope with influences of instruments that have also no predefined nature.

The fact that an actor network has no predefined hierarchy implies that the validity and consistency of the information it contains cannot be taken for granted from every perspective. Imperatively, decisions in the development cycle thus need to assess the quality of the available information as the basis for their decision. This seems to require substantial efforts, yet it actually allows for more design freedom as, in practice, all too often design processes are limited by unjust assumptions on the availability, completeness and reliability of information. In using the actor network, indefinitenesses automatically become part of the evolving information, instead of being temporal and ostensible certitudes based on which decisions are taken.

In this way, an important span between requirement specifications, concepts and product definitions is created: the discords between them can be traced back to actors that are struggling to convert uncertainties and ambiguities into contributions to the evolvement of the product definition (see section 4.4). In doing this, the uncertainties and ambiguities, within the contexts of the multiple life cycles and the strategies the product developers have to deal with, cause a multitude of 'possible futures'. Because the probability of these 'possible futures' become part of the decisions addressed by the solution, product development teams can knowingly address auspicious criteria and directions for solutions. By applying 'what-if' analyses to consider the consequences of alternative solution paths on beforehand, while taking (contradictory) aspects, viewpoints and interests into account, eventually the risk of undesirable incidents during and after the materialisation of the product can be decreased. Therefore, the next chapter elaborates on the instruments and opportunities to initiate purposeful evolvement of the product definition as captured in actor networks. 



\section{MECHANISMS AS TOOLING ENGINE}

Whereas the actor network offers a (minimum) viable solution to establish a source of interconnected information, a filled network in itself is a passive thing, just as a physical workpiece. In establishing the intended usage as derived from the workpiece analogy discussed in chapter five and elaborated in chapter six with the stated purpose and the decision impact model, the logical continuation is to focus on the enablers that collectively constitute the so-called tooling for the information workpiece. How to allow for interaction with the network in order to explore solution space and explicate potential consequences of design decisions?

There are already multiple information tools available used for information management. Tools range from generic software packages such as text-processing programs and email software, to design engineering specific tools covering CAD and elaborate PDM suites or even analogue notebooks (see section 5.2.3). Each type of tool can be used to either create, alter, document or search information. With the actor network a base is formed through which the outputs of such programs can be expressed in a unified format through which an information workpiece can be modelled. However, merely combining the various information sources in a network and just adding new information would hardly offer any benefits, let alone exploit the full potential of information-induced designer support that stems from the axiom introduced in chapter four. This chapter therefore focusses on analysis, discussing, defining and evaluating a principle solution in establishing an interface that allows for the purposeful evolvement of information. 


\subsection{REQUIREMENT SPECIFICATION}

Without a workpiece or the corresponding usage, information in product development trajectories is obviously also defined, processed and communicated. As outlined in section 5.2.3 there are abundant programs available for product developers. A significant part of those programs or information tools are indispensable, for instance defining the geometry of a product without the use of CAD would be well-nigh inconceivable in modern-day product development.

In current information usage, the dominance of some software systems do not always allow for efficient combinations between tools. While the possibilities might seem endless within the boundaries set by one software program, usually significant effort is required in combining various tools on the same information, despite standards such as described in section 5.1. There is no arguing in the indispensable usefulness of each tool. However, with a graph-based information workpiece (enabled by for instance the actor network as described in the previous chapter) a first, practical and basic step in unification of information is made. Whichever evolvement of information is needed in a product development cycle; it is assumed to be part of the same source of interconnected information. Similarly, there is potency for an interface in allowing any combination of tools. Consequently, existing software packages or any future information tools should be able to be used and combined. Moreover, a solution for establishing an interface between product developers and the information workpiece should not hinder any of such information tools from losing functionality.

With the desired workpiece usage, a new frame of reference for the tooling of information has been defined. In establishing this interface, the functionality of current information tools should be respected and embedded, while enabling the intended usage. This usage is aimed at efficiently using all explicitly available information in and of a product development cycle and defining this collection of information new functionality that is tailored towards governing the cycle. The principle solution should define interaction in such a manner that it enables to facilitate, initiate and direct effective and efficient design making. The three characteristic as defined in section 5.4 - reference, reciprocity and reflecting uncertainty - are used to deduce the requirements for such a definition.

With the actor network a solution has been defined that satisfies the precondition of having information available as one collection. With it, all explicitly available information and associated metadata can be bundled without changing the initial meaning In comparison with treatments on physical workpieces, changes in information are not that easily noticed. Obviously, there are possibilities to notify a user on recent changes, new documents or recent activity. But these possibilities are not necessarily aimed at covering such changes as a $\boldsymbol{\Delta} \boldsymbol{i}$ of a complete information collection. Moreover, such possibilities are not designed to aid the user in explicating consequences of decisions or identifying potential (future) information needs. With regard to establishing reciprocity, no evolvement should go unnoticed but the results of tooling and treating information should be available or conceivable as $\Delta i$. Consequently, administration of information evolvement is required, especially when considering the potential volatile, ambiguous and uncertain aspects of any situation. Consequently, a consistent manner of evolving the information is crucial to create a reference that is trustworthy and con- 
sistent with all other elements of the development cycle. This administration should not automatically entail that every change is constantly communicated to the actors. Rather, it should allow for a constituent and controlled evolvement.

Tooling should be aimed at enabling to build, perform and potentially even automate what-if analyses based on this $\boldsymbol{\Delta} \boldsymbol{i}$ and the entire workpiece. A such, potential consequences and the potential responses of the workpiece should be fostered by tooling to be made explicit.

It is essential to take into account the uncertainties that are at play as any decision that is presumed to be deterministic might display a certain degree of unpredictability or uncontrollability. If human actors make decisions, they also naturally and often implicitly make an estimation of the uncertainties that are caused by the decision and relate such uncertainties to the status of the project (as discussed in section 2.2.2). In establishing a reflection of such uncertainties in the information workpiece, one - by definition - cannot do without explicitly and purposefully assessing the uncertainties. If uncertainty is explicitly assessed, any bias on the notion uncertainty must be prevented. A lot of existing approaches in dealing with uncertainty focus on mitigating uncertainty or preventing uncertain decisions. While mitigating uncertainty might certainly in some cases be a sensible and valuable approach, it is not the definitive approach, especially not if product development is considered from an information perspective, as is the case in this thesis. If focus is put only on the negative effects of uncertainties, the complete influence of all (vuca) aspects of uncertainty as discussed in section 6.3.4 is not taken into account and the potential to use uncertainty as a driving force (as discussed in section 4.5.2) is nipped in the bud.

The establishment of an interface that allows for purposeful evolvement of information as outlined in this section is summarised in a desired usage scenario (figure 8-1). The relevant components of this prototype are the views for the actor network (bottom right), the scenario (top right), the ontology (top left) and the actor information (bottom left). The actor network view gives access to the network in its full complexity. It allows for navigation through the network, while having access to consequences of decisions, alternatives and effects of scenarios. Details on the selected entity are summarised in the actor information. The underlying structure of the network is shown in

Figure 8-1 Collective purpose of tooling illustrated using the actor network prototype as base

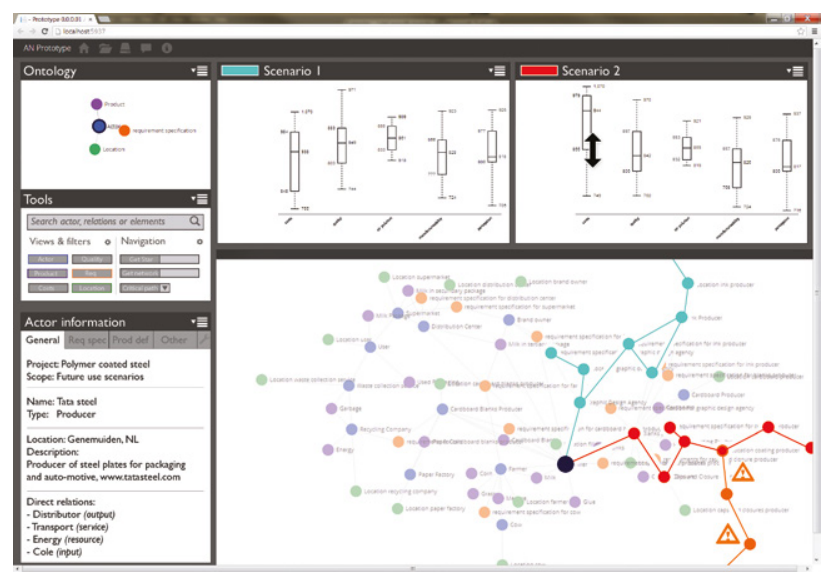


the ontology view. Tooling enables to construct what-if scenarios. These scenarios connect the (strategic) criteria to phenomena in the actor network. By adjusting a scenario (here actualised by tuning a slider), the network responds by indicating e.g. violated requirements, changed probabilities, warnings, bias towards certain alternatives.

In summary, the following requirements with respect to the tooling of the workpiece are defined:

\subsubsection{Allow any type of evolvement}

There are two reasons not to put any limitation on the content of the evolvement of information. First, there is no sensible demarcation to be made a priori in what type of evolvement might be needed in product development cycles. Since the solution is aiming to be applicable for any type of design situation. Thus should be free from any specific implementation characteristics, it is even assumed to be impossible to limit the type of content. Second, a result of any delineation causes a limitation that might affect the autonomy of the product developer. As discussed in section 2.4 the design(er) support should not interfere with this autonomy.

\section{Allow all existing and future tools (compatibility)}

If all types of information are allowed, then there should neither be any limits for the instruments, tools and techniques that are or can be used throughout the product development cycle. Consequently, in establishing the interface all existing and future tools to belabour information should be allowed and therefore, the interface should be compatible with existing tools already in use and anticipate upon any future tools that might become part of the toolbox of product developers.

\section{Allow combinations of tools (modularity)}

Just as an artisan can purposefully combine any set of tools and techniques to shape a workpiece, the interface should allow sensible combinations of tools and techniques. With regard to the facilitation, initiation and direction of decision making as defined in the stated purpose, such modularity can cater for the establishment of more elaborate operations on the information workpiece.

\subsubsection{Administer the establishment of information evolvement in a controllable manner} While no limits should be put on the types of content, the evolvement itself does need a certain degree of control. If the information workpiece is going to be the pivot for product development trajectories, the establishment of the armamentarium that enables operations on and therefore the evolvement of the workpiece should be reliable and logical. Especially in a non-deterministic setting, such control is needed to create an information workpiece that can be trusted. Controlling the evolvement of information in a non-deterministic setting therefore requires a carefully chosen balance between organizing a dependable and predictable administration and taking uncertainties into account.

\section{Create a controllable evolvement}

Based on the workpiece, product developers should be able to anticipate decisions and govern the product development cycle. Consequently, the workpiece and its (continuous) establishment should be fully dependable. The evolvement of information 
should be manageable in such a way that it introduces no (additional) vagueness or indistinctness.

\section{Explicitly address uncertainties as an aspect of information}

As developing products always happens under uncertainty, uncertainty in the establishment of the interface should not be neglected. Especially regarding the required administration, it is imperative to incorporate uncertainty. A workpiece reflects such uncertainties (see section 5.4). In a similar manner uncertainty should be incorporated in the information network. It is assumed that through the establishment of information, the effect of the various uncertainties as addressed in section 6.3.4 affect the information. Consequently, these uncertainties should be explicitly addressed in the establishment of that information.

In summary, in order to establish an interface that allows for the purposeful evolvement of information it is required to allow any type of information evolvement while carefully administering the evolvement itself. No limitation should be put in the type of instruments, tools and techniques that might be instrumental in the establishment. However, a modular approach in allowing to combine such a diverse range of tools is strived for to cater for effective and efficient combinations of tools. In administrating, the interface should assure an establishment that is dependable and that introduces no indistinctness itself. Furthermore, the uncertainty should be explicitly addressed. Table 8-1 shows a synopsis of the requirement specification.

For product development, actors are the principle resources and 'owners' of a product development cycle. With the decisions they make, actors constitute the evolve-

Table 8-1 Overview requirement specification for the instruments placed in the design brief format set in chapter six and related to workpiece usage as defined in chapter five.

\begin{tabular}{|c|c|}
\hline Functional requirements for the tooling & Related desired characteristics \\
\hline $\begin{array}{l}\text { Establish an interface that allows for } \\
\text { purposeful evolvement of information } \\
\text { (section 6.5): }\end{array}$ & $\begin{array}{l}\text { These functional requirements relate } \\
\text { to the } \\
\text { following desired aspects of informa- } \\
\text { tion usage as workpiece (section 5.4): }\end{array}$ \\
\hline $\begin{array}{l}\text { Allow any type of evolvement } \\
\text { - Allow all existing and future tools } \\
\text { - Allow combinations of any tools }\end{array}$ & Reciprocity \\
\hline $\begin{array}{l}\text { Administer the establishment } \\
\text { of information evolvement in a } \\
\text { controllable manner } \\
\text { - Create a controllable evolvement } \\
\text { - Explicitly address uncertainties } \\
\text { as an aspect of information }\end{array}$ & $\begin{array}{l}\text { Reference } \\
\text { Reflect uncertainties }\end{array}$ \\
\hline
\end{tabular}


ment of information or control and direct this evolvement. This involves all creative splurges, intelligent twists, and new insights actors bring to the table when defining a new product in non-deterministic settings. However, even in non-deterministic settings, many of the evolvements of the information content are more or less self-explanatory in nature. This yields true for many decisions, to name but a few: determining the cost price of an assembly in the make; making a bill-of-material; comparing material properties; calculating strengths; and processing drawings. Each of these decisions, that might be a logical consequence of more unpredictable and complex decisions, can - in certain contexts - be characterised as either straightforward, routinely, predictable or even mechanistic.

In simplifying this characterisation, a distinction can be made between non-deterministic and deterministic decisions. A deterministic decision is regarded as a decision in which the relation between cause and effect is known upfront. When repeated, a deterministic decision in a similar context, with equal input will lead to a predictable outcome. As such, typical of a deterministic decision is its controllability and repeatability in combination with an accepted quality of output. Logically, all decisions that do not adhere these aspects could be labelled as non-deterministic. Consequently, a non-deterministic decision describes decisions where the relations between cause and effect are not precisely defined or even unknown. Exactly with such complicated, intricately difficult decisions the before mentioned skills of actors - such as creativity, intuition - play an important if not decisive role. Product developers excel in creating unexpected and associative solutions for non-standard and non-trivial problems. However, product developers are also pestered with an abundance of repetitive and routine work. It is assumed that product developers add indispensable and irreplaceable value when dealing with non-deterministic decisions. However, with deterministic decisions one could state that this value is less irreplaceable and should not necessarily always be added by (human) actors. Indeed, in case of strong and long repeatability of relative simple decisions and tasks, some autonomous systems are more suitable due to either supreme capacity (calculations) or the lack of human aspects such as boredom or weariness. Examples are fully automated production systems in which the role of actors is to supervise, control and only interfere when problems arise.

It is assumed that a (significant) part of routine-like tasks can be presumed to be a deterministic decision. Especially in regard to the chosen what- if approach, there is a significant advantage in automating such routine processes that run in the background, already doing preliminary work such as calculating, searching, pre-sorting or selecting information.

Automating deterministic procedures should not be understood as an example of the automating design paradigm or adjacent field of Artificial Intelligence. Although there are apparent similarities, the underlying purpose is significantly different. Whereas the overarching goal for the 'automating design theme' is to 'emancipate human from the design workloads' (Yin et al., 2015b), here focus is put on the integration of humans and machines. As such, this approach can be understood to be based on the so-called human-machine integrated automating design paradigm (Yin et al., 2015a) where focus is put on the integration of the strong and favourable abilities of both man (creativity, intuition, experience) and machine (massive computation and logic deduction). Consequently, the approach advocated here is not focussed on automating a development 
cycle in its entirety or to capture and mimic human intelligence. Rather, focus is put on offering automated procedures as tools for the product developers. As such, the interface should establish such processes as tools and techniques as means to process information in which it offers both straightforward solutions for known problems as well as facilitating evolvement of information in relation to the decision at hand (Eric Lutters et al., 2014).

In using automating deterministic decisions as principle solution direction for the establishment of the interaction, the structured analysis and design technique (SADT) offers a modelling language that allows to describe any system in terms of a hierarchy of functions (Marca, D.A. \& McGowan, C.L., 1988). As part of this language the basic element is a function that has input and output, requiring resources and is subject to control (figure 8-2).

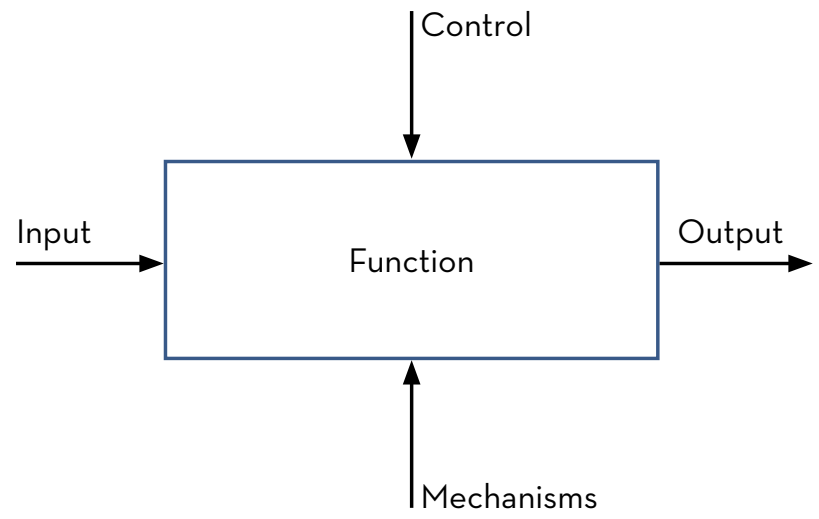

Figure 8-2 Elementary function block diagram of the SADT modelling language (Marca \& McGowan, 1987)

The four abstract interfaces together form a very complete set and are able to clarifying any system. A situation can be typified using a hierarchical set of functional block diagrams as the transformation of input objects and products into the desired output forms the rationale of an organisation; resources provide the resources needed to enable this process, for example machinery or energy and control are made up of the requirements and pre-conditions for the correct generation.

A distinct feature of the SADT method is the allowed gradual level of detail: a functional block can be elaborated in a more detailed diagram of several functional blocks. Within the idefo modelling language it is thus possible to use different levels of aggregation. For instance, the production process of a steel plate can be depicted as one function block that refers to another scheme in which the process is detailed into all relevant functions such as batching raw materials, heating batch, forming the plates and rolling sheets. Key element in the switching between various levels of detail is that the four types of relations of the aggregated functional block is equal to the sum of all the separate relations of the detailed blocks. The relative simple rule of equivalence is in fact an important element in describing any system as it provides a powerful control mechanism to supervise the multidirectional shift between various levels of detail.

While the SADT modelling language provides a sturdy basis there are some downsides. For a system based on a networked workpiece there is no need to adhere to the strict hierarchical subdivision that underlies the functional analysis methodology. 
Furthermore, the strict separation of inputs, resources, control and outputs cannot be maintained when using a multi-perspectives system as described in section 7.3.3. Consequently, an information entity can relate to each of the four interfaces in various ways. For example, a requirement can be the output of an actor, and the control of another actor. Likewise, the output of an actor may be a contribution to the product definition, whereas that same contribution is an input or resource for another actor. Moreover, the SADT modelling language does not explicitly take into account uncertainty.

In summary, autonomous processes have great potential to perform routine tasks and facilitate the product developers. For product developers, assistance in addressing such routine matters is beneficial, especially if that assistance can also address uncertainties.

\subsection{THE DEFINITION OF A MECHANISM}

In establishing an interface that allows for interaction with the information workpiece such autonomous processes can form the base for a workpiece-focussed armamentarium. For this reason, this research/thesis introduces so-called mechanisms. This section gradually builds up the defintion of mechanisms, starting with a simple but strict syntax. Mechanisms can assist designers, by taking on the more routine tasks involved in designing. Mechanisms can be considered as deterministic and autonomous means to reach decisions or make circumstances for decisions explicit, provided that the required input is available. Mechanisms can thus be considered as a principle means to formalise problems and questions in defining and executing what-if scenarios.

Mechanisms are autonomous processes that are capable of identifying patterns in the actor network based on the ontology and - based on those patterns - generate information and link this information to existing information entities and or to represent this information to an actor from a certain/ meaningful perspective/ view. The modelling technique for behind mechanisms is simple, straightforward and scalable. It regards any mechanism as a 'black box' regardless the complexity of the mechanism. Ranging from a simple formula that is automatically calculated towards any external complex software package, the syntax for mechanism is a strictly defined system that processes predefined inputs in an output (figure 8-3).

Mechanisms can have one or multiple input variables. To differentiate between these inputs, each of these inputs is numbered from 1 to $n$ (figure 8-4, next page).

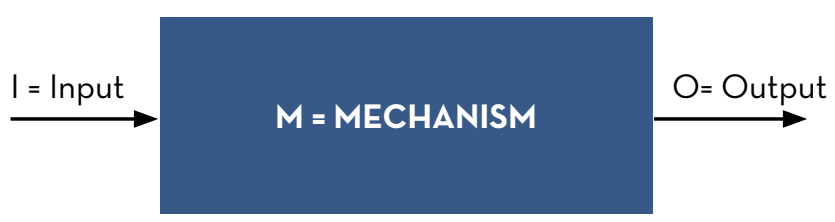

Figure 8-3 A mechanism in its simplest format. 


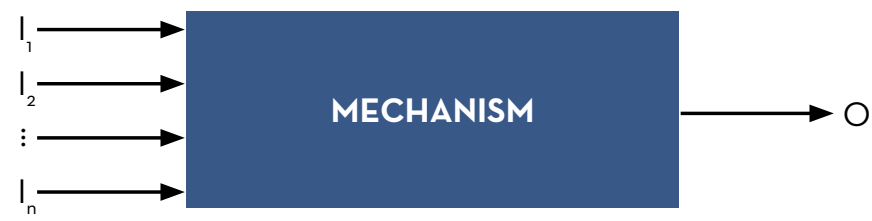

Figure 8-4 Numbered input variables.

\subsubsection{Modularity}

Mechanisms are modular. The output of a mechanism can serve as input for other mechanisms, and mechanisms can be combined in sensible series or workflows. To differentiate between the various mechanisms in such a series, each mechanism is numbered (figure 8-5). The mechanisms last in a series gets the lowest order. Logically, preceding mechanisms will successively be given a higher number.

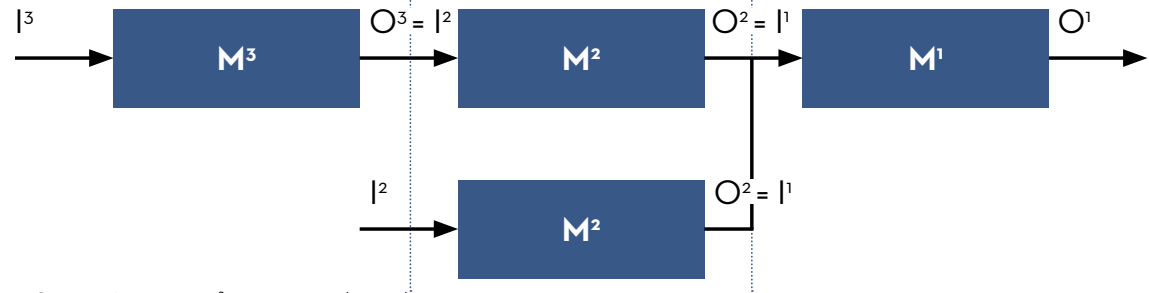

Figure 8-5 A series of connected mechanisms.

It is possible to define such a series of mechanisms as one mechanism. This more complex mechanism will execute the 'smaller' mechanisms in succession (figure 8-6). The input variables in such a series not stemming from a mechanism will form the set of input variables for the amalgamated mechanism. Similarly, the outputs of mechanisms that are not processes as inputs for other mechanisms will form the set of outputs of the 'larger' mechanism. As such, a mechanism can have more than one output. A constellation of mechanisms can thus be seen as a mechanism in itself, capable of generating more complex output, for example, the assembly costs of a product.

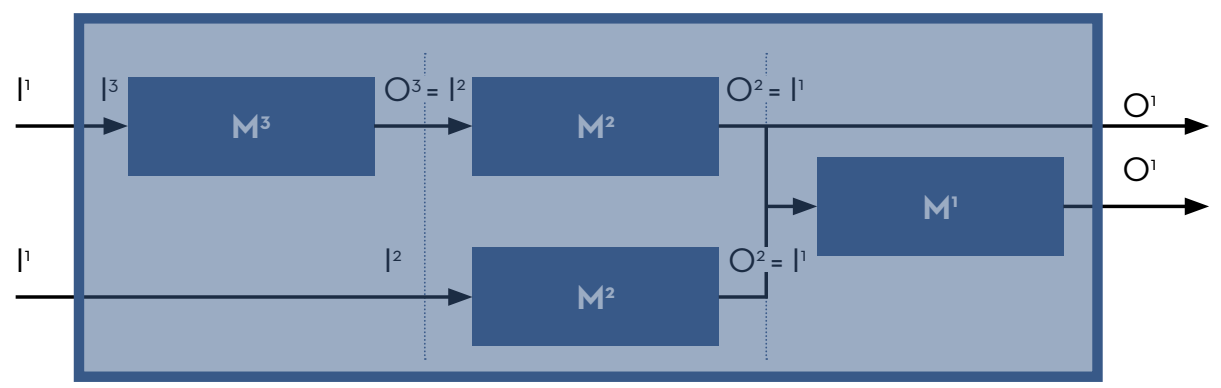

Figure 8-6 A constellation of mechanisms can be defined as one mechanism. 


\subsubsection{Intent}

Mechanisms as defined in this section provide a common syntax of how deterministic processes can be used to evolve information by transforming input(s) into an output. The definition of mechanisms deliberately does not state anything about the type/sort of output that can be generated. This output could be anything ranging from a simple conversion of numbers to a full life cycle analysis. As long as this output can be modelled in a type of subgraph all output in principle is allowed.

In allowing any combination of mechanisms, complicated sets of mechanisms are expected to develop. While the creators of such a consolidated mechanism might exactly know all the different mechanisms, and know about the rationale behind both these mechanisms and the order in which they have been put, future users of such a 'big' mechanism might not have that same knowledge. For instance, assume any Life Cycle Analysis (LCA) program to be a consolidated mechanism available for the information workpiece. After processing numerous input-variables, such a LCA mechanism will give its user several outputs that says something about potential life cycle impact of the product. It does not necessarily convey anything about the transformation process.

It is assumed to be unfeasible to convey all the details of a mechanism to users of the design(er) support system. This would potentially exhaust product developers with an overload of information that such a mechanism would hardly provide any benefits as to using the original program in isolation. However, it is important that the rationale behind mechanisms is conveyed. Therefore, a mechanism always has a defined intent. This intent obviously should convey the purpose of the mechanism, but it is also closely related to the design rationale. Based on this intent, arguments for selection, usage and evaluation can be made explicit.

Intent as terminology is a way of translating aspects of tool usage as described in the workpiece analogy of chapter five to information usage in product development cycles: reciprocity and reflecting uncertainty. Just as with tools and techniques used in a workshop, each mechanism has a specific purpose. A mechanism should also convey the range of possible operations that can be performed on the information, the so-called value range of information. As such, a mechanism is defined with the intention to serve a specific (set of) target(s). In other words, a mechanism has intent that conveys its purpose, and gives a sense of the possibilities and limitations of that particular mechanism.

However, mechanisms by definition are defined without the context in which they can or might be used. A hammer obviously can be used to put nails in a piece of wood. However, while this is the intended usage, it does not make sense to strictly limit its usage for that purpose. A craftsman might use the hammer to put different objects on wood or other surfaces, it might purposefully use it to chip of a piece of wood or as temporary clamp or whatever purpose the craftsman finds. Similarly, mechanisms when put to action - might serve various purposes. Consequently, while it is important to convey the intent of a mechanism, this does not limit its future usage. It only stipulates the intended meaning of the mechanism from which logical prerequisites can be derived. This entails the expected outcome, the (strict) arrangement of activities or (automated) tasks and the requirements or expectations on inputs.

With intent the suitability of a mechanism can be determined. As it covers the expected outcome and effect of a mechanism, it also addresses uncertainty in a generic sense. The intent of a mechanism thus covers not only the purpose of a mechanism, it 
also embodies the order of magnitude of the created output, the quality of that output, the tolerance/ accuracy. In summary the intent of a mechanism relates to:

- The (design) rationale

- The planned purpose of a mechanism

- The expectations on type, order of magnitude and range of the inputs and outputs.

Mechanisms should not be regarded as 'just' algorithms that calculate things, but as enablers that autonomously produce prognoses of information evolvement. In summary mechanisms autonomously:

- Identify patterns in information (based on the ontology of the actor network)

- Create information (with calculations, algorithms, software programs, expert systems, estimations)

- Assess the uncertainties of that information

- Link information (to entities in the network)

- And/or represent the information to the actor in a certain view

\subsection{UNCERTAINTY AND MECHANISMS}

With this section, mechanisms are considered in isolation. As such, this assessment of uncertainty should not be considered to be the definitive analyses for uncertainty, but as a prelude and necessary basis to be able to neutrally regard uncertainty. The overall aim in this neutral attitude towards uncertainty is to make uncertainty instrumental as the driver for product development cycles. The first step in enabling this approach is to allow the effect of uncertainties to manifest in the information as a reflection of these uncertainties. Based on the vuca-terminology as introduced in section 6.3.4, the relation between the aspects of a mechanism and uncertainty is assessed.

\section{Volatility leads to validity in information}

Volatility in a non-deterministic setting addresses the nature of change. It is important to understand that volatility could instantaneously disrupt a design equilibrium and would instigate the need of a multitude of re-assessments. However, in a deterministic context volatility leads to a limited tenability of results. With regard to mechanism, volatile address the validity of information or the mechanism. For a mechanism and its in- and output this might entail a limited currency. For instance, the fluctuations in prices of materials could be obviated by in limiting the period of validity.

\section{Signifying ambiguity}

Being a multi-perspectives system, the information structure will also capture certain perspectives on information. This might result in ambiguousness of information. For mechanism this results in two possible consequences. First, the inputs required by mechanisms should be clarified and strictly defined as to prevent ambiguousness. Secondly, specific mechanisms could be established that should also be able to help signify any opposing or different meanings for the same piece of information. In combination 
with the views component of the workpiece engine, such mechanisms can be used to compare various alternative perspectives and the ontology could be used to signify the variants.

\section{Uncertainty linked to the veracity of information.}

In comparison with ambiguity, uncertainty in the context of the VUCA framework has a more converging character. It conveys the probability that with effort one can be more certain about something. In other words, uncertainty is strongly linked with the accuracy and trustworthiness of information. This is defined as the veracity of that information.

\section{Value range of information}

In accepting uncertainty, it should not only be mitigated but made instrumental. This bandwidth, common for all information types, is called the value range of information. The adage 'to be as sure as possible' is not advised, instead you might want to use 'to be sure enough'. The information workpiece enables an evaluation that aids in answering the latter question. In relating these concepts to mechanisms, volatility and uncertainty have an apparent influence for all mechanisms. Validity expressed whether or not an information entity can be used. Uncertainty is related to the veracity of the information. Ambiguity cannot be explicitly addressed as an aspect of information when considering mechanisms. As discussed, based upon the ontology of the workpiece, it can be attempted to signify (known causes for) ambiguity. However, it is considered not to be of use to incorporate the probability of ambiguity in every mechanism.

When combining volatility and uncertainty with the definition of a mechanism, one important additional aspect must be considered. The sensitivity of information relative to the used mechanism conveys the coherence between input, mechanism and output. Figure 8-7 shows a synopsis on the discussed aspects reflected in a mechanism.

Collectively, these aspects constitute the so-called value-range of information. As such mechanisms not only convey the content but simultaneously address the sensitivity, veracity and the validity of that information.

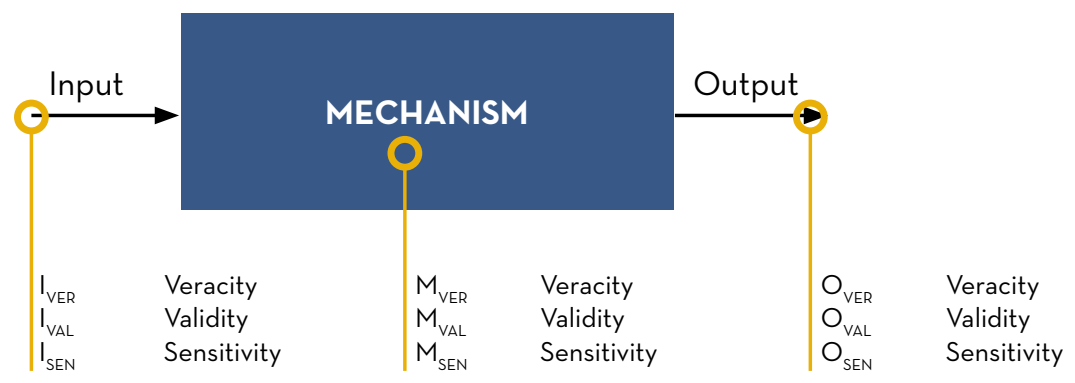

Figure 8-7 Aspects relating to the value range of information 
The coherence between veracity, sensitivity and the definition of a mechanism can be expressed as: $\mathrm{V}(\mathrm{O})=\mathrm{V}(\mathrm{M}) * \sum\left[\mathrm{V}\left(\mathrm{I}_{\mathrm{x}}\right) * \mathrm{~S}\left(\mathrm{I}_{\mathrm{x}}\right)\right]$

In which:

- $\quad \mathrm{V}(\mathrm{O})=$ Veracity output;

- $\quad V(M)=$ Veracity mechanism;

- $\quad V(I x)=$ Veracity input;

- $S(I x)=$ Sensitivity input;

Appendix E elaborates on this generic definition and illustrates how veracity can be expressed using reliability.

\section{Representing uncertainty}

That it should be possible to explicitly represent uncertainty is apparent considering the aspired aspects of workpiece usage. However, with what representation technique uncertainty should be expressed is not that easily determined. A common representation technique is to quantify the uncertainty as the probability of a certain event to happen within a scenario. This touches upon an entire scholarly field that practises all types of probability theories. This section discusses the aspect of using such measures for chance as an indicator for reliability.

There are several reasons to act carefully with using such representations for uncertainty. The information sources used for decision making must be suitable for the representation, information needs to be quantifiable and the type of uncertainty needs to be suitable for exact modelling. Each different representation technique based on math is posing different requirements on the used information. Whereas in the accompanied/ scholarly field these requirements and limitation are more or less accepted as a given, for the approach chosen in this research these limitations cannot be accepted for the entire structure as that would violate the very fundament of using the explicitly available information as starting point. A second reason to be careful with respect to quantifiable representation of uncertainty is the way mass interprets (non-experts) probability measures and the ease of misinterpretation. As it takes expert knowledge to model a situation before being able to calculate, it too requires a profound insight in how to interpret the percentages that result from math (Spiegelhalter, 2014).

As the envisioned design support is intended for a generic audience, caution must thus be practised when using expert techniques. However, taking into account the modularity of mechanisms, it is unwise to completely leave the representation unattended. For this reason, the concept of plausibility measures is worth mentioning (Halpern, 2001). Plausibility measures use the concept of relative likelihood to use non-numerical methods. As such, it can be considered a generalisation of uncertainty representation techniques that encompasses both numerical and non-numerical approaches. Therefore, plausibility measures are considered to be an interesting solution direction.

\section{Summary}

Mechanisms process their input while taking into account three properties of that input: veracity, validity and sensitivity. The veracity can be used to address the uncertainty and reliability of the subset of information available. The validity of information expresses the terms and conditions that may apply, e.g. an exchange rate for raw material prices, provisional information, or contextual boundaries that demarcate the legitimacy 
of the input. The mechanism itself also has a veracity property, relating to the level of repeatability, accuracy and reliability of the mechanism itself. For each mechanism, the interdependency between variables determines the sensitivity of each input. Uncertain input factors that highly influence the output, will have a higher impact on the accuracy of the outcome than uncertain input factors with a minor influence on the output. By making such interdependencies explicit, decision makers can much better determine the effectiveness of efforts to reduce the uncertainty of specific inputs.

\subsection{INTEGRATION OF MECHANISMS IN THE ACTOR NETWORK PROTOTYPE}

Both inputs and outputs are defined in a form of interconnected information that is compatible with the chosen actor network approach. This enables to match these predefined inputs and outputs of mechanisms with patterns in the ontology of a (information workpiece) network as illustrated in figure 8-8. Interestingly, the matching in- and output of a mechanism with patterns in the network in itself can be defined as a mechanism. By means of the ontology and the simple but strict syntax of mechanisms an interface between the toolset and the evolving information is created. This connection by no means devalues the flexibility of the network and does not enforce any specific rigorous structure. It simply enables a match between available information and avail-

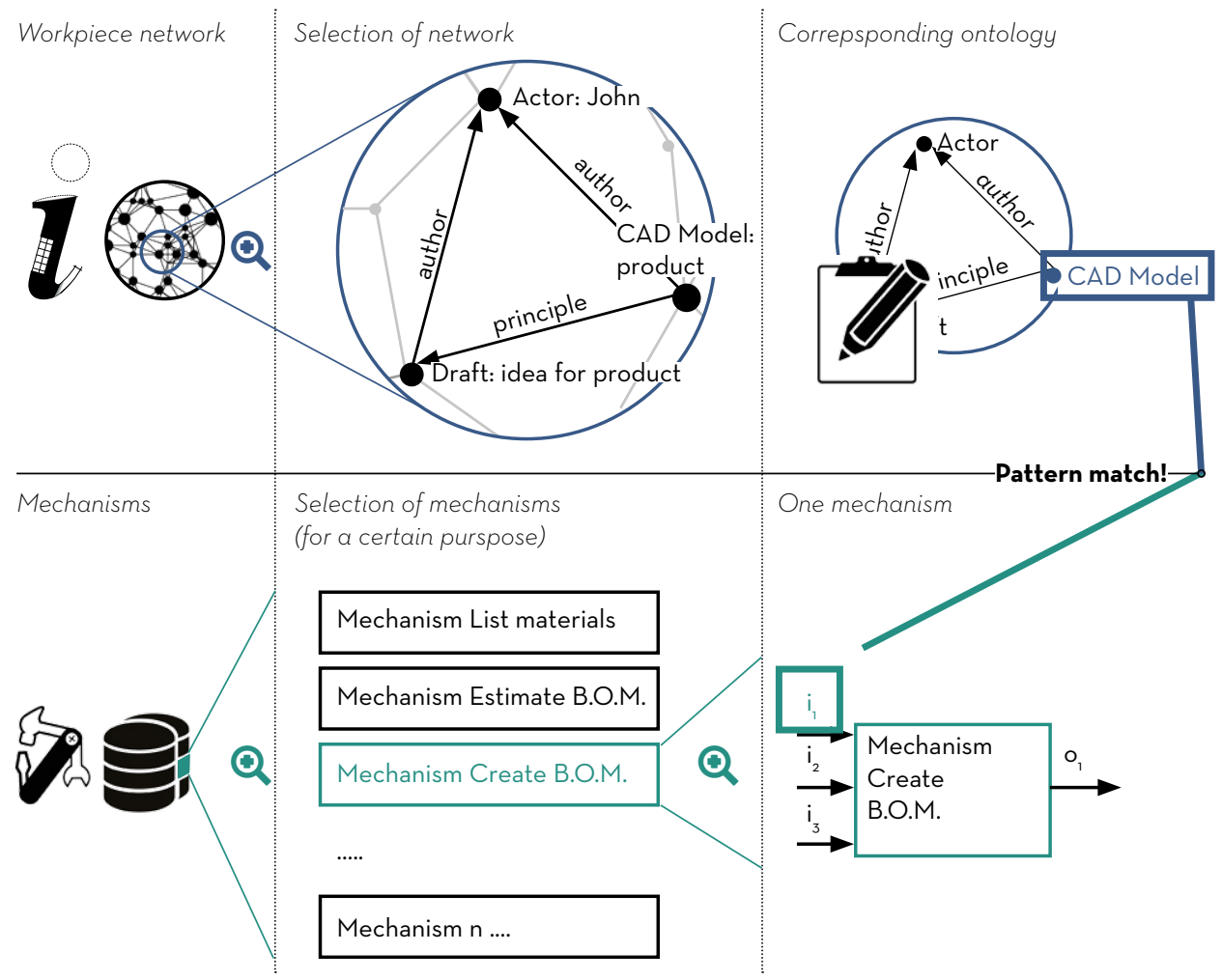

Figure 8-8 (simplified) illustration of identifying patterns. 
able mechanisms. If, for instance, the locations of two actors are known, the various transport options and the total distance can be determined by using mechanisms. If a material is known, properties such as the density can be determined. As such, these sets of mechanisms allow first rough estimates that aid in assessing the consequences of alterations, but can be build up to allow more advanced mechanisms.

For the prototype as used in the use case (section 7.4), this pattern matching is applied to suggest potential mechanisms to users of the system (figure 8-8). In this prototype, the execution of these suggested mechanisms is determined by the user, illustrating the principle functionality. Once a mechanism is chosen, a basic execution loop is activated in which the information inputs are selected from the network or, if unavailable or unclear, requested from the user; the information transformation is executed and the output is presented to the user and, if desired is processed in the network. In varying the involved parameters throughout a repetitive cycle of execution loops the effect of the output on the entire network can be assessed, illustrating the core functioning principles as defined in the future usage scenario (figure 8-9).

In the use case the influence of altering packaging material in a supply chain for a content/packaging combination was addressed, infused by environmental life cycle considerations. The resulting actor network clearly indicates the upheaval of relations

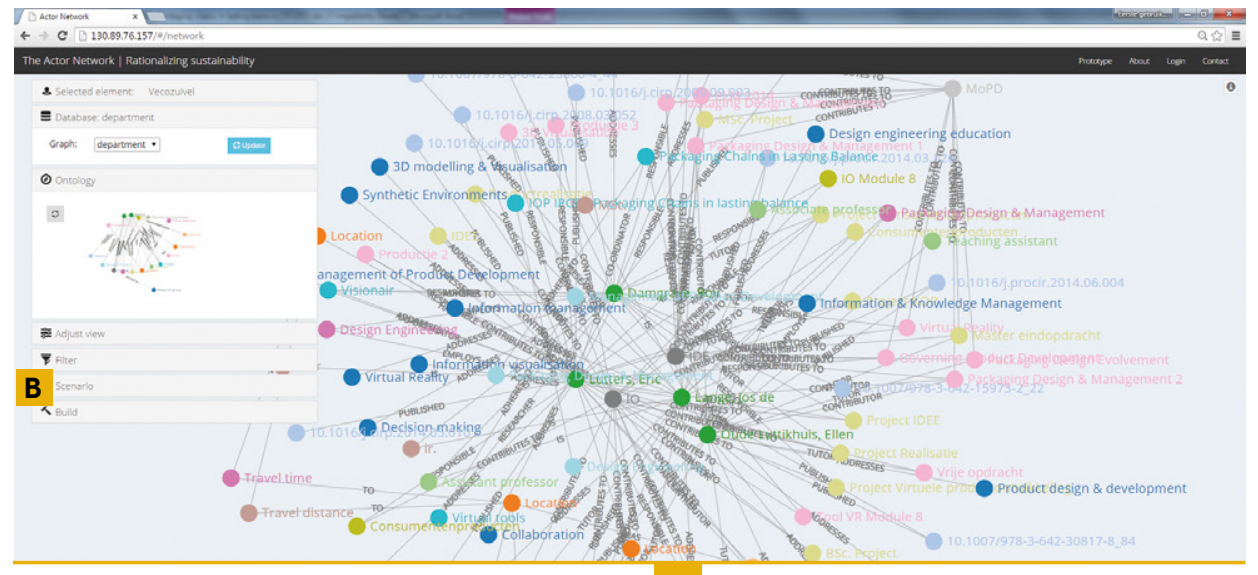

B Scenario

A Actor network

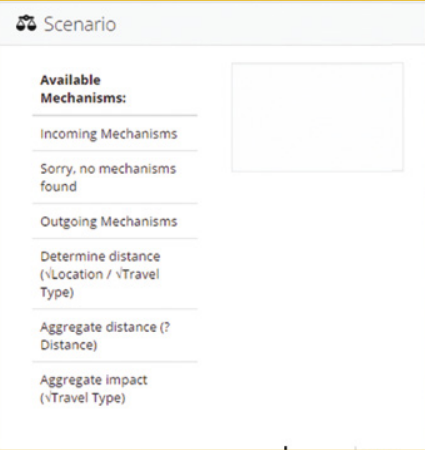

Figure 8-9 Mechanisms as integrated in the prototype 
between actors and the product definition when introducing the altered packaging material. The violation of requirements, (in)feasibility of alternatives, changed probabilities and variations of life cycle impacts is clearly indicated. An example is signalling incompatibilities between the packaging material and the recipe of the content, thus hinting at a change of that recipe.

\subsection{EVALUATION AND DISCUSSION}

This chapter has defined the concept of mechanisms as principle solution for the establishment of an interface with the information workpiece. This interface is tailored towards governing product development cycles while simultaneously allowing any type of evolvement.

The concept uses a straightforward but strict syntax in which every possible information tool is defined as one mechanism that has precisely defined inputs and outputs. How such a mechanism exactly converts these inputs into outputs is assumed to be deterministic, but need not exhaustively be defined within the concept, as long as the mechanism is available and its intent is clear. Whereas the definition of inputs and outputs is strict, this deterministic transformation process can take on any form. A mechanism can represent a relatively simple calculation or a complete software program using complex algorithms. As such, the concept of mechanisms caters for any type of evolvement.

Building upon the solution principle of the actor network, any input and output is expressed in a network structure. Combined with the suggested syntax, this ensures that mechanisms can be combined. This modularity allows to construct relative complex workflows that are build up out of a concatenation of mechanisms. These combined workflows collectively form a new mechanism. These more composite mechanisms are defined using the same syntax for singular mechanisms. As such, the concept of mechanisms does not prescribe any specific level of aggregation. As a result, mechanisms can cater for any desired tooling on the workpiece: whether this involves a simple conversion of metrics for one element, or a complex evaluation of the evolving product definition on technical specifications, involving hundreds of elements and relations.

Each mechanism - singular or composite - has a defined intent that conveys the purpose and rationale of the mechanism. Moreover, using the concept of value-range of information, this intent conveys the possible accuracy and reliability that the mechanism can achieve. As such, it is ensured that mechanisms can be paired with the information workpiece both on content as well as order of magnitude.

The value range of information is based on the effect of uncertainty on information and the coherence between the input, mechanism and output. Uncertainty is explicitly addressed as an aspect of information in an attempt to establish an information workpiece as a reference for the entire product development cycle. The vuca aspects have been translated into aspects of information where the focus is not on the exact quantification of such uncertainties but on the underlying coherence. As such, it can be determined which mechanisms, information inputs and outputs have an impact.

In this chapter one example based on the concept of reliability was outlined. However, this illustration should not be considered as the definitive manner of how uncertainty should be expressed. Depending on the context and environment, the veracity of 
information could well be addressed using a different concept, for instance quality. In recognizing the various types of uncertainty and the fact that not all uncertainty can be addressed in probabilities, the concept of plausibility measures that bundles a variety of representation techniques is an interesting research direction that seems to cater for consistency while allowing a versatile approach in representing uncertainty. While a logical or habitual tendency might be to 'measure' or calculate complex and hard-to-rationalise aspects, the recommendation here is not to put focus on these aspects first as this would only partly capture the potential of making uncertainty instrumental.

With the concept of mechanisms, focus is not put on the exact information transformation or on the full details of all possible information treatments. Rather, with mechanisms focus is put on a modular system of tooling, enabling a controllable yet flexible approach that caters for the diversity of all existing and future information tools. Moreover, the concept ensure that no information output goes without a value range, offering a way of explicating uncertainty and researching its potential impact.

With the definition outlined in this chapter, covering the syntax, intent, modularity and the value range, mechanisms offer the foundation to establish the required interfaces. Therefore, mechanisms are considered to offer a minimum viable solution to establish a tooling engine.

\subsection{CONCLUSION}

The solution direction for the required interfaces was found in making full use of computing power aiding the product developer in more deterministic choirs. This is done by so-called mechanisms: autonomous processes whereby information is generated. With mechanisms, a generic, general interface is defined that makes working with the workpiece possible. Mechanisms also enable to represent the effects of uncertainty.

To enable the use of a wide variety of (existing) tools in combination with the actor network, a modular and scalable approach is chosen. Mechanisms define these tools as process blocks that generate output from input variables (both quantitative and qualitative information). These mechanisms interact with the evolving information via the ontology. The abstract definition of mechanisms ensures a strict interaction with the network, each mechanism is called in the same manner for instance, while simultaneously the execution of the mechanisms and the definition of the mechanism itself is as flexible as possible.

Mechanisms provide the toolbox for any desired (future) tool or technique to be used on the information workpiece. For any evolvement of information, mechanisms are a means to express the expected $\Delta \boldsymbol{i}$ of deterministic decisions and address the value range of that output.

Mechanisms can be used to analyse consequences and help the user in determining the necessary information. Different mechanisms or combinations of mechanisms can be used to generate the same type of output. However, differences in required input variables and reliability of the output exist. By translating the necessary type of input variables into an effort and by indicating the reliability of the output, the user can choose the appropriate mechanisms for that moment. In some cases, a quick screening is sufficient, in other cases a more detailed and reliable analysis is needed.

The relevance of mechanisms does not only lie in the results they generate. As impor- 
tant is the fact that mechanisms also take into account the veracity of the outcome, while assessing the uncertainty of the variables used as well as the accompanying 'value bandwidth' of the outcome. Therefore, the use of the mechanisms can also be instrumental in determining the most relevant and influential variables. The mechanisms can aid in determining the most influential parts of a network or, in combination with ontology, hint at important information that is currently lacking. As such, it offers basic techniques to deal with the non-deterministic nature of the early phases of development trajectories and aid in overcoming the indefiniteness of used information in those phases.

In decision making, mechanisms are made instrumental in providing insight in the possible consequences. It enables using information as a workpiece and aids in making the (im-)possibilities, contradictions and gaps in the evolving product definition explicit. Evincing the uncertainties that underlie that information not only results in a more realistic representation, but simultaneously reveals the scope and margins of that information. Collating new, emerging information stemming from the decision under consideration with e.g. the requirement specification that reflects the achieved consensus, produces insight and fosters design acumen. This enables continuous awareness on the alignment between the intended purpose and the evolving product definition.

With mechanisms and the actor network the basic solution principles for the envisioned system have been defined. The next chapter elaborates on the content of this system, combining all elements of the information perspective as used in this thesis into a proposal for an architecture for content-driven design support. 



\section{ARCHITECTURE FOR CONTENT-DRIVEN DESIGN SUPPORT}

With the results of chapter seven and eight, the two basic constituents of the design(er) support system as stated in chapter six are available. Rudimentary speaking: the actor network can capture the evolving information content, and both actors and mechanisms can adequately master the evolvement of the information content. This chapter brings together these two concepts and uses it to define a so-called architecture that embodies the intended design support as defined in chapter six. This architecture obviously is an intermediary result in the overall process of establishing information-induced information systems. However, as it offers the blueprint for a wide variety of implementations, it also marks the end of this thesis. Based on the decision impact model, the actor network and mechanisms a delineation of functional specifications for the architecture is given and the architecture design is discussed. Moreover, out of the future usage scenarios described in section 6.4, three specific cases are elaborated to illustrate the (basic) usage of a system. Together with the architecture, these scenarios shoul function as the requirement specification for future research and development. 
Table 9-1 Recapitulation building blocks as defined in the previous chapters.

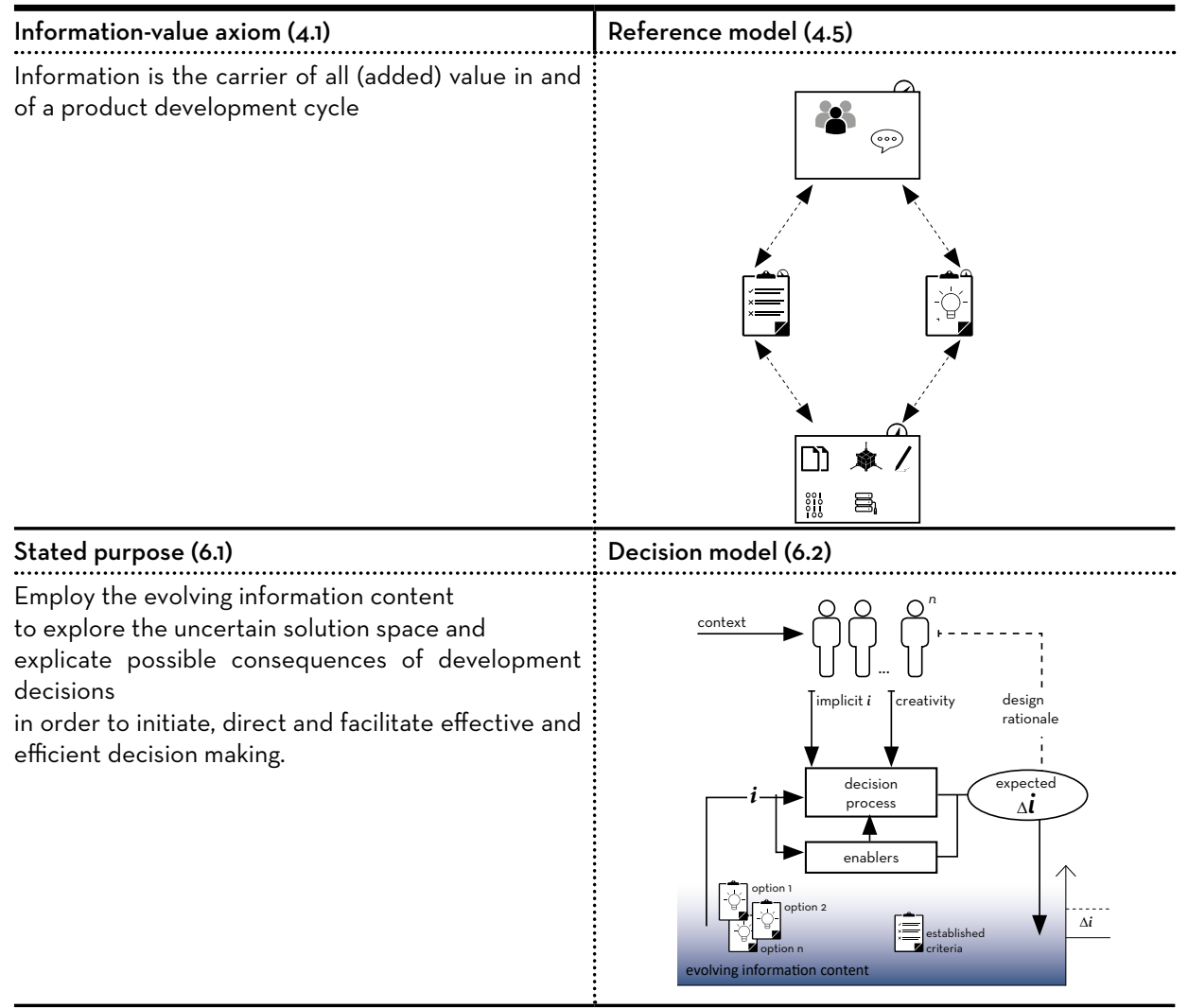

Workpiece engine (7)

Connect all explicitly available information

- Compatible with information sources

- Multi-perspectives system

Allow for meaningful access

- Capture context

- Structure and guide to structure

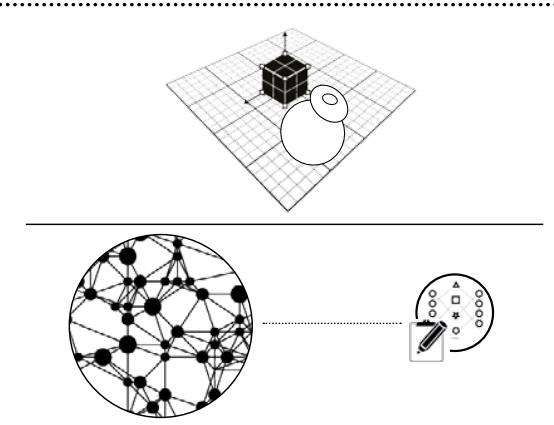

\section{Tooling engine (8)}

Allow any type of evolvement

- Allow all existing and future tools

- Allow combination of tools

Administer the establishment of information

- Create a controllable evolvement

- Explicitly address uncertainties

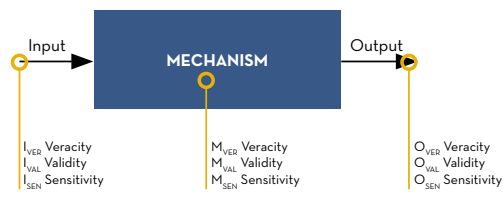


An architecture is a high level design in which that what is considered fundamental about the intended system is defined and embedded in its context (ISO/IEC/IEEE, 2011). As such, an architecture is a logical next step in defining design(er) support that is based on the information-value axiom. However, the architecture as presented in this chapter should not be regarded as a ready to use architecture for software development. This type of architecture is most definitely part of future work, but is considered to be beyond the scope of this thesis. Rather, the architecture should be read as an intermediary design proposal that synthesis all previously introduced solution elements and functionally defines the intended content-driven design support into modules and control principles. As such, the architecture combines all aspects previously defined building blocks into one coherent framework. Table 9-1 gives a synopsis of the solution components that have so far been identified and developed. The reference model (see section 4.4) has been used to elucidate the scenarios in section 6.4. For future use, the reference model can be used to scope the applicable environments in which the aspired design(er) support system should function. Similarly, the reference model and the decision impact model (see section 6.2) offer the context for the architecture. It is the purpose for the architecture to combine the two aspects of the system that are considered fundamental in offering the design(er) support: the workpiece and the tooling. In following the workpiece analogy (introduced in section 5.4), the architecture then offers a design proposal that functionally defines the intended design support. This blueprint should function as a starting point to further development, create and implement workbenches.

The two previous chapters have introduced the fundamental concepts in establishing both the workpiece and the instruments. With respect to the decision impact model, these concepts fill-in certain aspects. The actor network is considered to be a minimum viable solution to create the interconnected evolving information content that acts as the workpiece. The mechanisms in that sense do not cover one specific element of the model. Dependent on the implementation mechanisms offer tooling for a part of the enablers or can cover deterministic decision processes as well. Whichever application range for mechanisms is chosen, the mechanisms offer an interface that enables purposeful interaction with the workpiece. When the two fundamental concepts, are mapped on the decision impact model (figure 9-1, next page), the scope of the architecture becomes apparent. This combination offers a basic view of the context in which any future system based on this architecture has to operate. Obviously, the depicted actors are the (future) users. Each specific implementation will render certain sets of actors, each with specific needs and 'customer'-requirements for the system, captured by the actor demeanour as defined in the reference model. Apart from these implementation-dependent requirements, there are more generic actor requirements that should be considered. Important to highlight here is that respecting the aspects such as intuition and creativity are important prerequisites for the architecture design to adhere to the autonomy of a development team. Furthermore, whichever decision is made - a very simple, deterministic one performed by a mechanism or a complicated decision involving multiple actors, the workbench has some generic usage aspects. Whatever type of information evolvement is concerned, these aspects are considered to be fundamental and characteristic for the defined support. 
Figure 9-1 Scope of architecture.
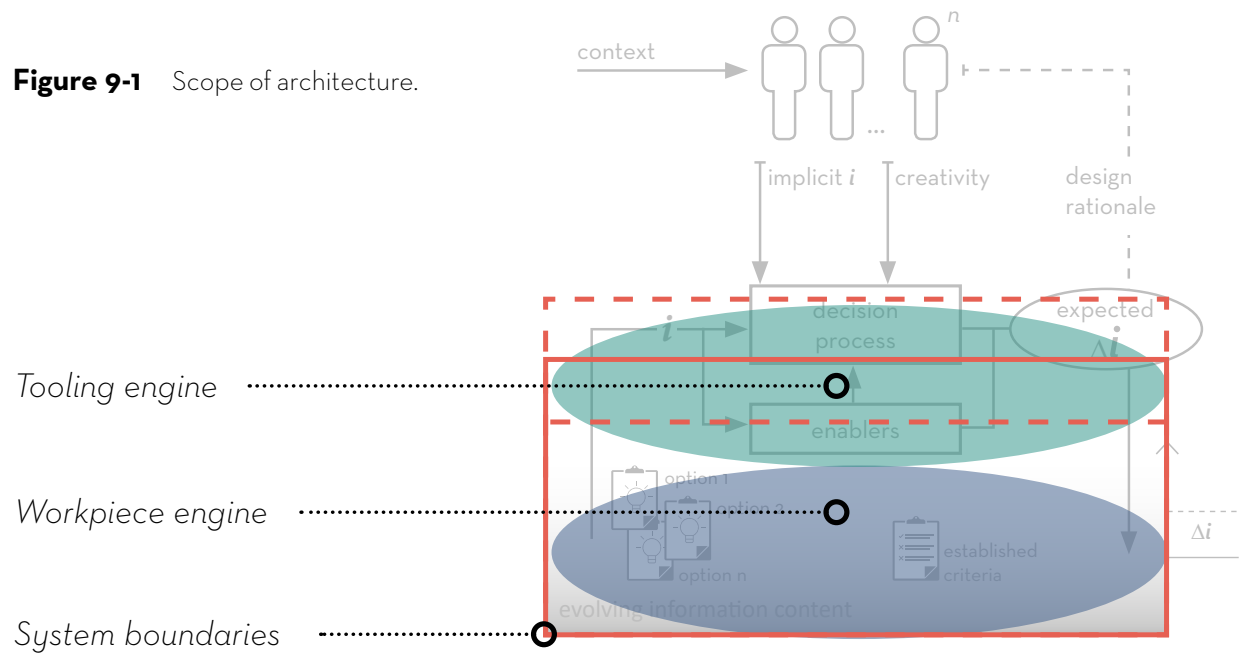

\subsubsection{Architecture requirements}

There is a large diversity in product development cycles: the type of products that are defined, the type of actors that are involved and the environment in which these development takes place can all vary significantly, as already outlined by the development situations in section 2.1. Since the approach has to be applicable for different types of organisations in the life cycles (from the manufacturer of materials to the company that recycles the waste) and thus many different types of products (roll of steel, cans, soup), a flexible design for the architecture is required. Consequently, the architecture should be suitable to construct a workbench for any type of product development cycle in any type of working environment. As such, its constitution should not be influenced by the number of users, systems or relative complexity that might be deduced from the development situations only. A workbench should maintain its efficiency and effectiveness independent of the size of the organisation or size of the project it is used in. Therefore, in using the architecture, a certain amount of flexibility and scalability is required.

The workbench should allow actors to play out various what-if scenarios in which variables and mechanisms can be changed to determine the effect of the expected outcome on the evolving information. By using computational speed in combination with the modularity of the mechanisms, such scenarios can be repeated innumerable times in which for instance a value of one input is gradually changed.

Both the workpiece and the expected $\Delta \boldsymbol{i}$ are available in a compatible format, in this case a network of entities and relations based on the actor network solution described in chapter six. If the output of a decision or mechanism is accepted the information workpiece logically is effected by the output and the consequences. In terms of the actor network this would mean that certain existing entities, relations or sub-networks will change of value, some entities and relations might disappear and new entities and relations are added. Furthermore, this evolvement might trigger subsequent mechanisms or decisions to become effective. Obviously, these evolvements are closely monitored. However, an important advantage of the information workbench is that such evolvements can be analysed before actually allowing the effect to materialise in the workpiece. A first and important base for this analysis is the ontology. Based on it, a number of potential relations, entities or contents can be derived. 
Second, in repeating a decision, patterns of the workpiece response can be characterised. For this, not only the information content is decisive, but the uncertainties are extremely important as well. A part of these uncertainties can be explicitly expressed as aspects of information. However, the architecture allows another way of using uncertainty. If uncertainty is an essential characteristic of any information entity or activity, this uncertainty will - in itself - carry meaning of that entity or activity. This implies that, just like an information entity can trigger an evolvement of the information content because of its denotation (see section 8.3), any uncertainty can trigger an evolvement in an analogous manner. When dealing with an abundance of uncertainties, or when uncertainties lead to ambiguousness rather than inaccuracies, it goes without saying that a purposeful strategy can be to disregard or neglect (types of) uncertainty. However, within a specific perspective and a specific aim, explicitly addressing uncertainties can be instrumental in evolving the information content. The simplest example is a situation in which an actor network almost literally contains a question mark: an entity is uncertain to such an extent that an answer cannot yet be formulated. With that, this uncertainty calls for a resolution, thus triggering either a mechanism or an actor to resolve this need for information. Obviously, an actor network flooded with question marks will ensure that the development cycle grinds to a halt. It goes without saying that, with the concept of information overload, the 'uncertainty overload' does clearly exist as well. There is, however, an important fundamental difference between how these two types of overloads can be met: information overload is often seen as something that can be overcome with brainpower or with sheer capacity, whereas uncertainty overload is usually seen as detrimental for the stability of the product definition or even the entire development cycle under consideration. The approach envisaged here aims to consider the different types of uncertainty as a neutral fact and aims to render uncertainty instrumental in the development cycle.

\section{$9.2 \quad$ ARCHITECTURE}

The architecture is a design of the information-induced product development support outlined in chapter six. It should be regarded as a proposal for a new type of design support that has its origins in the information value axiom introduced in chapter four. The architecture combines all previously introduced elements that together in principle enable the stated purpose and offers an addition and potentially an alternative for the design support methodologies discussed in chapter three. Based on the actor network and mechanisms the architecture allows to create workpiece of interconnected sources and tooling that enables the interaction. It strives to use the full potential of the information value while adhering to the required autonomy of product developers and regarding uncertainties neutral.

While the architecture forms the final design proposal of this thesis, the architecture should not be considered a final design. It rather should be understood as functional framework that forms the blueprint for building systems - or so-called workbenches for specific cases. The architecture describes the functional design of workbenches aimed at enabling the stated purpose. Such a workbench offers the environment to not only work on the product definition, but simultaneously use it to effectively and efficiently make decisions. 


\subsubsection{Basic components and structure}

The architecture has a modular structure in which each module offers a specific relatively independent task. Dependent on how and which modules are implemented, decision impact can be simulated, estimated (by users) and/or determined by the system. Whichever set of possibilities is chosen, there are three fundamental tooling categories to be distinguished: navigation, edit and administration. Each workbench combines the three tooling sets in combination with the workpiece. Therefore, the architecture has two sections: a workpiece section (indicated by the colour blue) and a tooling section (indicated by the colour green) as illustrated in figure 9-2.

Similar to tooling to hold or grasp (part of) a discrete workpiece such as a benchvice or a tongs, tooling is required to acquire a set of information entities. As such, tooling is required to navigate the information workpiece. This navigation covers the selection of information entities at a certain moment in time. With this navigation, is should also be recognised that this is always done from a certain viewpoint. In acknowledging the possibility and likelihood of multiple viewpoints on the same evolving product definition, navigation should also cover the perspective(s) on the selected information.

A second fundamental category of tooling is the actual editing of a workpiece that causes or creates an evolvement of information. It is the obvious tooling that often defines the craft of a craftsman, such as a chisel and (supportive) hammer for a sculptor. Here, the fundamental aspect of the decision, whether complex or fully deterministic, its required resources, the impact on how the potential effects should be assessed are important aspects to take into consideration.

The third category of tooling covers the administration of the performed activities and registration of users. While for an artisan such administration would be made by observation and memory alone, modern-day workshops offer a variety of 'logging systems' especially if processes are done autonomously. Consequently, for mechanisms, it is absolutely necessary to offer administration. This should cover the reporting about which set of tooling is used for which specific set of information under what circumstances. It should also cover the rationale of the expected activities on the workpiece and, the management that would result from such reports.

An overview of the architecture is given in figure 9-3, each section and module will be briefly discussed. For the core sections: workpiece, navigator and processor, each module is functionally defined.

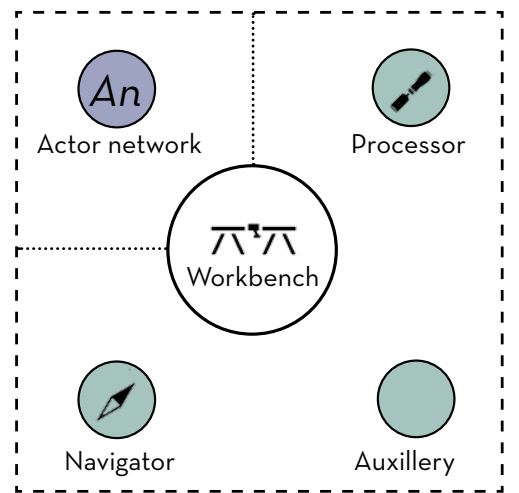

Figure 9-2 Basic elements of a workbench 


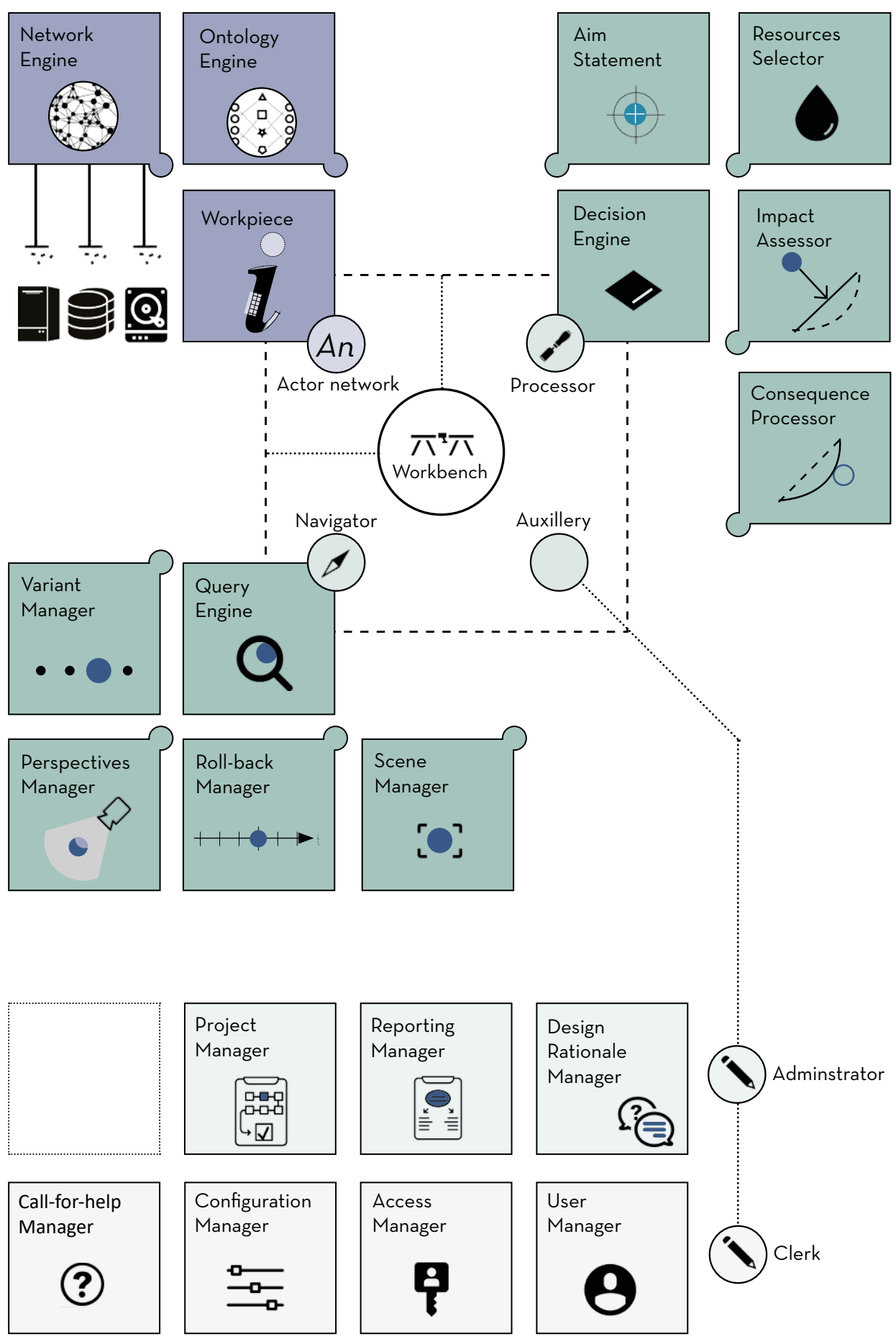

Figure 9-3 Overview architecture 


\subsubsection{Workpiece section}

The workpiece section is responsible for establishing the workpiece, one source of interconnected information. The resulting workpiece information network is enabled by a network engine and the ontology engine. The network engine is responsible for all methods enabling the network modelling language. Connecting to external sources. The ontology engine is responsible for capturing the rationale of any network structure. The workpiece network is the actual 'place' where the workpiece comes into existence, enabled by both engines. In summary, the workpiece section consists of the following modules:

- Network engine: provider of a graph-based representation that is capable of capturing all possible information structures and models.

- Ontology engine: captures the rationale of the network. It functions as a legend.

- Workpiece: the integrated collection of interconnected explicitly available information sources (enabled by both the network engine and the ontology engine), representing the product definition as well as the evolvement thereof.

\subsubsection{Tooling section}

The tooling for the workpiece covers three categories: navigation, editing and administration and registration/ administration.

\section{Navigator}

This tooling section provides all modules that allow access to the workpiece. Navigation is concerned with selecting the correct piece of the network. Which covers the perspectives manager, the variant manager, the track and trace manager and the query engine. Together with the workpiece network, this cluster of tools provide access to the information residing in the network. The perspectives manager focusses on how and in which context the information is represented. The variant manager assures the capability of dealing with variety in values of one entity or subgraph and as such allows the processing of repetitive workflows in which a multitude of varieties of one specific information entity can be sampled/ processed. The track and trace manager (roll back) captures the history of an entity or relation. It enables to roll-back or forward for information entities. The scene manager covers the context in which the information entity is viewed. In summary, the navigator section consists of the following modules:

- Query engine: establishes basic interaction between the workpiece and the users of the system

- Perspectives manager: creates views on the workpiece based on a specific set of information set in a specific context.

- Scene manager: establishes and coordinates the use contexts of the system and its users.

- Variant manager: controls versions and variants of information entities.

- Roll-back manager: enables to (re-)construct any previous (and potential future) state of the workpiece. 


\section{Processor}

With editing tooling the heart of the tooling section is addressed. Editing signifies all modules that conjointly allow for the actual change, establishment and evolvement of information. The aim statement gives direction to the editing process. Whether this is the strict intent of a mechanism or a set of aims in a multi-stakeholder decision making process. The mechanism engine offers a strict formulation and definition of the decision process. Based on this formulation the resource selector is responsible to make sure all required resources needed for the decision are available or, in case of shortage inform the user or operator. With a result (expressed in a subgraph) of the workpiece network, the impact assessor enables to explore how the decision affects the product definition. Whereas the consequence processor instigates future tasks and/ or actions that derive from the decision and its impact. In summary, the processor section consists of the following modules:

- Decision engine: modeller of any decision by means of applying mechanisms (as defined in section 8.3)

- Aim statement: establish the purpose of executing (a series of) decisions.

- Resource selector: identifies and collects the required resources for the decisions under consideration.

- Impact assessor: simulator of the effects the output of a decision (expected $\Delta \boldsymbol{i}$ ) on the workpiece (i)

- Consequence processor: monitor and/or controller of the actual establishment of outputs in the workpiece

\section{Auxiliary}

The final tooling cluster is not a complete set of modules as the other two clusters are. It covers two sections, an administrator section covering three modules that allow a certain degree of reporting, tailored towards managerial functions. And a registration section covering all modules that are involved with user management and settlement. For the administrator it is important to note that for now three modules are identified. However, additional reporting facilities in the future may require additional modules. The project management module is responsible for comparing decisions with previously established blueprints or schedules. The reporting manager logs events and offers a synoptic view of the activities of the system. Where the reporting manager offers more factual data on what has been achieved: The design rationale listener offers a comparable function on the why. The design rationale listener tries to capture any combinations of information entities that convey about the why. The assistance section acts as the reception for the support system and offers home to modules that somehow relate to the user: user manager, information access manager, configuration manager and callfor-help manager.

\subsection{SYSTEM CONSISTENCY}

Inconsistent behaviour of the workbench must be avoided. If one wants to use the evolving product information as the base upon which a development cycle can be managed, there should absolutely be no doubt or dispute possible about the workbench 
itself and its functioning. In other words, actors need to be able to fully rely on the workbench. Just as a workbench in a workshop should not break under the weight of the workpiece, the anvil should not deform as a results of impacts of the hammer and a bench-vice should not automatically release its beaks. Similarly, the workbench for the information workpiece should not show unpredictable behaviour. It is thus extremely important to have a consistency in performance, especially in product development where ambiguity, volatility and uncertainty could cause fragility.

This section reviews potential causes for fragility and explains how the architecture is designed to prevent such system responses.

\subsubsection{Potential causes for inconsistency}

\section{Avoid deadlocks and infinite loops}

In automated workflows, mechanism cause information evolvement that trigger other mechanisms. In this case system inconsistency could be caused by endless loops, if for instance two mechanisms result in information evolvement that trigger each other resulting in a continuous change in values for the same information entities without adding value. For the system to be consistent such deadlock activities need to be avoided.

\section{Invalid output}

In automated workflows of mechanisms, dependencies between mechanisms are a logical consequence. If the workbench however would not take these dependencies into account, such dependencies are potential causes for inconsistent behaviour and the possibility of or unreliable information caused by the workbench.

If for instance a mechanism would be able to automatically create a Bill-of Material based on assembly information in the workpiece, when would this information be updated? Or if one mechanism assigns materials to product parts and another lists all materials, when would the actor know how to trust the output of the latter?

If the workbench has no measures for determining the validity of the output, then no output could be trusted and would render the establishment of the workpiece inconsistent.

\section{Alignment}

To make sure mechanisms are used for the intend purposes, they are matched with information content based on the desired output. However, if only the type of output would be considered, mechanisms that mismatch the current status of the product definition might wrongfully become available. In a well-equipped workbench - fully integrated in the daily practise - it is possible that there are a lot of mechanisms that could cater for the same type of output in various degrees of quality and with various degrees of effort. In allowing a certain degree of autonomy there is a chance that mechanisms are enforced on the user that might be applicable for the type of information currently used, but is not suitable for the status. For example, the usefulness degrades if mechanisms are constantly enforced or even autonomously activated that do preparation choirs when the actual modelling in CAD has just begun. In its mildest form, this phenomenon would cause a potential nuisance amongst users. Furthermore, these mismatched mechanisms would cause a potential invalid information evolvement. Especially if a mechanism with high accuracy is used for information that has a high de- 
gree of uncertainty, this could even lead to information having a sense of certitude that cannot be justified. Consequently, the workbench should not only align mechanisms output with information type, it should align the accuracy of mechanism with the current status.

\subsubsection{Control principles}

\section{Communicate system boundaries}

In offering consistency, it is crucial to adhere to the limitations of using deterministic procedures. As such, system boundaries, when information is unavailable for instance should be clearly communicated.

\section{Timestamping}

The workbench needs to cater for a strict administration of activities. Based on this metadata, mechanisms can be used to: identify invalid information; assign a period of validity of information output; and/or rollback the entire workpiece to a desired past state. As such, the administration aspects of the mechanism are used to report on which mechanisms have been active for instance.

\section{Matching intent with content}

Using the value range of information as defined in section 8.4, the architecture caters for alignment between a collection of mechanisms and the information workpiece. In combination with the intent of a mechanism this offers the basic measures to avoid inconsistency in mechanism performance.

\subsection{SCENARIOS}

This section describes five future use scenarios ( figure 9-4, next page). Each scenario is based upon one or two development situations as described in section 2.1 and address the new 'workpiece' role of information and address several issues with information management as discussed in chapter five. The scenario functionally describes the desired workbench behaviour and elaborate on the themes addressed in the scenarios of the design brief in section chapter six.

The scenarios are intended to assess whether the architecture design proposal as described above matches the stated purpose as defined in chapter six. The scenarios fast forward to a future situation in which the workbenches are fully operational. The scenarios thus skip the actual system design and implementation of the design(er) support, in the context of these scenarios it is assumed that these are successfully been achieved. The reason to do so, is to use these scenarios as a validation of the functional design of the architecture. Therefore, for each described desired functionality in the scenario the architecture is evaluated. As such, the scope and limitations of the architecture are explored and the relevant importance of each module can be assessed. As such, these scenarios provide not a preliminary evaluation on the sensibility and applicability of the proposal developed in this thesis, they also provide input for future implementation studies. 


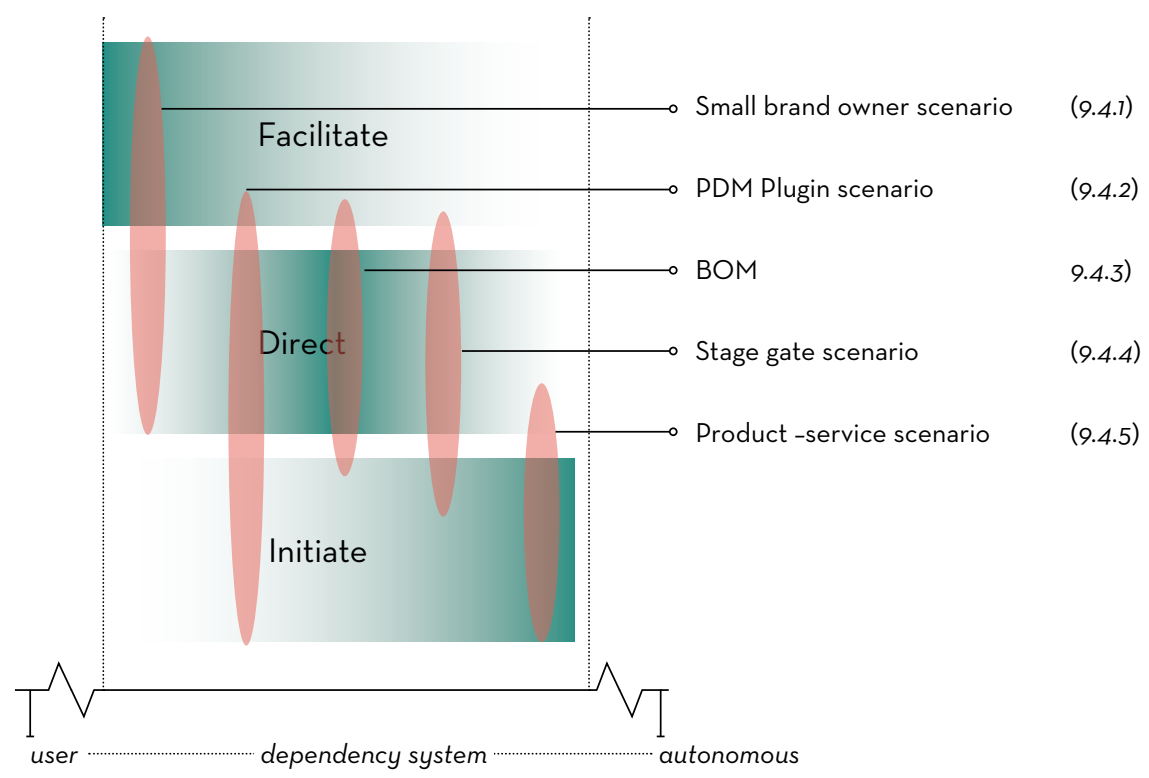

Figure 9-4 Overview of the five future use scenarios and the corresponding scope.

\subsubsection{Small brand owner scenario}

For a small brand owner, the envisioned workbench revolves around intricate decisions based on mostly unstructured information and (informal) communication. Associated documents are text-documents and presentations, that could be on a shared disk, personal computer system or only available as implicit information. This scenario is derived from the development situations based on retail and marketing as described in sections 2.1.2 and 2.1.4.

The key problem area for this brand owner is how to adhere to sustainability guidelines and pairing (rudimentary) lifecycle considerations with the biological infused legacy of the organisation and its brands. Being a relative small player that outsources all of its production to (first tier) co-packers and suppliers, the influence the company can exert is limited. For instance, an exact definition of the packaging material is hard to obtain or define as there is limited knowledge on these specific engineering topics. Topically, the responsibility is shared by the brand owner who relies on the knowledge and expertise of his suppliers (packed product) or the supplier's supplier (e.g. packaging material). As production runs are relatively small in comparison with established A-brands, demands for alteration on e.g. production lines are limited. On the other hand, the brand has a high visibility and is well-known amongst consumers. Therefore, its voice is one that cannot easily be ignored by retailers. Moreover, the organisational 
setup with suppliers allows them to relatively easily switch between suppliers for instance. And being at the forefront of the biological market segment, the organisation frequently pioneers with unconventional packaging concepts.

Here the workbench is focussed on fostering decisions on how to improve the sustainable performance of the product-packaging combinations using the packaging (components) as main variable. Based on the available information on the life cycle (based on the supply and retail chain) and information on packaging components, materials and decorations a workpiece is created that can serve as a base for sustainability issues. For instance, the information available can be used to create a so-called life cycle inventory to perform (environmental) life cycle analyses. Based on the quality of the information a variety of mechanisms are available ranging from guidelines evaluation, simplified LCA's to a full-fledged LCA based on expert software such as Gabi or SimaPro.

Based on the expected inputs of such mechanisms currently missing information or information that has the 'wrong' order of magnitude in terms of quality or accuracy can be determined. The user of the workbench can then choose to supply the additional information or to calculate using a mechanism, using generic substitute information derived from the ontology. Such a (simplified) LCA forms the basis to play out several scenarios in which the packaging components are (slightly) altered to determine the relative sensitivity and potential mutual causal relations. These examples of what-if scenarios could entail:

- What if a different supplier for the current packaging material is chosen?

- What if the biological guidelines for the food product would also apply for biobased materials?

- What if we skip a potentially superfluous packaging components?

The mutual relation between the evolving product definition and its (future) life cycle can be investigated. As with the change of a supplier, one could obviously explicate which aspects of the packaging and information in the network are affected. Moreover, in repeating such scenarios (using computing strength) users of the workbench can assess the influence of information. For instance, a user can determine how the overall quality of its output is improved when the material is defined more precisely (figure 9-5). In comparing the omission of one packaging component for instance, a cap for a drinking carton, not only the direct influence can be determined. The workbench also acts as an intermediary. As 'talking piece' the various viewpoints on the matter can be discussed and corresponding assumptions attempting to make the corresponding assumptions explicit while simultaneously making more implicit assets explicit. Form a lifecycle viewpoint losing the cap might have significant benefits. However, for the users of the pack, this obviously has some potential downsides in convenience and usability. Whereas the omission would allow an attention getter to explain the consumer the why.

Obviously, mechanisms can never replace such complex decisions. However relative simple mechanisms like various LCA's and various viewpoints can aid in playing out various what-if scenarios and mechanisms that aid in explicating certain viewpoints aid in finding, defending or defying argumentation and design rationale. Moreover, the completeness and indistinctness of the information that is available can be used to determine what to do next. 
Figure 9-5 Visual

synopsis small brand owner.

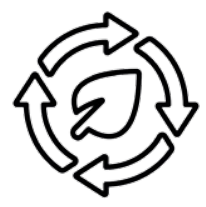

Figure 9-6 Visual synopsis PLM Scenario

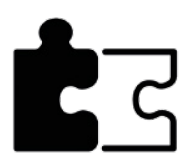

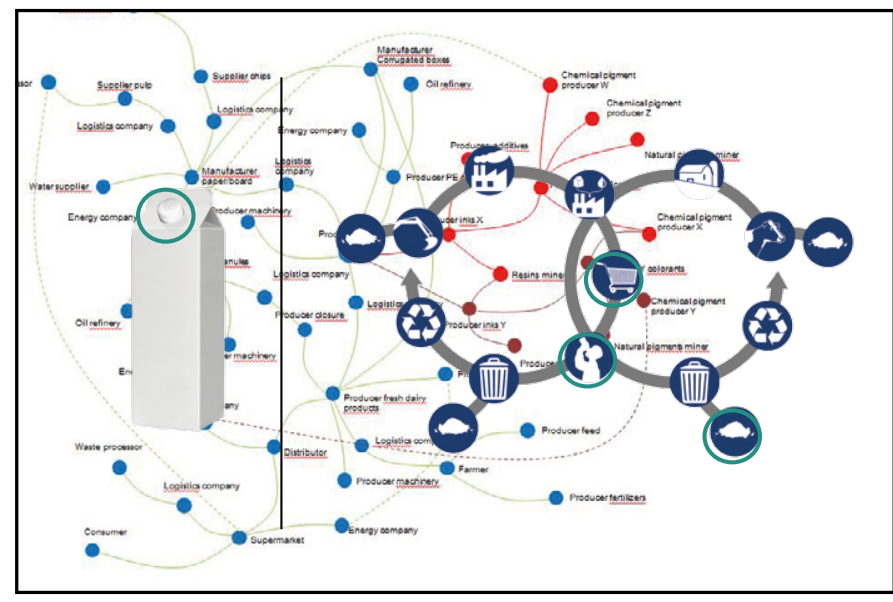

(i) AnWorkpiece 1.0

Reports

Today
4.0 Neutralized
0 threats
22 minutes ago
1 Pull Scan
1 month ago
Quick Scan
Never run

During last month

4 Neutralized

Q1 Full Scan

Q1 1 month ago

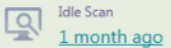

Vulnerablity Scan
Never run 


\subsubsection{PDM Plugin scenario}

This script is based on the engineering development situations (see sections 2.1.1 and 2.1.3) and is applicable if design engineering departments are already predominantly working with one dedicated system for CAD, PLM and or PDM. This scenario is tailored towards larger organisations, in which complex products such as machinery, cars, or airplanes are designed, engineered and manufactured by several teams, divided amongst several locations.

Here the workbench is not depicted as a standalone system but as an independent part or plugin of such a system. The workbench does not necessarily demand a prominent position in daily work situations, but predominantly acts as a scavenger in the background. This scenario highlights the strength of using combinations of relative simple mechanisms to guard and improve the consistency of the evolving product definition. Assuming that there is an elaborate collection of mechanisms available to execute relative simple tasks such as estimating a cost price, determining weight, determining production time etc. Based on this collection combinations of mechanisms can be used as automated workflows that run in the background or when actors do not use the PLM system. Relative simple mechanisms can be used to check for the validity of information. When for instance the modification date of an input parameter is more recent than the calculated outcome, the workbench can signal the user about the potentially out-dated information. Or the workbench automatically updates this information. Obviously to what extend the workbench automatically deals with what type of potential inconsistencies is adjustable dependent on the type of implementation.

Using meta-data on time and moderation, mechanisms can be used to check on invalid information. Based on the ontology, such automated workflows can be made flexible and hint an administrator on potential new mechanisms available to perform the same task but with different quality of input. And, if this process has been done and traced a significant period of time, the experience captured by the ontology can be used to create even more elaborate advice. The workbench for instance could request new information or a quality improvement based on which a set of new mechanisms would become available. Moreover, using standardised configurations what-if scenarios can be automated enabling e.g. sensitivity analysis on the workpiece. If new sources of information, e.g. data on use cycles of currently available products, are available, the same approach can be used to automate reports (figure 9-6) that in turn could feed dashboard software. As such this scenario illustrates the strength of using combinations of simple mechanisms to administer a diversity of control and check tasks.

\subsubsection{Bill of Material}

This scenario is intended for the later stages of development in which the product definition needs to be filed in systems such as ERP for the realisation and production of products. It is influenced by the development situations based on design engineering and marketing (see sections 2.1.1 and 2.1.2). As indicated in section 5.3.1., the influence of such systems can be significant or even dominate information management during product development cycles. The workbench for this particular case (figure 9-7) is focussed at eliminating the negative effects such as rigidity, prescriptiveness and lack of access and aid in harmonizing the transition from evolving product definition in development to a product definition information package based on which instantiations can be successfully produced. 
Figure 9-7 $\vee$ isual synopsis BOM Scenario

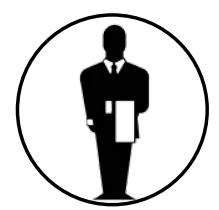

Figure 9-8 Visual synopsis Stage gate scenario:a heatmap of stage-related information

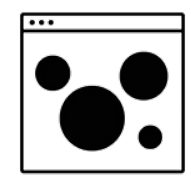

Figure 9-9 Visual Synopsis Product Service Scenario focussing on various perspectives.

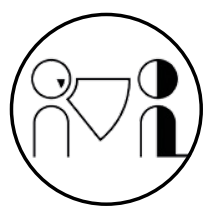

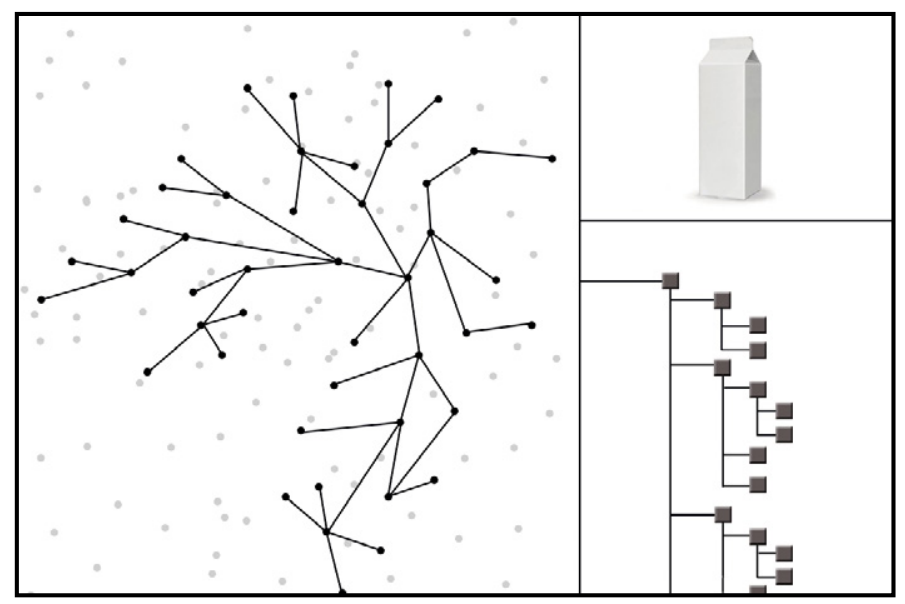
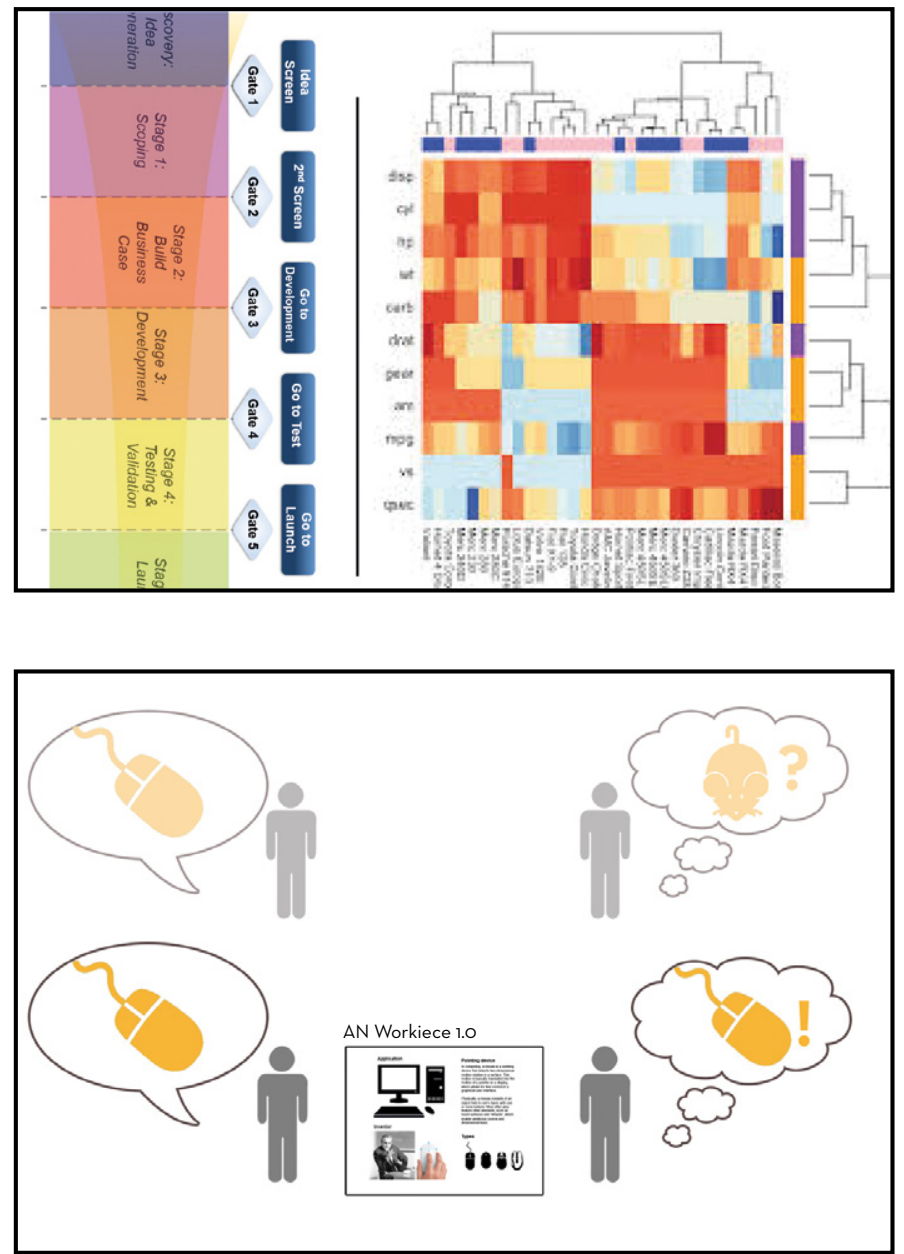
For this scenario the so-called Bill-Of-Material (BOM) is the backbone to fill the ERP system. This transformation process has several key moments in which evolving product information is translated into (more or less) rigid and frozen information in the ERP system. Each transition has a reservation for both new and existing article numbers once the components are determined and are not likely to change. In succeeding stages, the key idea is to fill in the required information from the product development domain into the production domain. However, practise shows that this process is not linear and always has several iterations in which article numbers are merged, new article numbers are required and already frozen information needs to be altered. Moreover, often the available information in these ERP systems is also needed as input in the development phase, especially when it concerns similar past products or information about production lines.

With the envisioned workbench supports the government of such transitions and enables a more versatile use of the information while trying to avoid the negative dominant influence. With mechanisms expressing the expected information in a structure and language suitable for ERP an evolving Bill of Material for instance can be used to evaluate its readiness for ERP implementation. With this comparison information gaps can be pointed at and the 'status' of the development cycle relative to the ERP standpoint can be made explicit. Based on this status the workbench can offer a number of functionalities. It could (aid) in identifying information subject that are currently lacking and suggest, if available, a number of mechanisms that can (partly) deliver/ output the required information. The status can be compared to similar already finished products and point at synoptic information about those projects and aid in more easily finding information resources, whether these are explicit or point at the actors that have worked on these projects. With such a transition phase supported by a workbench, the transition is not a linear one-way process, but it fosters the mutual exchange of information between two product life cycles phases: development and production. Information aspects based on existing articles and already processed information of editable information the specific organisation wants to allow. The workbench can help in signalling when decisions or future decisions looming might affect these restricted areas in the workpiece. Moreover, the decision to make such information areas restricted for 'development influence' can be assessed using the actual information content. Furthermore, the workbench can use the information content to actively instigate workflows for ERP when a certain threshold of reliability is met.

\subsubsection{Stage gate scenario}

This scenario is tailored towards design practise situations in which standardised procedural development approaches such as stage-gate are used. This scenario is partly based on the development stations based on design engineering and marketing (see sections 2.1.1 and 2.1.2).

For a large fast moving consumer goods company control and communication in research and development is governed by a standardised stage-gate procedure that compartmentalises the process in manageable chunks divided by formal checkpoints. Each phase has dedicated activities and deliverables. In line with these expected efforts, each phase also has dedicated resources for time, finances and man-power. Although in daily practise the stage-gate procedure is not necessarily used as strict as intended, the 
majority of involved actors have accepted the methodology as the agreed upon working approach. Project teams are around ten to twenty actors and led by both marketing and engineering representatives.

The workbench for this scenario is constructed to act as the counterpart of the formalised stage-gated procedure (figure 9-8, p170). It focusses on the comparison of the procedure with the actual information content. It enables assessments of the similarities and differences between the formal procedure and daily practise. As such, the workbench fosters improvement of the effectiveness and efficiency of decision making within the development cycles. Here the workpiece is strongly rooted in contextual meta-information such as author, dates on creation and modifications on the one hand and subjects and clusters of information on the other hand. In order to create an overview of who has worked on which information subject in a certain period of time. As such, based on the evolvement of information workpiece a so-called heat map (figure 9-8) can be constructed that can be used to control and steer the information evolvement. It is important to note that such an overview does not require significant effort to be maintained. The overview can be generated on the fly as a 'by-product' of having the workpiece available. Based on the formalised stage-gate procedure and for instance a project planning another view can be constructed and compared with the information heat map.

A direct benefit of having such an overlay available for the product development team is that in principle every actor involved can check who is working on what. Moreover, activities can be checked with the formalised procedure. If unexpected information subjects emerge, action can be taken to check, correct or adjust the plan. If for instance, important information subjects belonging to a next phase emerge before the formal gate has been passed, involved actors can be asked for motivation and either get the team back on the intended track or adjust the track.

A more mid-term advantage is the ability to create reports on entire development trajectories. Such reports could then be used to evaluate a project, compare projects and compare reality with the stage-gate model. In 'overlaying' the standardised procedure with the actual process of information evolvement, common hiatuses and outliers of both the model and the reality can be determined. This type of evaluation fosters the mutual alignment between daily practise and the agreed upon standard.

In the long run a much more flexible approach can be acquired by creating for instance suggestions for gate meetings when information is available and let the workbench pro-actively suggest future information requests based on the stat. Moreover, next to or even instead of working through a standard set of prescribed decisions, the workbench could highlight potential volatile decisions or uncertain information parts that have a large impact and potentially need attention. As such the power of stage-gated procedures can be combined with different working approaches without losing focus on the evolving information content. The workbench in this case is intended to foster continuous improvement and simultaneously keep stage-gate or any standardised procedure within their respective scopes, using them as tools in the development cycle and not as exalted methodologies for all development cycles. 


\subsubsection{Product -service scenario}

The scenario for the producer of office furniture in product-service combinations is based on the development situation (see section 2.1.5) Key subject in this scenario is the abundance of complex but required software suites such as CAD/CAM, PLM and ERP systems. Making matters more complex, it is not uncommon for the organisation to use different, potentially conflicting software programs within one domain. For instance, for CAD, the organisation is forced to use both architectural suites for office environments and buildings and CAD/CAM software for the definition of the furniture and production. The underlying models are not easily exchangeable, putting pressure on data management. Furthermore, the company is gradually shifting from a product-selling organisation to a product-service oriented organisation using smart technologies to capture data when furniture is in use, estimate when maintenance is needed.

The workbench in this organisation focusses on maintaining one workpiece that unifies all different sources of information and using this to explicate the relevant perspectives (figure 9-9, p170). It is expected to foster the data-management department in relieving a set of work and aid in explicating the dominant viewpoints to foster alignment in the product development cycles. First, all different models stemming from different sources and programs are captured in the network. Based on the ontology various models can be rendered as various instantiations of the same (evolving) product definition. While this unification does not influence the working habits in using the various programs, it does aid in efficient data management and can foster or guide necessary conversions from one program to another. Given that with past experience is partly captured using mechanisms. While initially this demands a significant involvement and investment in combining the various sources and standardise conversion procedures. With each mechanism however, the workbench automatically has new tooling available for everyone involved, and not solely for the ones that have the (personal) experience. Moreover, the reliability of these conversions are managed as well.

Based on the perspectives module and the ontology of the network can be scavenged to look for certain types, clusters or classifications of information. In fully exploiting the autorarchic characteristic of the workpiece network, the workbench can simultaneously create views on the evolving product definition, making these (explicit) views comparable and discussable. For instance, the client view based on a configuration software can be made comparable with the architectural studio's view and the engineering's viewpoint. In this case, these views are used to foster alignment and create a more efficient and effective overall workflow.

For instance, standardised procedures in the workshop can be aligned with the client's expectations by directing restricting the colour options to the available stock or to test if standard solutions that might fail certain strict technical customer demands are sufficient. Obviously, this alignment is unidirectional and the procedure in standardised modules can be changed according to (cumulative) customer demands. If for instance, the standard functional dimensions of (parts of) a product can be put in a range instead of having one explicit value. Addressing certainty and capturing ambiguity using perspectives in combination with the ontology is crucial to foster understanding and enables to explicitly capture a significant part of the rationale. 


\subsubsection{Preliminary contextual requirements}

The five scenarios as outlined in this section aim to illustrate and explore the added value of design support based on the proposed architecture. These scenarios are based on the design engineering situations as described in section 2.1, to ensure a fit with various product development practises. However, there is a second purpose these scenarios have. Collectively, these scenarios can be used to outline a basic set of contextual requirements for any initiative to realise an implementation based on the architecture.

In any such implementation initiative, a bottom-up approach should be used, rather than trying to establish the definitive, all-encompassing solution at once. As the architecture and corresponding design support approach are scalable, an implementation can initially focus on one key functionality or aspect of the content-driven design support, and can gradually adopt the full support opportunities. While the approach does advocate a new paradigm in offering design support, this does not automatically entail that this design support should be the only design support offered. In other words, there is no reason why this content-driven design support cannot be (temporarily or partially) combined with other approaches.

In anticipation of making scalable implementations, any new or altered functionality should be balanced against the required effort. For instance, in a development practise with highly sophisticated and standardised (digital) engineering software, the best strategy might be to devote implementation efforts to an add-on type of system rather than to yet another stand-alone application. In a development practise without such systems, the efforts required to reach added value for the actors involved is expected to be lower. Here, the challenges in implementation might rather stem from a substantial unavailability of explicit information sources. The extent of that unavailability (or even the unawareness thereof) may be such that that common sense easily prevails over any support system.

Consequently, any implementation strategy in a given environment will directly be related to the number, type, scope and consequence explicitly available information sources in that environment. While it is pointless to quantify such aspects of information sources, the occurrence and impact of information issues as defined in section 5.3 are instrumental in determining the suitability for implementation.

\subsection{CONCLUSION}

With the architecture defined in this chapter, the two constituents of the design(er) support system have been combined in a blueprint that has all the necessary modules to cater for the stated purpose as defined in chapter six. With the architecture, the actor network as described in chapter seven and the mechanisms as defined in chapter eight are no longer stand-alone principle solutions, but are put to use in the context of supporting product development cycles. Together, the actor network and mechanisms form the fundamental concepts upon which the architecture is based.

The architecture is meant to be used as a blueprint for all types of implementation, covering the development situations described in chapter two and the corresponding scenarios outlined in chapter six. To illustrate the potential usages and benefits of the information-induced design(er) support based on the architecture, basic system configurations have been outlined for five specific scenarios. As such these scenarios 
continue where the scenarios in chapter six stopped. In other words, the black box systems in chapter six - putting focus on the purpose and desired behaviour - have now been (partly) replaced by desired system design behaviour. It concretises the design of the new support based on the information value axiom presented in chapter four. It illustrated how the evolvement of information can be used to govern a product development cycle. The mechanisms in this offer the formalised syntax to systematically construct and execute what-if scenarios. These scenarios offer a wide range of possibilities. For instance, facilitating multi-stakeholder decision making by e.g. making potential consequences of decision and the various perspectives on the information explicit. Based on the same workpiece-mechanism construct, routine tasks can be executed by the system (in various degrees of autonomy - ranging from simple calculating tasks, building up to fully automatic workflows.

The architectural design anticipates on the potential non-deterministic aspects of product development. It offers a consistency by controlling principles. Preventing a system from showing unintended or unpredictable behaviour, which ever non-deterministic aspects are at play. For each scenario, making uncertainty and its potential effects explicit is what lies at the heart of the approach. As uncertainty inevitable plays an important but often impalpable role in product development trajectories, this approach offers tools to explicitly address uncertainty as an aspect of information and simulate potential effects of various types of uncertainties on the product definition. As such, the architecture offers a set of tools that aim to make uncertainty instrumental. 



\section{CHAPTERTO \\ CONCLUSIONS \\ AND RECOMMENDATIONS}

\subsection{CONCLUSIONS}

This thesis has resulted in an architecture for content-driven design support for the government of product development cycles. With it, a new type of design support is proposed that is based on the actual (and evolving) status quo in any product development cycle. Contrary to the basis of most design method(ologie)s, the architecture is not based on collective expert knowledge clenched into a predominantly prescriptive process or an assumptive deep understanding of how designers work, or how they descript the design process. Rather, the architecture starts from the daily practise of any product development cycle. Remarkably, this stance points at a gap in the field of design theory and methodology.

The architecture intends to form a starting point for developing implementations of content-driven design support in which information functions as the so-called workpiece of product development cycles. Based on the information-value axiom in which information is defined as being the carrier of all added value of in and of that cycle, the architecture manifests information as pivotal in this support. With the basic concepts of an interconnected system of information sources and a controlled and versatile interaction framework, the architecture ensures that any (type of) implementation uses the evolving information content as the basis to initiate, facilitate and direct effective and efficient decision making.

The solution direction has a strategic purport. In this, the architecture should be understood as a proposed design to establish stepping stones for content-driven design support. As such, this thesis advocates a new design support paradigm in which product development is recognised as a balance between deterministic and non-deterministic disciplines. Moreover, information is recognised as the key for versatile support that is suitable for a broad range of product development cycles in a variety of environments.

To illustrate why this architecture is regarded as a new concept in design support that has the potential to fill the hiatus in DTM, it is best to revisit the initial situation sketch as described in the introduction chapter of this thesis. This sketch addressed a key decision moment somewhere in the middle of a product development cycle aimed to determine a concept direction; it encompasses several actors, incomplete information and significant amounts of uncertainty.

With the proposed architecture a so-called information workpiece with a corresponding workbench and tooling is introduced in the sketch. Together they aim at supporting effective and efficient decision making. With the architecture, design support focusses in the entire set of information available - with all incompleteness and un- 
§ 1 Introduction

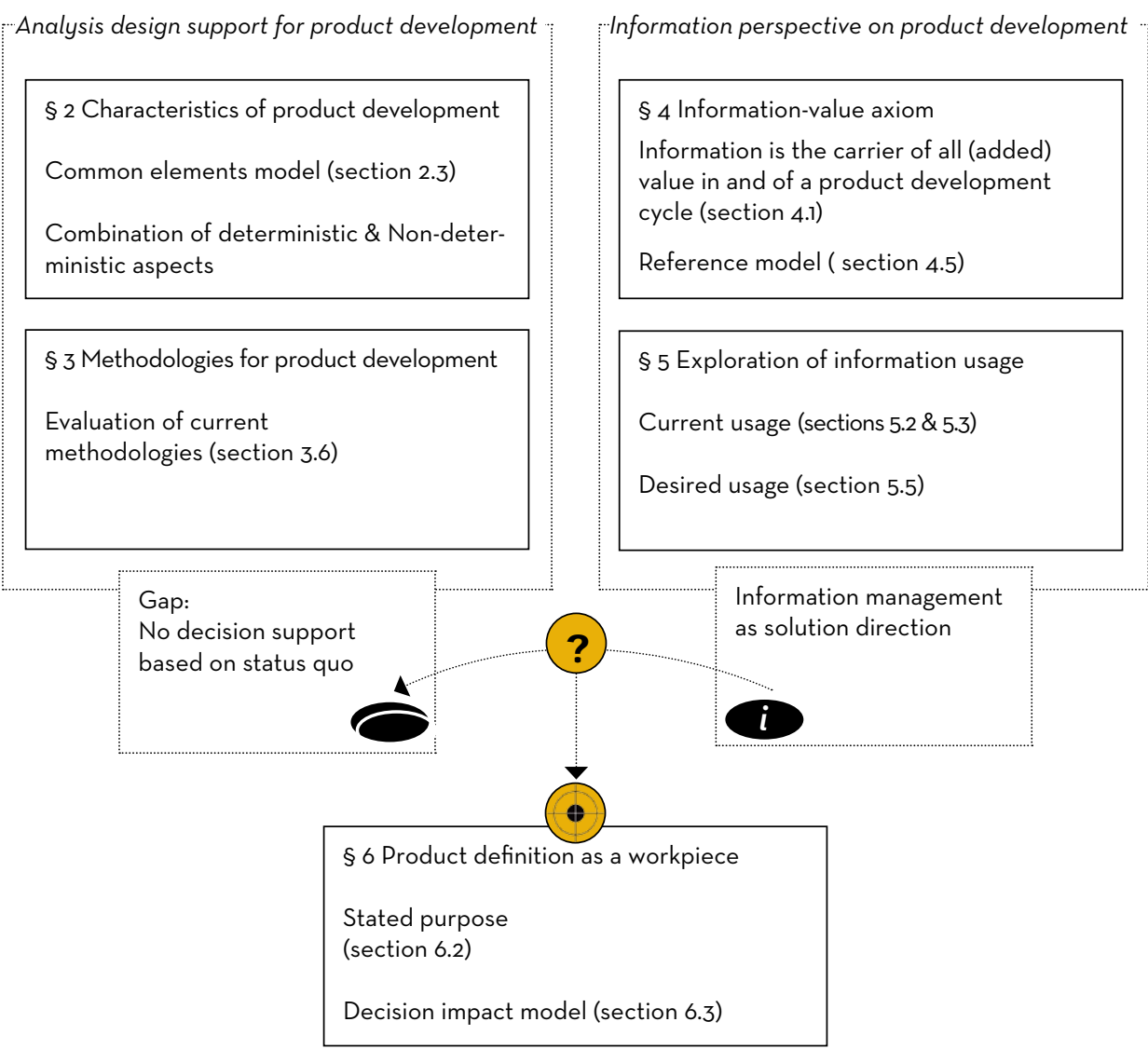

Solution principles

$\S 7$ Actor network as workpiece engine

$\S 8$ Mechanisms as tooling engine

Actor network (7.4) to establish workpiece

Mechanisms (8.4 \& 8.5) to establish tooling

§ 9 Architecture for content-driven design support

Architecture for

content-driven design support

$\S 10$ Conclusions \& recommendations

Figure 10-1 Synopsis of this thesis. 
certainty involved. Out of all separate sources one so-called information workpiece is established. Just as with any other workpiece, the consequences of decisions manifest in this information workpiece. This workpiece-characteristic is fully exploited in order to support the development team in making these consequences explicit. Other than physical workpieces, the information workpiece comes with undo-functionality and as such, allows for example for simulating the consequences of any decisions before they materialise.

These consequences of decision are modelled as an expected or envisaged evolvement of the entire product definition that comes with or results in a certain impact. The architecture enables to explicitly address this impact. As such, it enables the (automatic) enactment of what-if scenarios, making the repercussions on the information workpiece explicit.

The information workpiece aims to be at the centre of the discussions and important decision processes. It will not necessarily make a decision easier to make, nor will it make information less incomplete or make uncertainty disappear. Rather, it accepts these aspects as inevitable consequences of product development and give product developers meaningful ways to deal with these aspects. It uses the available information on the product definition to its full extent and defines new functionalities for information that enables users to govern the development cycle while working at the product definition.

\section{Contributions}

The overview in figure 10-1 shows a synopsis of this thesis. It uses the same structure as outlined in the introduction (see figure 1-2). Instead of a colour characterisation based on analysis, synthesis and evaluation (as used in the introduction), it highlights the relevant contributions of each chapter and references back to the corresponding sections of the thesis.

The core contribution of this research is a design approach for content-driven design support. This design proposal consists out of the following building blocks:

- The information-value axiom used as starting point for reasoning about this new type of design support.

- The reference model that defines an information perspective on product development

- The decision impact model that defines a new principle of design support that models each output of a decision as an intended $\cdot$ i. This links any decision back to the information workpiece. In other words, the output of any decision within a product development cycle should be captured and represented in the information workpiece.

- The two solution principles: the actor network for the information workpiece and mechanism as tools to establish the desired design support interface.

- The architecture synthesises all previously mentioned aspects into a blueprint for developing content-driven design support. This exhibits the required core functionalities of the content-driven design support as well as the required core control principles. 
As singular contributions, each of these building blocks should not be regarded as a new scientific contribution. Each building block is based on well-established principles and previous scientific work. It is the application to design theory and methodology and the product development practise that makes these contributions unique and meaningful. Collectively, the building blocks construct the original contribution of this research: to support product development cycles via information on the evolving product definition.

\section{Added value}

In comparison with traditional formal approaches in DTM, content-driven design support has advantages that interlock with trends in digitization in product development and manufacturing, multi-disciplinary product development teams and the incorporation of life cycle engineering aspects.

The design proposal is deemed suitable for any product development practise. The starting point for design support is the evolving product definition instead of a certain accepted standard working approach within a certain field of disciplines. This starting point or base is established by the information created by the involved actors themselves. In other words, it starts from the languages and jargon spoken, written and used in product development practice by the many different stakeholders, whereas it does not impose any other language or make one language dominant. This makes this type of design support suitable for multidisciplinary design, regardless of which disciplines are exactly involved and which information is involved and which languages are spoken.

The proposed design approach respects the autonomy of involved actors - it even start from that sovereignty. It does not give actors instructions on what to do or how to do it, rather it shows the (potential) consequences of their decisions as the impact on the information workpiece. This is based on the assumption that explicating these consequences of design decisions gives insight for the involved actors so they can improve the development cycle. Consequently, this type of design support does not emphasize or presuppose any straitjacket of certain prescribed procedures, but presupposes that the actors involved are the experts to determine the course of actions. In explicating the potential consequences, the intent is to exploit the purport of uncertainty instead of trying to mitigate its potential negative effects.

This entails freedom and a responsibility that suits the autonomy that product developers need to deal with, both considering the deterministic and non-deterministic aspects that characterise product development cycles.

\section{Towards a new design support paradigm}

The architecture spurs content-driven design support that offers an addition to - or a potential alternative for - process-driven design support as a means to govern product development. The architecture is tailored towards both the deterministic and the non-deterministic aspects of product development in which the autonomy of product developers is respected and encouraged in order to become instrumental. It uses an approach in which uncertainty is recognised as being instrumental in explicating the potential evolvement of a product definition, the consequences of decisions and the exploration of any solution space.

For now, this does not overthrow the way in which products are developed, but it 
does substantiate an understanding of decision accuracy, reliability and sensitivity. This already allows for a change in how designers are supported in reaching decisions on the short term. In the long run, however, using the information workpiece as the pivot of development cycles can open up new possibilities in product development, for example by new ways of using PLM, CAD and other tools in development cycles.

\subsection{RECOMMENDATIONS}

This thesis has addressed the core concepts for content-driven design support, using a development cycle as the research director, resulting in an architecture. Developing this industrial design engineering architecture into an architecture for software systems is regarded as one of the first logical next steps, in which the involvement of disciplines in software engineering and computer science is considered indispensable. Therefore, a logical next step would be to consider the requirements for and trajectory towards actual implementation. There are a multitude of possibilities - each of the described scenarios described in chapter nine could feed more than one project proposal on its own for an implementation study of the architecture. Detailing any of such proposals would neither be instrumental nor effective but be disproportionate; even more, it would not do justice to the generic nature of the architecture.. However, there are three recommendations that are considered essential in furthering this research:

- Depict two or more extreme usage situations per scenario

- Establish the relation between the information workpiece and digital twin representations of products

- Address educational implications of content-driven design support

\section{Two extreme usage situations per scenario}

To prevent implementation studies from becoming individualistic endeavours and to ensure an overall coherence between different implementation studies and the architecture, the following approach is recommended. Each implementation study should incorporate at least two extreme usage scenarios (figure 10-2). The first is a usage sce-

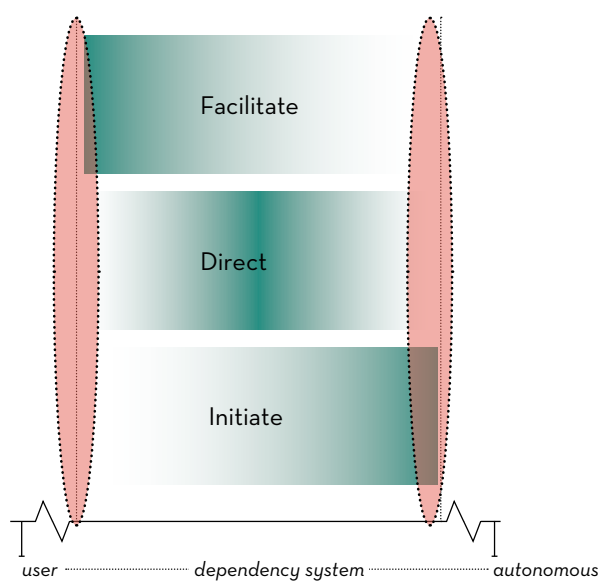

Figure 10-2 Two extreme use scenarios for implementation 
nario in which the expected input of users is relatively high. The second is a situation in which a system automatically initiates most of the decisions. While it is expected that such implementations do not render a solution in which the added value of the architecture fully blossoms, it does allow for better determination of the possibilities and limitations of the information-induced design support in various specific industry settings. Pairing these extreme usage situations with implementation studies is expected to improve the quality of the implementation.

\section{Relation with digital twin}

The principle solution for the information workpiece uses a network modelling approach towards information management. As the concept of the information workpiece is based on a reference model in which various development systems can be characterised from an information perspective, the concept has a strong connection with the concept of digital shadows or digital twins. The combination of the network approach with an a-posteriori-determined ontology and the views concept offering versatile and meaningful access to information has potential beyond a product information workpiece alone. The principle solutions as defined in this thesis are therefore considered to be potential enablers for establishing and enriching digital twins. Considering the relevance of this topic, it is recommended to have a key focus on this theme in implementation studies - especially in combination with the introduced PLM scenarios. The amalgamation of the network approach with digital twins can be seen as so-called synthetic environments; not only being a suitable context for such studies but also has the potential of shortening iteration cycles and improving the impact thereof. A synthetic environment allows versatile simulations of the above described scenarios without the need to fully develop or engineer the solutions. Simultaneously, synthetic environments offer a versatile discussion space in which all stakeholders can actively participate and contribute to the solution and implementation study (Damgrave, 2017).

Educational implications of content-driven design support

Although not being a central theme in this research, education is a relevant future direction of research. As concluded in the analysis of current design methodologies for product development in chapter three, design support stemming from the field of Design Theory and Methodology has had a dominant influence on the establishment of product development curricula such as Industrial Design Engineering. Moreover, this design support played a significant role in providing students with a toolbox that enables them to master the discipline of product development.

The information perspective on product development as defined in this thesis will offer relevant and purposeful additions to these curricula. For instance, the information-value axiom together with the reference model could be used as a theoretical treatise, underpinning the importance of information in a development cycle and in addressing the balance between deterministic and non-deterministic aspects of product development. In depicting the core of product development as a continuously evolving product definition, this work could support understanding of how to actively use a requirement specification as a continuously evolving core reference document for decision making in product development, valuing design rationale over impeccable formulation. 


\section{Education as part of research}

The department of Design, Production and Management at the University of Twente has always had the good habit of combining (masters) education with research. As such, it would be inconceivable if education would not play an important part in the future research on the topic of content-driven design support.

Using principles such as project-led education and just-to-late teaching (W. Dankers, Schuurman-Hemmer, van den Boomgaard, \& Lutters, 2013), education purposes can be combined with research objectives. For instance, as the start of implementation studies, a course in which students get acquainted with the fundamentals of the information-induced design support can be combined with an assignment in which solutions are developed based on the architecture proposed in this thesis. 



\section{REFERENCES}

Adams, K. (2015). Design Methodologies. 28, 15-43. doi:10.1007/978-3-319-18344-2_2

Ahmed, S., Blessing, L., \& Wallace, K. M. (1999). The relationships between data, information and knowledge based on a preliminary study of engineering designers. Paper presented at the ASME Design, Theory and Methodologie, Las Vegas, Nevada.

ALA Glossary of Library and Information Science. (2013). (M. Levine-Clark \& T. M. Carter Eds. 4th ed.). Chigago: ALA

Albers, A., Sadowski, E., \& Marxen, L. (2011). A New Perspective on Product Engineering Overcoming Sequential Process Models. In H. Birkhofer (Ed.), The Future of Design Methodology (pp. 199-209). London: Springer London.

Allard, S., Levine, K. J., \& Tenopir, C. (2009). Design engineers and technical professionals at work: Observing information usage in the workplace. Journal of the American Society for Information Science and Technology, 60(3), 443-454. doi:10.1002/ asi.21004

Andreasen, M. M., Hansen, C. T., \& Cash, P. (2015). Conceptual Design.

Aurisicchio, M., Bracewell, R. H., \& Wallace, K. M. (2012). Characterising the information requests of aerospace engineering designers. Research in Engineering Design, 24(1), 43-63. doi:10.1007/s00163-012-0136-y

Badke-Schaub, P., Daalhuizen, J., \& Roozenburg, N. (2011). Towards a Designer-Centred Methodology: Descriptive Considerations and Prescriptive Reflections. In H. Birkhofer (Ed.), The Future of Design Methodology (pp. 181-197). London: Springer London.

Badke-Schaub, P., \& Frankenberger, E. (2004). Design Representations in Critical Situations of Product Development. In G. Goldschmidt \& W. L. Porter (Eds.), Design Representation (pp. 105-126). London: Springer London.

Bayazit, N. (2004). Investigating Design: A Review of Forty Years of Design Research. Design Issues, 20(1), 16-29.

Berlow, E. L. (1999). Strong effects of weak interactions in ecological communities. Nature, 398, 330. doi:10.1038/18672

Berlow, E. L., Neutel, A.-M., Cohen, J. E., De Ruiter, P. C., Ebenman, B., Emmerson, M., Petchey, O. (2004). Interaction strengths in food webs: issues and opportunities. Journal of Animal Ecology, 73(3), 585-598. doi:10.1111/j.0021-8790.2004.00833.x

Biemans, F. P. M. (1989). A reference model for manufacturing planning and control. PhD Thesis.

Biemans, F. P. M., \& Vissers, C. A. (1989). Reference model for Manufacturing Planning and Control Systems. Journal of Manufacturing Systems, 8, 35-46.

Birkhofer, H. (2011). The future of design methodology. Conference Proceedings. London: Springer London. 
Blessing, L. T. M., \& Chakrabarti, A. (2009). DRM, a Design Research Methodology. London: Springer-Verlag.

Boisot, M., \& Canals, A. (2004). Data, information and knowledge: have we got it right? Journal of Evolutionary Economics, 14(1), 43-67. doi:10.1007/s00191-003-0181-9

Bonnema, G. M. (2008). Funkey architecting : an integrated approach to system architecting using functions, key drivers and system budgets. (PhD.), University of Twente, Enschede.

Browning, T. R. (2001). Applying the design structure matrix to system decomposition and integration problems: a review and new directions. IEEE Transactions on Engineering Management, 48(3), 292-306. doi:10.1109/17.946528

Buckland, M. K. (1991). Information as thing. Journal of the American Society for Information Science and Technology.

Chandrasegaran, S. K., Ramani, K., Sriram, R. D., Horváth, I., Bernard, A., Harik, R. F., \& Gao, W. (2013). The evolution, challenges, and future of knowledge representation in product design systems. Computer-Aided Design, 45(2), 204-228. doi:10.1016/j. cad.2012.08.006

Chen, Y., Zhao, M., Xie, Y., \& Zhang, Z. (2015). A new model of conceptual design based on Scientific Ontology and intentionality theory. Part II: The process model. Design Studies, 38(C), 139-160. doi:10.1016/j.destud.2015.01.003

CIRP Encyclopedia of Production Engineering. (2014). In L. Laperrière \& G. Reinhart (Eds.), CIRP Encyclopedia of Production Engineering (Vol. I). Berlin Heidelberg: Springer-Verlag.

Coad, P., \& Yourdon, E. (1990). Object-oriented analysis. Englewood Cliffs, NJ: Prentice Hall.

Cooper, R. G. (1990). Stage-gate systems: A new tool for managing new products. Business Horizons, 33(3), 44-54. doi:10.1016/0007-6813(90)90040-I

Cooper, R. G. (2001). Winning at New Products: Accelerating the Process from Idea to Launch, (3rd edition ed.). Reading MA: Perseus Books.

Cooper, R. G. (2008). Perspective: The Stage-Gates Idea-to-Launch Process-Update, What's New, and NexGen Systems. Journal of Product Innovation Management, 25.

Crilly, N. (2010). The Structure of Design Revolutions: Kuhnian Paradigm Shifts in Creative Problem Solving. Design Issues, 26(1), 54-66.

Crilly, N., Maier, A., \& Clarkson, P. J. (2008). Representing artefacts as media: Modelling the relationship between designer intent and consumer experience. International Journal of Design, 2(3), 15-27. doi:http://dx.doi.org/10.1108/17506200710779521

Cross, N. (1993). Science and Design Methodology : A Review. Journal of Engineering Design, 63-69. doi:10.1007/BFo2032575

Cross, N. (2006). Designerly Ways Of Knowing. London: Springer Verlag.

Cross, N. (2011). Design thinking:understanding how designers think and work. Bloomsbury Academic, London.

Culley, S. J. (2014). Revisiting Design as an Information Processing Activity. In M. M. Andreasen, T. J. Howard, \& H. P. L. Bruun (Eds.), An Anthology of Theories and Models of Design (pp. 173-195). 
Dankers, W. (2014). What-If Design. In L. Laperrière \& G. Reinhart (Eds.), CIRP Encyclopedia of Production Engineering (pp. 1310-1311). Berlin, Heidelberg: Springer Berlin Heidelberg.

Dankers, W., Schuurman-Hemmer, H. M., van den Boomgaard, A., \& Lutters, E. (2013, 2013). Bringing practice to the theory: Project-led education in Industrial Design Engineering. Paper presented at the Proceedings from the 2nd International Conference for Design Education Researchers.

Design council (2006). The Design Process: What is the Double Diamond? Retrieved from https://www.designcouncil.org.uk/news-opinion/design-process-what-double-diamond

De Koeijer, B., De Lange, J., \& Wever, R. (2017). Desired, Perceived, and Achieved Sustainability: Trade-Offs in Strategic and Operational Packaging Development. Sustainability, 9(10), 1923.

De Lange, J., Oude Luttikhuis, E. J., \& Lutters, E. (2014). Networked Design Decisions in Balanced Life Cycles. Paper presented at the 24th CIRP Design Conference, Milano, Italy. http://www.scopus.com/inward/record.url?eid=2-s2.0-84915807829\&partnerID=tZOtxzy1

De Lange, J., Oude Luttikhuis, E. J., \& Lutters, E. (2016). Incertitudes in design decisions - impediments or instruments? Paper presented at the COMA International Conference on Competitive Manufacturing, Stellenbosch, South Africa.

De Lange, J., Oude Luttikhuis, E. J., ten Klooster, R., \& Lutters, E. (2013). Towards Integrating Sustainability in the Development of Product/Packaging Combinations. Paper presented at the CIRP Design conference, Bochum, Germany. http://link. springer.com/10.1007/978-3-642-30817-8

Dirken, H. (1997). Productergonomie: ontwerpen voor gebruikers. Delft: Delft Academic Press.

Dorst, K. (2011). The core of 'design thinking' and its application. Design Studies, 32(6), 521-532. doi:10.1016/j.destud.2011.07.006

Dorst, K., \& Cross, N. (2001). Creativity in the design process: Co-evolution of problem-solution. Design Studies, 22(5), 425-437. doi:10.1016/S0142-694X(01)00009-6

Drukker, J. W. (2003). De Revolutie die in haar eigen staart beet. Utrecht: Lemma.

Erbuomwan, N. F. O., Sivaloganathan, S., \& Jebb, A. (1996). A survey of design philosophies, models, methods and systems. Proceedings of the Institution of Mechanical Engineers, Part B: Journal of Engineering Manufacture, 210(4), 301-32O.

Es-Soufi, W., Yahia, E., \& Roucoules, L. (2016). On the Use of Process Mining and Machine Learning to Support Decision Making in Systems Design. In R. Harik, L. Rivest, A. Bernard, B. Eynard, \& A. Bouras (Eds.), Product Lifecycle Management for Digital Transformation of Industries: 13th IFIP WG 5.1 International Conference, PLM 2016, Columbia, SC, USA, July 11-13, 2016,

Esterhuizen, D., Schutte, C. S. L., \& du Toit, A. S. A. (2012). Knowledge creation processes as critical enablers for innovation. International Journal of Information Management, 32(4), 354-364. doi:https://doi.org/10.1016/j.ijinfomgt.2011.11.013

Farrell, R., \& Hooker, C. (2015). Designing and sciencing: Response to Galle and Kroes. 
Design Studies, 37, 1-11. doi:10.1016/j.destud.2014.12.003

Finger, S., \& Dixon, J. R. (1989a). A Review of Research in Mechanical Engineering Design. Part I: Descriptive, Prescriptive, and Computer-Based Models of Design Processes. Research in Engineering Design(1), 51-67.

Finger, S., \& Dixon, J. R. (1989b). A review of research in mechanical engineering design. Part II: Representations, analysis, and design for the life cycle. Research in Engineering Design, 121-137.

Fu, K. K., Yang, M. C., \& Wood, K. L. (2016). Design Principles: Literature Review, Analysis, and Future Directions. Journal of Mechanical Design, 138. doi:10.1115/1.4034105]

Galle, P. (2009). The ontology of Gero's FBS model of designing. Design Studies, 30(4), 321-339. doi:10.1016/j.destud.2009.02.002

Galle, P., \& Kroes, P. (2015). Science and design revisited. Design Studies, 37, 67-72. doi:10.1016/j.destud.2014.12.005

Gericke, K., Kramer, J., \& Roschuni, C. (2016). An Exploratory Study of the Discovery and Selection of Design Methods in Practice. Journal of Mechanical Design, 138. doi:10.1115/1.4034088]

Gero, J. S. (1990). Design prototypes: a knowledge representation schema for design. Al Mag., 11(4), 26-36.

Gigerenzer, G., \& Gaissmaier, W. (2011). Heuristic decision making. Annual review of psychology, 62, 451-482. doi:10.1146/annurev-psych-120709-145346

Glattfelder, J. B., \& Battiston, S. (2009). Backbone of complex networks of corporations: The flow of control. Physical Review E, 80(3), 036104.

Halpern, J. Y. (2001). Plausibility measures: a general approach for representing uncertainty. Paper presented at the Proceedings of the 17th international joint conference on Artificial intelligence - Volume 2, Seattle, WA, USA.

Hatchuel, A., \& Weil, B. (2003). A new approach of innovative design: an introduction to $c-k$ theory. Paper presented at the International Conference on Engineering Design (ICED), Stockholm.

Hatchuel, A., \& Weil, B. (2009). C-K design theory: An advanced formulation. Research in Engineering Design, 19(4), 181-192. doi:10.1007/s00163-008-0043-4

Hauser, J. R., \& Clausing, D. (1988). The House of Quality. Harvard Business Review, May/June, $63-73$.

Haverkort, B. R., \& Zimmermann, A. (2017). Smart Industry: How ICT Will Change the Game! IEEE Internet Computing, 21(1), 8-10. doi:10.1109/MIC.2017.22

Heisig, P., Caldwell, N. H. M., Grebici, K., \& Clarkson, P. J. (2010). Exploring knowledge and information needs in engineering from the past and for the future-results from a survey. Design Studies, 31(5), 499-532. doi:10.1016/j.destud.2010.05.001

Hertzum, M. (2014). Expertise seeking: A review. Information Processing \& Management, 50(5), 775-795. doi:http://dx.doi.org/10.1016/j.ipm.2014.04.003

Hertzum, M., \& Pejtersen, A. M. (2000). The information-seeking practises of engineers: searching for documents as well as for people. Information Processing \& Management, 36, 761-778. 
Horváth, I. (2004). A treatise on order in engineering design research. Research in Engineering Design, 15(3), 155-181. doi:10.1007/s00163-004-0052-x

Howard, T. J., Culley, S. J., \& Dekoninck, E. (2008). Describing the creative design process by the integration of engineering design and cognitive psychology literature. Design Studies, 29(2), 160-180. doi:https://doi.org/10.1016/j.destud.2008.01.001

ISO/IEC/IEEE. (2011). 42010-2011 - Systems and software engineering - Architecture description. In: IEEE.

Kahneman, D. (2003). A perspective on judgment and choice: mapping bounded rationality. The American psychologist, 58(9), 697-720. doi:10.1037/0003-066x.58.9.697

Kals, H. J. J., \& Lutters, D. (1998). The role of information management in intelligent manufacturing. Paper presented at the Proceedings of the CIRP international seminar on intelligent computation in manafacturing Engineering (ICME 98), Capri, Italy.

Kennon, D., Schutte, C. S. L., \& Lutters, E. (2015). An alternative view to assessing antifragility in an organisation: A case study in a manufacturing SME. CIRP Annals, 64(1), 177-180. doi:https://doi.org/10.1016/j.cirp.2015.04.024

Khan, S., Kanturska, U., Waters, T., Eaton, J., Bañares-Alcántara, R., \& Chen, M. (2016). Ontology-assisted provenance visualization for supporting enterprise search of engineering and business files. Advanced Engineering Informatics, 30(2), 244-257. doi:http://dx.doi.org/10.1016/j.aei.2016.04.003

Kitamura, Y., \& Mizoguchi, R. (2004). Ontology-based systematization of functional knowledge. Journal of Engineering Design, 15(4), 327-351. doi:10.1080/0954482041 0001697163

Klooster, R. (2002). Packaging Design: A methodological development and simulation of the design process. (PhD.), Delft,

The Knowledge Graph. Google Inside Search. Retrieved from https://www.google.com/ intl/es419/insidesearch/features/search/knowledge.html

Krishnan, V., \& Ulrich, K. T. (2001). Product Development Decisions: A Review of the Literature. Management Science, 47(1), 1-21. doi:10.1287/mnsc.47.1.1.10668

Kryssanov, V. V., Tamaki, H., \& Kitamura, S. (2001). Understanding design fundamentals: How synthesis and analysis drive creativity, resulting in emergence. Artificial Intelligence in Engineering, 15(4), 329-342. doi:10.1016/So954-1810(01)00023-1

Latour, B. (2005). Reassembling the social - An introduction to Actor-Network-Theory. Ocford University Press, Oxford.

Le Masson, P., \& Weil, B. (2013). Design theories as languages of the unknown: Insights from the German roots of systematic design (1840-1960). Research in Engineering Design, 24(2), 105-126. doi:10.1007/s00163-012-0140-2

Lowe, A., McMahon, C., \& Culley, S. (2004). Characterising the requirements of engineering information systems. International Journal of Information Management, 24(5), 401-422. doi:http://dx.doi.org/10.1016/j.ijinfomgt.2004.06.008

Lutters, D., \& Klooster, R. t. (2008). Functional requirement specification in the packaging development chain. CIRP Annals - Manufacturing Technology, 57(1), 145-148. doi:10.1016/j.cirp.2008.03.052 
Lutters, D., \& Van Houten, F. J. a. M. (2013). Ambiguity and uncertainty of Requirements in Product Development. COMA'13; International Conference on Competitive Manufacturing.

Lutters, D., Vaneker, T. H. J., \& van Houten, F. J. A. M. (2004). 'What-if' design: a synthesis method in the design process. CIRP Annals, 53(1), 113-116. doi:https://doi. org/10.1016/So007-8506(07)60657-X

Lutters, E. (2001). Manufacturing integration based on information management. (PhD) University of Twente, Enschede.

Lutters, E. (2014). Design Methodology. In L. Laperrière \& G. Reinhart (Eds.), CIRP Encyclopedia of Production Engineering (pp. 386-388). Berlin, Heidelberg: Springer Berlin Heidelberg.

Lutters, E., Dankers, W., Oude Luttikhuis, E. J., \& De Lange, J. (2014). Network based requirement specification. CIRP Annals - Manufacturing Technology, 63(1), 133-136. doi:10.1016/j.cirp.2014.03.095

Lutters, E., van Houten, F. J. a. M., Bernard, A., Mermoz, E., \& Schutte, C. S. L. (2014). Tools and techniques for product design. CIRP Annals - Manufacturing Technology, 63(2), 607-630. doi:10.1016/j.cirp.2014.05.010

Marca, D. A., \& McGowan, C. L. (1987). SADT: Structured Analysis and Design Technique. New York, NY, USA: McGraw-Hill, Inc.

McAlpine, H., Cash, P., \& Hicks, B. (2017). The role of logbooks as mediators of engineering design work. Design Studies, 48, 1-29. doi:10.1016/j.destud.2016.10.003

Miedema, J., van der Voort, M. C., Lutters, E., \& van Houten, F. J. A. M. (2007). Synergy of Technical Specifications, Functional Specifications and Scenarios in Requirements Specifications, In: Krause FL. (eds) The Future of Product Development. Springer, Berlin, Heidelberg

Mol, A. (2010). Actor-Network Theory: sensitive terms and enduring tensions. Kölner Zeitschrift für Soziologie und Sozialpsychologie. Sonderheft, 50, 253 - 269. doi:urn:nbn:nl:ui:29-374993

Morse, E., Dantan, J.-Y., Anwer, N., Soderberg, R., Moroni, G., Qureshi, A., Jiang, X. J. (2019 (tbp)). Tolerancing: managing uncertainty from conceptual design to final product. CIRP Annals.

Nieberding, F. H. M. (2010). Selecting and Tailoring Design Methodologies in the Form of Roadmaps for a Specific Development Project. (PhD.), Stellenbosch University, Stellenbosch.

Nonaka, I., \& Takeuchi, H. (1995). The Knowledge Creating Company. New York: Oxford University Press.

Oude Luttikhuis, E. J., De Lange, J., Lutters, E., \& ten Klooster, R. (2015). Evolving Product Information in Aligning Product Development Decisions across Disciplines. Paper presented at the 22nd CIRP conference on Life Cycle Engineering, Sydney, Australia. http://www.sciencedirect.com/science/article/pii/S221282711500089X

Oude Luttikhuis, E. J., De Lange, J., Ten Klooster, R., \& Lutters, E. (2014). Project-led Education in Packaging Development and Management. Paper presented at the 24th CIRP Design Conference, Milano, Italy. http://www.sciencedirect.com/science/article/pii/S2212827114006660 
Pahl, G., Beitz, W., Feldhusen, J., \& Grote, K.-H. (2007). Engineering design: a Systematic Approach. Springer-Verlag London, 10.1007/978-1-84628-319-2

Raharjo, H., Brombacher, A. C., \& Xie, M. (2008). Dealing with subjectivity in early product design phase: A systematic approach to exploit Quality Function Deployment potentials. Computers \& Industrial Engineering, 55(1), 253-278. doi:https://doi. org/10.1016/j.cie.2007.12.012

Reed, N., Scanlan, J., Wills, G., \& Halliday, S. T. (2011). Knowledge use in an advanced manufacturing environment. Design Studies, 32(3), 292-312. doi:10.1016/j.destud.2010.10.002

Reich, Y. (1995). A critical review of General Design Theory. Research in Engineering Design, 7(1), 1-18. doi:10.1007/BF01681909

Reich, Y. (2010). My method is better! Research in Engineering Design, 21(3), 137-142. doi:10.1007/s00163-010-0092-3

Riel, A., Neumann, M., \& Tichkiewitch, S. (2013). Structuring the early fuzzy front-end to manage ideation for new product development. CIRP Annals - Manufacturing Technology, 62(1), 107-110. doi:10.1016/j.cirp.2013.03.128

Robinson, M. A. (2010). An empirical analysis of engineers' information behaviors. Journal of the American Society for Information Science and Technology, 61(4), 640-658. doi:10.1002/asi.21290

Robinson, M. A. (2012). How design engineers spend their time: Job content and task satisfaction. Design Studies, 33(4), 391-425. doi:10.1016/j.destud.2012.03.002

Roozenburg, N. F. M., \& Eekels, J. (1995). Product Design: Fundamentals and Methods: John Wiley \& Sons.

Roucoules, L., \& Tichkiewitch, S. (2015). Knowledge synthesis by least commitment for product design. CIRP Annals, 64(1), 141-144. doi:https://doi.org/10.1016/j. cirp.2015.04.022

Roucoules, L., Yahia, E., Es Soufi, W., \& Tichkiewitch, S. (2016). Engineering design memory for design rationale and change management toward innovation. CIRP Annals, 65(1), 193-196. doi:https://doi.org/10.1016/j.cirp.2016.04.046

Rowley, J. (2007). The wisdom hierarchy: representations of the DIKW hierarchy. Journal of Information Science, 33(2), 163-180. doi:10.1177/0165551506070706

Rzevski, G. (1981). On the design of a design methodology. Paper presented at the Design: Science: Method proceedings of the 1980 Design Research Society conference, Surrey, Westbury House.

Salzberg, S., \& Watkins, M. (1990). Managing information for concurrent engineering: Challenges and barriers. Research in Engineering Design, 2(1), 35-52. doi:10.1007/ bfo2O2982O

Schon, D. A. (2008). The reflective practitioner: How professionals think in action: Hachette UK.

Schrödl, H., \& Turowski, K. (2014). Risk management in hybrid value creation. Decision Support Systems, 58, 21-30. doi:10.1016/j.dss.2012.12.042

Schutte, C. S. L., \& Preez, N. D. d. (2008, 27-31 July 2008). Knowledge networks for managing innovation projects. Paper presented at the PICMET '08 - 2008 Portland 
International Conference on Management of Engineering \& Technology.

Shear, P. A. (1971a). Engineering design as an information processing activity. Part One: The changing tasks. Electronics \& Power, 4.

Shear, P. A. (1971b). Engineering Design as Information Processing Activity. Part two: Information sources and processing. Electronics \& Power, 4.

Silventoinen, A., Denger, A., Lampela, H., \& Papinniemi, J. (2014). Challenges of information reuse in customer-oriented engineering networks. International Journal of Information Management, 34(6), 720-732. doi:http://dx.doi.org/10.1016/j.ijinfomgt.2014.07.001

Simon, H. A. (1996). The sciences of the artificial: MIT press.

Singhal, A. (2012). Introducing the Knowledge Graph: things, not strings. Retrieved from https://googleblog.blogspot.nl/2012/o5/introducing-knowledge-graph-things-not. html

Sowa, J. F. (1984). Conceptual Structures: Information Processing in Mind and Machine. Reading, MA: Addison-Wesley.

Spiegelhalter, D. J. (2014). The future lies in uncertainty. Science, 345(6194), 264-265. doi:10.1126/science.1251122

Standardization, I. O. f. (2014). ISO 10303 - Industrial automation systems and integration -- Product data representation and exchange.

STEP - The grand experience. (1999). (S. J. Kemmerer Ed.): National Institute of Standards and Technology.

Stiehm, Hicks, J., \& Townsend, N. W. (2002). The U.S. Army War College: Military Education in a Democracy. The U.S. Army War College: Military Education in a Democracy, 6-6.

Suh, N. P. (1991). Principles of Design. Oxford University Press, New York.

Suh, N. P. (1998). Axiomatic Design Theory for Systems. Research in Engineering Design, 10(4), 189-209. doi:10.1007/s001639870001

Taleb, N. N. (2012). Antifragile: things that gain from disorder: Random House.

Thomke, S., \& Reinertsen, D. (1998). Agile product development: Managing development flexibility in uncertain environments. California Management Review(1), 8-30.

Tomiyama, T., Gu, P., Jin, Y., Lutters, D., Kind, C., \& Kimura, F. (2009). Design methodologies: Industrial and educational applications. CIRP Annals - Manufacturing Technology, 58(2), 543-565. doi:10.1016/j.cirp.2009.09.003

Tuladhar, A. M., van Dijk, E., Zwiers, M. P., van Norden, A. G. W., de Laat, K. F., Shumskaya, E., de Leeuw, F.-E. (2016). Structural network connectivity and cognition in cerebral small vessel disease. Human Brain Mapping, 37(1), 300-310. doi:10.1002/ hbm.23032

Ullman, D. G. (2015) The Mechanical Design Process (4th edition ed.): McGrawl Hill. New York.

Ulrich, K. T., \& Eppinger, S. D. (2015). Product Design and Development (6th edition ed.): McGraw-Hill Education, New York. 
van Houten, F., \& Lutters, E. (2006). 'What-if' Design as an Integrative Method in Product Design. In H. A. ElMaraghy \& W. H. ElMaraghy (Eds.), Advances in Design (pp. 37-47). London: Springer London.

van Riel, A., C. R., Semeijn, J., Hammedi, W., \& Henseler, J. (2011). Technology-based service proposal screening and decision-making effectiveness. Management Decision, 49(5), 762-783. doi:10.1108/00251741111130841

Vermaas, P. E. (2014). Design Theories, Models and Their Testing: On the Scientific Status of Design Research. In A. Chakrabarti \& L. Blessing (Eds.), An Anthology of Theories and Models of Design (pp. 47-66). London: Springer-Verlag.

Vijaykumar, G., \& Chakrabarti, A. (2008). Understanding the Knowledge Needs of Designers During Design Process in Industry. Journal of Computing and Information Science in Engineering, 8(1), 011004-011004-011009. doi:10.1115/1.2840776

Vitali, S., Glattfelder, J. B., \& Battiston, S. (2011). The Network of Global Corporate Control. PLOS ONE, 6(10), e25995. doi:10.1371/journal.pone.0025995

Ward, A. C., \& Sobek II, D. K. (2014). Lean Product and Process Development. Cambridge: Lean Enterprise Institute.

Weissman, A., Petrov, M., \& Gupta, S. K. (2011). A computational framework for authoring and searching product design specifications. Advanced Engineering Informatics, 25(3), 516-534. doi:10.1016/j.aei.2011.02.001

Yassine, A., Falkenburg, D., \& Chelst, K. (1999). Engineering design management: an information structure approach. International Journal of Production Research, 37(13), 2957-2975.

Yin, Y. H., Nee, A. Y. C., Ong, S. K., Zhu, J. Y., Gu, P. H., \& Chen, L. J. (2015). Automating design with intelligent human-machine integration. CIRP Annals, 64(2), 655-677. doi:https://doi.org/10.1016/j.cirp.2015.05.008

Yoshikawa, H. (1987). General Design Theory as a Formal Theory of Design., Intelligent CAD I, Nonh-Holland, 51 Paper presented at the IFIP WG 5.2 Workshop on Intelligent CAD, Cambridge, MA, .

Zheng, C., Bricogne, M., Duigou, J. I., \& Eynard, B. (2014). Survey on mechatronic engineering: A focus on design methods and product models. Advanced Engineering Informatics, 28, 241-257. doi:10.1016/j.aei.2014.05.003 


\section{LIST OF FIGURES}

Figure 1-1

Figure 1-2

Figure 2-1

Figure 2-2

Figure 2-3

Figure 2-4

Figure 2-5

Figure 3-

Figure 3-2

Figure 3-3

Figure 3-4

Figure 3-5

Figure 3-6

Figure 3-7

Figure 3-8

Figure 4-

Figure 4-2

Figure 4-3

Figure 4-4

Figure 4-5

Figure 4-6

Figure 5-1

Figure 5-2

Figure 5-3

Figure 5-4

Figure 5-5

Figure 5-6

Figure 5-7

Figure 6-1

Figure 6-2

Figure 6-3

Figure 6-4

Figure 6-5

Figure 6-6
Basic design cycle elements with an overall characterisation of this thesis per element Subject and characterisation of chapters, coherence of thesis structure

in five main components

Overview development situation based on design engineering

Factors influencing the development cycle (Nieberding, 2010)

Examples of (parts of) product definitions

Model of actors, artefact, activities and assets and corresponding key characteristics

Cohesion of requirement specification types (D. Lutters \& Van Houten, 2013)

Double diamond model of design (Design council, 2006)

Overview of design methodologies characterised according the a4-model.

Stage gate process (R. G. Cooper, 2001; Robert G. Cooper, 2008)

Process model by Pahl \& Beitz (Pahl et al., 2007)

Encapsulated design model (Andreasen et al., 2015)

C-K Theory (Hatchuel \& Weil, 2003)

DSM Matrix (Browning, 2001)

FBS Model of design as a process (Gero, 1990)

Shannon-Weaver model of communication'

Wisdom hierarchy (Rowley, 2007)

Information, knowledge and data in context of communication.

Reference model Biemans (Biemans, 1989)

Reference model Lutters (Eric Lutters, 2001)

Reference model for information-based product development

An example of an early graphical user interface

using the physical desktop as reference: Apple Macintosh (1984)

Examples of hierarchical structuring principles applied for interaction in software systems: Operation system file explorer (a), ERP system (b), CAD System (c) 68 Overview of information usage in design engineering practise $\quad 72$ Overview of used media, in product development (Chandrasegaran et al., 2013) 74 Workpieces in workshop setting, historic

Communication with a workpiece

Sculpture as workpiece'

48

The decision-impact model: decision-making explained in terms of information transformation

Synopsis design brief 
Figure 7-1

Figure 7-2

Figure 7-3

Figure 7-4

Figure 7-5

Figure 7-6

Figure 7-7

Figure 7-8

Figure 8-1

Figure 8-2

Figure 8-3

Figure 8-4

Figure 8-5

Figure 8-6

Figure 8-7

Figure 8-8

Figure 8-9

Figure 9-1

Figure 9-2

Figure 9-3

Figure 9-4

Figure 9-5

Figure 9-6

Figure 9-7

Figure 9-8

Figure 9-9

Figure 10-1

Figure 10-2
An example of entity-relation construct (Eric Lutters, 2001)

Examples of network modelling $\quad 118$

Basic building block $\quad 120$

Illustrative visualisations of actor networks made for IOP project. $\quad 120$

Views represented as layers

Overview actor network concept

Interface of the prototype : the actor network, the information panel,

ontology, filter options and building options.

Basic elements of the web-based prototype of the actor network

Collective purpose of tooling illustrated using the actor network prototype as base

Elementary function block diagram of the SADT modelling language

(Marca \& McGowan, 1987)

A mechanism in its simplest format.

$\begin{array}{ll}\text { Numbered input variables. } & 142\end{array}$

A series of connected mechanisms.

A constellation of mechanisms can be defined as one mechanism. $\quad 142$

Aspects relating to the value range of information $\quad 145$

(simplified) illustration of identifying patterns. $\quad 147$

$\begin{array}{ll}\text { Mechanisms as integrated in the prototype } & 148\end{array}$

Scope of architecture. $\quad 156$

$\begin{array}{ll}\text { Basic elements of a workbench } & 158\end{array}$

Overview architecture $\quad 159$

Overview of the five future use scenarios and the corresponding scope. $\quad 164$

Visual synopsis small brand owner. $\quad 166$

$\begin{array}{ll}\text { Visual synopsis PLM Scenario } & 166\end{array}$

Visual synopsis BOM Scenario $\quad 168$

Visual synopsis Stage gate scenario:a heatmap of stage-related information $\quad 168$

Visual Synopsis Product Service Scenario focussing on various perspectives. $\quad 168$

Synopsis of this thesis.

Two extreme use scenarios for implementation $\quad 179$ 
APPENDICES 


\section{APPENDIXA LIST OF PUBLICATIONS}

Below a list of publications of the author is given. Per publication the relation with this thesis is given and the role of the author is highlighted.

\section{Journal papers:}

De Koeijer, B., De Lange, J., \& Wever, R. (2017). Desired, Perceived, and Achieved Sustainability: Trade-Offs in Strategic and Operational Packaging Development. Sustainability, 9(10), 1923.

- Relation with thesis: part of the design engineering situations as described in section 2.1 are based on this work (interviews for 7 of the 12 cases).

- Role: co-author, key contributions to the development of the methodology and the corresponding tools, and executing, documenting and reviewing the interview sessions, reviewing and revising

Lutters, E., Dankers, W., Oude Luttikhuis, E. J., \& De Lange, J. (2014). Network based requirement specification. CIRP Annals - Manufacturing Technology, 63(1), 133-136. doi:10.1016/j.cirp.2014.03.095

- Relation with thesis: tread throughout the entire thesis with focus on requirement specification, actor network and prototype application

- Role: co-author, key contributions to prototype and the use case, reviewing and revising

\section{Peer-reviewed conference papers:}

De Lange, J., Oude Luttikhuis, E. J., \& Lutters, E. (2016). Incertitudes in design decisions - impediments or instruments? Paper presented at the COMA International Conference on Competitive Manufacturing, Stellenbosch, South Africa.

- Relation with thesis: decision impact model and uncertainty sections as presented in chapter 6

- Role: main author

Oude Luttikhuis, E. J., De Lange, J., Lutters, E., \& ten Klooster, R. (2015). Evolving Product Information in Aligning Product Development Decisions across Disciplines. Paper presented at the 22nd CIRP conference on Life Cycle Engineering, Sydney, Australia. http://www.sciencedirect.com/science/article/pii/S221282711500089X

- Relation with thesis: presents early version of actor network and link with decision making

- Role: co-author, main contributions to sections 3 to 6 concerning product development, the actor network, decisions, reviewing and revising 
Oude Luttikhuis, E. J., De Lange, J., Lutters, E., \& Ten Klooster, R. (2014). Using actor networks in decision making during content-packaging development. Paper presented at the 21st CIRP Conference on Life Cycle Engineering, Trondheim, Norway.

- Relation with thesis: describes solution principles and future usage scnearios of an early version of the actor network

- Role: co-author, main contributions to actor network, describing scenarios, reviewing and revising

De Lange, J., Oude Luttikhuis, E. J., \& Lutters, E. (2014). Networked Design Decisions in Balanced Life Cycles. Paper presented at the 24th CIRP Design Conference, Milano, Italy. http://www.scopus.com/inward/record.url?eid=2-s2.0-84915807829\&partnerID=tZOtxzyr

- Relation with thesis: describes a preliminary design of the prototype application for the use case as described in chapter 7 .

- Role: main author

Oude Luttikhuis, E. J., De Lange, J., Ten Klooster, R., \& Lutters, E. (2014). Project-led Education in Packaging Development and Management. Paper presented the 24th CIRP Design Conference, Milano, Italy. http://www.sciencedirect.com/science/article/pii/S2212827114006660

- Relation with thesis: packaging development and recommendations

- Role: co-author, key contributions to packaging development, educational descriptions, reviewing and revising

De Lange, J., Oude Luttikhuis, E. J., ten Klooster, R., \& Lutters, E. (2013). Towards Integrating Sustainability in the Development of Product/Packaging Combinations. Paper presented at the CIRP Design conference, Bochum, Germany. http://link. springer.com/10.1007/978-3-642-30817-8

- Relation with thesis: paper concerning the IOP project Packaging Chains in Lasting balance in which the Actor network was developed, focus on sustainable development.

- Role: main author. 


\section{APPENDIX B \\ ADDITIONAL INFORMATION DESIGN PRACTISE SITUATIONS}




\begin{tabular}{|c|c|c|c|}
\hline Scenario & Keywords & Case & Sources \\
\hline \multirow[t]{3}{*}{$\begin{array}{l}\text { Development based } \\
\text { on design engineer- } \\
\text { ing }\end{array}$} & \multirow[t]{3}{*}{$\begin{array}{l}\text { Packaging; } \\
\text { Engineering; } \\
\text { Management }\end{array}$} & Canister & $\begin{array}{l}\text { Interview Jos Oostendorp on crate } \\
\text { development (Design game); }\end{array}$ \\
\hline & & Crate & $\begin{array}{l}\text { Interview Judith van Voorthuizen } \\
\text { on project merge canisters (IOP); } 5 \\
\text { Interviews CUTA (IOP); Meta-data } \\
\text { workshops (IOP); }\end{array}$ \\
\hline & & Container & $\begin{array}{l}2 \text { Interviews Philips on packaging de- } \\
\text { velopment and management (Design } \\
\text { game) }\end{array}$ \\
\hline \multirow[t]{3}{*}{$\begin{array}{l}\text { Development based } \\
\text { on marketing }\end{array}$} & \multirow[t]{3}{*}{$\begin{array}{l}\text { Packaging; } \\
\text { Marketing; } \\
\text { Management }\end{array}$} & Cask & $\begin{array}{l}8 \text { Interviews Heineken on develop- } \\
\text { ment (Design game); Work master } \\
\text { student Alexandra van der Meer }\end{array}$ \\
\hline & & Sachet & 4 interviews Wessanen (Design game) \\
\hline & & $\begin{array}{l}\text { Glass jars } \\
\text { and metal } \\
\text { containers }\end{array}$ & $\begin{array}{l}\text { Master thesis Euroma Jos de Lange: } \\
\text { Interviews; Simulation session; Test } \\
\text { session }\end{array}$ \\
\hline \multirow[t]{2}{*}{$\begin{array}{l}\text { Material develop- } \\
\text { ment and manufac- } \\
\text { turing }\end{array}$} & \multirow{2}{*}{$\begin{array}{l}\text { Packaging; } \\
\text { Manufacturing; Tech- } \\
\text { nology; } \\
\text { Marketing }\end{array}$} & Can & $\begin{array}{l}3 \text { interviews cuta (IOP); } 4 \text { Interviews } \\
\text { (Design game); Meta-data Worshops } \\
\text { (IOP) }\end{array}$ \\
\hline & & Material & $\begin{array}{l}\text { Interview Jaap van der Heide (IOP); } \\
\text { Interview protact (IOP); Meta-data } \\
\text { workshops IOP }\end{array}$ \\
\hline \multirow[t]{3}{*}{ Retail } & \multirow[t]{3}{*}{$\begin{array}{l}\text { Food; Packaging; Mar- } \\
\text { keting }\end{array}$} & Drink carton & $\begin{array}{l}\text { Interview Bio+, Plus and Veco Zuivel } \\
\text { (IOP); Interview Bio+ and Baltussen } \\
\text { (IOP); Work master student Jennifer } \\
\text { Bijkerk on Bio+ and Naturelle (IOP); } \\
\text { Work master student Erna Leusink } \\
\text { (IOP); Meta-data workshops IOP }\end{array}$ \\
\hline & & $\begin{array}{l}\text { Flexible pack- } \\
\text { aging }\end{array}$ & 2 Interview session (Design game) \\
\hline & & Ahold & $\begin{array}{l}\text { Interview session Ahold, Work Niek } \\
\text { van den Hout }\end{array}$ \\
\hline $\begin{array}{l}\text { Development based } \\
\text { on product-service }\end{array}$ & $\begin{array}{l}\text { Furniture; } \\
\text { Development; Manufac- } \\
\text { turing }\end{array}$ & Furniture & $\begin{array}{l}8 \text { Groups of student work for course } \\
\text { PLM (2016-2017); Work master } \\
\text { student Anouk Schoonderbeek; Info } \\
\text { Ahrend for course PLM }\end{array}$ \\
\hline
\end{tabular}

Overview cases for design situations and the corresponding sources

The contents of the interviews and educational material is confidential. Below the two main approaches and, per method, one corresponding (anonymised) outcome are given as well as the result of the mentioned workshop. 


\section{CUTA}

\section{Protocol user research cuta}

\section{Introduction}

Aim: To clarify where we come for and indicate that we mainly want to take the practical experience with us

Method: We explain

Requirements: Clearly defined goal and clear description of how we want to achieve this goal. It is important that we tell the same story for each respondent

What is the purpose of the research?

The goal of our project is to integrate sustainability into a development process of product-packaging combinations. The solution we have come up with is a software tool that stores important information about different life cycles. With this information the user can get an overview of the consequences of possible choices. The aim of this research is to ensure that the final tool is compatible with Blablba.

How do we want to achieve this?

What is very important is that the tool connects with daily practice and experiences. For that we need you and especially your experiences. We will first briefly outline a picture in which we think the tool can help. Then we would like to ask you to give an example from daily practice. With the help of this example, we will search together for a tool that could be useful in such a situation.

\section{Procedure}

Goal: Taking care of it that the user can empathize with a certain situation, make sure we talk about the same, description of the situation in which the tool could be used Method: place (self-filled) cards in order

Necessities:

- For each respondent an image of the daily practice in which he / she works

- A clearly defined task

- Cards that can be filled in (with task and actor)

- Pens

- Camera to record order

Roadmap

- We first briefly outline a context ourselves

- We give the respondent a (realistic) task

- We ask the respondent to describe his / her working order by means of maps with tasks and actors.

- Then we validate the cards 


\section{Decision critiria}

Goal: Determine what information is needed where necessary. This is necessary in determining how this should eventually be displayed

Method: Add new (self-filled) cards to previous phase

Necessities:

- New tickets

- Pens

Roadmap

- First focus on costs

- Then focus on sustainability / environmental impact

- Ask if they want to add this information to the procedure that was created in the previous phase.

- New maps with 'information that is needed'

\section{Tool}

Goal: Building blocks for interface

Method: Presenting interfaces and asking each of the interfaces what they see as advantages and disadvantages. Which would they choose and why? By means of an interview or by means of fill-in form?

Necessities:

- 3 different interfaces (excel structure, network structure, document structure (onenote))

- Clear and well-drafted questions

\section{Walktrough}

Purpose: To specify the requirements and wishes regarding the display of information in the tool

Method: Display the step-by-step plan with the help of building blocks

Roadmap

- Building blocks (based on the 3 interfaces)

- Procedure as described earlier 


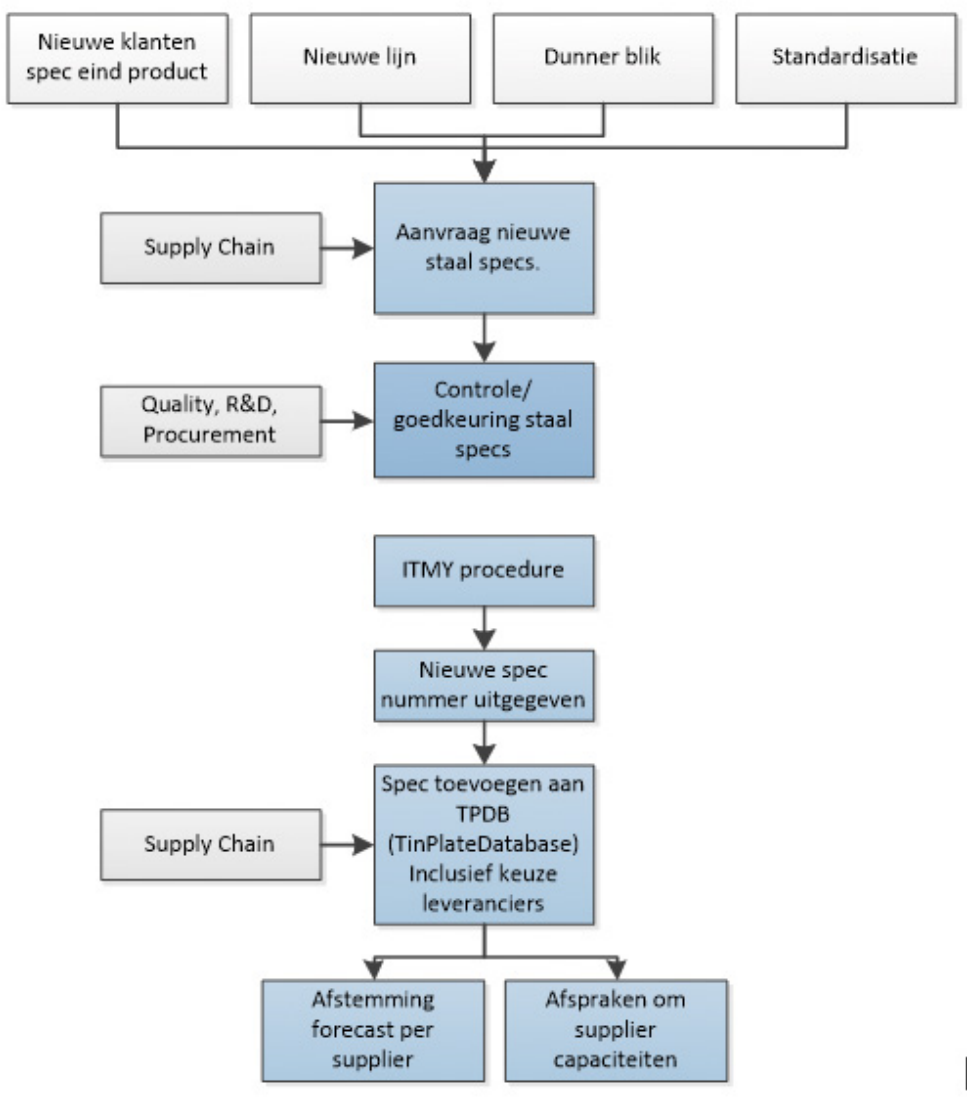

Figuur $\mathrm{C}_{7}$ Cards layout 


\section{Illustrative example outcome CUTA session \\ (in dutch, outcome has been anonymised)}

\section{Respondent: -}

Functie: -

Datum: 3 november 2014

Dagelijkse werkzaamheden

Functie: XXX inkopen voor alle vestigingen in Europa ( 45 bedrijven - ongeveer 20 daarvan hebben $X X X$ als grondstof nodig). moet ingekocht worden. Participant is verantwoordelijk, samen met een andere collega, voor de inkoop.

Inkoop bij verschillende bedrijven: (10 bedrijven genoemd) Azie. 85\% van het materiaal wordt bij de eerste 4 bedrijven geleverd (TP4). Binnen europa, 1 Japanse, 1 Koreaanse 1 Chineese leveren beste kwaliteit. Rest is van mindere kwaliteit. Minder kwaliteit = lagere prijs = meer uitstoot.

$\mathrm{XX} \%$ van de prijs is grondstof. $\mathrm{Bij}$ bedrukt blik is dat wat lager (omdat er een grotere toegevoegde waarde wordt gecreëerd). Contracten worden afgesloten in overleg met management. Optimalisatie wat betreft kwaliteit en kosten.

Duurzaamheid

XXX-impact speelt (nog) geen rol. Alleen als dit gestuurd is door de wet.

$\mathrm{Er}$ is een database waarin staat wat er bij wie besteld wordt. Belangrijke beslissingscriteria zijn de specificaties. Deze hangen af van: productafmetingen, lijnen (smal vs breder), machines (oud vs niew bepaald hoe dun het materiaal kan), product dat erin afgevuld wordt (agressief product = dikkere laag XXX), hardheid in XXX. Zo zijn er ongeveer 1000 specificaties.

Database is een eigen ontwikkeld systeem dat wordt gebruikt om aan te geven wat er nodig is en de forecast van het product. Het liefst zijn er meer dan 1 bedrijf gekwalificeerd, om zo onafhankelijk te zijn van 1 bedrijf. Condities en beperkingen relevant.

Normen zijn van belang bij de selectie van een leverancier. Elk bedrijf heeft een portfolio met wat ze kunnen (boek, cd-rom, etc).

Supply chain stuurt een aanvraag waarbij ze aangeven wie zij als leverancier willen. R\&D, quality en procurement moeten dit goedkeuren. Er wordt een nieuw specificatienummer toegevoegd aan tinplatedatabase, en deze wordt vervolgens door procurement meegenomen in de forecast. Trial is vaak al gedaan in het voortraject, afstemming forecast afspraken/capaciteiten.

In XXX staat de behoefte > SC bepaald forecast voor komende 12 weken. Procurement gaat over 4,5,6 maanden en geeft door wat er op jaarbasis nodig is. 


\section{Design game}

The approach used for the so-called design game interview sessions was published in: De Koeijer, B., De Lange, J., \& Wever, R. (2017). Desired, Perceived, and Achieved Sustainability: Trade-Offs in Strategic and Operational Packaging Development. Sustainability, 9(10), 1923.

Below the outline of the approach and one illustrative outcome (anonymised).

\section{Approach}

\section{WHO ARE YOU AND WHO ARE WE?}

\section{A. Introduction}

\section{Who are we?}

- UTwente Researchers, Industrial Design Engineering

- Jos de Lange: Role of information in product development

- Bjorn de Koeijer: Methods for sustainable packaging development

- Ellen Oude Luttikhuis: Decision support in product development

Goals

- For us: insight into design practice

- For participant: evaluation of the method of design

Confidentiality

- External: Information about company and projects is anonymised

- Internal: Information can be shared with each other, unless otherwise indicated

Session planning

- 5 min. Introduction

- 60 min. Game

- 15 min. Closure

\section{B. Game explanation (context and validation)}

1. Key personal contributions within a project

2. Process description of the realization of this contribution

3. Mapping information and communication flows using the following materials:
a. Actors> who were involved
b. Sources> Which (information) sources have been used
c. Decisions $>$ What decisions have been made
d. Decision criteria> Which criteria were important here
e. Eventually a network is created and the materials have to be linked together. These label cards can be used to indicate a link. 
4. It is possible to create your own legend. Actors and sources have different colors, it is possible to give a meaning here. In addition, it is possible to make different connections.

5. Here we have briefly shown an example: Suppose you are part of R \& D and have to make a decision about a material. Sales can be asked which specifi cations are required and what that costs. From production you get the possi bilities in terms of production and an ERP is used to compare different mate rials.

6. The actor can indicate to what extent he or she was involved and what his or her influence was.

\section{Project introduction}

Information based on Part 1

- Ask the participant if he / she can remember his project

- Audit question: recency project

- Ask for a short description

- Which design methods are used?

- Which project management structure?

\section{KEY CONTRIBUTIONS}

\section{A. Identification of most important contributions.}

Contributions (3-5) are described on corresponding cards

Direct: immediately ask the key question.

Can you describe your most important contributions to this project? These are personal contributions, but that does not mean that the work should only be done.

Helping: start easily and slowly make the most important contributions (especially suitable for traces of uncertainty, doubt, etc.)

If you have to explain in 1 minute what you have done in this project, how would you do that

(Preliminary question, by keeping the time limit at a high aggregation level.)

Linking to the answer, giving the interviewer the most important contribution:

- Could you describe XXXX as an important contribution?

So that was a valuable contribution to project right?

\section{B. Brief explanation of key contributions}

Possibly with $2 b$ at the same time, depending on the situation / interviewee allows.

Ask to describe / explain the most important contributions

In this respect: does the interviewer understand the contribution?

\section{ESTIMATION IMPORTANT CONTRIBUTION}




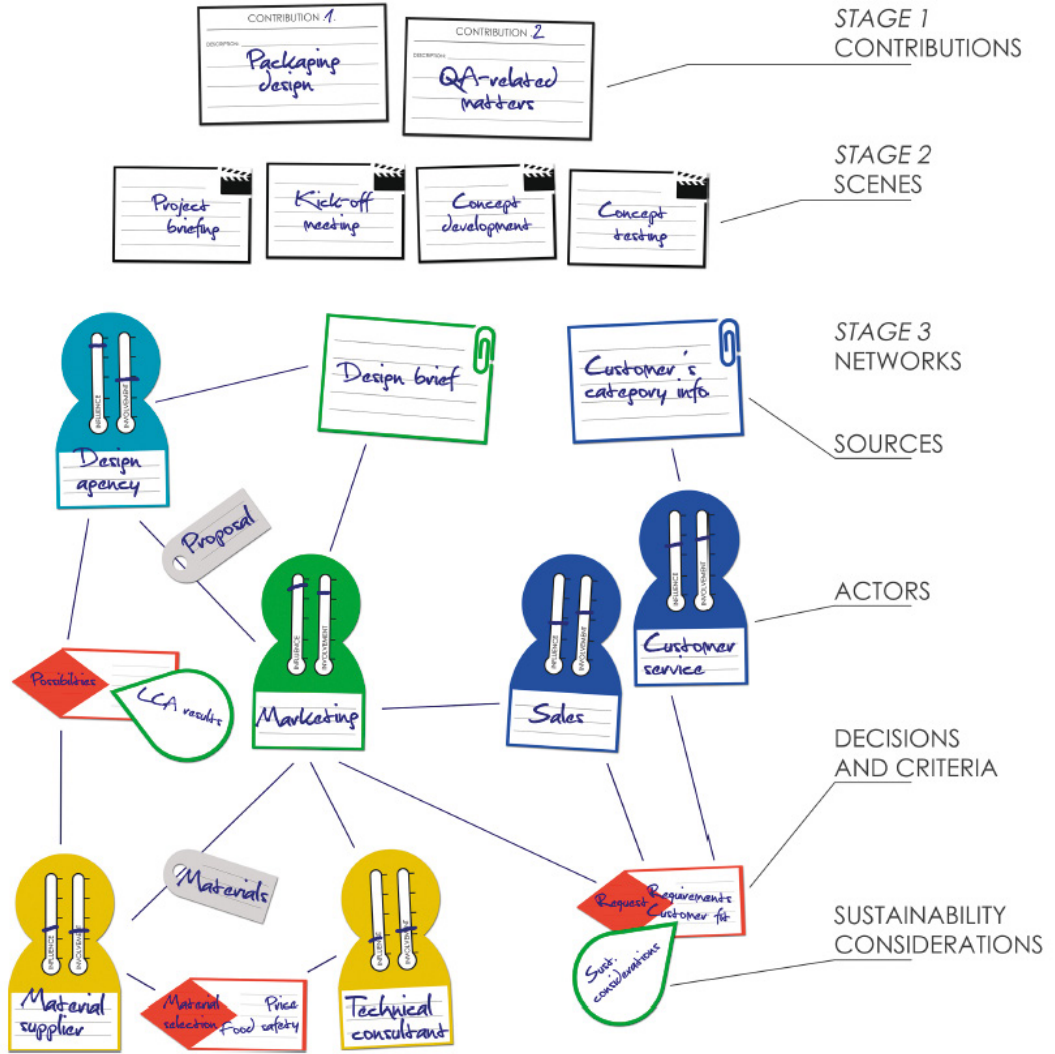

Figuur $\mathrm{C}_{2}$ Outcome 
Scenery cards are used to record a short process description of the contribution

Can you indicate which steps have been taken to come to this contribution?

\section{Map a network}

All other materials can now be placed. There is no specific order here. The questions we can ask:

- Who were involved? Internal external

- What information source did you use?

- What information did you need?

- What decision did you take? Were more people involved in this?

- hat were important criteria in this? How did you find out about that information?

- How much influence did that person have? And what was his involvement in the realization of this contribution?

\section{ROUNDUP}

\section{Appointments}

Continuation (appointments): We would like to schedule another session in which different actors involved in this project jointly play a game to see the interactions between different people. Would you like to participate? 


\section{Workshop IOP}

\begin{tabular}{|c|c|c|c|c|c|c|c|}
\hline 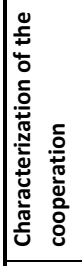 & 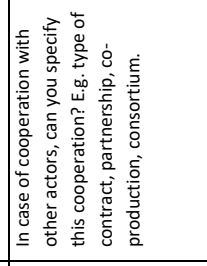 & 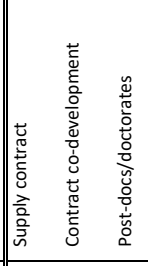 & 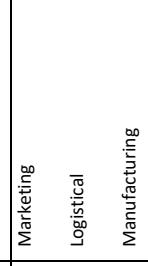 & 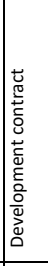 & 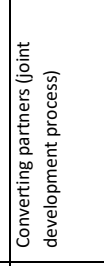 & 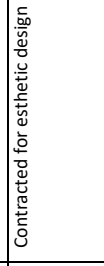 & 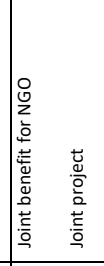 \\
\hline 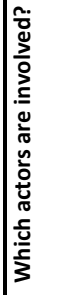 & 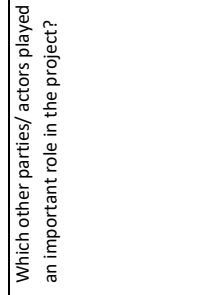 & 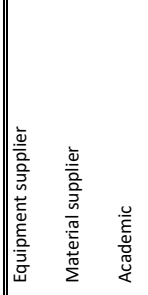 & 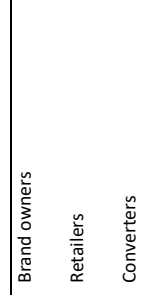 & 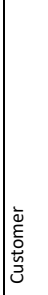 & 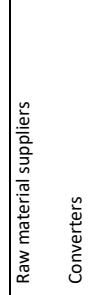 & 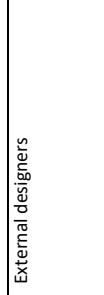 & $\stackrel{\circ}{2}$ \\
\hline 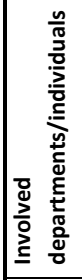 & 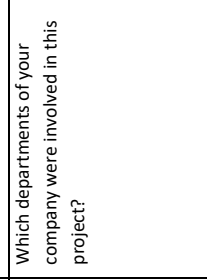 & 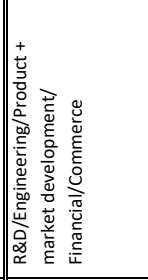 & 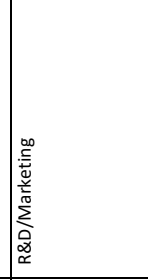 & 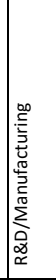 & 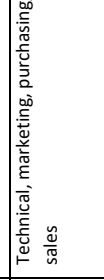 & 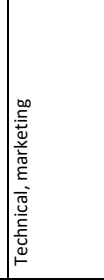 & 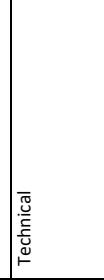 \\
\hline 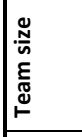 & 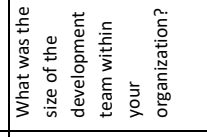 & $\tilde{2}$ & $m$ & i & + & $\sigma$ & N \\
\hline 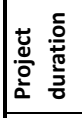 & 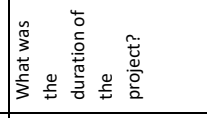 & 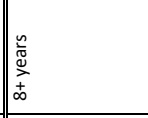 & 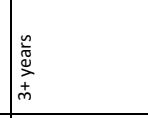 & 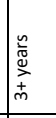 & 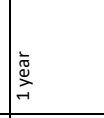 & 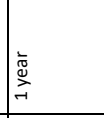 & 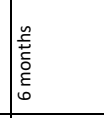 \\
\hline 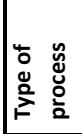 & 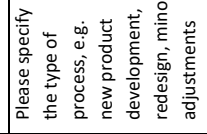 & 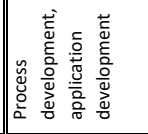 & 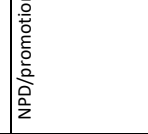 & 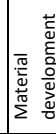 & 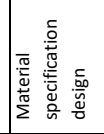 & 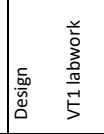 & 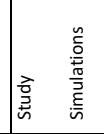 \\
\hline 㤎 & 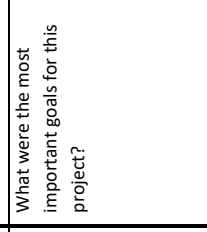 & 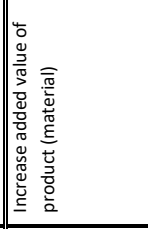 & 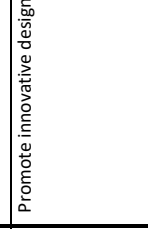 & 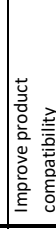 & & 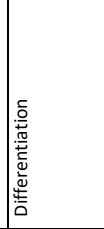 & 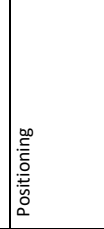 \\
\hline 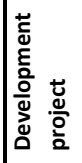 & 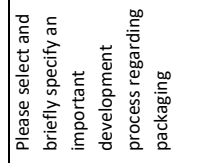 & $\ddot{z}$ & y & $\hat{x}$ & 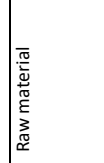 & 咅 & 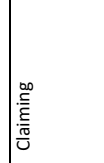 \\
\hline & & \multicolumn{3}{|c|}{$\forall$ иоп̣еs!̣ues̆ } & \multicolumn{3}{|c|}{ g иоп!еs!̣uеs. } \\
\hline
\end{tabular}




\begin{tabular}{|c|c|c|c|}
\hline 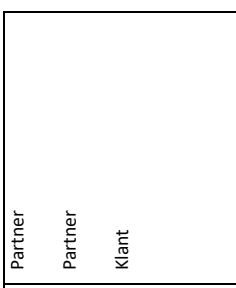 & \begin{tabular}{|l} 
离 \\
离 \\
\end{tabular} & 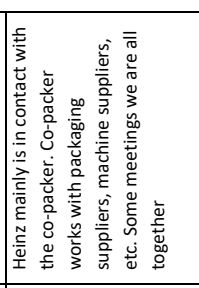 & \\
\hline 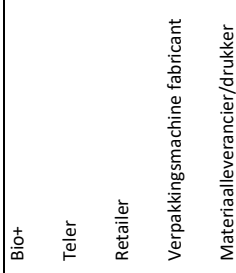 & 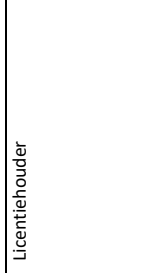 & 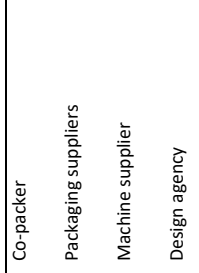 & 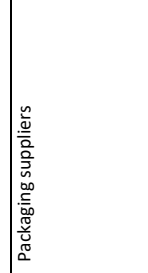 \\
\hline 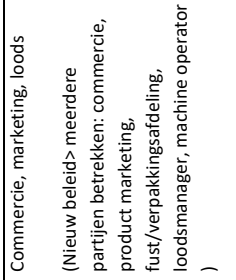 & 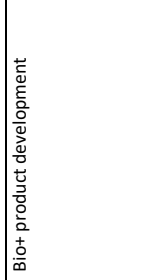 & 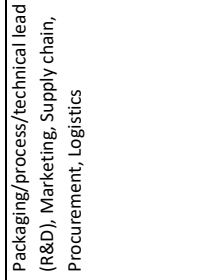 & 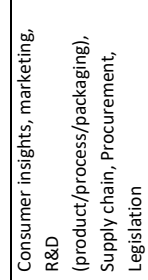 \\
\hline$\stackrel{2}{m}$ & 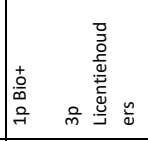 & $\stackrel{9}{2}$ & . \\
\hline 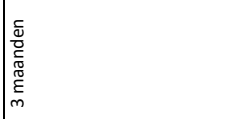 & 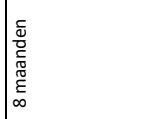 & 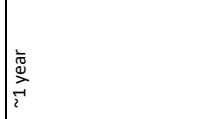 & . \\
\hline 曾 & $\mid$ & 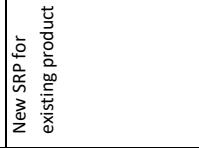 & $\frac{a}{2}$ \\
\hline 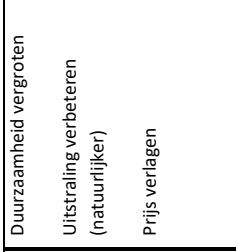 & 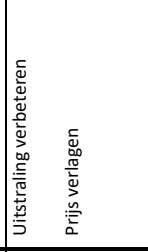 & 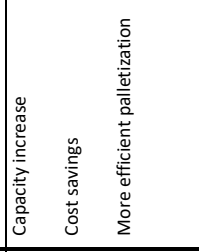 & 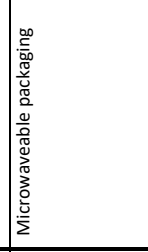 \\
\hline 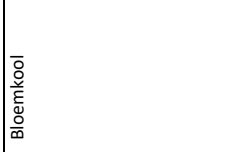 & 总 & 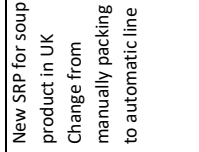 & 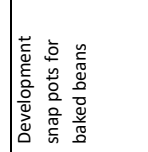 \\
\hline \multicolumn{2}{|c|}{ 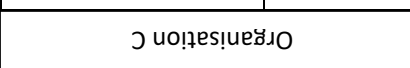 } & \multicolumn{2}{|c|}{ व uo!̣eș̣ues̆ı } \\
\hline
\end{tabular}




\section{APPENDIXC OVERVIEW DESIGN METHODOLOGIES AND CORRESPONDING REFERENCES}




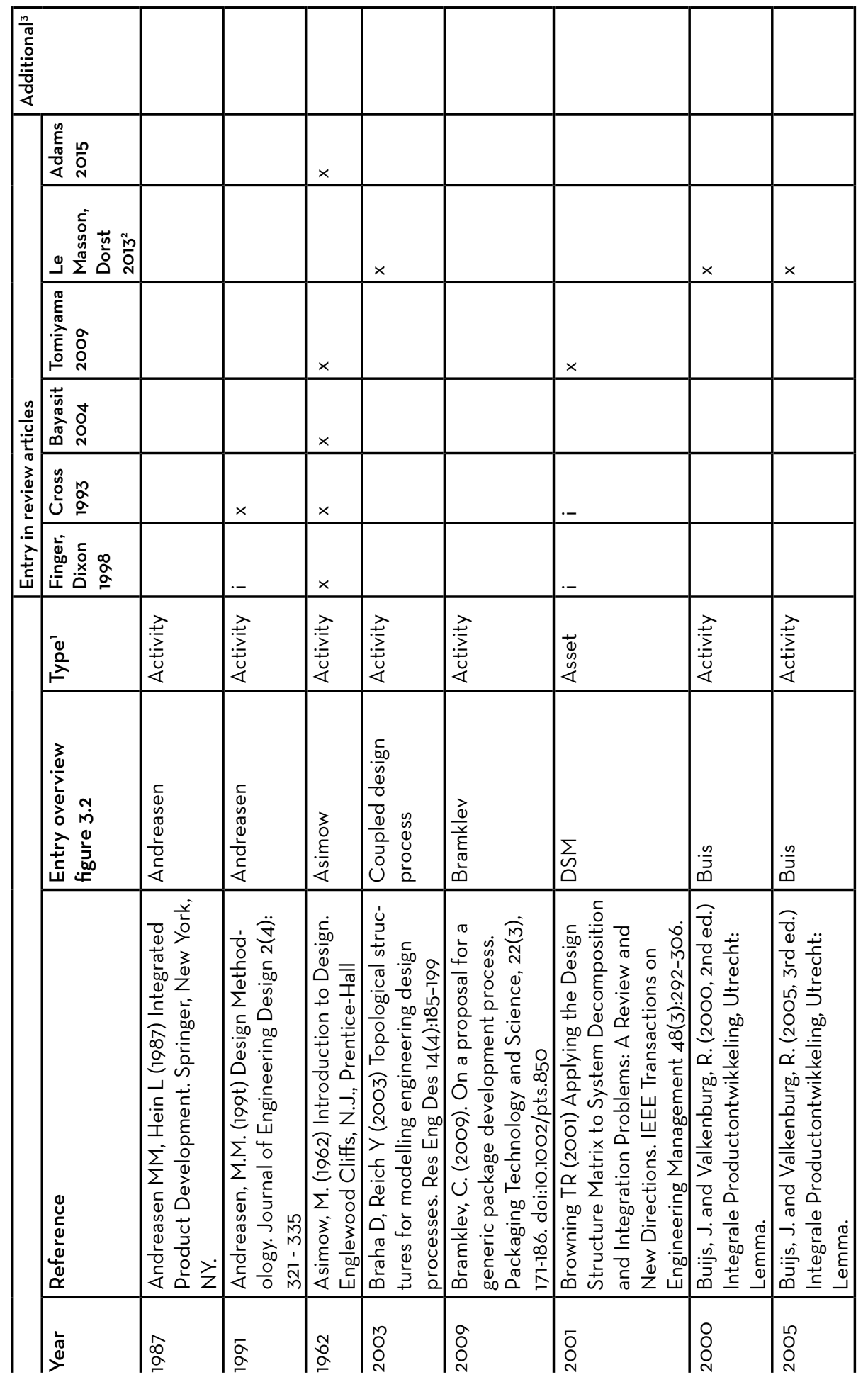




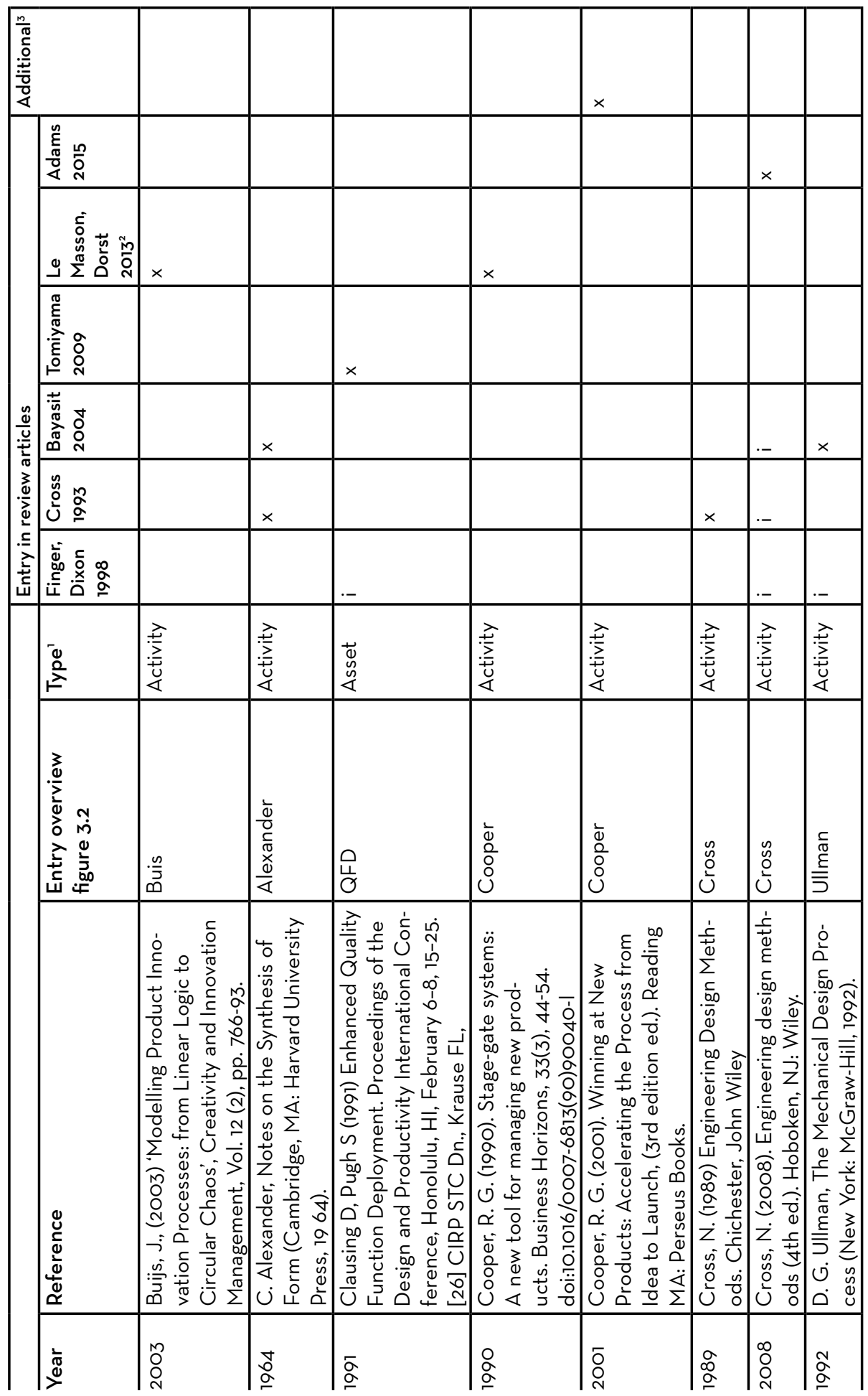




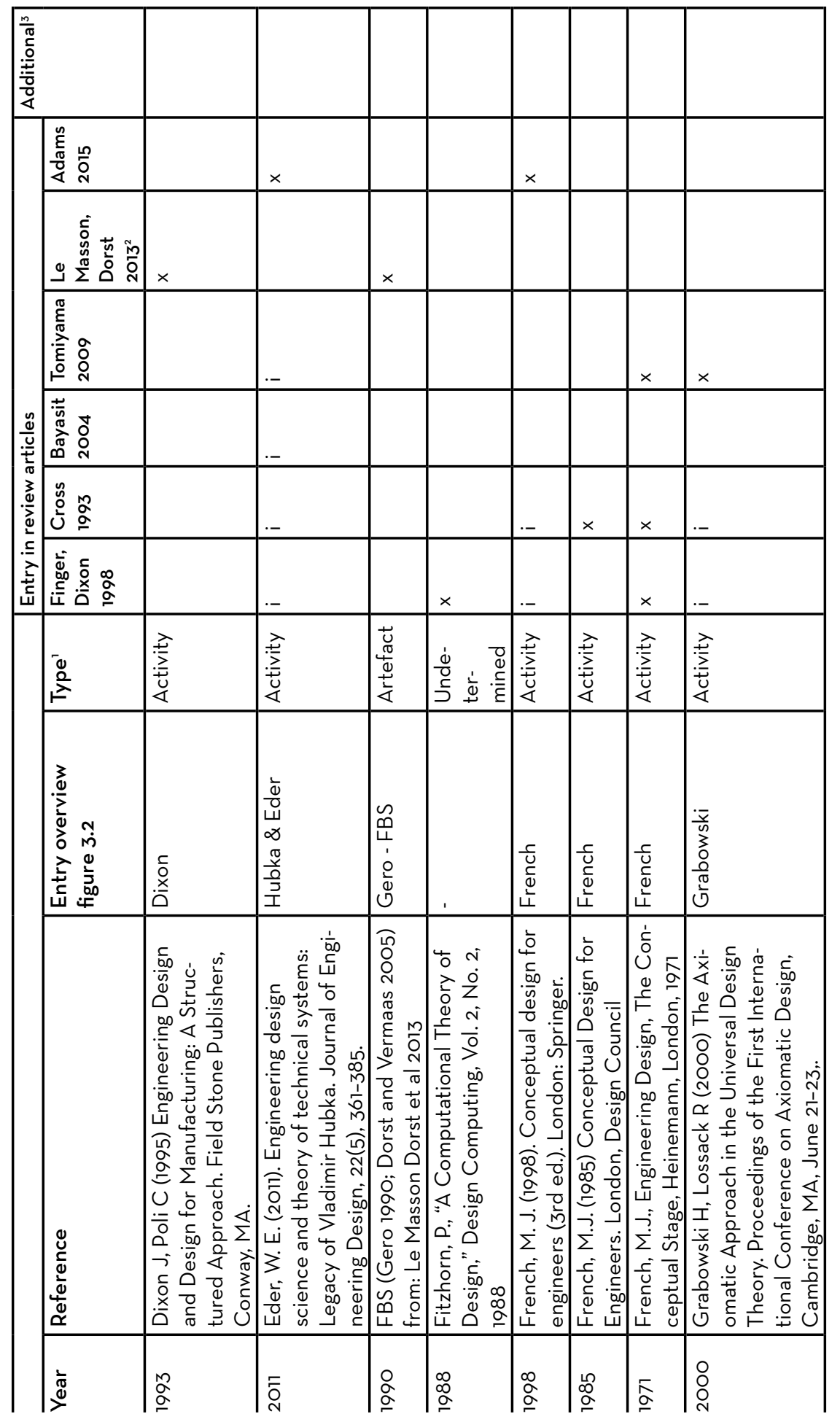




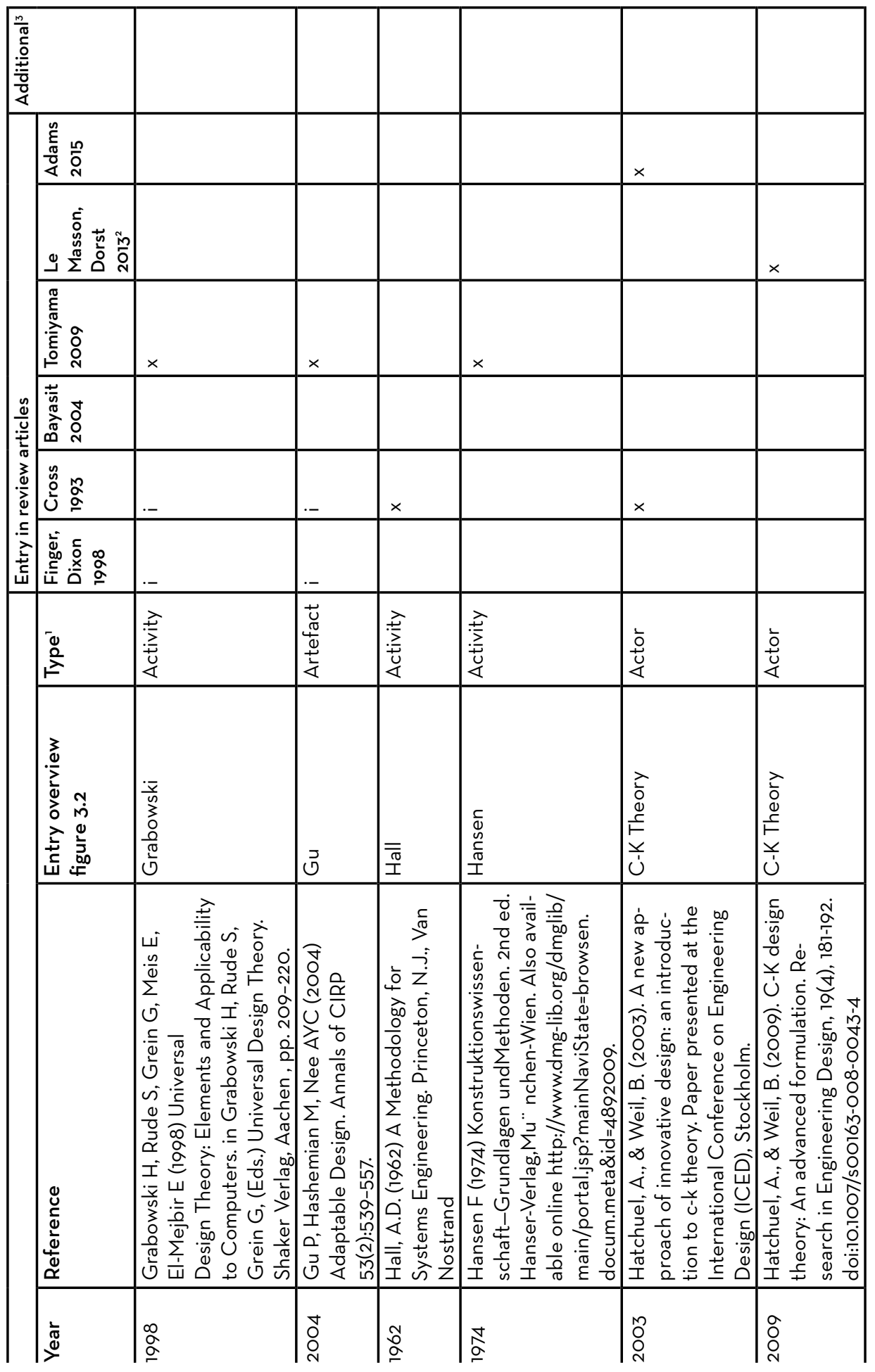




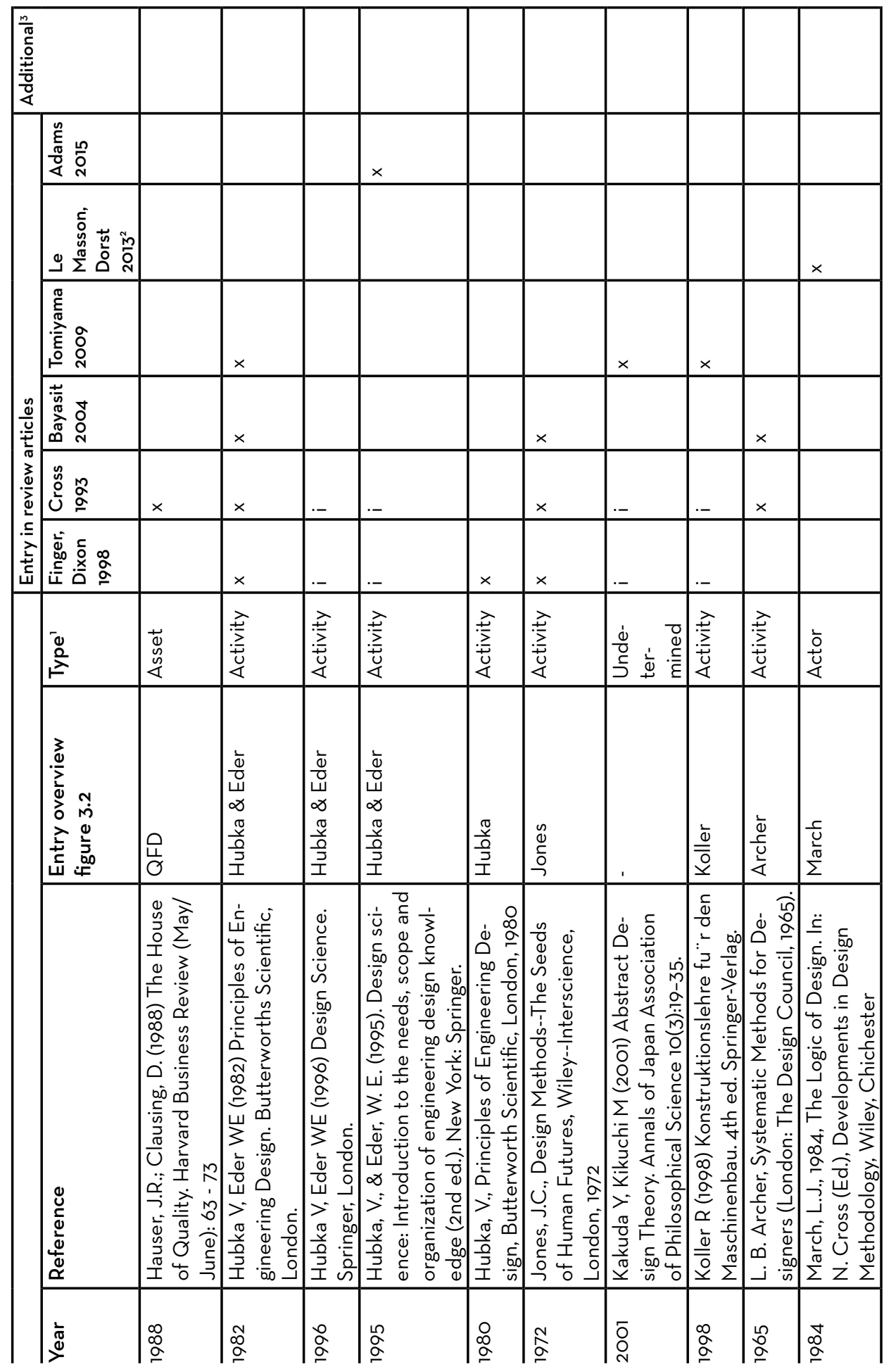




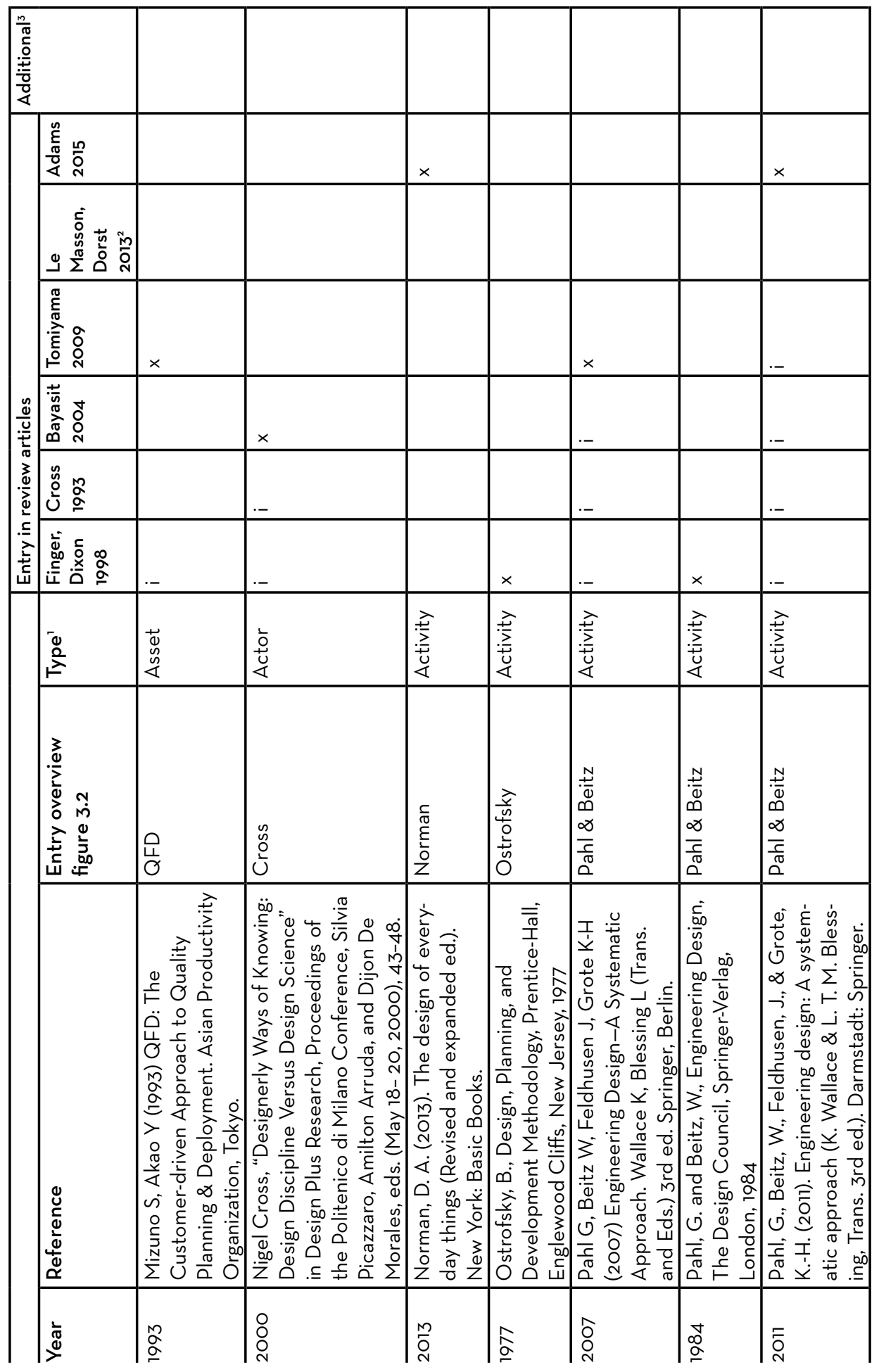




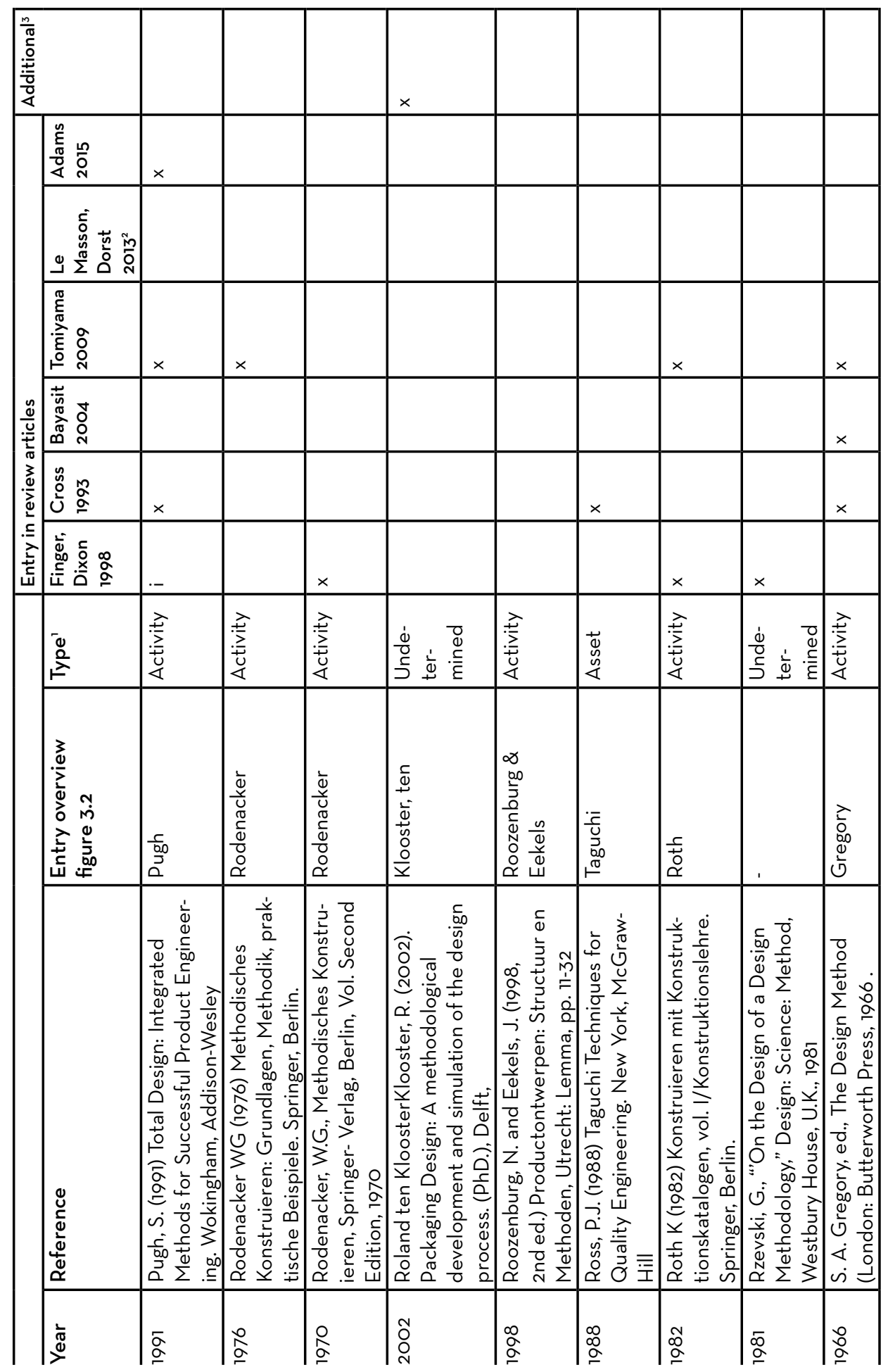




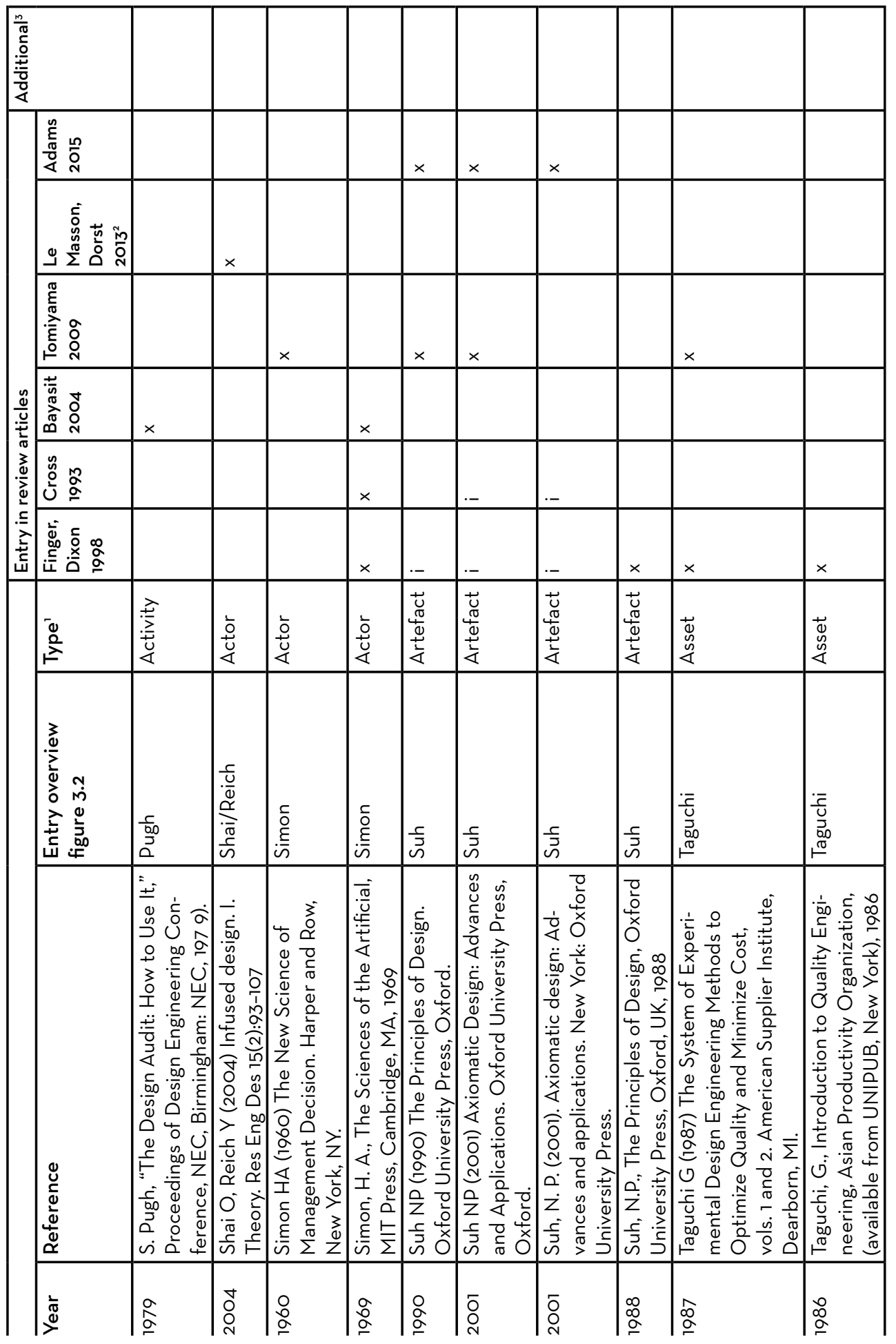




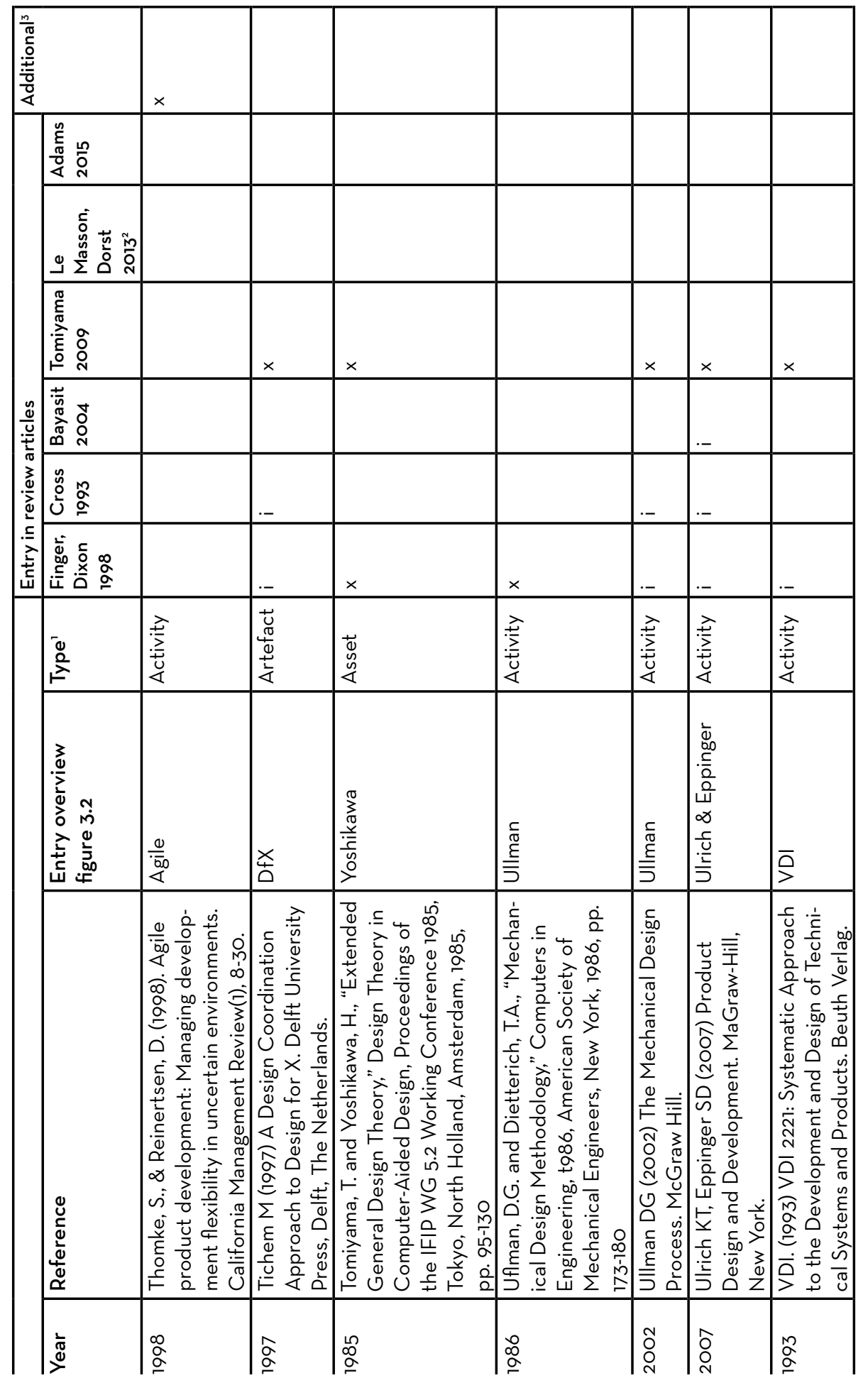




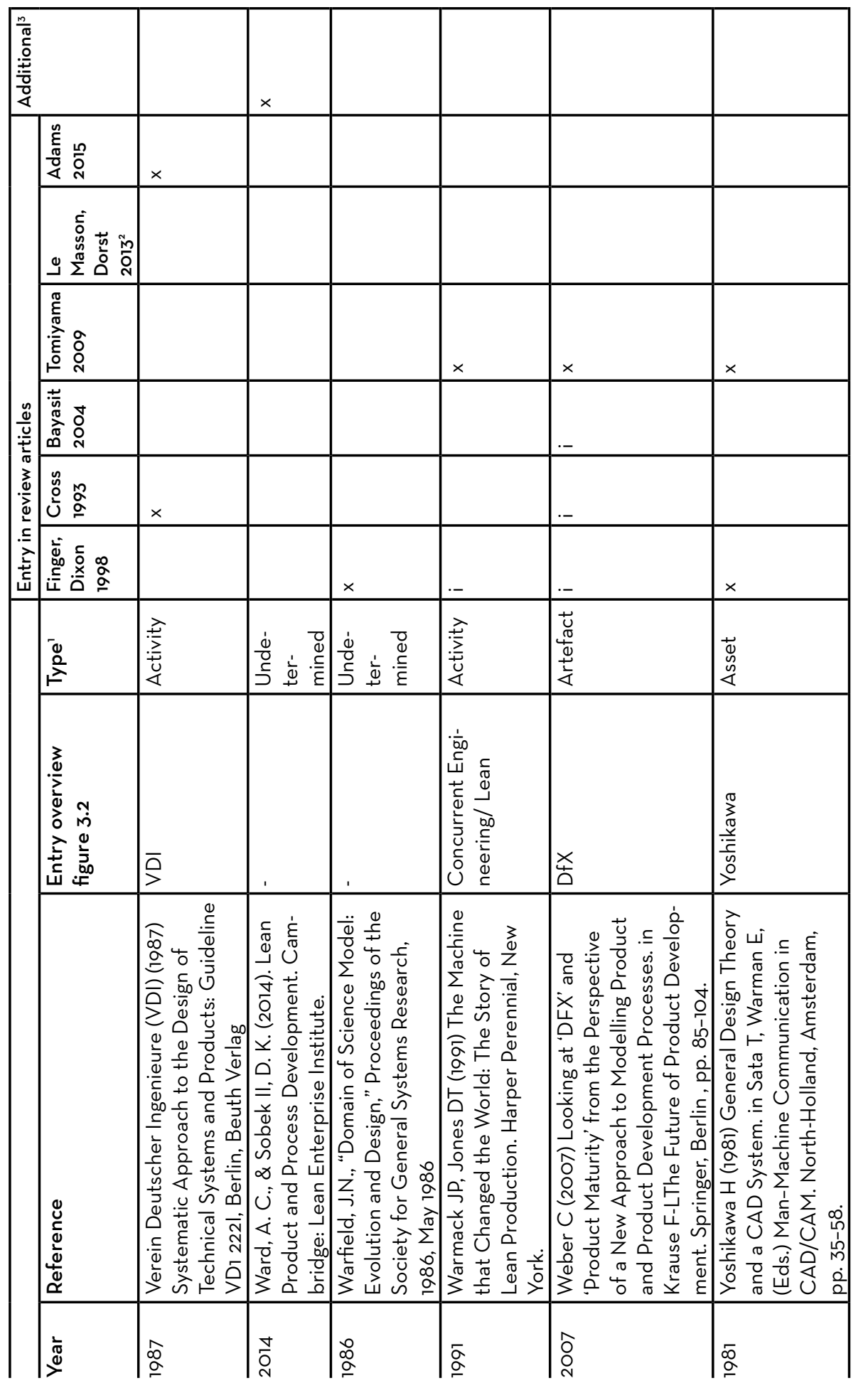




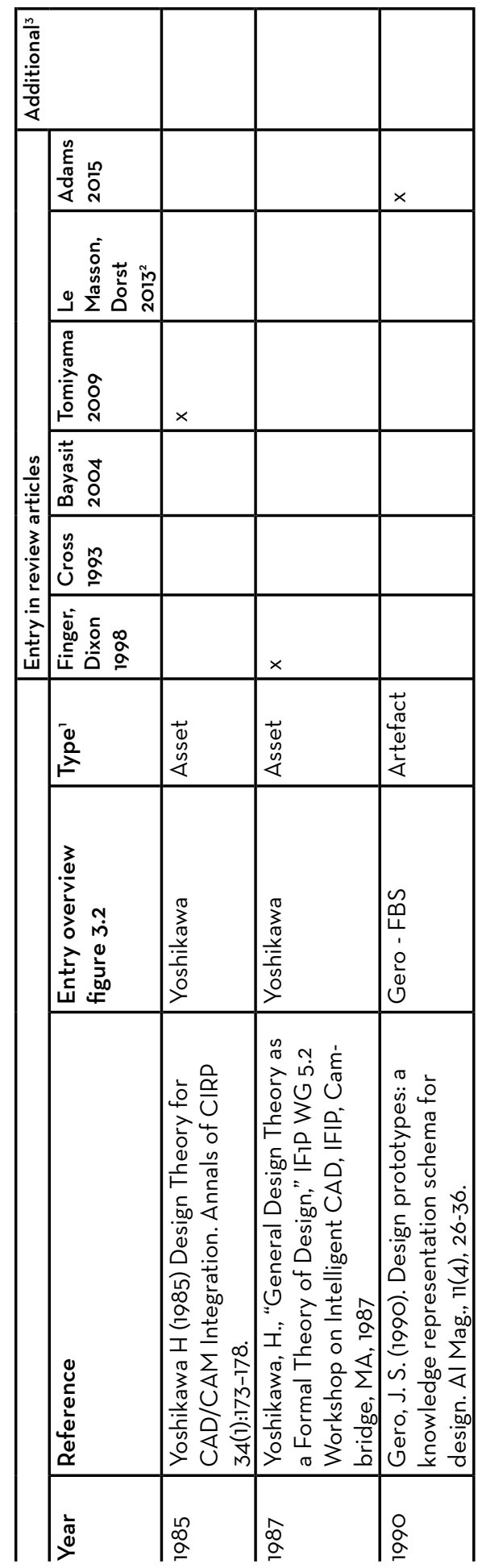




\section{APPENDIX D EXCERPTS USE CASE SUSTAINABLE PACKAGING}

Source: A hitchhikers guide to the actor network, 2015. Final report IOP Project "packaging chains in Lasting Balance", Oude Luttikhuis, E.J., De Lange, J., Lutters, E. , Ten Klooster, R. 


\section{A HITCHHIKER'S GUIDE TOTHE ACTOR NETWORK}

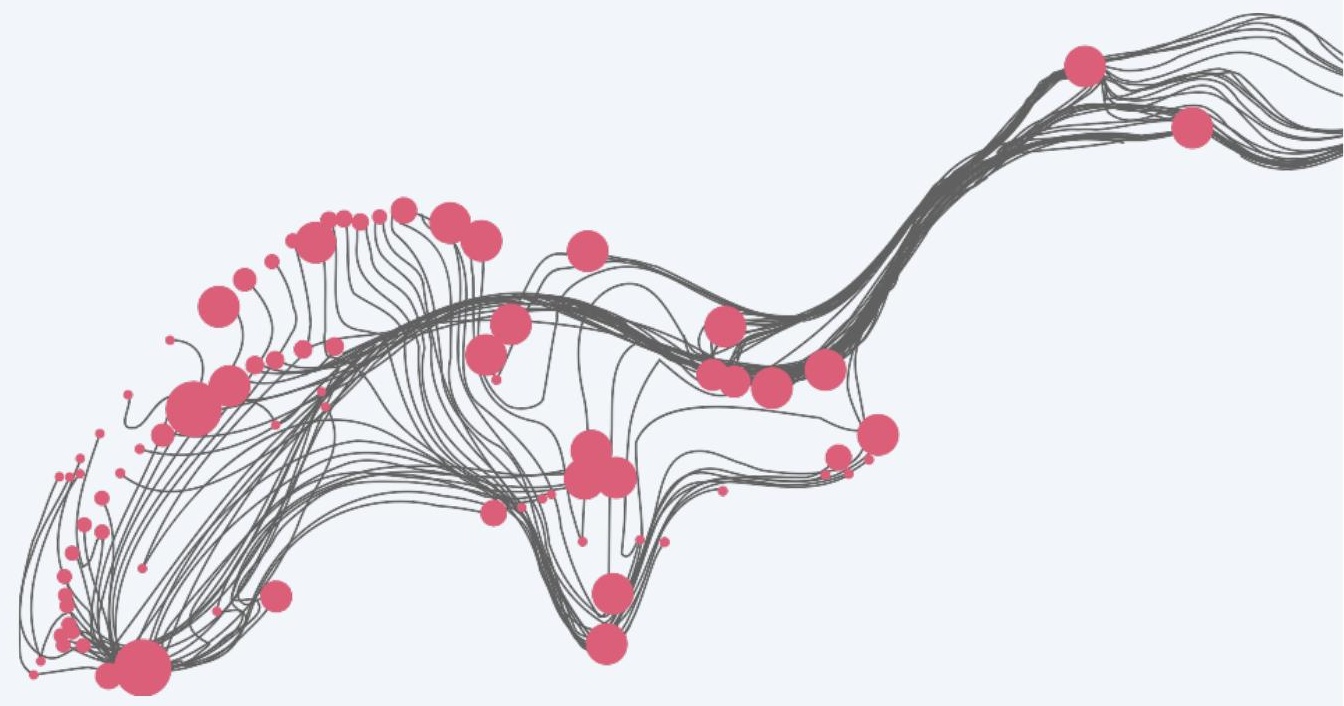




\section{Research project at a glance}

\section{Factsheet}

\section{Subject}

Optimisation of sustainable development in the packaging life cycle.

\begin{abstract}
Aim
Developing specifications for sustainable development in the entire packaging life cycle and convert these specifications into tools for improvements that do more justice to the definition of sustainable development and help organisations from the field of packaging in developing chainoriented solutions
\end{abstract}

\section{Results}

- Framework for optimising sustainable development in the field of packaging

- New tools, design methods and development of theory for broader analysis of the chain and integral implementation of sustainable development in the life cycle.

- Expert centre aimed at dissemination of results and active implementation in industry

Research period: March 2012 till March 2015

\section{Consortium}

\section{Research team}

- Project manager: Prof.dr.ir. Eric Lutters

- Project consultant: Prof. dr. ir. Roland ten Klooster

- Researcher (0,5 Fte): Ir. Jos de Lange

- Researcher (1 Fte): Ir. Ellen Oude Luttikhuis

\section{Industry partners}

- Tata Steel: Manufacturer of steel for the automotive industry, construction industry and packaging industry

- Ardagh Group: Manufacturer of glass and metal packaging

- Rexam: Manufacturer of metal packaging (beverage cans)

- Heinz: Food manufacturer, filling packaging

- SM Bio+: Brandowner of the brand Bio+, retailer of biologic food products

- Paardekooper: Trader in plastic disposables

- NVC: Dutch packaging centre, association of organisations involved in the packaging industry

- RVO: Funder of the project 'Packaging chains in lasting balance'

- University of Twente: Leading party in the project, executor of the research

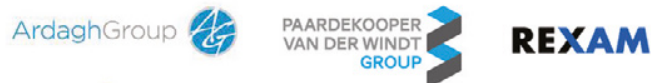 Bio+ Heinz тNT STEEL N1}

\section{Third parties}

Other parties that were involved (to a lesser extend) in the project: Kenniscentrum papier en karton, kennisinstituut duurzaam verpakken (KIDV), Facilitair bedrijf (University of Twente), the Greenery, Baltussen conserven, Oerlemans, Ahold, DS Smith De Hoop, Grolsch, de Zuivelhoeve, zuivelboerderij 't Hoepel

\section{Acknowledgement}

We gratefully acknowledge the support of the Innovation-Oriented Research Programme Integral Product Creation and Realisation (IOP IPCR) of the Netherlands Enterprise Agency. 


\section{Rationalise sustainability}

Many definitions and translations of the concept of sustainable development exist ${ }^{1}$. Most used and referred to is the definition that is developed by the Brundtland commission in 1987: "development which meets the needs of current generations without compromising the ability of future generations to meet their own needs".

In their report "Our common future", the commission postulated the three main principles of sustainable development: social equity, economic prosperity and environmental protection, laying the foundations of

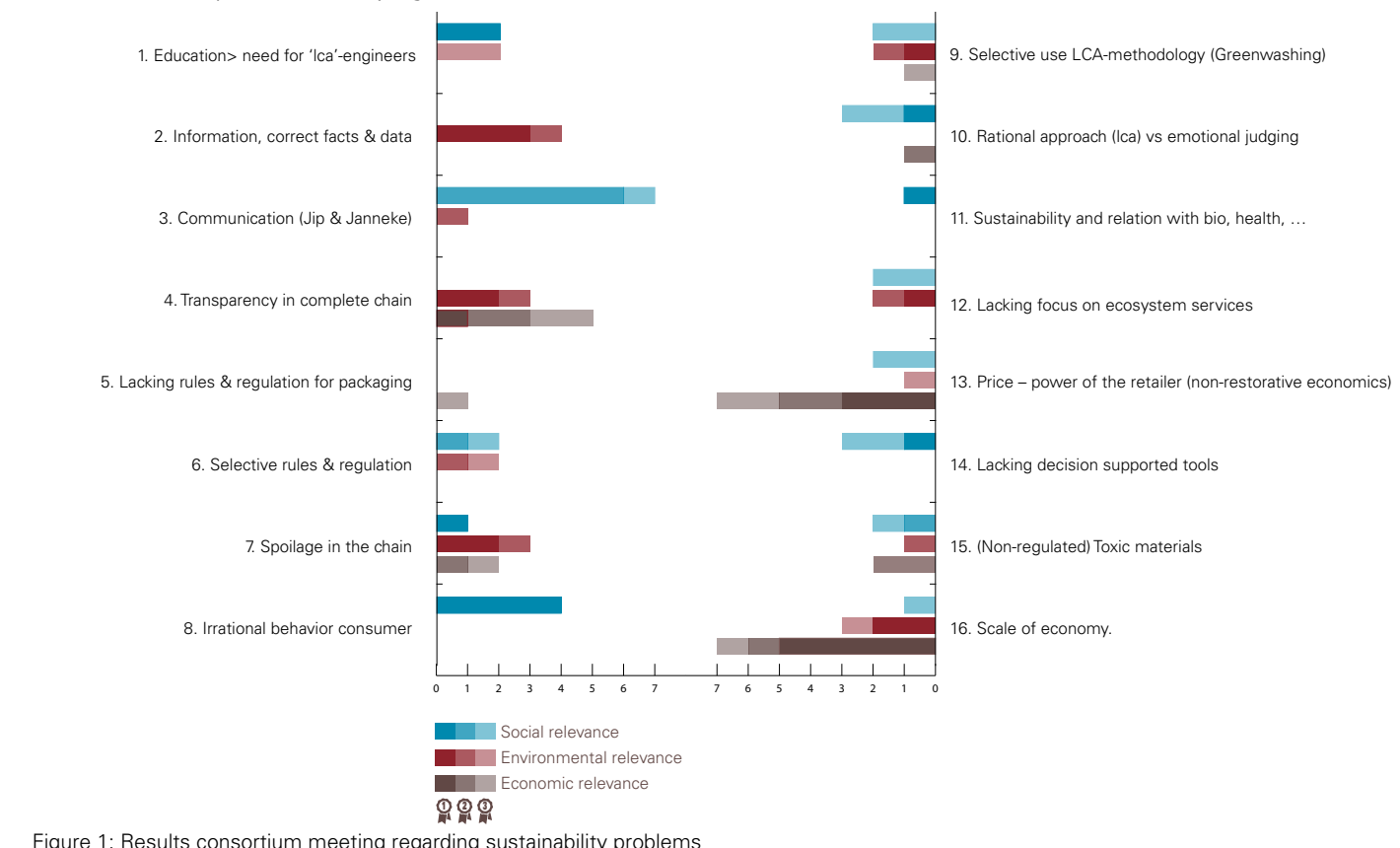

Figure 1: Results consortium meeting regarding sustainability problems 'sustainability', as it is now commonly referred to.

While it is a concept that is hard to disagree with, effectuating a visionary concept like sustainable development in product and packaging development trajectories remains a challenging and problematic endeavour. Sustainable development is strongly rooted in well-nigh every mission statement and the 'sustainability' hype is gradually replaced by 'new' trends such as 'circular economy'. However, the successful integration of life cycle aspects in the everyday practice of product-packaging development is nowhere near complete (figure 1). Sustainability is a complex subject, it is therefore well-nigh

\footnotetext{
11969 - IUCN Mandate: The perpetuation and enhancement of the living world - man's natural environment - and the natural resources on which all living things depend', which referred to management of 'air, water, soils, minerals and living species including man, so as to achieve the highest sustainable quality of life.

1972 - United Nations Conference on the Human Environment in Stockholm: Possibility to achieve economic growth and industrialisation
without environmental damage.
}

1987 - Our common future, Brundtland commission: Development that meets the needs of the present without compromising the ability of future generations to meet their own needs

Another definition is found in a Dutch dictionary (van Dale):

- (Langdurend) Long lasting

- (Weinig aan slijtage of bederf onderhevig) Little affected by wear and decay

- (Het milieu weinig belastend)Low environmental impact 
impossible to give an unequivocal workable definition. Through the years it has been shaped into a multi-faceted and all-encompassing representative of 'everything environmental'.

Minimising the environmental impact of packaging material is often focus point in packaging development. However, sustainable development as defined by Brundtland is a much broader concept. While the environmental aspect is most certainly important and should be decisive, it is not the impact of a package or product itself that should be crucial. Sustainable development needs to be translated into 'long lasting' for the society, incorporating the environment as a prerequisite (figure 2). In order for a society to 'sustain', organisations that for example provide the society (directly or indirectly) for food, need to survive. Longterm thinking and taking the economic aspect into account are necessary while taking responsibility regarding the environment (stewardship).

With this focus, the Afrikaans term for sustainability - volhoudbaarheid - gives a more appropriate and down-to earth, workable notion to sustainability. To 'volhouden' or persevere is namely a fundamental principle of managing an organisation and designing products. There is not a reason why sustainability or sustainable development are not inherent to the foundation of an organisation, because there is no reason to not practice volhoudbaarheid.

The focus of this research is not to deliver the next 'big green thing' in packaging development. There is not one definitive strategy or answer to the complex issues that need to be addressed when adhering to sustainable development. Finding the right approach, is dependent on many factors like the type of company, the location of the company and the type of products that are produced. With this research the aim is to find a way to rationalise sustainability, aiding in finding concrete and workable answers for the involved stakeholders. The main question that needs to be answered in this research is:

"How to integrate (an aspect like) sustainability in the development of product-packaging combinations."

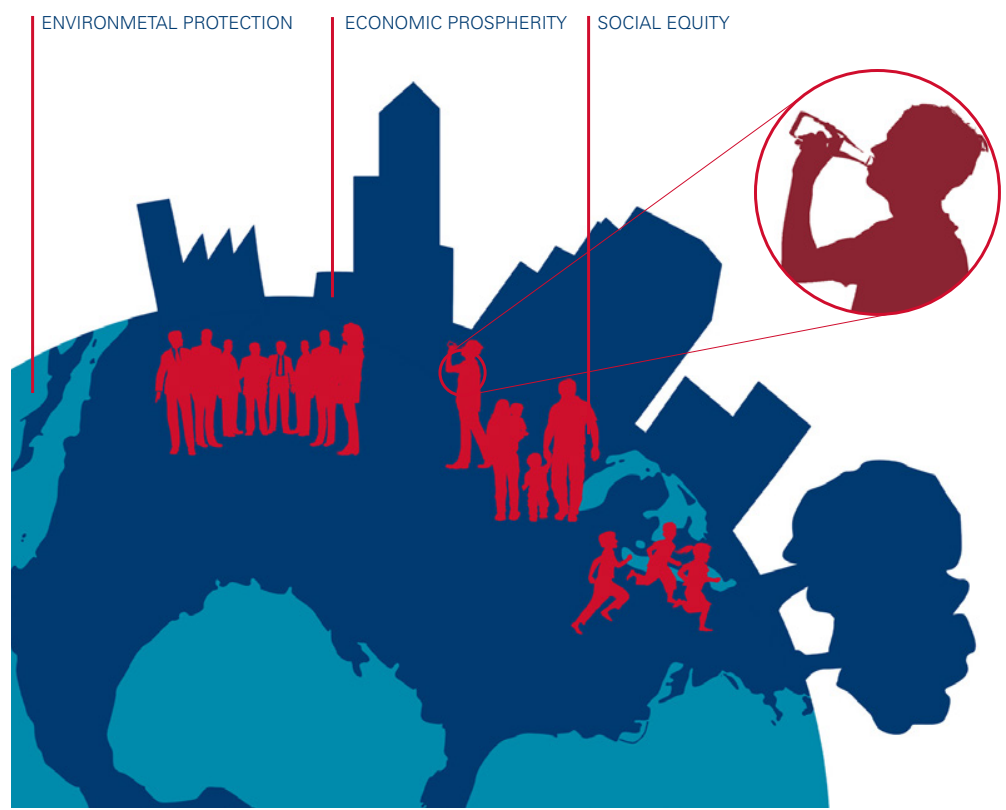

Figure 2: Volhoudbaarheid 


\section{Problem statement: what to solve}

Integrating a complex subject as sustainability in an adequate, efficient and univocal way in a productpackaging development environment is challenging. The product-packaging life cycle is interwoven with many other life cycles, of e.g. related products, other projects, other products within an organisation, machinery, etcetera. Consequently, stakeholders encounter a large variety of interrelated variables and requirements, in different states of evolvement, belonging to many different life cycles.

In making decisions regarding the product system, determining the advantages and disadvantages of different alternatives is a basic necessity that becomes well-nigh impossible to perform properly. The complexity of the life cycles involved and the amalgamation of stakeholders that comes with it, hampers from considering life cycle engineering aspects of the product-packaging combination. Furthermore, the uncertainty and ambiguousness of the involved information makes it even more difficult to successfully determine (dis)advantages of design decisions in the total life cycle. As a result, in what may seem a decent solution from one specific perspective, can lead to sub-optimisation when the overall life cycle is considered, resulting in a situation out of balance.

This sub-optimisation needs to be avoided when integrating (an aspect like) sustainability in a development trajectory. Minimal prerequisites when making decisions are: transparency in the chain, cooperation between stakeholders with different perspectives and exchange of (confidential) information. Therefore, all stakeholders need to negotiate and collaborate to eventually succeed in reaching consensus on the entire set of decisions to make, including the way in which requirements will be met. To arrive at an optimal solution, it is advisable to reach such consensus through logical reasoning rather than through sheer hierarchical privilege or dominance. 


\section{Solution direction: how to solve it}

The solution direction that is developed in order to overcome these difficulties is based on prerequisites that are derived from the researches described in previous sections (figure 10). Important prerequisites are:

- Employing existing sustainability tools \& the possibility to integrate different (sustainability) strategies

- Use a life cycle engineering approach to avoid sub-optimisation

- Always take both the content and packaging into account in which packaging is servant to its content

- As decisions about a product-packaging system made in the early phases of the development trajectory determine the larger part of the potential impact mostly, it should be possible to use the solution in these phases

- Taking into account different perspectives (of both organisations and individuals)

- Simultaneously taking into account multiple aspects, as sustainable development entails multiple aspects like the environmental, economic and social impact.
These prerequisites lead to an approach:

'Development of a method/tool that can assist (packaging) designers in decision making, by analysing consequences of potential decisions regarding several aspects and other actors involved in the product-packaging life cycles.

In order to analyse consequences of potential decisions, information about the productpackaging life cycle alternatives is necessary. An information management system is needed to store this information. The product-packaging life cycle is evolving during the development trajectory, this requires a dynamic information management system. Moreover, in the early phases of the development trajectory, information is not certain, is not reliable or even missing. Therefore, uncertainty has to become an inherent part of analysing possible consequences of the potential decision. Furthermore, multiple actors with different perspectives and interests have to obtain information relevant for them. Therefore, the dynamic information management system has to adhere to these different viewpoints.

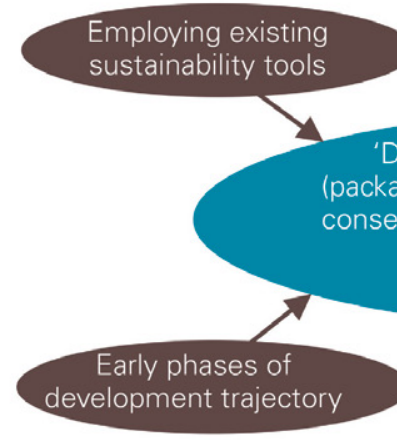

'Development of a method/tool that can assist (packaging) designers in decision making, by analysing consequences of potential decisions regarding several aspects and other actors involved in the product-packaging life cycles.

\section{development trajectory}

Figure 10: Solution direction

\section{LCE approach}

Content \& packaging 

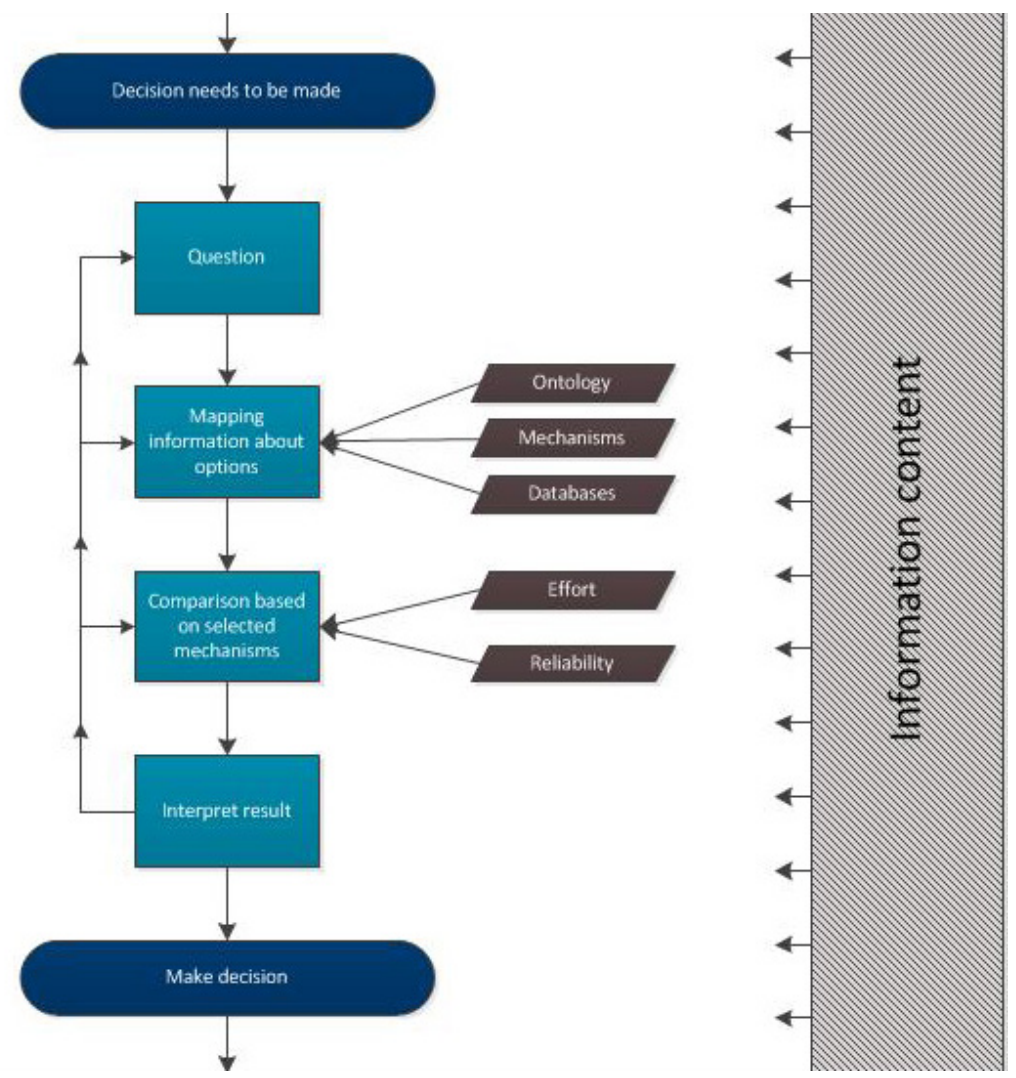

Figure 11: Basic approach when using the actor network 


\section{Prototype development}

In validating the theory and evaluating the use and key functionalities of the tool, a prototype is developed to proof the basic principles, while simultaneously the preferred interaction and functionalities of (future) users are established in a wireframe mock-up (section 'future GUI').

Figure 15 shows a representation of the basic elements of the web-based prototype, the database representing the flexible information structure, the server that interacts with this database and the last part of the tool: the frontend that constitutes the interface with the tool.

The relevant components of the prototype are the views for the actor network, the scenario, the ontology and the actor information (figure 16). The actor network view gives access to the network in its full complexity. It allows for navigation through the network, while having access to consequences of decisions, alternatives and effects of scenarios. Details on the selected entity are summarised in the actor information. The underlying structure of the network is shown in the ontology view. Here, the way in which different types of information are related is depicted, rather than all individual information entities; this ontology thus reflects the inherent backbone structure of the overall network.
The interface contains the preferred view on the information structure (in the prototype an actor view) and a repository for the so-called conventional product view that contains the available information of the product under development. An elementary version of the interface is shown in figure 17. It shows an actor network view (figure17), which indicates the actors and relations between actors involved in a product life cycle. Within this view, the characteristics of the actors can be found and edited by selecting the actor (figure 17c). The corresponding product information is shown in the product view (figure 17b), which shows a commonly used design scene with (for example) a product hierarchy. This product view is the link between the product (from a certain perspective) and its involved actors. The link between product related information and the actor network is realised by the flexible setup of the information structure, a product-element can thus be related to an involved actor.

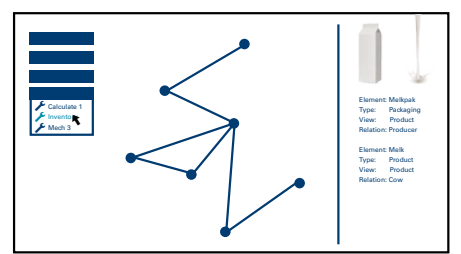

Graphic User Interface

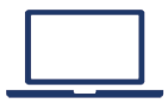

CLIENT
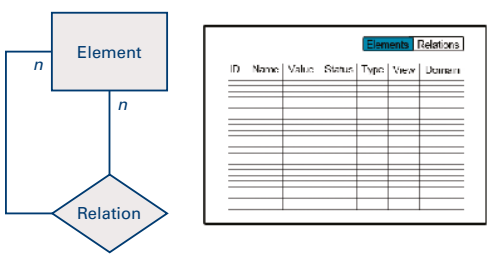

Structure

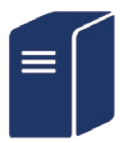

SERVER

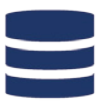

DATABASE
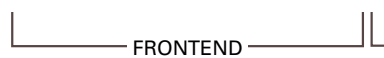

BACKEND

Figure 15: Basic elements of the web-based prototype 


\section{Using the actor network}

This section describes the intended use of actor networks. Scenarios that describe the possibilities of the actor network tool from specific use situations are described in the publications (appendix A). The generic steps, as depicted in section $\mathrm{x}$ are explain in more detail and illustrated using the prototype. Furthermore, the future user interfaces are described.

\section{Deriving the question}

Any project will start with a specific projectpackaging combination and an idea of the type of question(s) that needs answering. This forms the casus from which the basic product-packaging life cycle can be already modelled.

An example of a question: Which packaging material, material $x$ or material y (alternatives), have the lowest environmental impact for our filling company (perspective) using the ReCiPe method v1.06 (criteria).

Another example: Which packaging material, material $x$ from supplier $x$ or material $y$ from supplier $y$ (alternatives), have to be selected for our can manufacture company (perspective) regarding the material cost taking into account the quality (criteria, needs to be defined).

\section{Mapping life cycles}

The actor artefact network enables building a scenario around the often incomplete, uncertain and scarce information sources that are available in development trajectories. Both structured and unstructured information sources that already play a crucial part in this daily practice can form the starting point for the network, ranging from first drafts for a new production line to complete bills of material from ERP or PLM systems in use. All this information can be stored in the database in the same way (elements and relations) to avoid hierarchy and thus a pre-defined perspective. Obviously, information from earlier projects is available in the database, therefore it can easily be reused as a kind of template to speed up the construction of the network. Figure 16 shows

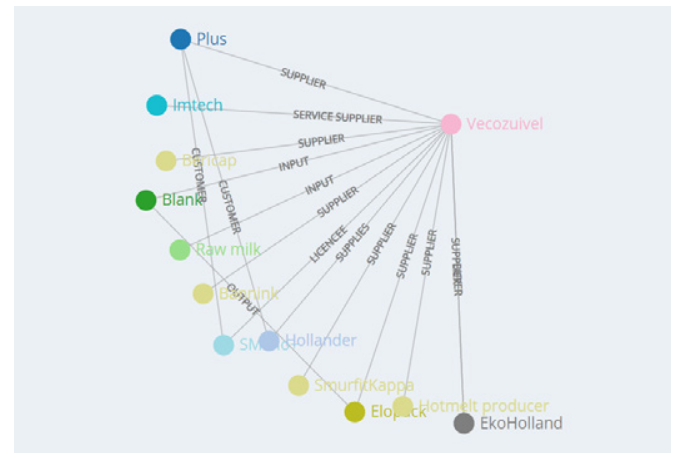

Figure 16: Prototype: start modelling from a specific perspective

an example of the start of modelling a life cycle. Important suppliers and customers from the perspective of the organisation in consideration can be modelled by linking elements of different types with the considered organisation. Between the organisation and the different elements, different type of relations can be specified.

In the prototype, the network can be modelled by adding elements and relations (figure 17a, next page). In the future software tool, dynamic information forms can be generated from the ontology in order to quickly build up the information network. In the information section on the right side of the window (figure 17b), information about the selected elements can be found.

By selecting mechanisms before mapping the product-packaging life cycle, the required information, or most influential parameters, can be indicated. The ontology of the mechanisms can guide the user in determining which information needs to be known and modelled in the network prior to making decisions. This creates overview in the information required from other individuals, departments or organisations in order to prevent making unbalanced decisions.

For example: By selecting the ReCiPe 1.06 mechanism, in order to evaluate the environmental impact of two packaging materials, the relevant input variables can be indicated on beforehand, preventing collecting unnecessary information and providing non-LCA experts with the necessities for the execution of an LCA. 
Another example: by providing a mechanisms that can analyse the (im)possibilities regarding in-house production facilities, the marketing department can determine the required input information and collect this information (in collaboration with other departments) to analyse if their alternatives can be manufactured in-house.

\section{Using the ontology}

In building up the network, the ontology of that network (figure 17c), keeps track of the various elements and relations. In figure 17 a relative complex network is shown. The ontology of that network gives an overview in the current types of elements and types of relations. As such, the ontology is an important starting point when information is not readily available. While the specific information about a new packaging material or a new supplier might be unknown, the few details that are known - a principle material group or product catalogue - can be used to find similar structures in the ontology. These structures can then serve as a general template that outlines a certain part of the product or life cycle. Furthermore, the ontology serves as a legend that allows the user to understand and 'read' the structure of the network. It allows to put focus on a certain part of the network in filtering on certain types of actors or artefacts, while in the background the entire network is still available. The filter options (figure 17d) can be employed in switching between perspectives and navigating through the network.

\section{Selecting mechanisms to compare product- packaging life cycle alternatives}

Once the life cycle is modelled, mechanisms have to be selected to compare the life cycle alternatives regarding the selected aspects. In a similar manner as building the life cycle network, the ontology gives access to so-called mechanisms that enable calculations based on the available information. If, for instance, the locations of two actors are known, the various transport options and the total distance can be determined by using different mechanisms. If a material is known, properties such as the density can be determined by a mechanism. As such, these sets of mechanisms allow first rough estimates that aid in assessing the consequences of alterations, but can be build up to allow more advanced algorithms if more detailed information becomes available. Figure 17 e shows the prototype and the mechanisms section. When an element is selected, the ontology provides for the mechanisms that can be used. Depending on the type of information and types of relations directly or indirectly linked to that element, mechanisms can be selected to execute a quick screening regarding a specific aspect or a detailed analysis depending on the available time and resources.

\section{Interpret results}

The mechanisms can aid in determining the most influential parts of a network or, in combination with ontology-based templates, hint at important information that is currently lacking. More importantly, it offers basic techniques to deal with the non-deterministic nature of the early phases of development trajectories and aid in overcome the indefiniteness of used information in those phases. But the relevance of mechanisms does not only lie in the results they generate. As each mechanism important is the fact that mechanisms also take into account the probability of the outcome, while assessing the uncertainty of the variables used as well as the accompanying bandwidth of the outcome. Therefore, the use of the mechanisms can also be instrumental in determining the most relevant and influential variables.

Important in interpreting the results is determining if the results give answer to the question and to determine if it is possible to make a decision. However, transparency in the input variables and in the mechanisms that are used (including the reliability and the effort) is always part of the result. 
Figure 17c: Ontology

\section{The Actor Network | Rationalizing sustainability}

$\mathbf{8}$ Selected element: 1 I gable top milk

Ð Database: department

(2) Ontology

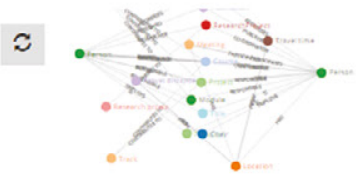

응 Adjust view

FORCE LAYOUT PARAMETERS

alpha

charge

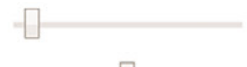

friction

gravity

linkDistance

linkStrength

W Default

Filter

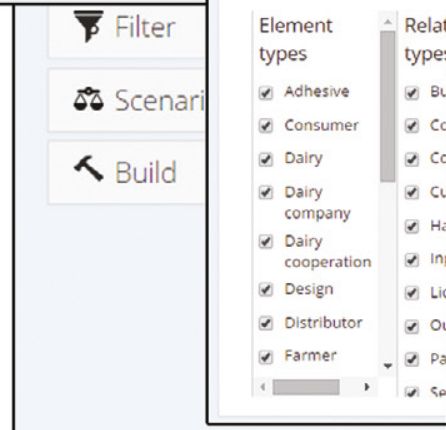

Figure 17d: Filter

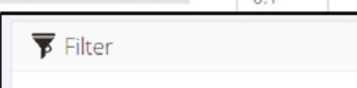

NETWORK TYPE

\begin{tabular}{lll} 
Star $\quad$ Star $2 \mathrm{n} \quad$ Network \\
\hline
\end{tabular}

FILTERS
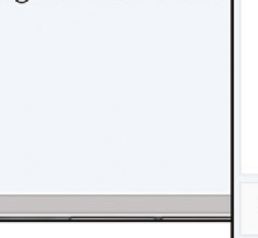

Figure 17d: Mechanisms

\section{nability}




\section{Future GUI}

This section is based on the results from user researches. These user researches are aimed at getting an overview of the daily activities of stakeholders involved in product-packaging development trajectories and the current software tools they are using. Whereas the prototype is aimed at proving the fundamentals of the actor network approach, the future user interface(s) depicts the desired interaction from a user's point of view. Scenarios, given in the publications in appendix A, describe diverge future use situations and desired functionalities of the actor network. In figure 18, the basic elements of the concept for the user interface in given. In figure 19 a more detailed version of a possible interface is shown that adheres to the user requirements resulting from the user researches.

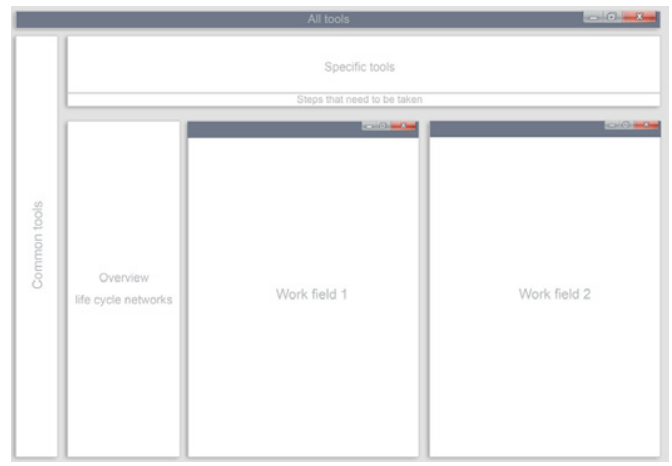

Figure 18: Concept of future GUI

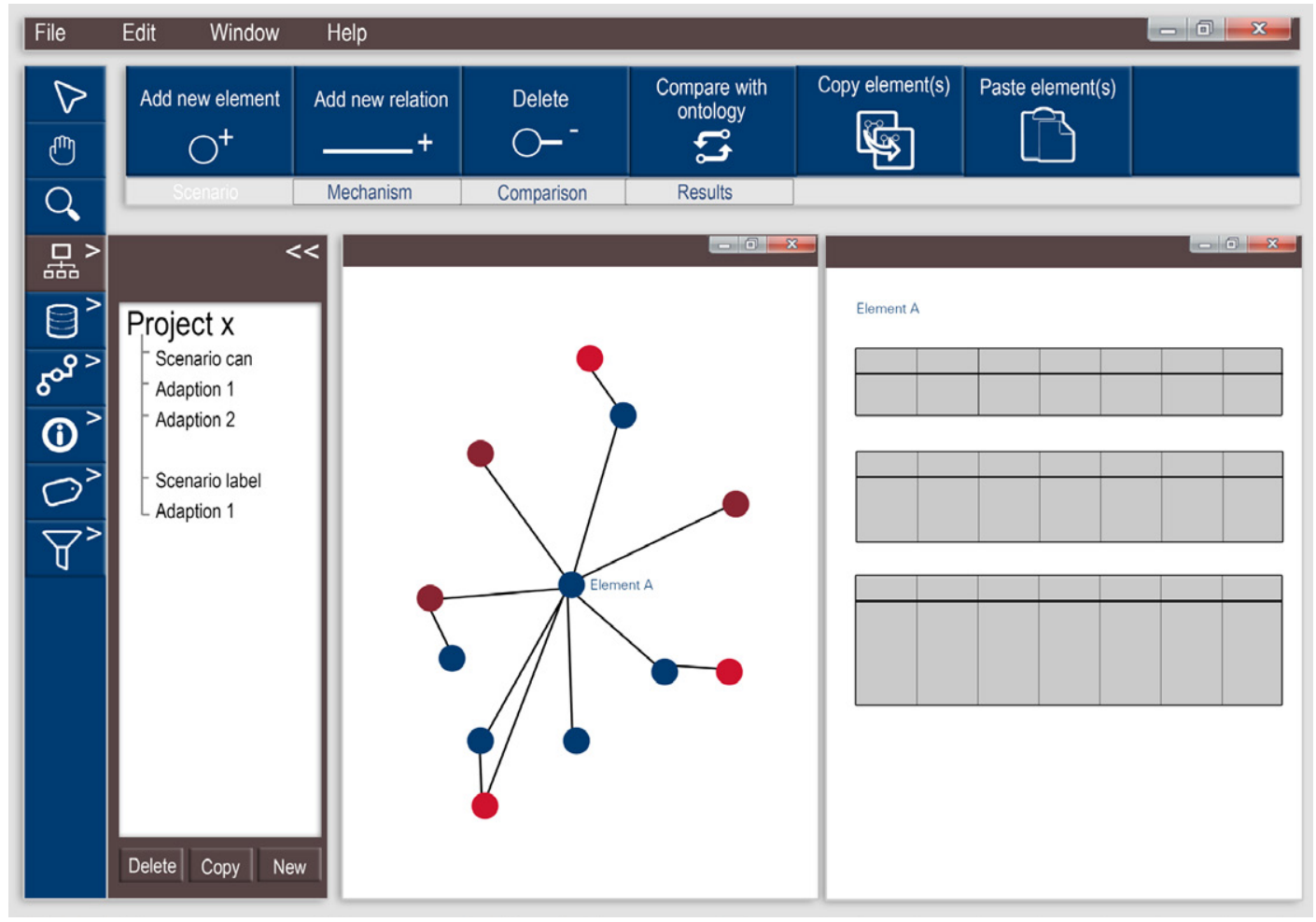

Figure 19: Concept of future GUI 


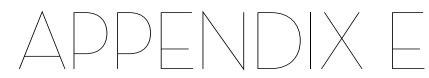

\section{RELIABILITY OF MECHANISMS}

This appendix contains (translated) excerpts from the Caipta Selecta "Mechanismes" by Nora Roebers, Tutored by Lutters, E., Oude Luttikhuis, E.J., De Lange, J. 


\section{Reliability mechanism}

The reliability of a mechanism in theory involves two aspects, namely whether the model is determin-istic or not and how close the given output parameter lies with the actual output parameter. The first aspect can be investigated fairly easily, by checking whether or not the mechanism returns the same output variable when the same input variables are returned several times. The second aspect can also be investigated by looking at what the error $(\varepsilon)$ is between the output variable supplied by the mech-anism and the actual variable.

\section{$\varepsilon=\mid$ Oexact-Omechanism $\mid /$ Oexact}

For a deterministic mechanism, the error will be equal if multiple input variables are delivered multiple times. For a non-deterministic model, the error may differ.

In other words, determining those two aspects is good to do. However, linking these aspects to a val-ue for the reliability of the mechanism can be very difficult. With a mechanism that always gives (so deterministically) the exact value, the reliability is of course $100 \%$. Even when a mechanism provides the same error (so deterministically), the reliability could be determined by, for example, setting: $\mathrm{B}(\mathrm{M})=1-\varepsilon$.

However, when a mechanism is non-deterministic, it is difficult to assign a value for reliability. After all, this is different because the mechanism always provides other output variables with other errors. This makes the mechanism by definition very unreliable. One possibility of giving one value to the reliability of this mechanism is by:

$\mathrm{B}(\mathrm{M})=1-\varepsilon \max$.

Emax is the highest measured error of that mechanism. Of course, there may be a bigger error in theory. Nevertheless, this seems to be a reasonable indication; Certainly, even in a non-deterministic mechanism, the output variable (and thus the error) often vary within a certain range.

In some cases, different mechanisms with the same input parameters can provide the same output parameters. The choice between these different mechanisms depends not only on the reliability of the mechanisms but also on the "effort" needed to implement a mechanism. The effort can cover a number of people, computers or tools, but also time, money, fuels, etc. When a mechanism has greater reliability and requires less effort than another mechanism, the choice is made quick. What is more often the case, however, is that a mechanism with greater reliability requires more effort. In that case, it is up to the user to make a choice by weighing reliability and the required effort. Two as-pects that play an important role in that selection process are the required or desired reliability of the output parameter and the available effort. The latter can be different for each user and at any time.

To clarify this selection process between different mechanisms, an example will be given. In this ex-ample, three mechanisms will determine how many boxes fit in a container, given the length $(\mathrm{L})$, width $(B)$ and height $(H)$ of both the (inside) of the container (C) and the (outside of) boxes (D).

When we assume that every small mechanism costs as much effort, we quickly conclude that mecha-nisms 2 and 3 need 74 times as much effort as mechanism 1. Also, we 
assume that the boxes should only be stacked flat in the container and that the parameters have the following values:

- $\quad \mathrm{Lc}=4.0$ meters

- $\mathrm{Bc}=2.5$ meters

- $\mathrm{Hc}=3.0$ meters

- $L d=0.3$ meters

- $\quad \mathrm{Bd}=0.2$ meter

- $\quad H d=0.1$ meter

The output variables of the three mechanisms are then as follows:

- Mechanism 1: 5000 boxes / container

- Mechanism 2: 4680 boxes / container

- Mechanism 3: 4800 boxes / container

We know with this simple example that the reliability of Mechanisms 2 and 3 is $100 \%$. The calculations of both mechanisms are correct, but by another configuration of boxes utilized mechanism 3 optimizes the space in the container than mechanism 2 does. Logically, the mechanism with the most efficient configuration will be chosen. When, as in Mechanisms 2 and 3, multiple mechanisms have the same reliability, a choice must be made based on the most advantageous outcome. This selection process could also be done using a mechanism.

The reliability of mechanism 1 equals $1-\varepsilon=1-|4800-5000| 4800=95.8 \%$. Compared with mechanism 3, this is about $5 \%$ less accurate. However, there is also 47 times (almost half) less effort. The choice between these two mechanisms and the corresponding considerations lie with the user.

\section{Reliability input}

There are two possible options to determine the reliability of input parameters. These options depend on how the values of the input parameters are determined. First of all, the user could fill in the input parameter and provide a corresponding reliability that indicates how certain the user is about the val-ue of the entered input parameter. Another option is that the input parameter and associated reliabil-ity are automatically determined based on more frequently used data from the past.

Just as the output value of a mechanism may be an input value of the following mechanism in the se-quence, the corresponding reliability of the output value will be equal to the corresponding input val-ue of the following mechanism.

Determining the reliability of an input value can be very difficult in some cases. This is certainly the case at the beginning of a design process in which few decisions have been made. Further in this report will be made clear how the sensitivity of an input parameter can control this decision-making process.

\section{Role of sensitivity in reliable definition}

Sensitivity sends what information is causing a particular impact. Which makes the most contribution to it. It helps find / locate in the sense of information (needs) that should be investigated first or just lat-er. Can thus give direction. It does not matter as much about reliability. 
In addition to the reliability of the input parameters and the mechanism, the sensitivity of the input parameters is at least as important for determining the reliability of the output parameter. The sensi-tivity of an input parameter tells you how much influence this parameter has on the final response. The sensitivity is related to the first partial derivative of the mechanism to the input parameter. In ad-dition, the derivative is scaled in such a way that the sum of the sensitivities of the input parameters associated with one mechanism together is 1 (100\%). The following formula shows this:

Hereby $M$ can hit both a small and a big mechanism. In addition, it is important to note that when it comes to a small mechanism, $G(I x)$ represents the sensitivity of the input parameter $\mathrm{Ix}$ to the small mechanism output parameter. In the case of a large mechanism, G (Ix) for the sensitivity of the input parameter Ix is on the output parameter of the large mechanism, and thus on the output parameter of the last small mechanism in the series.

When the mechanism is known, the sensitivity of the input parameters is easy to determine, as can be seen in the following examples. Hereby the number of input parameters will be limited to two to keep the examples clear:

- $\quad \mathrm{M} 1=\mathrm{I} 1+\mathrm{I} 2 \mathrm{G}(\mathrm{I} 1)=0.5$ and $\mathrm{G}(\mathrm{I} 2)=0.5$

- $\quad \mathrm{M} 2=2 \mathrm{I} 1+3 \mathrm{I} 2 \quad \mathrm{G}(\mathrm{I} 1)=0.4$ and $\mathrm{G}(\mathrm{I} 2)=0.6$

- $\quad \mathrm{M} 3=\mathrm{I} 12+2 \mathrm{I} 23 \mathrm{G}(\mathrm{I} 1)=2 \mathrm{I} 12 \mathrm{I} 1+6 I 22$ and $\mathrm{G}(\mathrm{I} 2)=6 I 222 \mathrm{I} 1+6 I 22$

In the above three examples, the input parameters are independent of each other. This is the case if $\partial M \partial I x$ is not a function of input parameters other than Ix. $M 1$ and $M 2$ are linear functions of both $\mathrm{I}$ and $\mathrm{I} 2$, so the sensitivity of both input parameters is constant for each value of $\mathrm{I} 1$ and $\mathrm{I}_{2}$. M3 contains higher power of input parameters, which means that $G\left(I_{1}\right)$ and $G\left(I_{2}\right)$ are different for different values of $I_{1}$ and $I_{2}$.

When the input parameters are dependent on each other, $\partial M \partial I x$ will be a function of a different pa-rameter than Ix. This is the case, for example, in the following examples:

- $\mathrm{M} 4=\mathrm{I} 1 * \mathrm{I} 2 \quad>\quad \mathrm{G}(\mathrm{I} 1)=I 2 I 1+I 2$ and G (I2) $=I 1 I 1+I 2$

- $\mathrm{M} 5=\mathrm{I} 1 \wedge \mathrm{I} 2 \quad>\quad \mathrm{G}(\mathrm{I} 1)=I 2 * I 1 I 2-1 I 2 * I 1 I 2-1+I 1 I 2 * \log (I 1)$

As can be seen clearly from the counter of the fractures, the input parameters of mechanisms 4 and 5 are dependent on each other. This means that for different values of 11 and 12 one time 11 can be more sensitive and next time 12 . This can be seen in the following two situations for M4:

- $1=1$ and $\mathrm{I} 2=2 \quad>\quad \mathrm{G}$ (I1) $=23$ and $\mathrm{G}$ (I2) $=13$ with $\mathrm{G}$ (I1) $>\mathrm{G}$ (I2)

- $\quad \mathrm{I} 1=2$ and $\mathrm{I} 2=1>\mathrm{G}(\mathrm{I} 1)=13$ and $\mathrm{G}$ (I2) $=23$ with G (I2) $>\mathrm{G}$ (I1)

Although $G\left(I_{1}\right)$ in the first situation is greater than $G\left(I_{2}\right), G\left(I_{1}\right)$ is still a function of $I_{2}$. This makes $G\left(I_{2}\right)$ in this situation equal to $G(I 1)$.

In general, when two (or more) input parameters depend on each other, they all get the sensitivity of the dependent input parameter with the highest sensitivity:

$G(I y)=\max (I 1, I 2, \ldots, I m-1, I m)$

Where $I y$ is a set of interdependent input variables that is part of $I x$ and y runs from 1 to $\mathrm{m}$. Determining the sensitivity of the different input parameters becomes more difficult when the mech-anism is not known. This is the case with SimaPro, for example, the mechanism for many users is not (direct) clear. In that case, the SimaPro mecha- 
nism is a large black box that provides an output param-eter for a certain set of input parameters.

To determine the effect of one input parameter on the final answer, this input parameter will be var-ied between its minimum and maximum possible value while the remaining input parameters are kept constant. The output variable (vertical axis) can then be plotted against the input variable (horizontal axis). The sensitivity of the input variable is also now related to the first derivative, and thus the slope of the resulting graph. When the same is done for the other input parameters, a kind of mountain land landscape is formed in a $(n+1)$-dimensional axis system. Again, the output variable on the vertical axis and the input variables are plotted on $n$ horizontal axes. In theory all axes should be at an angle of $90^{\circ}$, but with more than three axes this is no longer possible. In the illustration below, therefore, the an-gles between the different horizontal axes smaller than $90^{\circ}$ in the hope can be an image that clarifies the $(n+1)$ dimensional axle system.

Determining the full function of the mechanism and thus creating a full $(n+1)$ dimensional figure is an unfinished work. Even if this would be calculated with the computer. For this reason, the full mecha-nism will not be looked into, but to only a small area on the mountain landscape (for example, the gray square). Where this area is exactly depending on the values that have the input parameters. The size of the area is related to the reliability of those input parameters: the greater the reliability, the more confident the user is that an input parameter has a certain value and the smaller the range of possible other values on the axis for the relevant input parameter. Conversely, a low reliability input parameter will have a greater range of possible values and the area in the direction of the axis in question will be larger.

By looking only at such a small area in the mountain landscape, it is possible to say something locally about the behaviour of the mechanism and thus the sensitivity of the input parameters.

In order to determine the sensitivity of $\mathrm{Ix}$, at least the following three measurements are made, with Wstart being the chosen values of the relevant input parameters.

- Measurement 1: Determine O1 for: o Input Parameters = Wstart_I

- Measurement 2: determine O2 for: o Input parameters other than Ix = Wstart_l o Ix $=1.05 *$ Wstart_lx

- Measurement 3: determine $\mathrm{O} 3$ for: o Input parameters other than $\mathrm{Ix}=$ Wstart $\circ \mathrm{Ix}$ $=0.95 *$ Wstart_l $\mathrm{x}$

Hereby, 5\% (0.05) of Wstart is an example of a step size. Greater or smaller steps could also be taken. A line can be drawn between the results of the last two measurements. The slope now says some-thing about the local sensitivity of Ix, and can be expressed as follows:

slope $=02-030,1 *$ Wstart_Ix

By doing two more (or more) additional measurements, it is possible to examine which values of Ix within the area it is allowed to assume this constant slope. For the other 
variables, similar measure-ments are made to determine the slopes.

Also now there may be input parameters that are dependent on each other. Again, both input param-eters get the sensitivity of the most sensitive dependent input parameter. The fact that two or more input parameters (local) depend on each other could be investigated by doing four measurements.

The example below shows whether, for example, 11 and 12 are dependent on each other. Measurement A: Determine OA for:

- Input parameters other than $11=$ Wstart $I$

- $\quad 11=1.05 *$ Wstart_l 1

Measurement B: Determine OB for:

- Input parameters other than $I_{1}=$ Wstart_l

- $\quad 11=0.95 *$ Wstart_l 1

Measurement C: determine OC for:

- Input parameters other than 11 and $12=$ Wstart_I

- $\quad 11=1.05 *$ Wstart_l1

- $\quad 12=1.05 *$ Wstart_l2

Measurement D: Determine OD for:

- Input parameters other than 11 and $12=$ Wstart_I

- $\quad \mathrm{I}_{1}=0.95 *$ Wstart_1 1

- $12=1.05 *$ Wstart 12

Then do not determine one, but two slopes, between the first two and the last two outcomes of $\mathrm{O}$

slope $1=O A-O B 0,1 *$ Wstart_I 1

slope $2=O C-O D 0,1 *$ Wstart_I1

If slopes 1 and 2 are now equal, $I 1$ is independent of $\mid 2$. If the 2 slopes are different, $I 1$ is dependent on I2. In the above, it was only investigated whether two input parameters depend on each other or not. By any combination of two input parameters

\section{Reliability output}

The final subject will discuss the reliability of the output parameter. If the output parameter has high reliability, its user can be meaningful to that output value. The user can then compare the output value with his desired response. If the user's difference is small enough, then the user will be satisfied. If the user finds the difference too large, then adjustments must be made to the input parameters.

However, in practice, an output parameter will not often have high reliability. Certainly at the begin-ning of the design process, input parameters are often uncertain which results in low reliability of the final response. Now it is also important to look at the input parameters: it will have to be investigated or established to ensure that the reliability of the input parameters (and thus of the output parame-ter) is increased.

In both cases described above, it is the question of which input parameter should be investigated or modified. This choice depends on three aspects.

- The sensitivity of the input parameter to the output parameter:

When an input parameter has a high sensitivity, the input parameter needs to be ad- 
justed little, or its reliability is low, to realize a relatively large difference in (the reliability of) the final response.

- The reliability of the input parameter:

The higher the reliability of an input parameter, the less space left is to make adjustments to this input parameter. The range of possible values for this input parameter was already low because of its high reliability.

- The effort needed to further investigate or adjust the input parameter:

Just as it was the case with the choice of a mechanism, effort here may include a number of people, computers or tools, but also time, money, fuels, etc. Ultimately, the user will have to make a distinc-tion between the various aspects and have to choose which input parameter he will adjust or further investigate. However, the actor network can give the user insight into the often unknown mechanism, using the topics discussed below:
- $\quad-\mathrm{R}(\mathrm{O})$ = Reliability output parameter;
- $\quad-\mathrm{R}(\mathrm{M})=$ Reliability mechanism;
- $\quad-\mathrm{R}(\mathrm{Ix})=$ Reliability input parameter;
- $\quad-S(I x)=$ sensitivity input parameter. 



ISBN: $\quad 978-90-365-4539-6$ 